Florida International University

FIU Digital Commons

3-29-2019

\title{
Memoria, identidad y literatura del yo: narrativas de la segunda generación de escritores exiliados por la Guerra Civil española
}

Juan Antonio Godoy

Florida International University, jgodo010@fiu.edu

Follow this and additional works at: https://digitalcommons.fiu.edu/etd

Part of the Comparative Literature Commons, Latin American Literature Commons, Modern Literature Commons, and the Spanish Literature Commons

\section{Recommended Citation}

Godoy, Juan Antonio, "Memoria, identidad y literatura del yo: narrativas de la segunda generación de escritores exiliados por la Guerra Civil española" (2019). FIU Electronic Theses and Dissertations. 4038. https://digitalcommons.fiu.edu/etd/4038

This work is brought to you for free and open access by the University Graduate School at FIU Digital Commons. It has been accepted for inclusion in FIU Electronic Theses and Dissertations by an authorized administrator of FIU Digital Commons. For more information, please contact dcc@fiu.edu. 


\section{FLORIDA INTERNATIONAL UNIVERSITY}

Miami, Florida

\section{MEMORIA, IDENTIDAD Y LITERATURA DEL YO: \\ NARRATIVAS DE LA SEGUNDA GENERACIÓN DE ESCRITORES EXILIADOS \\ POR LA GUERRA CIVIL ESPAÑOLA}

A dissertation submitted in partial fulfillment of

the requirements for the degree of

DOCTOR OF PHILOSOPHY

in

SPANISH

by

Juan Antonio Godoy Peñas 
To: $\quad$ Dean John F. Stack, Jr.

Steven J. Green School of International and Public Affairs

This dissertation, written by Juan Antonio Godoy Peñas, entitled Memoria, identidad y literatura del yo: narrativas de la segunda generación de escritores exiliados por la Guerra Civil Española, having been approved in respect to style and intellectual content, is referred to you for judgment.

We have read this dissertation and recommend that it be approved.

$\begin{array}{r}\hline \text { Ricardo Castells } \\ \hline \text { Santiago Juan-Navarro } \\ \hline \text { María Asunción Gómez, Co-Major Professor } \\ \hline \text { Santiago López-Ríos, Co-Major Professor }\end{array}$

Date of Defense: March 29, 2019

The dissertation of Juan Antonio Godoy Peñas is approved.

Dean John F. Stack, Jr. Steven J. Green School of International and Public Affairs

Andrés G. Gil

Vice President for Research and Economic Development and Dean of the University Graduate School

Florida International University 2019 
(C) Copyright 2019 by Juan Antonio Godoy Peñas

All rights reserved. 


\section{DEDICATION}

A mis padres y a mis hermanos.

A cada una de las personas que, en algún momento, tuvieron que poner tierra de por medio para buscar un futuro mejor. A cada una de las personas que, desafortunadamente, se ven forzados a hacerlo actualmente.

A cada una de las personas que se refugian en una pluma y un papel para escapar de un mundo que los oprime y les impone una forma de ser. 


\section{ACKNOWLEDGMENTS}

En primer lugar, quiero dar las gracias a mis padres, hermanos y amigos de la infancia por creer en mí en todo momento, por apoyarme en las noches de tinieblas y en los días de claridad, por respetar mis horarios de trabajo, por colmarme de libros, por recibirme con abrazos y besos, por alegrarse tras la escritura de cada línea, por vivir este proyecto como algo suyo, por aceptar mi exilio voluntario.

En segundo lugar, quiero agradecer al comité de esta tesis--Dr. Ricardo Castells, Dra. Aurora G. Morcillo, Dr. Santiago Juan-Navarro, Dra. María Asunción Gómez y Dr. Santiago López-Ríos-- por apoyarme y animarme a terminar un proyecto tan amplio y por respetar mis deseos y opiniones. Quiero agradecer especialmente a mis dos directores de tesis --iqué fortuna la mía!-- por haber sido el pilar de apoyo en las horas más bajas, tanto personales como profesionales y por haber entendido mis necesidades en los distintos ámbitos que implica este viaje en el mundo de la investigación.

En tercer lugar, quiero dar las gracias tanto a Florida International University por sus inolvidables clases y por su apoyo económico a través de diversas becas y trabajo, como a la Universidad Complutense de Madrid por desarrollar un plan investigador internacional que me permitiera aprovechar lo mejor de los dos mundos académicos de los que bebo. También quiero agradecer a Harvard University por su flexibilidad mientras que ponía fin a estas líneas. Como parte del equipo de FIU, quiero agradecer especialmente al Dr. Shlomi Dinar por haber apoyadome en la firma de mi convenio internacional con la Universidad Complutense de Madrid y a la Dra. Pascale Bécel, la jefa del Departamento de Lenguas Modernas, quien ha hecho también posible que este trabajo haya llegado a su final y a la que estaré enormemente agradecido por su apoyo y 
dedicación durante el tiempo que fui Visiting Instructor en la Universidad de Qingdao (China), y a la Dra. Melissa Baralt, quien ha sido una profesora, una maestra, una mentora, una amiga, un espejo en el que mirarme.

También quiero dar las gracias al Ateneo Español de México por ponerme en contacto con algunos de las figuras más representativas de la segunda generación de escritores exiliados por la Guerra Civil española, al sabio James Valender por aconsejarme y recibirme, a Cecilia Elío y Diego García Elío por acercarme más a la figura de María Luisa Elío Bernal.

Por último, quiero darles las gracias a todos y a cada uno de los profesores, compañeros/as, investigadores, amigos/as con los que me he cruzado a lo largo de mi vida en el mundo de la investigación desde que comencé mi carrera en 2008 en la Universidad de Málaga y que, de una forma o de otra, han contribuido a mi éxito: Jessica, Emilio, Aurora, Salvador, Belén, Gaspar, Amparo, Maribel, Vicky, Mónica, Álvaro, Guille, Ximena, Alicia, Ángela, Javier, Rebecca, Denisse, Joan, Maida, Vanessa, Jorge, Lucía, Eric, Beatriz, Ezequiel, Alberto, Claudia, Azucena, Claudia, Nico, Mariana, Jose y Xiomara. 


\begin{abstract}
OF THE DISSERTATION
MEMORIA, IDENTIDAD Y LITERATURA DEL YO: NARRATIVAS DE LA SEGUNDA GENERACIÓN DE ESCRITORES EXILIADOS POR LA GUERRA CIVIL ESPAÑOLA

by
\end{abstract}

Juan Antonio Godoy Peñas

Florida International University, 2019

Miami, Florida

Professor María Asunción Gómez, Co-Major Professor

Professor Santiago López-Ríos, Co-Major Professor

The victory of the dictator Francisco Franco, after the Spanish Civil War (19361939), resulted in the political repression of thousands of citizens who had been loyal to the Republican government, and the exile of more than 200,000 civilians. The studies of Spanish Civil war exile literature have paid more attention to the first generation of exiled writers. However, the purpose of this dissertation is to study the construction of the self in the autobiographical and auto-fictional works written by the second generation. These authors -- born between 1920 and 1938-- left Spain as children and reached adulthood in different host countries; therefore, they have in common a nomadic identity, which was mainly shaped in the exile.

This study explores the relationship between nation, space, time, language, and culture in the autobiographical narratives of the second generation of Spanish Civil War exiled writers. It focuses on several elements that are intertwined throughout their work: (1) the cultural negotiation that these writers establish when they are forced to confront 
two national identities, that of the country of origin and that of the host country; (2) the temporal dialectic established between the past (in Spain) and the present of their own lives; (3) the capacity of language to apprehend the past through memory; (4) the narrative strategies that these writers develop in response to the interstitial situation of exile; (5) the dynamics played out in relation to language and culture (these narratives become the sites of intersection between the native and the acquired language, between the self and the other); (6) the importance of memory, forgetfulness, and trauma in the representation of the self in relation to individual and national identity.

Finally, I point out new areas of research and reflect on how the individual autobiographical accounts under study contribute to create a collective history and how through them we can rethink the political and social narratives of the Spanish Civil War. 


\section{TABLE OF CONTENTS}

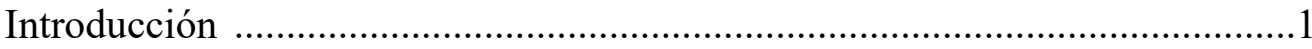

I. Consideraciones teóricas. Cuestionando la identidad de los exiliados ...........23

Exilio e identidad: nación, tiempo y lenguaje......................................26

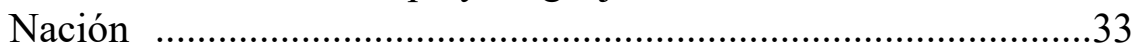

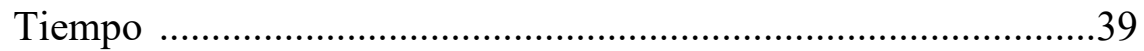

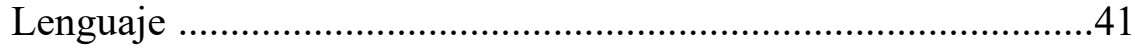

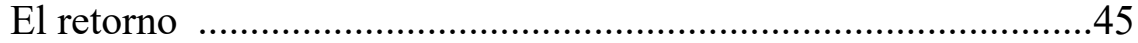

Memoria y literatura del yo........................................................46

II. España fuera de España (I). Niños convertidos en escritores: narrativas reconstructivas de la identidad

III. España fuera de España (II). Niños convertidos en escritores: una identidad en lucha con los conceptos de nación, tiempo y lenguaje

IV. María Luisa Elío Bernal: "Y Ahora Me Doy Cuenta Que Regresar Es Irse"

Semblanza biográfica ................................................................182

La escritura como proceso reparador: el retorno a los orígenes ............189

La formación de la identidad: de una niña española a una mujer ¿mexicana?

V. Jorge Semprún: "Había Hecho del Exilio una Patria" .................................226

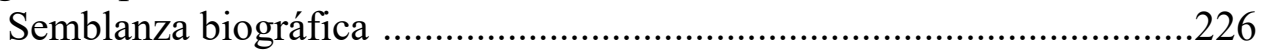

La reescritura como búsqueda identitaria ........................................238

La construcción de la identidad: en búsqueda de nuevos parámetros ...267

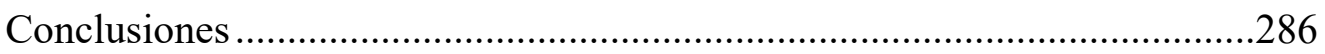

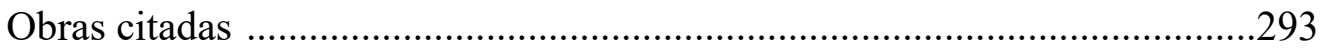

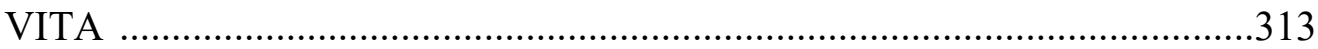




\section{Introducción}

El 18 de julio de 1936 la insurrección simultánea de un grupo militar en distintos puntos del territorio español conllevó el inicio de una larga y sangrienta guerra civil española. Tres años más tarde, esta acabó con la proclamación del general Francisco Franco como jefe estado, posición que ocupó hasta su muerte el 20 de noviembre de 1975. Su victoria causó numerosos episodios de represión así como la muerte de miles de ciudadanos que habían permanecido fieles al gobierno republicano, incluso cuando este se deshacía y marchaba en desbandada al exilio. Esta situación provocó también la salida del país de más de doscientos mil españoles por miedo a ser encarcelados y/o ejecutados. Entre ellos se encontraban algunos de los intelectuales más destacados del momento, cuya obra fue víctima de la censura que la mantuvo en un profundo silencio dentro de las fronteras españolas hasta principios de los años 60. Tras la muerte de Franco, España inició un periodo de transición democrática que permitió a algunos de los exiliados, ya en avanzada edad en la mayoría de los casos, el regreso a su país de origen. Sin embargo, ello no conllevó la posibilidad de discutir y analizar muchos de los temas relacionados con el exilio y la dictadura debido al "Pacto del Olvido". El objetivo de este era unir a un país que estaba totalmente dividido. Para ello, se promulgó el "perdón" y el "olvido" de los crímenes cometidos por ambas partes durante la Guerra Civil y el régimen autoritario de Franco. Si bien es cierto que muchos de los crímenes cometidos por los republicanos habían sido juzgados y sentenciados durante la dictadura, no se repitió esta situación en el caso de los pertenecientes al bando fascista quienes habían perpetrados dichos delitos también. 
En 2006, bajo el gobierno de José Luis Rodríguez Zapatero, España declaró el “Año de la Memoria Histórica”. Esto provocó un gran debate público sobre la guerra civil, el exilio y el franquismo, así como el estallido de un significativo número de publicaciones que abogaban por un estudio en profundidad del conflicto bélico y apuntaban nuevos campos de trabajo. En los años 90 del siglo XX, había surgido un grupo de investigación en la Universidad Autónoma de Barcelona denominado Gexel que tenía como objetivo restaurar la memoria histórica, cultural y literaria de los exiliados en 1939. En un primer momento, este grupo centró su atención en aquellos escritores que habían marchado al exilio con un importante número de publicaciones, tales como Max Aub, Francisco Ayala o Ramón J. Sender, dejando, en un segundo plano, a una generación de escritores, los cuales habían marchado al exilio siendo niños y habían crecido en la encrucijada de dos países, su país de origen y su país de acogida.

Manuel Aznar Soler, director de GEXEL, al plantear la problemática existente en torno a la creación de una historia de la literatura propia del exilio de 1939 en su artículo "La historia de las literaturas del exilio republicano español de 1939: problemas teóricos y metodológicos", se preguntaba:

¿Hasta qué punto podemos seguir olvidando en nuestra historia literaria de los años cuarenta el valor de las novelas publicadas durante esa década por Max Aub, Ayala o Sender; de los versos de Alberti, Cernuda o Salinas; de las obras dramáticas de Bergamín, Dieste o José Ricardo Morales, o de los ensayos de Enrique Díez-Canedo, Juan Larrea o María Zambrano? (12)

De manera similar, ¿hasta qué punto podemos seguir olvidando en nuestra historia literaria del siglo XX el valor de las novelas publicadas por Blanco Aguinaga, Carmen 
Mieza o Roberto Ruiz; los versos de Jomí García Ascot o Tomás Segovia; las obras dramatúrgicas de Teresa Gracia o Maruxa Villalta; las memorias de FernándezMontesinos, Angelina Muñiz-Huberman, Luis Santamaría o Aurea Matilde Fernández Muñiz; o los ensayos de José de la Colina o Manuel Durán, por mencionar tan sólo a algunos?

En 2016, Gexel publica su Diccionario bibliográfico de los escritores, editoriales y revistas del exilio republicano de 1939, el cual, más de veinte años después, seguía teniendo como fin recuperar esa parte de la memoria de España. Por esta razón, sus autores recordaban algunos fragmentos del manifiesto que redactó el grupo de investigación en el momento de su creación:

El mejor homenaje a un escritor, vivo o muerto, consiste en leerlo, tarea particularmente difícil en el caso del exilio. Al margen de aquellos autores cuya obra ha sido total o parcialmente recuperada, una gran parte de nuestros escritores exiliados nos son aún hoy inaccesibles. (...) La mayoría de nuestros escritores exiliados, a quienes la política del franquismo condenó al silencio y al olvido, siguen siendo escritores ignorados.

Apelamos a la conciencia y a la sensibilidad de la sociedad española para que repare esta injusticia y salde, de una vez por todas y con la debida dignidad, esa deuda moral contraída con aquellos españoles que pagaron con el destierro forzoso su fidelidad a la legalidad democrática republicana y su defensa de la libertad de nuestra cultura. Apelamos a la necesidad y urgencia de recuperar este patrimonio cultural y literario. (pos. 34-42) 
Este trabajo de investigación es, sin lugar a duda, una respuesta a esa apelación que se hacía ya en 1993. En un mundo en el que los nacionalismos, las fronteras y las segregaciones sociales parecen gozar de una cierta acogida por algunos sectores de la sociedad, es necesario sacar a la luz testimonios y narrativas que defiendan una forma diferente de relacionarse con la nación de origen. No obstante, es significativo que actualmente, en 2019, aún no se hayan llevado a cabo los estudios necesarios para recuperar ese patrimonio al que hacía referencia este grupo también ni que las instituciones estatales hayan hecho el esfuerzo necesario para compensar el silencio al que han estado sometidos. Es por eso que este trabajo no es sólo una respuesta a esa apelación, sino que es también un nuevo llamamiento a seguir excavando en el patrimonio cultural del exilio republicano para recuperar otra parte esencial de lo que actualmente se viene denominando como España y así dar espacio a un nuevo discurso identitario nacional por parte de ciudadanos nacidos dentro de las fronteras españolas. El hecho de que algunos de los escritores que aparecen en este trabajo no aparezcan en una obra tan reciente como el diccionario ya mencionado, así como el hecho de que algunos de los libros autobiográficos a los que hago referencia hayan sido publicados en 2017 e incluso en 2018 son un perfecto ejemplo de actualidad, así como de la necesidad de seguir investigando sobre este asunto. Por esta razón, pretendo también animar a otros investigadores a unirse a este camino que tantas alegrías me ha producido como recompensa a infinitas horas de trabajo y esfuerzo.

Desde el momento del estallido de la guerra civil, se organizaron numerosas expediciones para que los niños saliesen del país, fuese bien con sus padres, con sus familiares o acompañados de personal de la República. Alicia Alted Vigil data las 
primeras salidas oficiales de niños al extranjero en marzo de 1937. Ya en esta época se evacuaron 100 niños procedentes de Madrid y Valencia a la Unión Soviética y unos 450 niños vascos a Francia, a la colonia "Casa Dichosa". De estos últimos, 300 se quedaron en París y el resto marcharon a Bélgica ("Los niños de la guerra civil" 51). En este mismo trabajo, Alicia Alted se encarga también de recoger las cifras de niños que fueron acogidos por distintos países: 20.000 por Francia, 4.000 por Inglaterra, 5.000 por Bélgica, 2.900 por la Unión Soviética, repartidos en cuatro expediciones, 455 por México, unos 800 por Suiza y un grupo de 100 por Dinamarca. Fueron, en total, unos 33.000 niños evacuados durante la guerra, a los cuales hay que sumar los que partieron con sus familiares (52-53). Ahora bien, aunque muchos de estos niños fueron repatriados, especialmente los que estaban en Francia, por la insistencia del gobierno franquista y por el llamamiento que muchos de sus familiares hicieron una vez acabada la guerra, los que decidieron quedarse en los países de acogida tuvieron que hacer frente a las mismas circunstancias que muchos adultos a pesar de las diferencias de edad. De entre todos estos niños, este trabajo se enfoca en aquellos que nunca regresaron de forma permanente a España o lo hicieron en una edad ya de madurez mental y con una clara conciencia de lo peculiar de su condición. Se trata de una generación marcada por varios elementos que van a determinar profundamente sus vidas. En primer lugar, la marcha involuntaria o, al menos, no por decisión propia. Con excepción de algunos casos como el de Isabel Argentina Álvarez, todos marcharon al exilio por decisión de sus padres o familiares. Además, no emigraban por sus ideales, sino por los de sus familiares ya que, en la mayoría de los casos, eran demasiado jóvenes para haber desarrollado una conciencia de lo que estaba sucediendo. En segundo lugar, se encontraban en un periodo de formación 
personal y profesional especialmente importante en el desarrollo de un ser humano que se ve interrumpido de repente. Se ven obligados a convertirse en adultos demasiado pronto, sufriendo así, en algunos de los casos, un trauma debido a una infancia perdida y la imposibilidad de establecer un lazo entre el yo-infantil y el yo-adulto. En el momento de su partida, la imagen de España que tienen es una visión idealizada debido a su pronta edad, imagen que permanece, en muchos casos, inmutable durante décadas debido a las numerosas historias y recuerdos que, durante su exilio, escucharon en boca de su entorno más cercano. Además, esta imagen idealizada de España idealizada suele estar basada en recuerdos de los demás más que en los suyos propios, lo que añade un significativo grado de ficción a sus obras. Así, se trata de una generación que vive en los límites entre dos países, el de nacimiento y el de acogida, entre dos culturas - a veces tres e incluso cuatro si han pasado por varios países durante su exilio-, entre dos lenguas, entre esperanzas por volver, sueños sin cumplir y recuerdos de una colectividad.

No es hasta 2009 que esta generación recibe la atención de la crítica a través de la celebración del primer congreso —y único hasta el momento — dedicado a la misma. Dos años más tarde, sale a la luz un volumen titulado El exilio republicano de 1939 y la segunda generación que recoge las ponencias celebradas en dicho encuentro. No obstante, no puede considerarse un estudio en conjunto en el sentido clásico del término, ya que no establece relaciones entre los miembros de la generación pertenecientes a diferentes países de acogida, sino que son breves trabajos individuales sobre diversos temas de dicha generación que bien es cierto que dejan clara la necesidad de una investigación más en profundidad. Al margen de esta obra, Susana Rivera había publicado Última voz del exilio: el grupo poético hispano-mexicano (1990), término que 
la crítica ha designado a la segunda generación de escritores residentes en México. Por otro lado, Eduardo Mateo Gambarte, precursor también de los estudios de esta generación desde un punto de vista literario, había publicado en 1996 el libro Los niños de la guerra. Literatura del exilio español en México ${ }^{1}$. Angelina Muñiz-Huberman, niña de la guerra, publica en 1999 un trabajo titulado El canto del peregrino: hacia una poética del exilio en el que dedica los dos últimos capítulos a su generación. No obstante, a excepción de estos trabajos mencionados, el resto de estudios se trata de artículos individuales, entre los que destacan los de Carolyn Galerstein², Eduardo Mateo Gambarte ${ }^{3}$ y Roberto Ruiz ${ }^{4}$, o trabajos individuales sobre algunos de los autores, como María Luisa Elío Bernal. La vida como nostalgia y exilio, de Mateo Gambarte, El exilio en la poesía de Tomás Segovia y Angelina Muñiz-Huberman, de Eduardo Tasis Moratinos, así como El escritor y el intelectual entre dos mundos: lugares y figuras del desplazamiento, coordinado por

\footnotetext{
${ }^{1}$ Es necesario hacer la distinción entre estudios desde un punto de vista literario y los que se hacen desde un punto de vista histórico porque sí son muy numerosos los trabajos desde esta última perspectiva que se han dedicado a los niños de la guerra. Véanse, entre otros, Los niños de la guerra, de Teresa Pamies; Los niños de Morelia, de Dolores Pla; Los niños españoles evacuados a la URSS, de Enrique Zafra, Rosalía Crego y Carmen Heredia; Les enfants espagnols réfugiés en France, 1936-1939, de Pierre Marqués; Los Niños. Histoire d'enfants de la Guerre civile espagnole exilés en Belgique (1936-1939), de Emilia Labajos-Pérez y Fernando Vitoria-García; Los niños de la guerra de España en la Unión Soviética. De la evacuación al retorno (1937-1999), de Alicia Alted, Encarna Nicolás y Roger González; o Los hijos del exilio vasco: arraigo o desarraigo, de José Ángel Ascunce Arrieta y María Luisa San Miguel.

2 "The Second Generation in Exile".

${ }^{3}$ Entre otros, "La vuelta a un vacío llamado recuerdo: segunda generación del exilio republicano español en México"; "La segunda generación del exilio español en México: ¿españoles o mexicanos?"; "Segunda generación del exilio español a México: la presencia del exilio en su obra".

4 "La segunda generación de escritores exiliados en México"; "Homenaje a la segunda generación"; "Presencia: una revista de la segunda generación exiliada".
} 
Cecile Chantraine-Braillon, Norah Giraldi y Faitha Idmhand, que recoge numerosos estudios en torno a Fernando Aínsa, o Encuentros en la diáspora: ensayos en honor de Carlos Blanco Aguinaga, de Mari Paz Balibrea, Rosaura Sánchez, Beatrice Pita y Jaime Concha. Destaca también la labor que se ha hecho desde la revista Laberintos, editada por la Biblioteca Valenciana Nicolau Primitiu y a cargo también de Manuel Aznar Soler. Esta ha dedicado secciones a algunos de los escritores de la segunda generación, como el homenaje hecho a Angelina Muñiz-Huberman en el número 15 que recoge diez estudios de diversa índole sobre la escritora.

Este breve recorrido por algunos de los estudios en torno a la segunda generación de escritores exiliados por la guerra civil española -el cual debe completarse con un estudio más pormenorizado de la bibliografía disponible al final del trabajo- deja ver claramente unos vacíos importantes en el campo de la investigación literaria. En primer lugar, la no existencia de un estudio que recoja a todos los niños de la guerra, sin tener en cuenta el país de acogida, puesto que todos ellos comparten un mismo elemento en común: marchar al exilio siendo un niño por el deseo de sus padres o familiares. En segundo lugar, la primacía del estudio de los niños de esta generación establecidos en México frente a aquellos otros niños-escritores que se asentaron en otros países como la URSS, Francia, Reino Unido, Cuba, República Dominicana, EEUU o Uruguay, y de los cuales apenas hay rastro hoy en día. ${ }^{5}$ En tercer lugar, la supremacía de los estudios

\footnotetext{
${ }^{5}$ Véase el caso de Manuel Fernández Montesinos, Luis Santamaría, Manuel Arce o Isabel Argentina Álvarez Morán.
} 
poéticos frente a aquellos que exploran la narrativa o el teatro; ${ }^{6} \mathrm{y}$, en cuarto lugar, un mayor aproximamiento desde el punto de vista histórico que literario. Es en este vacío en el campo de la crítica literaria donde cabe ubicar este trabajo de investigación que pretende reunir todas o casi todas las obras narrativas clasificables dentro de la literatura del yo - ya sean autobiografía/autoficciones, memorias, diarios, etc. - con el fin de reunir un corpus lo suficientemente amplio que nos permita identificar unos puntos de contacto entre todos estos niños que sufrieron una misma experiencia común: el exilio "involuntario". 7

Con el objetivo de cumplir dicha tarea, este trabajo pretender estudiar estos discursos narrativos en relación con dos aspectos importantes en la construcción de la identidad: por un lado, el concepto de "nación" y la relación de este con el espacio, el

${ }^{6}$ Véase la abundancia de obras en torno a la poesía y la apenas inexistente bibliografía sobre la narrativa específicamente: Segunda generación de poetas españoles del exilio mexicano, Francisco Giner de los Ríos; Ecos del exilio. 13 poetas hispanoamericanos. Antología, de Bernard Sicot; el trabajo ya citado de Susana Rivero Última voz del exilio. El grupo hispano-mexicano; "Visita a seis poetas hispanomexicanos. Exilio y memoria", de Enrique López-Aguilar; o "De éxodos, exilios, guerras, poetas y generaciones. Poesía española del exilio republicano de 1939: la segunda generación de poetas del exilio en México", de Enrique de Rivas.

${ }^{7}$ Es difícil asegurar la inclusión completa de todas estas obras por diversas razones: en primer lugar, por la escasa difusión que muchas recibieron en el momento de su publicación; en segundo lugar, por la mínima bibliografía que hay en torno a ellas; en tercer lugar, por la posible publicación de estas en otros idiomas hablados en los países de acogida cuyos títulos han podido pasar desapercibidos ante mis ojos; en cuarto lugar, por la difícil categorización de estas obras, ya que muchas de ellas están entre varios géneros y quizá yo haya considerado dentro de la literatura del yo obras que otros críticos no las consideran, o viceversa; y, en quinto lugar, por la existencia, aún hoy en día, de muchas obras sin publicar y cuyo acceso a los manuscritos me ha sido imposible como el caso de La travesía, de José Carmona. No obstante, el trabajo de investigación ha sido muy exhaustivo y este trabajo hace referencia a gran parte de estos trabajos. 
tiempo y el lenguaje; y por el otro lado, el papel del yo a través de la escritura y sus relaciones con la memoria y el trauma. Únicamente se recogen textos dentro de la literatura del yo al considerarse este género el más propicio para la interiorización personal y la confesión, necesarias para poder conocer algo tan íntimo como la identidad, dejando de lado el género poético tan estudiado ya en algunos casos. Ello no significa que, en algún momento, no pueda hacerse referencia a alguna novela en la que el autor revele parte de su ser, aunque no sea el propósito de este trabajo ni ofrezca un exhaustivo estudio de este otro tipo de narrativas.

Hasta ahora he hecho referencia al término "exiliado" para referirme a estos individuos que tuvieron que salir huyendo de España para proteger sus vidas dejando de lado lo que implica ser exiliado o refugiado. Exiliarse comporta el forzoso abandono del país natal debido al miedo a las represalias políticas. Este fenómeno provoca un sentimiento de vacío y desplazamiento marcado por la dificultad de formar parte del nuevo lugar de residencia, así como por las contrariedades que supone la reconciliación temporal con el momento histórico del país de acogida. Por lo tanto, esta experiencia provoca una dislocación que nos lleva a revalorizar los conceptos de patria, nación, espacio, tiempo y lenguaje, a los que hacía referencia anteriormente. Tal es así que Homi Bhabha elabora su idea sobre la liminalidad e hibridez para definir el espacio creado por el exilio para producir un discurso diferente al de la posición dominante. Estos conceptos apuntan a un mejor entendiendo de los escritos autobiográficos de la segunda generación ya que sus narrativas están caracterizadas por una indeterminación que señala pasajes 
transitorios, un perturbador estar entre polos opuestos y una hibridez cultural que explora la diferencia y rechaza jerarquías rígidas e inmutables. ${ }^{8}$

En relación con la problemática de la identidad nacional, analizaré los textos autobiográficos como ejemplos del transnacionalismo y la aculturación que muchos de estos autores experimentan en el exilio. Es especialmente importante destacar las teorías de Deleuze y Guattari sobre la desterritorialización que, aplicada al caso de esta generación, puede entenderse como una ruptura con los límites inherentes al sistema dictatorial español. En esta tesis, exploro también la ruptura del orden cronológico-lineal que sufren algunas de las narrativas del yo como consecuencia del exilio, así como la tensión dialéctica establecida entre presente, pasado y futuro para explicar cómo conforman una identidad a través del tiempo.

Otro elemento importante a considerar es la representación del yo a través de la literatura, así como el papel que juega la memoria en las obras autobiográficas. Sidonie Smith define la autobiografía como el espacio literario en el que el sujeto "shapes an identity out of an amorphous subjectivity" (A Poetics 5). Esto conlleva una recategorización del concepto de "verdad", el cual deviene en "verdad autobiográfica". Por lo tanto, debe entenderse la autobiografía como el espacio del nacimiento de un yo en relación a la escritura (Eakin), elemento especialmente importante en relación con la segunda generación de escritores exiliados. Paul Ricouer establece una dicotomía entre mneme and anamnesis, dependiendo de si la memoria "comes in the way of a condition" o si esta "consists of an active research", respectivamente (36-37). Esta búsqueda activa

\footnotetext{
${ }^{8}$ Entiéndase el uso del término "autobiográfico" como sinónimo de "literatura del yo".
} 
es aparente en este grupo de autores y el retorno a España se dibuja como la expresión final de su necesidad de comprender su relación con su país natal. En último lugar, presto atención a la interacción entre memoria individual y memoria colectiva, entendidas ambas dentro de un marco social.

De este modo, en el primer capítulo, "Consideraciones teóricas. Cuestionando la identidad de los exiliados", pretendo desarrollar el marco teórico al que vengo haciendo referencia brevemente en estas páginas para poder establecer los elementos clave a la hora de estudiar los textos autobiográficos de la segunda generación de escritores en el exilio. Por lo tanto, en primer lugar, se esboza la problemática existente en torno a la diferente terminología que se ha usado para hacer referencia al exiliado y las implicaciones que conlleva cada término. Es necesario señalar el estudio de Paul Tabori en el que analiza el origen de la palabra "exilio" y posteriormente establece las diferencias con otros vocablos como "refugiado", "inmigrante" o "desterrado". En segundo lugar, se dibujan las principales consecuencias del fenómeno del exilio. De este modo, se plantean cuestiones como la relación con un espacio geográfico, con un tiempo lineal e histórico, así como con el lenguaje. En tercer lugar, se establecen las relaciones existentes entre la "Historia", entendida esta como exposición de acontecimientos de un pueblo o nación de forma objetiva, e "historia", siendo esta última el relato de un sujeto o un grupo colectivo minoritario que se ha visto marcado por el transcurso de la "Historia". Es la influencia de la "Historia" sobre la "historia" la que ha dado lugar al nacimiento de unas narrativas que intentan escapar del yugo de esta "Historia" para crear así un discurso narrativo que de espacio a otras identidades culturales. En cuarto lugar, se hace un repaso por los estudios teóricos más importantes de dichas identidades, desde las teorías de 
Claudio Guillén, pasando por Michael Ugarte y Michael Seidel, hasta llegar a los estudios de Sophia McClennen que explora los discursos narrativos del exilio como una dialéctica. A partir de estas teorías se desarrollan los conceptos teóricos que nos permiten responder preguntas tales como a qué espacio geográfico pertenecen estos escritores o en qué espacio geográfico se sitúan a sí mismos, así como en qué tiempo histórico están inscritos.

Así, teniendo en cuentas los estudio de Benedict Anderson, Homi Bhabba y Gellner y el nacimiento de conceptos como transnacionalismo y transculturación, se produce un acercamiento a las teorías de desterritorialización de Gilles Deleuze y Félix Guattari como mecanismo para escapar de las garras restrictivas del concepto de nación y se plantea también el concepto de sujeto nómada tan defendido por Pierre Joris y Rosi Braidotti como elemento de lucha contra las convenciones sociales. En cuanto a la concepción del tiempo, se hace un repaso de las teorías de Tabori y Wittlin sobre la doble temporalidad y se revisa el concepto de destiempo creado por Guillén para valorar la existencia de múltiples esquematizaciones temporales dentro de una misma obra. También a partir de las teorías expuestas anteriormente se aborda la problemática del lenguaje como herramienta para aprehender la realidad, en este caso la experiencia del exilio, y como sistema de comunicación que se enfrenta al choque entre la lengua materna y la lengua del país de acogida. Por otro lado, este capítulo ofrece una serie de planteamientos necesarios en relación con la literatura del yo. Tras un acercamiento a las teorías de Georges Gusdorf, Paul de Man, James Olney, Philippe Lejeune, John Eakin y Ángel Loureiro, reflexiono sobre qué papel juega la imaginación y la memoria como elementos constructivos de un discurso narrativo de la identidad, la verosimilitud del 
relato y la ficcionalización de este, el rol de la memoria colectiva en contraposición a la individual y la presencia del trauma (Ricouer, Halbwachs, Bergson y Todorov).

En el segundo capítulo, "España fuera de España (I). Niños convertidos en escritores: narrativas reconstructivas de la identidad", se lleva a cabo un estudio de las principales características de la segunda generación de escritores exiliados por la Guerra Civil Española. Cabe aclarar que el hecho de utilizar el término "generación" no es más que una herramienta metodológica que tiene como fin unir a un grupo de autores, nacidos en un intervalo concreto, cuyo origen es el hecho de ser víctimas de una guerra civil en la que nunca tuvieron capacidad de decisión. Esto no quita, por otra parte, que existan unos rasgos comunes en su obra, en este caso, en su obra narrativa autobiográfica o autoficcional, pues es este el campo de estudio de este trabajo, ni, por lo contrario, que se niegue el papel de la individualidad tan importante en unos autores que buscan crear un espacio en el que transmitir su voz. Cronológicamente han sido varios los periodos propuestos por otros críticos como Eduardo Mateo Gambarte, Susana Rivera, Bernard Sicot, Angelina Muñiz-Huberman, Enrique de Rivas o Roberto Ruiz. No obstante, creo que el más amplio es el propuesto por el crítico Fernando Larranz por acoger de forma más completa a un conjunto de ciudadanos si afirmamos que el nexo original de unión es el hecho de no ser responsables del conflicto (Memoria y autorrepresentación 584). Según este crítico la segunda generación estaría compuesta por aquellos niños nacidos entre 1920, que son aún adolescentes cuando explota la guerra civil, y 1942, habiendo así nacido los más jóvenes en los primeros años de sus padres en el exilio. No obstante, y a pesar de las numerosas clasificaciones, propongo una nueva categorización que tenga en cuenta no las fechas de nacimiento, sino la edad con la que estos niños parten al exilio, tal 
y como justifico detenidamente en este capítulo. Una vez establecidos los rasgos principales de esta generación, en este apartado realizo un estudio sobre los principales temas en común existentes entre los miembros de dicho grupo, tales como la infancia, las relaciones familiares o la presencia del retorno. Asimismo, realizo una clasificación general de los diferentes subgéneros de la literatura del yo a los que recurre dicha generación para configurar su identidad (autobiografía, memoria, diario, cuaderno de apuntes o novelas del yo). Tras hacer una división entre escritores profesionales de la escritura y escritores no profesionales, exploro el lugar de la autoficción como elemento característico de los miembros más profesionales para crear un discurso identitario en el que la desaparición de las fronteras entre ficción y verdad tienen una correlación con la desaparición de las fronteras geográficas, temporales o lingüísticas que desarrollo en el siguiente capítulo. Para llevar a cabo dicho estudio, analizo tres obras principalmente: Dulcinea encantada, de Angelina Muñiz-Huberman, Un tiempo tuyo de Carlos Blanco Aguinaga y Tanguy. Histoire d'un enfant d'aujourd'hui de Michel del Castillo.

En el tercer capítulo, "España fuera de España (II). Niños convertidos en escritores: una identidad en lucha con los conceptos de nación, tiempo y lenguaje”, se explora la creación de un discurso identitario por parte de la segunda generación de escritores en relación a los términos de nación, tiempo y lenguaje. En primer lugar, intento responder a la pregunta sobre la existencia de una identidad nacional propia de dicho grupo. Para ello, analizo la influencia del papel de la identidad de sus padres, de los centros especiales creados para los exiliados, así como de la visión imaginaria de España que muchos de ellos tienen y el papel del primer viaje de regreso a España en la configuración de su propia identidad. Tras esto realizo una clasificación de los distintos 
procesos que ha sufrido dicha generación en cuanto a su formación como sujetos ligados a un espacio geográfico. De este modo, se encuentran varios grupos: aquellos que asumen la experiencia del exilio de forma natural y construyen una identidad sin enfrentarse a graves conflictos personales, como es el caso de Carlos Blanco Aguinaga o María Casares. En segundo lugar, existe un grupo de escritores que se aferran a su identidad española en un primer momento aunque esta sufre tres resultados distintos: por un lado, la pérdida de fuerza con el paso del tiempo, tal y como sucede en los casos de Enrique de Rivas o Jorge Semprún; por otro lado, su permanencia intacta hasta el momento del regreso por primera vez a España que pone fin con la imagen existente de esta en sus mentes, como es el caso de María Luisa Elío Bernal o Emilia Labajos, y que los obliga a reconfigurarse como sujetos; y, por último, la existencia de un grupo que, a pesar de sufrir un cuestionamiento personal sobre sí mismos durante el exilio, se reafirman en su identidad nacional española tras el viaje de regreso, como por ejemplo Tatiana Pérez o Manuel Fernández Montesinos. En tercer lugar, existe un grupo de escritores que se mantienen fieles a su identidad nacional española desde su salida del país y esta no sufre ningún trastorno grave con el paso del tiempo. En este subgrupo encontramos a Nieves Cuesta o María Álvarez del Vayo. De hecho, esta última afirma: “Mi identidad sigue siendo la misma después de tantos años de residencia en Francia” (Patria 130). Finalmente, existe un grupo de escritores cuya obra autobiográfica no ofrece una reflexión sobre su identidad nacional, tales como son los textos de Luis de Santamaría o Manuel Arce.

Ahora bien, independientemente del proceso que hayan sufrido para llevar a cabo la configuración de su identidad nacional, esta ha conllevado el resultado de dos formas 
predominantes: por un lado, la desterritorialización como elemento desvinculante de un espacio geográfico, es decir, como habilidad de relacionarse con diferentes naciones sin establecer jerarquía entre ellas. De hecho, Braidotti se apoya en este concepto para desarrollar su teoría del sujeto nómada que lucha contra el discurso narrativo nacionalista impuesto desde los círculos de poder. Por otro lado, la existencia de una identidad nacionalista arraigada en España tan fuerte como la de los miembros de la primera generación.

Una vez analizado el discurso identitario nacional, exploro sus relaciones con el fenómeno temporal. Reflexionando sobre la afirmación de Mateo Gambarte que apunta al tiempo como el gran problema del exilio, exploro la convivencia de las diferentes esquematizaciones temporales existentes en la obra autobiográfica de esta generación como elemento característico, tal y como expone McClennen en relación a la obra de Goytisolo, Peri Rossi y Dorfman. De esta forma, se observa la existencia tanto de un discurso temporal en el que se combinan pasajes enfocados en el momento previo al exilio con otros que asumen la imposibilidad de ser parte del presente histórico de su país de origen así como el sentimiento de una repetición cíclica de castigo, la sensación de un "destiempo" o la creación de un tiempo propio e individual. Por lo tanto, analizo de qué forma puede encontrase dicha convivencia como elemento del discuro identitario de esta generación y si puede extenderse de forma general a la generación o sólo se ajusta a ciertos miembros.

En último lugar en este capítulo estudio la doble concepción del lenguaje, tanto como elemento identitario de una comunidad como herramienta para representar la "Historia" de un grupo de sujetos subalternos. Por lo tanto, estudio cómo influyó el hecho 
de que, en su mayoría, fueran escritores bilingües, o incluso políglotas en algunos casos, en la creación de un discurso identitario. Así, la transculturación idiomática se percibe como un elemento característico de esta generación que, al igual que señalaba a la hora de hablar de desterritorialización, ha desvinculado al sujeto de una nación única y restrictiva. En último lugar, es también dicha transculturación un elemento que utiliza esta generación para crear un discurso cultural opuesto al que se ha escrito durante muchos años bajo el franquismo y durante los años de democracia también en los que se ha silenciado su historia a través del pacto del olvido.

Los capítulos cuarto y quinto se centran en las figuras de María Luisa Elío Bernal y Jorge Semprún, respectivamente. La elección de estos autores ha de justificarse tras un análisis de las diferencias y semejanzas existentes entre ellos. Bien es cierto que existen otros autores a los que podría haber dedicado un capítulo aparte, pero tuve que renunciar a ello por cuestiones de espacio. Con una diferencia de tan sólo tres años, ambos autores habían nacido en familias acomodadas, pertenecientes a la clase alta de la sociedad, pamplonesa en el caso de Elío Bernal y madrileña en el caso de Semprún, y ambos habían sufrido el exilio al ocupar sus padres importantes cargos dentro de la República. No obstante, mientras que Semprún quedó en Francia y fue víctima de la invasión nazi, Elío Bernal huyó junto a su familia a México. Ahora bien, más allá de las similitudes o diferencias biográficas que podemos encontrar en ambos autores, el principal nexo de unión entre ellos es el resultado identitario al que llegan, a pesar de que el proceso hasta él haya sido muy diferente en cada caso, así como la utilización que los dos autores hacen de la escritura para expresar un discurso narrativo identitario propio. Aunque el trauma aparece tanto en los relatos del uno como del otro, en el caso de la escritora pamplonesa 
este está aferrado a la pérdida de su patria mientras que, en el caso del autor madrileño, este está marcado, fundamentalmente, por su experiencia en el campo de concentración de Buchenwald. Aún así, este último consigue integrar dicha experiencia en su discurrir como ser humano de una forma más natural que Elío Bernal, en cuyo relato se observa cómo el trauma impide su desarrollo como individuo hasta el momento del regreso por vez primera a España. Por lo tanto, a pesar de las diferencias en cuanto al papel del trauma y el lugar de la memoria tanto en sus obras como en sus identidades respectivas, afirmo que ambos escritores utilizan la escritura para superar a sus traumas. Al mismo tiempo, a través de la re-escritura de su experiencia consiguen configurar una identidad que, en ambos casos, resulta estar totalmente desterritorializada, en la que aceptan la desaparición de las fronteras geográficas, la multiplicidad de estructuras temporales y su mestizaje lingüístico como elemento característico de una identidad que, de una forma u otra, se ha forjado en la lucha contra una forma de ser impuesta por los círculos de poder franquista.

Nacida en Pamplona en 1926, María Luisa Elío Bernal marchó al exilio con tan sólo 8 años tras la detención de su padre el día del alzamiento y, después de cuatro años en Francia, llegó a México en 1940, donde se instaló hasta su muerte en 2009. Vivió durante toda su vida en el exilio y sólo regresó a España durante cortos periodos de tiempo. En el momento de su muerte, dejó tras de sí una película basada en su propia vida, En el balcón vacio (1962), realizada junto a su marido, Jomí García Ascot, y ganadora de varios premios; dos obras narrativas, Tiempo de llorar (1988) y Cuaderno para apuntes (1995), publicadas en España bajo el título de Tiempo de llorar y otros relatos; y una obra póstuma, publicada por su hijo Diego con el título Voz de Nadie 
(2017). A pesar de la escasa y corta obra literaria, esta destaca por su excelente calidad literaria y por la, paradójicamente, escasa atención que, salvadas excepciones, ha recibido por parte de la crítica. Su relato autobiográfico parte de su primer viaje de regreso a España en 1970 para sumergirse en una búsqueda identitaria basada en la oposición entre pasado y presente. La obra constituye un discurso intimista y sincero en la que la autora expone la problemática relación entre ella y su país de origen, su infancia y su madurez en la que la escritura parece ser la única salida a dicho conflicto. El reencuentro con una España que no correspondía con la imagen que tenía en su cabeza incrementa la sensación de vacío causada por el exilio. De esta forma, se produce también un enfrentamiento entre los diferentes yoes de la autora: el yo-infantil anclado al pasado y el yo-adulto suspenso en el vacío, en un presente sin raíces. De esta forma, este capítulo explora la construcción de la identidad nacional basada en la contraposición entre ambos países que se materializa a través del viaje de regreso y la lucha entre los yoes. En segundo lugar, se expone el papel que juega la escritura en la creación de dicha identidad y la función de esta como mecanismo curativo del trauma de la escritora.

Finalmente, nacido en 1923 en una de las familias más poderosas de la aristocracia madrileña, Jorge Semprún marchó al exilio en 1936. Fue detenido en 1943, en Francia, y fue ingresado en el campo de concentración de Buchenwald hasta 1945. A partir de 1953 empezó a colaborar en la clandestinidad en España con el PCE durante diez años. Tras su expulsión de este en 1964, se dedicó a la escritura hasta que en 1988 se convirtió en ministro de Cultura. A los 68 se retiró de la vida política y murió en 2011. Para entonces había publicado una importante obra literaria y cinematográfica. Sin embargo, sólo nos interesa con motivo de este trabajo su obra autobiográfica o 
autoficcional. La crítica María A. Semilla Durán ha realizado una clasificación de la obra de Semprún según las relaciones entre las representaciones ficticias del yo y su propia persona. De este modo, ha categorizado su obra en tres grupos: en primer lugar, aquellas obras en las que el "doble legítimo" del autor es el producto de una narración ficcionalizada de los eventos que él mismo experimentó, como es el caso de El largo viaje y El desvanecimiento; en segundo lugar, se encuentran aquellos relatos que contiene un "doble legítimo" cuya vida coincide únicamente de forma parcial con la del autor, tal y como ocurre en La montaña blanca; y, finalmente, en la tercera categoría incluye obras como La algarabía o La segunda muerte de Ramón Mercader, en las que el protagonista, cuyo nombre es bien ficticio o bien real, y su trayectoria no coinciden con la del autor, aunque puedan encontrarse rasgos autobiográficos (158). Por lo tanto, únicamente las obras pertenecientes al primer grupo son objeto de análisis de este trabajo, ya que se considera que la reflexión sobre la identidad es más propicia en aquellas narraciones de gran contenido autobiográfico. Las obras que, desde mi punto de vista, deben pertenecer a esta categoría son: El largo viaje, El desvanecimiento, Autobiografía de Federico Sánchez, Aquel domingo, Federico Sánchez se despide de ustedes, La escritura o la vida, Adiós, luz de los veranos ... y, en menor medida, Viviré con su nombre, morirá con el mío. Aún así es posible encontrar referencias a otras obras ya que toda la narrativa del escritor madrileño se caracteriza por estar compuesta de toques autobiográficos que, en algún momento, pueden ser de utilidad para entender la construcción de la identidad, como es el caso de la reflexión sobre el lenguaje en La algarabía o la reconstrucción de la infancia, el exilio y la nostalgia en obras como Veinte años y un día. A través del análisis de las obras mencionadas, este capítulo pretende dar respuesta a varios 
interrogantes: por un lado, de qué forma la escritura funciona como proceso para la construcción de una identidad tras la salida de España, para lo cual es necesario analizar el perspectivismo presente en su obra a causa del relato de un mismo acontecimiento desde distintos momentos históricos, como es el caso de la narración de su experiencia en el campo de concentración o su infancia. Por otro lado, explora los mecanismos para aproximarse a la realidad y en qué medida se establece una dialéctica entre ficción y realidad. Esto nos lleva a plantearnos la cuestión de la multiplicidad de géneros literarios dentro de la literatura autobiográfica utilizados por el escritor madrileño, así como el papel de la memoria y, concretamente, de la tensión entre memoria colectiva y memoria individual en la narración literaria y en la construcción identitaria a través del recuerdo.

En definitiva, esta tesis centra su estudio en varios elementos que se entrelazan en la narrativa autobiografía de la segunda generación de escritores españoles exiliados cuya inestable identidad fue configurada en el exilio. Por lo tanto, exploro: 1) la negociación cultural que estos escritores establecen al ser forzados a confrontar dos identidades nacionales, la de su país de origen y la de su país de acogida; 2) la dialéctica temporal establecida entre el pasado y el presente de sus vidas en los países adoptivos; 3 ) la capacidad del lenguaje para aprehender el pasado a través de la memoria; 4) las estrategias narrativas que desarrollan en repuesta a su situación de inbetweeness causada por el exilio; 5) las dinámicas creadas en los trabajos autobiográficos bajo revisión en relación con el lenguaje y la cultura, y la conversión de estas narrativas como lugares de intersección entre la lengua natal y la lengua adquirida, entre el yo y el otro; 6) la importancia de la memoria, el olvido y el trauma en la representación del yo. 


\title{
Capítulo I
}

\section{Consideraciones teóricas. Cuestionando la identidad de los exiliados}

\author{
Mis raíces prefiero que \\ estén al viento y que se puedan \\ hundir en cualquier tierra
}

Tomás Segovia

Estas palabras de Tomás Segovia son la reflexión de un escritor que ha hecho del exilio su aprendizaje vital. Pero, ¿cuál es su patria?, ¿adónde pertenece?, ¿quién es él? En este capítulo pretendo explorar, en primer lugar, las cuestiones teóricas relevantes en torno a la relación existente entre exilio e identidad. Hablar de identidad conlleva igualmente discutir los conceptos de nación, espacio, tiempo y lenguaje, conceptos moldeables y cambiantes en el discurso de unos individuos que, como ya se aclaró en la introducción, están aún en formación. En un segundo apartado, procederé a explicar la importancia que tiene la literatura del yo para un sector de la sociedad que ha visto silenciada su voz por su oposición al poder vigente. Asimismo, este estudio lleva consigo entender cómo funciona la memoria debido a la relevancia que tiene esta a la hora de hablar de textos del autos, usando los términos de James Olney. ${ }^{9}$ Para terminar, destacaré la necesidad de un replanteamiento teórico del elemento temático del "mito del retorno", así como del "viaje de retorno", pues son dos aspectos decisivos en la formación de la identidad con la que se comienza este apartado.

\footnotetext{
${ }^{9}$ Esta referencia al autos es el punto clave de la nueva dirección que toma la teoría crítica de la autobiografía, por el que esta no se centra en la vida en sí, el bios, sino en el sujeto.
} 
La palabra exilio tiene numerosas connotaciones para el que lo vive: expulsado de su casa, de su clase social, de sus relaciones familiares, de su trabajo, de su patria, de su Historia -incluso de su historia con minúscula en ocasiones-, de su tiempo, de su cultura, de sí mismo. En definitiva, significa ser desahuciado por un poder que tiene absoluta confianza en la superioridad de una cultura única y centralizada (Guillén "On the Literature” 275). Este es el caso de la segunda generación de escritores del exilio español de 1939. Efectivamente, la proclamación de la victoria franquista el 1 de abril de 1939 supuso la salida al exilio de más de 200.000 civiles debido a las discrepancias con el régimen instaurado. Estos ciudadanos que abandonaron su patria por sus diferencias con la ideología política establecida arrastraron con ellos a sus hijos e hijas, que no fueron sino otras víctimas del conflicto. Estos niños aún no tenían una plena consciencia de lo que estaba sucediendo, desconocían el significado de la palabra "guerra", ignoraban lo que representa el término "patria" y, por lo tanto, no habían desarrollado una postura ideológica que les permitiera decidir por sí mismos su posición ante tal contienda. De este modo, la guerra civil supone una ruptura en su formación como ser humano sin una justificación aparente. Esto nos lleva a cuestionarnos diferentes temas en relación a la configuración de la identidad. Considerando los términos de espacio y tiempo, elementos clave en la formación de dicha identidad, es necesario preguntarse en qué espacio geográfico se situarían dichos escritores, si es posible dibujar un espacio para ellos, así como a qué tiempo histórico pertenecen. Esto conlleva indagar en la problemática creada entre un país que no le ha permitido vivir en él y un país que no los ha visto nacer. Además, el lenguaje es también un rasgo identificativo imprescindible de la identidad, por lo que hay que resolver la problemática que surge entre este como capacidad de 
aprehender la realidad y como herramienta comunicativa, así como el choque surgido entre la lengua materna y la lengua del país de destino ${ }^{10}$.

Evidentemente, estas preguntas no tienen una respuesta única. Las situaciones individuales de cada miembro de dicha generación --edad en el momento de partida, género, educación, clase social, ciudad de origen, desarrollo en el país de acogida, círculos sociales - van a afectar considerablemente en el desarrollo del individuo. Sin embargo, muchos de ellos recurren a un mismo tipo de literatura: la literatura del yo. Esto conlleva también una serie de planteamientos que exploraré en este capítulo, ya sea el por qué se acogen a la literatura del yo, o bien la dicotomía entre verdad y mentira en dichas narraciones. En otras palabras, reflexionaré sobre qué papel juega la imaginación y la memoria en estos textos y delimitaré cuáles son las fronteras entre los distintos géneros de la literatura del yo o, en un segundo nivel, entre la autobiografía y la auto-ficción. ${ }^{11}$

La combinación de todos estos elementos hace de la narrativa de la segunda generación del exilio de 1939 un terreno de trabajo especialmente fructífero que, sin embargo, no ha sido suficientemente explorado, tal y como ha quedado demostrado en la introducción previa. Por lo tanto, en las siguientes páginas se va a desarrollar el marco teórico de los distintos aspectos ya mencionados para, en el segundo y el tercer capítulo, poder analizar los textos de dicha generación.

\footnotetext{
${ }^{10}$ En este caso habrá que hacer una diferenciación entre aquellos países que comparten un mismo idioma, que no una misma forma de hablar, y aquellos cuyos países utilizan lenguas distintas.

${ }^{11}$ Término creado por el teórico francés, Serge Doubrovsky, tras la publicación de su obra Fils en 1977 y tras un profundo estudio de algunas novelas hasta ese momento denominadas autobiográficas.
} 


\section{Exilio e identidad: nación, tiempo y lenguaje}

En su estudio "DissemiNation: Time, Narrative, and the Margins of the Modern Nation”, Homi Bhabha hace referencia al exilio como ese fenómeno de reunión, de reunión con el otro, con otro tiempo, con otra nación, con otra lengua, con otro espacio y discurso, con otra vida:

I have lived that moment of the scattering of the people in other times and other places, in the nations of others, becomes a time of gathering. Gatherings of exiles and emigrés and refugees, gathering on the edge of 'foreign' cultures; gathering at the frontiers; gatherings in the ghettos or cafés of city centres; gathering in the half-life, half-light of foreign tongues, or in the uncanny fluency of another's language; gathering the signs of approval and acceptance, degrees, discourses, disciplines; gathering the memories of underdevelopment, of other worlds lived retroactively; gathering the past in a ritual of revival; gathering the present. Also the gathering of the people in the diaspora, indentured, migrant, interned; gathering of incriminatory statistics, educational performance, legal statutes, immigration status. (291)

Exiliado, expatriado, refugiado, inmigrante, desterrado o desarraigado son todos términos que indican un movimiento en el espacio desde la tierra de origen hacia un nuevo destino. Sin embargo, no todos ellos tienen las mismas implicaciones. En The Anatomy of Exile, Paul Tabori analiza el origen etimológico de la palabra "exilium" de la que proviene "exilio". "Ex" significa "salir" y "solum" representa "tierra", por lo que 
exilio podría ser definido como "fuera de la tierra". Sin embargo, hay que afinar más para distinguir esta palabra de las muchas otras enunciadas anteriormente. ¿Por qué se encuentra el sujeto fuera de la tierra?

El término exilio implica que el desplazamiento es forzoso; es decir, no por voluntad del sujeto, sino que son las circunstancias políticas las que lo obligan a marchar $^{12}$. Puede argumentarse que el expatriado o el inmigrante se ha visto comprometido también por las circunstancias económicas de su país a salir, pero su vida no está en riesgo, sino que es el deseo de prosperar el motor de dicha partida. Sin embargo, desde un punto de vista legal, Tabori señala que el término exiliado y refugiado comparten las mismas condiciones, ya que este último significa "huir o escapar". Los términos de destierro o desarraigo han ocupado un lugar menos importante en la teoría crítica, probablemente por la dificultad de su traducción al inglés, aunque el primero de ellos aparece ya en la obra de El Cantar de Mio Cid (McCleenen 20). De hecho, Claudio Guillén, uno de los padres de la teoría del exilio, aboga por el uso del vocablo "destierro". Sin embargo, a pesar de esta breve distinción entre esta maraña de términos, Sophia A. McClennen, a la cual me sumo, aboga por el uso del empleo del término "exilio" como un sentimiento, es decir, sentirse exiliado no implica necesariamente temer por tu vida por discrepancias con el régimen político, sino sentirse como tal por el hecho de "dejar de estar para tener que ser": "If exiled writers use 'exile', or some variation of the word, to describe their condition, and if their writing attempts to represent the

${ }^{12}$ El término "exilio" no forma parte del Diccionario de la Real Academia hasta 1956 y, de hecho, se registra el sustantivo, pero no el adjetivo como cualidad adherente a una persona. Esto ya evidencia las relaciones entre poder y lenguaje a las que haré referencia más adelante. 
experience of exile, then those writers produce exile literature" (21). Es desde esta perspectiva que se considera a la literatura de la segunda generación de escritores exiliados como tal, pues a pesar de que no fueron ellos los que eligieron la salida de su patria, sino sus familiares, ellos mismos se sienten exiliados y hablan del exilio como tal.

Escribir desde el exilio sobre el exilio conlleva, entre otros muchos elementos, por un lado, no estar presente en el lugar de partida pero tampoco ser parte del nuevo lugar (Kaminsky Reading 30); por otro lado, significa haber sido expulsado del tiempo histórico de tu nación y una imposible reconciliación temporal con el momento histórico del país de acogida, como también habla de ello la propia exiliada Angelina MuñizHuberman (El canto 156). La condición de refugiado implica la re-conceptualización de la percepción de los significantes patria-nación. El escritor se ve obligado a interrogarse en relación a su lugar de pertenencia; se enfrenta al dilema por resolver de si es posible ser de un lugar en el que no se puede estar y en qué afecta la relación existente entre ambos espacios a su formación como sujeto; $y$, además, tiene el reto de vivir en su propia piel el miedo a quedar en el vacío por el resto de sus días. A la misma vez el exilio conlleva una reformulación del tiempo. El cruce de la frontera supone una ruptura temporal en la trayectoria del exiliado, una ruptura del cordón umbilical existente entre la madre (la patria) y su hijo (el ciudadano). Esto supone un trastorno en la esquematización del tiempo, que se traduce de varias formas: en primer lugar, un enfoque en el tiempo existente anterior al exilio; en otros casos, la percepción de desarraigo temporal con el momento histórico en el que se produce la salida; tercero, un sentimiento de repetición cíclica de dicho momento; o finalmente, del mismo modo que señalaba al hablar del espacio, una sensación de no pertenencia a ningún tiempo, ni al del país de origen ni al 
del país de llegada. En esta reconceptualización inherente al exilio, el lenguaje es un elemento clave. La diferenciación semántica propia del español entre los verbos "ser" y "estar" funciona como punto de partida para la representación del sujeto en el exilio. En un mundo de vacíos, la escritura, es decir, el lenguaje se convierte en su única medida para visibilizarse y reafirmar unos códigos ocultos por el poder dominante.

Como bien afirma Claudio Guillén, el exilio como hecho histórico no puede ser desasociado de los cambios sociales-económicos del momento, cambios que repercuten en la formación del sujeto, un ente formado en relación con el otro, con la comunidad ("On the Literature" 271). Es la conexión existente entre el exilio como circunstancia de vida y la formación del sujeto lo que ha provocado un enorme desarrollo del género autobiográfico, lo cual se ampliará detenidamente un poco más adelante. Esto ha provocado el nacimiento de una serie de narraciones que emergen fuera de los márgenes de los discursos existentes hasta ahora, lo cual se ve potenciado por el advenimiento de las teorías posmodernistas. Dichas teorías son relevantes por dos motivos: en primer lugar, por la relación existente entre la crítica postmodernista de las masternarratives y la crítica de los exiliados hacia los discursos autoritarios; y, en segundo lugar, por su voluntad de privilegiar los "margines over the center, absence over presence, anarchy over hiearchy, open form over closed, difference over sameness, etc.” (McClennen 25). Estos textos son discursos que resisten y producen identidades culturales. Desde tiempo de San Agustín se había priorizado la aproximación a unos textos que preconizaban un discurso identitario y político filtrado por una determinada clase social, un determinado sexo y una determinada raza. Es a través de los estudios posmodernistas y de las teorías existentes en torno a los escritos feministas cuando se produce una revolución en dichos 
estudios y se presta atención a los nuevos discursos identitarios creados por los grupos marginados. Amy Kaminsky, en su capítulo “The Presence in Absence of Exile”, encuentra una aproximación entre los discursos creados por exiliados y mujeres puesto que "have both been rendered invisible, though in different ways" (Reading 29). Esta misma autora afirma que la narrativa del exilio es una escritura del deseo; se trata de un deseo de recuperar, reparar y volver. Aunque no es el momento de detenerse ahora en el caso específico de la generación que analizo en este trabajo, considero oportuno especificar que no creo que sean narrativas de un deseo de "volver" en esta específica generación, aunque sí de reparar, pero ya argumentaré el por qué de esta afirmación en su debido momento. No obstante, la función reparadora de la narración ha sido un elemento clave de los estudios sobre el exilio. También Aleksandra Hadzelek señala el poder de la escritura narrativa del exilio, específicamente de su capacidad reconstructora de la identidad. Hablar de identidad significa hablar de un fenómeno a doble escala: a nivel personal, como individuo único, con una determinada clase social, raza, género, orientación sexual y preferencias políticas; y por otro lado, a nivel social, como perteneciente a una comunidad mayor con la que comparte, supuestamente, una serie de rasgos. Es necesario recurrir de nuevo a Homi Bhabha al hablar de identidad, ya que se encarga de destacar la formación de la identidad en relación al otro. Esto me lleva a destacar la importancia del contexto social e histórico como elemento motriz. Antes ya decía que las circunstancias históricas en cuestión repercutían en la formación del sujeto y esto lo hacía por la influencia que ejerce en el establecimiento de una identidad a la que se viene haciendo referencia. De hecho, si se habla de una identidad política en el caso de las minorías, Nikos Papastergiadis expone la necesidad de destacar la importancia de las 
circunstancias históricas sobre la representación de la identidad (31). Para reclamar una identidad propia, esta debe construirse en oposición a ese otro, un otro perteneciente a unas estructuras privilegiadas de poder a las que también hacía ya referencia previamente.

En definitiva, las narrativas del exilio han sido entendidas como una oposición de rasgos. Ya Claudio Guillén titulaba su ensayo con el nombre de "On the Literature or Exile and Counter Exile", es decir, como una dicotomía excluyente. También desde sus orígenes se ha descrito la literatura del exilio como universal o local, y a esta purga clásica se ha sumado la de estudios posteriores que creaban una contienda entre la literatura del exilio como poderosa o como insignificante, como autoritaria o como liberadora, como comunicativa o como confusa, etc. Por su lado, Michael Seidel también estableció una dualidad entre el exilio como fuente de imaginación y la realidad misma del fenómeno. Sin embargo, es a partir de los estudios de Edward Said cuando se empieza a teorizar sobre la posibilidad de hablar de multiplicidad de formas sin tener que oponer obligatoriamente dos versiones. Sophia A. McClennen se encarga de realizar un estudio en profundidad que propone un marco teórico del exilio a partir del término "dialéctica", es decir, no como lucha de dos polos opuestos, sino como multiplicad de formas entre ambos polos. De hecho, ella afirma:

Exile writing often contains the following unity of opposites: the condition of exile is depicted as physical and mental; exile is a state that both liberates and confines the writer; writing is both the cause of exile and the way to supersede it; exile is both spiritual/abstract and material; exile is personal/individual and political/collective; exiled writing 
recuperates the past and re-imagines it; exiles write about the past and also about the future; the experience of exile is both unique and universal; exile improves and also restricts the writer's work; exile heightens both regionalism and cosmopolitanism, both nationalism and globalization. (39)

No se trata de entender el exilio como la lucha entre dos extremos, sino como una narrativa cultural fruto del diálogo entre dos polos, que no tienen que estar enfrentados. Es decir, se trata de la multiplicidad de opciones de un segmento delimitado por dos vértices. Desde esta perspectiva me acerco a la segunda generación de escritores exiliados y a la creación de una narrativa cultural identitaria a partir de los textos autobiográficos/autoficcionales. Por lo tanto, en los capítulos segundo y tercero se desarrolla cómo se configura el discurso identitario del ya mencionado grupo de autores, unidos todos ellos por un mismo hecho histórico: un exilio involuntario. No obstante, antes de llevar a cabo dicha tarea, es necesario establecer el marco teórico de los elementos que componen ese discurso identitario: nación, tiempo y lenguaje. 


\section{Nación}

“¿En qué país vivo? Esta es la gran pregunta” (Con acento 103). Estas palabras de Fernando Aínsa, exiliado establecido en Uruguay, sintetizan la sensación de dislocación con la que debe luchar el refugiado durante el resto de su vida, incluso después de volver a su patria posteriormente. Este sentimiento de no pertenencia a ningún lugar parte de un principio básico sin el cual nada de la teoría en torno a los términos de nación, estado, patria e identidad tendría sentido. Dicho principio no es otro que la creencia en la existencia de un vínculo entre el individuo y el lugar de nacimiento.

Ahora bien, afirmar "yo soy de aquí" implica "no ser de allí", es decir, delimitar unas fronteras, no sólo físicas, sino también psíquicas, que reducen al individuo a una serie de rasgos que lo identifican con ese espacio ${ }^{13}$. Benedict Anderson afirma que la nación, la nacionalidad y los nacionalismos son "cultural artifacts of particular kind" (4). El empleo del vocablo "artefacto" ya indica que el concepto de identidad nacional es una construcción cultural. Tal es así que el propio Anderson propone la siguiente definición del término "nación": "it is an imagined political comunity — and imagined as both inherently limited and sovereign" (6). Según Anderson, es imaginaria en cuanto que los miembros de dicha nación jamás conocerán a la mayoría de sus compatriotas, con los que comparten unos rasgos que les hace sentirse miembros de una misma comunidad. Así como imaginaria, la nación es limitada por la existencia de unas barreras, más o menos flexibles, y también soberana por el nacimiento del concepto en un momento en el que la

${ }^{13}$ El término "nación" adquiere especial relevancia mundial tras la lucha por la independencia en los países colonizados, especialmente en Sudamérica en el siglo XIX. Posteriormente, en el siglo XX son numerosas las guerras y conflictos que se desatan bajo el lema de "protección de la nación". 
Ilustración y la Revolución estaban destruyendo el orden dinástico-jerárquico.

Finalmente, el sentimiento de comunidad crea un efecto de camaradería entre millones de personas, muchas de ellas incluso dispuestas a morir por su nación.

El origen de los nacionalismos reside en el sentimiento de un grupo de personas de pertenencia a un mismo territorio. Esto, a su vez, implica el nacimiento de una identidad nacional, una identidad con la que, supuestamente, debería identificarse cada miembro de dicha nación. Sin embargo, el problema reside, en muchas ocasiones, en definir qué características la componen. Según Homi Bhabha, la identidad nacional es la esencia de una tradición nacional, continua y constante desde el punto de vista pedagógico. Del mismo modo, es también subjetiva y un aspecto narrable discontinuo de la propia nación en lo que atañe al aspecto performativo. Es en la fricción existente entre ambos aspectos donde dicho autor sitúa su concepto de liminalidad o hibridez, que permite al marginado (en su teoría, el colonizado) construir un discurso en contra del poderoso (el colonizador). Así Bhabha propone la liminalidad como el espacio desde el cual pueden crear su discurso las minorías, en nuestro caso, los exiliados. Sin embargo, ya algunos críticos han señalado la dificultad de hablar de la liminalidad como espacio al referirse a las minorías, puesto que no hay espacio para ellos. De ahí la sensación de no pertenencia que normalmente experimenta el exiliado.

Aun así, bien es cierto que la existencia de un exilio provoca un fenómeno por el que, aparentemente, se crean dos conceptos diferentes de nación. Según McClennen, "the exile's nationalism is usually contrary to the versions of nationalism and national identity fostered within the nation's borders" (26). En Nations and Nationalism, Gellner expone que esto es debido, entre otras razones, al control del discurso nacional por el sector de la 
sociedad que ostenta el poder. En oposición a dicho poder, en este caso, al discurso nacional creado por el franquismo, la segunda generación de escritores exiliados genera una nueva narración, objeto de análisis en nuestros dos próximos capítulos, aunque cabe anticipar su carácter activo, es decir, un discurso en constante movimiento, en constante evolución, en constante creación. No obstante, como ya afirma Michael Ugarte, la conciencia de estar lejos de la nación les hace sentirse aún más nacionalistas en algunos casos: "they [the writers in exile] ironically become more nationalistic that those who cast them out and therefore less concerned with the universal" (18). Pero, paradójicamente, es la propia experiencia del exilio la que los hace universales por ser un fenómeno del que pocas sociedades a lo largo de la historia se escapan.

Son también muchos los estudios que hablan de un nacionalismo cultural puesto que es supuestamente la existencia de una cultura en común lo que mantiene a dicha comunidad unida. Cabría, entonces, preguntarse qué elementos son clave para una cultura y si una nación comparte una cultura única. De ahí las controversias y tensiones políticas que pueden surgir en países como España, debido a su multiculturalidad religiosa y lingüística, entre otros factores. Según McClennen, el exilio desafía dicha cultura nacional de dos formas: o bien provee una cultura nacional alternativa, o bien a través de una crítica al concepto de cultura nacional existente. Habrá que especificar entonces en qué medida el discurso de la segunda generación de narradores exiliados se sitúa frente a la cultura nacional ya existente.

Es a partir de los años 70 cuando se empieza a hablar también del concepto de transnacionalismo, según el cual las fronteras de la nación son insignificantes, fenómeno incrementado por el estallido de la globalización y la expansión de las tecnologías 
surgidas a finales del siglo XX. Las corrientes postestructuralistas abogan por la supresión de cualquier tipo de forma opresiva de existencia que limite, en alguna medida, la formación de la identidad. De esta forma, si la identidad nacional se consideraba como un mecanismo opresor por la necesidad de que todos los miembros encajasen en unos parámetros impuestos por el poder, el transnacionalismo es considerado como un elemento liberador. Esto también conlleva la eliminación, de alguna forma, de ese principio básico que se exponía al comienzo de este apartado según el cual existía un vínculo entre el ser humano y la tierra que lo había visto nacer. De esta forma, en el exilio la frontera sufre una doble revalorización. Por un lado, es menospreciada por la limitación que supone el espacio en cuanto a la cultura del individuo; y por otro lado, es defendida puesto que es el motor de la división existente entre los términos "fuera" y "dentro", "nativo" y "extranjero" (McClennen 32). Este concepto es especialmente útil para hablar de exilio puesto que, a pesar de los límites impuestos por la identidad nacional de una comunidad, ellos pueden encontrar lazos de unión con otros miembros de otras naciones que están sufriendo la misma circunstancia vital. Por este motivo, en el apartado anterior, se señalaba la necesidad de hablar de identidad a un doble nivel, como perteneciente a una comunidad, pero también como ser individual, con una determinada raza, género, clase y sexualidad. McClennen afirma que son las conexiones culturales, tanto diacrónicas como sincrónicas, las que unen a los exiliados. Además, esto les permite ser conscientes de la universalidad de su situación y de la creación de una identidad a la vez general y local, nacional y transnacional, histórica y atemporal (32).

Un último concepto importante a la hora de hablar de nación es el de "transculturación". Este es el resultado del impacto sufrido por una identidad cultural a 
través del contacto con otra cultura. De esta forma, se crean zonas de contacto entre las dos culturas. Cabría analizar entonces en el siguiente capítulo qué papel desempeñan los núcleos o instituciones de exiliados creados en los países de destino que intentan resistir, de alguna forma, dicha transculturación. Sin embargo, hay un hecho muy importante y bastante polémico según mi opinión. La transculturación supone que ninguna de las dos culturas sufre una posición privilegiada y que ambas coexisten en un estado fluido. Esto resulta imposible en el caso del exilio, ya que la cultura del país de acogida va a tener una predominancia mayor debido, entre otros factores, a estar en el poder, como ya se comentó anteriormente. Este concepto sería más aplicable a zonas fronterizas en las que existe una contaminación mutua, véase el sur de Galicia y el norte de Portugal. Hay que tener en cuenta también el temor al que se ven sometidos los países que se ven invadidos por exiliados (u otro individuo ajeno a la nación) cuya cultura podría replantear una nueva definición del concepto de identidad nacional, de lo que ya habla Octavio Paz en El laberinto de la soledad.

Una vez explicados los términos de nación, nacionalismo, nacionalismo cultural, transnacionalismo y transculturación, es importante recurrir a las teorías de Deleuze y Guattari que sitúan al exiliado en un espacio de "deterritorialización" enfrentado este al concepto de "territorialización". El primero de ellos hace alusión al desprendimiento de los vínculos restrictivos sociales del deseo, mientras que el segundo de los términos implica una represión del deseo sometiendo y limitando su energía productora. De esta forma, presenta dicho concepto como un estado ideal que se enfrenta a la represión del capitalismo. Es aquí la coincidencia con la condición del exiliado, puesto que este está fuera del sistema autoritario-capitalista bajo el que había nacido. Es decir, el exiliado ha 
decidido no vivir bajo el régimen opresor, en su caso autoritario (capitalista, en las teorías de Deleuze y Guattari) y buscar un sistema diferente, aunque algunos exiliados se instalen bajo un sistema capitalista, como el de EEUU. De esta forma, ambos críticos destacan la figura del nómada como persona que resiste la territorialización y el poder estatal: "If the nomad can be called the Deterritorialized par excellence, it is precisely because there is no reterritorialization afterwards as with the migrant ... With the nomad, on the contrary, it is deterritorialization that constitutes the relation to the earth" (Nomadology 52). A partir de este concepto de desterritorialización, tanto John Durham Peters como Pierre Joris y Rosi Braidotti han desarrollado la teoría del nómada. Esta última se ha encargado de establecer al sujeto nómada como un individuo capaz de encajar en multiples categorías, ya sea raza, etnia o género o cualquier otra, de forma simultánea. De hecho, elabora su teoría nómada basada en la conciencia crítica social del individuo que se resiste a las convenciones impuestas (30-31). Sin embargo, esto plantea una cuestión práctica que se examinará también más adelante: ¿hasta qué punto el exiliado o el inmigrante puede aceptar su estado de deterritorialización teniendo en mente que ha sido educado en una sociedad en la que se ha fomentado la existencia del vínculo entre la tierra y el individuo? O reformulado de distinta forma, ¿no puede considerarse este un estado al que se llega a través de una evolución en la formación del individuo y ante la constatación de la imposibilidad de un regreso al lugar de origen? La respuesta a esta pregunta se planteará cuando se ponga en su lugar la relevancia que tiene el viaje de regreso a la patria en la formación del concepto de nación del individuo en el caso de los exiliados. Este estado de desterritorialización, en una fase última, conllevaría una identidad libre, sin restricciones. 


\section{Tiempo}

A lo largo de los años, en la escritura de los discursos nacionales, y, en concreto, de la historia de España, el tiempo tiende a mantener una estructura lineal, concatenando los hechos en el espectro causa-consecuencia. Sin embargo, el fenómeno del exilio tiene el poder de romper cualquier concepción pre-existente del tiempo. María Luisa Elío Bernal, una de las escritoras que se investigan en este trabajo, escribe:

Es increíble cómo pasa el tiempo... cuántas veces había oído decir esta frase y ahora estaba ahí, conmigo, era yo quien la repetía: “es increíble cómo pasa el tiempo”. ¿Por qué no me habían dicho antes lo que era el tiempo? ¿Por qué no me lo habíais puesto entre las manos y me lo habíais enseñado? "Mira niña, esto es el tiempo.” El tiempo son diez días para contarlo, tengo siete años, cinco de la mano derecha y dos de la izquierda. Y después el tiempo es Navidades, "la otra Navidad y la Navidad próxima". Y después deja de ser tiempo y se hace fecha, mi santo, mi cumpleaños y el día de mi primera comunión. Y después el tiempo se hace distancia, cinco años después de la guerra, nueve años después de la guerra, quince años después de la guerra... Y después no hay, ya no hay tiempo contado, sólo hay tiempo que pasa: seis años... siete años... o una tarde agradable, pasada en casa. (Tiempo 25)

Y es que el inicio de la guerra era, también, el inicio del exilio y, por tanto, de la pérdida de la tierra. No estar presente en el espacio implica, de este modo, no estar presente tampoco en el momento histórico de dicho espacio. El franquismo eliminó de la historia de España a los españoles exiliados durante casi cuarenta años, viéndose así obligados a empezar una nueva vida, obligados a volver a nacer, como ya lo reflejan las 
palabras de María Luisa Elío Bernal, “cinco años después de la guerra, nueve años después de la guerra...”. Así se produce una ruptura de lo que hasta ahora había sido la concepción del tiempo normal del individuo, un tiempo cronológico, lineal. El exiliado muere cuando marcha al exilio y debe volver a nacer en otro espacio. Esto ejemplifica uno de los conflictos temporales que expone Sophia A. McClennen, quien afirma que son cuatro los problemas en relación al tiempo que se encuentran en las obras de los exiliados, a su vez, entrelazados. Ya hemos mencionado la exclusión del tiempo histórico de la patria al no estar presente en su país de origen. Sin embargo, esto tiene dos consecuencias en cuanto a la narrativa temporal. Por un lado, es posible que el refugiado tenga que renunciar al tiempo histórico de su nación, pero consiga reinsertarse -como si de un preso se tratase- en el presente de su país de acogida. Frente a esto, sucede también que el exiliado es incapaz de incorporarse a dicho tiempo, por lo que queda flotando en una espacie de vacío atemporal. A estas dos acepciones cabe sumarle otras dos más. La primera de ellas es la nostalgia como enfoque en el pasado. Si tenemos en cuenta que los escritores exiliados de la segunda generación dejaron España siendo apenas niños o adolescentes, es previsible hacer referencia a la infancia como cronotopo en la mayoría de sus obras, como ya se encarga de señalar Fernando Larranz ("Memoria”). Prueba de ello son los títulos de algunas de sus obras, como Por el mundo: infancia, guerra y principio de un exilio afortunado, de Carlos Blanco Aguinaga, o Una infancia llamada exilio, de Federico Patán. Es un intento de volver a recuperar un tiempo irrecuperable. En segundo lugar, se entiende el exilio como un ciclo repetitivo de castigo, especialmente presente en aquellas narraciones traumáticas, como la de María Luisa Elío Bernal. 
Estos conflictos temporales han llevado a autores como el citado por Paul Tabori, Jozef Wittlin, a hablar de una doble temporalidad del espacio. El exiliado vive tanto en el presente como en el pasado, es decir, el presente de su nueva tierra, y el pasado de su tierra de origen. Sin embargo, son varios los autores que, posteriormente, han descartado dicha teoría, puesto que, en muchos casos, el aferramiento al pasado imposibilitó el paso hacia el presente: "Me habían quitado el pasado. Ahora me quitaban el recuerdo del pasado, del que yo hacía el presente, y sin tener ninguno de los dos me era imposible en el futuro. ¿Cómo puede haber un futuro sin pasado ni presente? No había nada" (Elío Bernal Tiempo 22). Esto ha hecho que otros críticos hayan hablado del pasado como el único tiempo posible en el pasado, acusando a la nostalgia de elemento privativo de una nueva temporalidad. Por otro lado, Claudio Guillen creó el concepto de "destiempo" para explicar la imposibilidad de insertarse en ningún momento histórico, ni en el pasado, ni en el presente ni en el futuro (Múltiples 83).

\section{Lenguaje}

El lenguaje como forma de representación o el lenguaje-idioma como medio de comunicación son los dos principales enfoques entre los que se ha escindido la crítica de la teoría del exilio en relación con este tema. Ser de un lugar implica compartir un mismo idioma con el resto de miembros de dicha comunidad. Ser expulsado de un lugar, por lo tanto, puede conllevar el abandono de tu lengua materna para tener que adoptar la del país de origen. Frente a esto, el lenguaje ha sido y será el medio a través del cual el ser humano puede manifestar su experiencia de vida con el otro. A quién le pertenece ese lenguaje y la capacidad de este para traducir un suceso como el exilio son también cuestiones a resolver. 
En su obra La escritura o la vida, Jorge Semprún relata: “El verdadero problema no estriba en contar, cualesquiera que fueren las dificultades. Sino en escuchar ... ¿Estarán dispuestos a escuchar nuestras historias, incluso si las contamos bien?” (140). Aunque Semprún no pone en entredicho la capacidad del lenguaje para captar la complejidad de dicha experiencia -elemento también cuestionado por algunos críticos-, sí duda sobre la voluntad del otro, probablemente de aquel que no marchó al exilio, para escucharlo. Y es que, de esta forma, se da paso a una de los aspectos más importantes de la literatura del exilio que se desarrollará aún más extensamente en el siguiente apartado al hablar de la importancia de la autobiografia: ¿Quién puede escribir y para quién? En su libro The Psychic Life of Power, Judith Butler elabora un profundo estudio de los conceptos de poder y sujeción. Según Butler, el poder es un elemento formativo del individuo, pero, al mismo tiempo, subordinante. Es decir, es dicho poder el que le da un espacio como miembro válido y representativo de una comunidad pero también el que relega a un segundo plano al que no dispone de él. De esta forma, el exiliado, derrotado por el otro, queda en una posición inferior. Esto conlleva no tener la opción de hacer que su discurso sea oído en su nación ni forme parte del discurso de identidad nacional que desde esta se proyecta. De esta forma, el exiliado y, en general, el silenciado hace de la escritura su método de resistencia. Sophia McClennen lo expresa así: “they [exiles and women] too must use speech and writing as a means of resistance, or else face invisibility and disappearance, i.e., non-being. Such acts of resistance require a belief in the ability of language to communicate and to affect the world in which we live (154). No tener poder hace que la escritura se convierta en la única herramienta necesaria para no desaparecer 
de su historia, por eso el carácter testimonial de su literatura que ya señala Michael Ugarte (20).

Por otro lado, como sistema de símbolos que el individuo usa para referirse a los objetos y personas que les rodean, el lenguaje tiene un importante impacto en la formación de la identidad. Muchos son los exiliados que han registrado en sus testimonios el impacto que supuso escuchar "allez, allez" por parte de los gendarmes, lo que atestigua ese primer choque cultural. En su obra El lenguaje, Edward Sapir explica la creación de este en estrecha relación con la cultura, es decir, como un elemento influenciado por esta última. Por lo tanto, cambiar de patria significa cambiar de cultura $\mathrm{y}$, en consecuencia, de lenguaje, incluso cuando en el país de acogida se habla el mismo idioma. La creación de un lenguaje, de una forma de hablar peculiar, es un rasgo distintivo. Esta distinción puede aplicarse a nivel nacional, es decir, a la totalidad de una comunidad, o también a sectores más pequeños que han creado un argot particular debido a su clase social, raza, etc. Por lo tanto, tras la salida de otro país, la falta de reconocimiento entre la forma de hablar del sujeto y la del individuo del país de acogida incrementa la sensación de vacío, de no pertenencia a ese lugar. Como bien indicia Eduardo Mateo Gambarte, “esto hace que lo que en origen ya es diferencia entre la lengua que [los exiliados] traen y conservan en casa, colegios, y entorno cerrado en que se mueven, adquiera a su vez otro significado de primer orden como marca de exilio que es la conservación de una identidad" (“La identidad" 40). Esta situación de diferenciación se observa de forma más clara en el caso de aquellos exiliados que marchan a países cuya lengua es totalmente diferente, como Francia o la URSS. En este caso, la relación entre el individuo y el idioma puede tener varias salidas: por un lado, la total aceptación del 
nuevo idioma como gesto de su capacidad de inserción en la nueva sociedad; en segundo lugar, el aprendizaje de este como simple herramienta de supervivencia, pero no como reflejo de su identidad; en un tercer caso, la total oposición a esta y su marginación de la sociedad debido al rechazo del nuevo idioma.

En suma, los estudios teóricos del exilio establecen una doble postura en cuanto a la exposición sufrida por los exiliados hacia un nuevo contexto lingüístico: por un lado, es un elemento positivo, pues libera de cualquier restricción y lo empuja hacia un uso del lenguaje original y transcultural, es decir, no como reflejo de una cultura única, sino del mestizaje entre ellas; por otro lado, es presentado también como un medio restrictivo por la predominancia de la nostalgia.

El retorno

A pesar de los numerosos estudios en cuanto a la importancia que tuvo el deseo de un pronto regreso a la patria y el posterior viaje a ella por primera vez, considero que ha habido una falta de interpretación teórica sobre las implicaciones de ambos conceptos en la formación de la identidad por parte de los exiliados. Según Paul Illie, la expresión "regresaré mañana" acompaña inevitablemente al exiliado ${ }^{14}$ (Literature 61). Volver al lugar de partida significa un intento de volver a donde todo empezó $\multimap$ o terminó, depende del punto de vista—. Mónica Jato apunta que volver conlleva la producción de unos nuevos recuerdos del país de origen que acaben con los ya existentes (149). No obstante, también conlleva la constatación de que la existencia de esa patria aún latente en sus

\footnotetext{
${ }^{14}$ Tanto es así que denomina a la esperanza de regresar como la "cuarta dimensión" en conexión con el teatro de Max Aub.
} 
corazones y en sus mentes ya no existe. Hasta ese momento, la patria había dejado de ser un espacio geográfico para ser un ideal imaginario en la mente del exiliado, como explica Vicente Llorens:

La patria suele ser para el desterrado la imagen de todos los bienes. Juventud, afectos, bienestar, personas y paisajes familiares, todos los recuerdos de un pasado mejor se van agrupando en su mente hasta formar un cuadro perfecto. Con la lejanía y el tiempo esa imagen no hace sino depurarse y embellecerse. Los contornos ásperos se suavizan o desaparecen, lo delicado se afina todavía más, lo minúsculo cobra de improviso insospechado relieve, y todo concurre a dar al conjunto un mágico atractivo. La patria deja de corresponder a una realidad geográfica determinada para convertirse en una especie de paraíso terrenal. (123)

Por lo tanto, este viaje de regreso a España supone un cambio en su posición de enfrentarse al mundo, de reubicarse socialmente, es decir, de encontrar su lugar en la sociedad. Esto implica repensar las cuestiones que hasta ahora se han tratado: ¿quién soy? y ¿de dónde soy? Por lo tanto, el primer viaje de retorno es el fin de una etapa como exiliado para empezar a formar un nuevo sujeto social. Se planteará en el siguiente apartado en qué medida este viaje afecta la formación de la identidad nacional de la segunda generación de escritores exiliados. 


\section{Memoria y literatura del yo}

Desde los primeros textos autobiográficos en los tiempos helénicos, muchos han sido los cambios que se han producido en cuanto al género y muchos también han sido sus intentos de definición y categorización. La crítica parece estar unánimemente de acuerdo con la consideración del trabajo de Georges Gusdorf, "Conditions and Limits of Autobiography", como el punto de partida para establecer las bases de una nueva teoría crítica en torno a la autobiografía a partir de la segunda mitad del siglo XX. Ya en este estudio se define el giro más importante acometido en torno a dicho tema en el momento en el que la autobiografía deja de considerarse una mera reproducción de una vida para entenderse como la creación o re-creación de un yo:

La autobiografía no consiste en una simple recuperación del pasado tal como fue, pues la evocación del pasado solo permite la evocación de un mundo ido para siempre. La recapitulación de lo vivido pretende valer por lo vivido en sí, y, sin embargo, no revela más que una figura imaginada, lejana ya y sin duda incompleta, desnaturalizada además por el hecho de que el hombre que recuerda su pasado hace tiempo que ha dejado de ser el que era en ese pasado. (...)

El paso de la experiencia inmediata a la conciencia del recuerdo, la cual lleva a cabo una especie de recapitulación de esa experiencia, basta para modificar el significado de esta última. Aparece una nueva modalidad de ser. (13-14)

Hasta este momento no se habían considerado problemáticos -no al menos de forma tan científica- los temas filosóficos y psicológicos relacionados en torno al ser: 
identidad, auto-definición, auto-aceptación, etc. No obstante, en el momento en el que se entiende la autobiografía como un "process through which the autobiographer struggles to shape an "identity" out of amorphous subjectivity, the critic becomes a psychoanalist of sorts, interpreting the truth of an autobiography in its psychoanalyst of sorts, interpreting the truth of an autobiography in its psychological dimensions rather than in its factual or moral ones" (Smith A Poetics 5). De este modo, si hasta ese momento se había hablado de la autobiografía como fuente testimonial o copia de la realidad, ahora debe recategorizarse el concepto de verdad. Es decir, en lugar de verdad cabría hablar de verosimilitud o "verdad autobiográfica". En palabras del exdirector de la Real Academia Española, Darío Villanueva, estamos ante "ficción para el que la escribe, verdad para quien la lee" (28).

En el apartado "The Rethoric of Autobiography" de su obra The Ethics of Autobiography, Ángel Loureiro desarrolla de forma magistral la fenomenología en torno al concepto de mimesis partiendo de una hipótesis en la que se cuestiona, por un lado, el método según el cual se produce la aprehensión de la realidad y, por otro lado, la reproducción de la referencialidad a través del lenguaje (15-30). De este modo, es necesario enunciar la triple dimensión temporal de la mímesis dependiendo de si esta conecta con los tres tiempos cronológicos posibles: pasado, presente y futuro. Paul de Man se encarga también de vincular la referencialidad de dicha mímesis con el presente (refiriéndose al presente de la escritura) y el referente temporal de la narración. Entiéndase así que dicha conexión varía según el momento de la escritura, es decir, si la narración del pasado depende del momento actual de la escritura, ese pasado no es algo fijo y estable, sino también de una situación variable. Por lo tanto, "mimesis produces, 
and not merely reproduces, reference" (Loureiro The Ethics 17). De hecho, la ya mencionada Sidonie Smith analiza la autobiografía como una interpretación del pasado no fijo. En este proceso de mímesis, de recreación de la realidad, el lenguaje cobra un protagonismo que no siempre ha sido otorgado así por la historia crítica de la autobiografía. Tanto De Man como Loureiro destacan la importancia de dos figuras retóricas: la prosopopeya y el apóstrofe. El segundo de estos términos hace referencia al otro, cuestión que se tratará un poco más adelante. De momento, cabe ocuparse de la primera de las figuras mencionadas. De Man argumenta que la prosopopeya es el recurso a través del cual el individuo enuncia la muerte de su voz al intentar comunicar su mundo al otro a través del lenguaje:

As soon as we understand the rhetorical function of prosopopeia as positing voice or face by means of language, we also understand that what we are deprived of is not life but the shape and the sense of world accessible only in the private way of understanding. Death is a displaced name for a linguistic predicament, and the restoration of mortality by autobiography (the prosopopeia of the voice and the name) deprives and disfigures to the precise extent that it restores. ("Autobiography as DeFacement" 80-81)

Ante esta situación según la cual sería imposible llegar a un conocimiento de la realidad puesto que una mímesis "auténtica" no sería viable, Loureiro sugiere examinar "the productive workings of mimesis not as re-presentation but as a desire and belief in representation, that, as such, is not a re-creation but a discursive creation of reality" (The Ethics 18). La prosopopeya y la mímesis ya no funcionan como elementos desfiguradores 
de la realidad, sino como prácticas discursivas que producen una realidad, pero una realidad autobiográfica. La mímesis autobiográfica funciona así puesto que existe un pasado al que el lenguaje puede hacer referencia, pero no reproducir, ya que la vida siempre superará cualquier discurso que pretende atraparla. Dicho de otra forma, "life has no meaning; autobiographical texts do" (The Ethics 19).

Este planteamiento en cierta medida filosófico conlleva otra problemática inevitable, también desarrollada por Loureiro. Si la vida no tiene significado más que a través de la mímesis autobiográfica y esta última tiene como función crear un discurso realístico para ser comunicado a través del lenguaje, ¿dicho discurso realístico no está sometido a una narrativa colectiva capaz de descifrar el mundo creado?

Así entra en juego la otra figura retórica a la que se hacía referencia anteriormente: el apóstrofe. Ya en los años setenta del siglo pasado, Philipe Lejeune hablaba del pacto autobiográfico según el cual el receptor debe ser capaz de reconocer una correspondencia entre el autor, el narrador y el personaje. A partir de lo escrito en la obra el agente externo debería ser capaz de verificar dicha reciprocidad. Sin embargo, esta comprobación implica una segunda aseveración. El lector, es decir, el otro debe ser también capaz de reconocer el discurso creado como una exposición real -entiéndase real como verosímil, no como verdadero-. A pesar de que el pasado no puede ser reproducido por el lenguaje, "the constitutive alterity of the subject requires that it respond to the other, and in autobiographical writing that response cannot be measured in terms of truth or mimetic restoration because as ethical gesture it remains outside the domain of thematics and epistemology" (Loureiro The Ethics 20). De esta forma, la construcción del sujeto autobiográfico se constituye dentro de una mimesis autobiográfica como respuesta 
y como legado hacia la alteridad. Podría decirse que la autobiografía deja de ser del sujeto para pasar a las manos del otro, pues viene de él y se dirige a él.

Si se aplica esta teoría sobre la importancia del otro en la escritura autobiográfica a los trabajos narrativos de la segunda generación de escritores del exilio, surge una importante pregunta, la misma pregunta que ya se había Francisco Ayala en su artículo "Para quien escribimos" o, dicho de otra forma: ¿quién conforma ese ser?, ¿qué papel juega la variedad de lectores?, ¿hasta qué punto puede usarse un único referente de alteridad en la escritura en un grupo social que, en realidad, no pertenece a ninguna comunidad? Aunque son muchas las preguntas que surgen en torno al tema, se intentará responder a ellas en el próximo capítulo cuando se analice el nacimiento de la segunda generación de narradores exiliados como escritores y sus referentes.

Analizando ese giro en torno a los textos autobiográficos que planteaba al principio de la exposición por el cual la autobiografía pasa a ser una creación o recreación del yo, Paul John Eakin da un paso más allá e intenta establecer un diálogo que responde a la dialéctica entre el lenguaje y la formulación del yo. Para ello, parte de la siguiente hipótesis: "Is the self autonomous and trascendent, or is it contingent and provisional, dependent on language and others for its very existence?” (181).

Para dar respuesta a esta pregunta, Eakin enfrenta las posturas de dos de los críticos más importantes de la narrativa autobiográfica. Por un lado, en su estudio Metaphors of the Self, James Olney argumenta que el lenguaje ofrece un abanico de posibilidades, no una privación, tanto para el escritor como para el lector, para conocer el yo: 
The self expresses itself by the metaphors it creates and projects, and we know it by those metaphors; but it did not exist as it now does and as it now is before creating its metaphors. We do not see or touch the self, but we do see and touch its metaphors: and thus we "know" the self, activity or agent, represented in the metaphor and the metaphorizing. (34)

En oposición a Olney, se encuentra el pensamiento de Paul de Man que contradice las tesis tradicionales que consideran la autobiografía un campo de cultivo para la autoexpresión y el auto-desconocimiento. Para el crítico belga el lenguaje se impone al yo, desplazándolo y privándolo de su capacidad para referenciar la realidad tal y como es.

Tras esta oposición de pareceres, Paul John Eakin argumenta que la autobiografía es un recurso narrativo para la invención de un yo a través de la escritura al mismo tiempo que permite el acceso del individuo a su identidad en el momento de la adquisición del lenguaje. Así, puede interpretarse la autobiografía -entendida en su sentido más amplio- como el espacio para el nacimiento de un yo en relación con la escritura. Es decir, "the writing of autobiography emerges as a symbolic analogue of the initial coming together of the individual and language that marks the origin of selfawareness" (Eakin 213).

Cabe, entonces, cuestionarnos, una vez más, dicho aspecto teórico aplicado a la segunda generación de escritores del exilio de 1939. Ya se dijo anteriormente que el exiliado se encontraba en un espacio a-geográfico y atemporal y que recurría al lenguaje como medio para configurar una identidad en contacto con el otro -queda aún por determinar quién es ese otro-. Por lo tanto, ¿no puede considerarse el lenguaje como patria, como único espacio que le permite al exiliado encontrar su yo y situarse en una 
realidad autobiográfica?, es decir, ¿no es realmente el lenguaje el creador de un mundo "real" para el exiliado, de concienciación del por qué de su situación? Aunque la respuesta a esto también forme parte del siguiente capítulo, quiero mencionar brevemente al ejemplo de María Luisa Elío Bernal para entender de qué forma el lenguaje se convierte en la patria del escritor, en el medio para la plasmación de un mundo que sólo existía en la mente de estos escritores. En Tiempos de llorar puede claramente verse el proceso de escritura como la toma de conciencia de un yo que, tras el viaje de regreso a su patria, se descubre fragmentado entre su yo-infantil y su yo-adulto, su pasado y su presente, y la escritura de ello sirve para comprender un nuevo yo alejado de cualquier representación posible de la realidad, un yo que sólo es posible en la escritura narrativa.

Hasta ahora hemos discutido el enfoque del concepto de autobiografía, qué se entiende como mímesis y la tensión dialéctica entre el lenguaje y el yo. Sin embargo, quedan por definir qué elementos afectan a la formación de ese yo. ¿Qué papel juega el concepto de nación en la formación de dicha identidad? ¿hasta qué punto son importantes las relaciones de poder entre el exiliado y el que lo exilia?

Los estudios sobre autobiografía femenina defienden que la literatura del yo escrita por mujeres ha sido marginada por la crítica debido a su falta de correspondencia con la sociedad en la que estaban insertadas sus escritoras. De hecho, Jelinek afirma que la autobiografía masculina constata la conexión con la sociedad, con una cultura, mientras que la autobiografía femenina no lo había hecho hasta entonces, no al menos con la cultura patriarcal imperante. Tanto el poder como la nación están sometidos normalmente a la existencia de una cultura dominante que controla y regula la imagen proyectada por ambos. Surgen así las teorías propuestas por críticos como Michel 
Foucault o, posteriormente, Iris Zavala que hablan de la dicotomía entre una ideología dominante y una ideología subalterna. Estos estudios se basan en el abuso del poder para imponer una posición sobre el otro puesto que "el carácter cognitivo está filtrado por la cultura dominante, que controla los medios de difusión y, lo más importante, autoriza y garantiza a determinados emisores (hombres-blancos -nobles o burgueses- europeosheterosexuales) y desautoriza y silencia a otros (mujeres, extracomunitarios, homosexuales)" (Zavala 31). Esto conlleva la marginalización de todo aquel sector de la sociedad que no tuviera poder. De esta forma, una de las características que han utilizado dichas teorías feministas para hablar de una autobiografía femenina en particular ha sido el uso de dicho género para dar espacio a una voz hasta ahora silenciada, como ya mencionó Ángel Loureiro: "It has been quite common for autobiographers to envision their lives both as a process of liberation from false or forcefully imposed self-images and as a (re)encounter with what they believe to be their true identities" (The Ethics 14). De esta forma, asevera Loureiro el valor de la autobiografía para dicho fin, pero cabe recordar que la recuperación de esa voz se hace en relación con el otro. Una persona no puede afianzar su voz en una sociedad si no es porque previamente ha sido silenciada por esta y ahora quiere enfrentarse a ella argumentando, de alguna forma, por qué merece un espacio.

Ahora bien, la crítica ha pasado por alto la analogía existente entre los textos de autores subalternos con las obras de muchos escritores exiliados. Si las mujeres, los homosexuales, los negros, forman parte todos de una comunidad subalterna y, por ello, fuera de la cultura "aceptada”, ¿no comparten los exiliados también dicha posición al estar sometidos a una cultura dominante, en este caso, a la cultura que les ha expulsado 
de su patria? La respuesta a esta pregunta es necesariamente ambivalente. Por un lado, es cierto que sus textos no conectan con la sociedad dominante ni defienden un mismo concepto de cultura-patria-identidad, sino que establecen una nueva cultura o una nueva identidad. Por otro lado, no todos los escritores comparten dicha posición. A pesar del poder igualatorio del exilio, como si de la misma muerte se tratara, no todos ocupan idéntica posición subalterna por el simple hecho de ser exiliados. Muchos de los exiliados eran hombres, pertenecientes a familias de clase social media-alta (Carlos Blanco Aguinaga, Jorge Semprún) que, por consiguiente, formaban parte de ese sector de la sociedad considerado dominante hasta ese momento. Sin embargo, es curioso que, aunque no comparten los mismos rasgos que esos otros exiliados que sí podrían considerarse como miembros de la ideología subalterna, todos ellos recurren a la autobiografía para enfrentarse, en alguna medida, al poder, a España. De esta forma, una vez más surge la pregunta "What makes the subject receptive to certain discourses and not others?" (Loureiro The Ethics 3). Como ya decía Laura Freixas, se trata de una literatura que nace de la confrontación con la identidad impuesta. ${ }^{15}$

Una vez definidas las principales líneas de aproximación en cuanto al género autobiográfico, es importante explorar el papel que desempeña la memoria en la narrativa autobiográfica. Además, es necesario analizar en qué medida los conceptos de memoria y trauma se relacionan con la literatura del yo. Ya anteriormente se hacía mención a la tensión existente entre los conceptos de verdad y verosimilitud, los cuales se ponen aún más en entredicho si se presta atención a los tres ejes en torno a los que gira la memoria

\footnotetext{
${ }^{15}$ Conferencia «Las escritoras y lo autobiográfico» de Laura Freixas en la Biblioteca Nacional Española el 11/03/2014 con motivo del ciclo «Libro, mujeres y feminismo».
} 
según Elizabeth Jellin. El primero de ellos es el propio sujeto. ¿Hasta qué punto podría ser fiable el discurso de un sujeto si sabe que su imagen depende de lo proyectado en su obra? ¿Acaso todos serían tan valientes como Semprún para aceptar que también dispararon su fusil? ¿No es el sujeto el primer lector y, por lo tanto, auto-censurable? Por otro lado, el segundo de los ejes hace referencia a los contenidos: qué se recuerda y qué se olvida. A esto habría que añadir también qué se recuerda pero no se escribe, algo que pasa por alto la crítica argentina. Y esto, a su vez, entronca con otra problemática ¿con qué intención se recuerda y con qué intención se escribe? El autor, como dice el propio Jorge Semprún, tiene un poder absoluto sobra la obra: "Pues quien escribe soy yo, soy el Dios todopoderoso de la narración" (La escritura 287). Finalmente, el último eje que hay que considerar es cómo y cuándo se recuerda y cómo y cuándo se olvida: ¿en qué momento el escritor se acerca al papel para "transcribir" sus experiencias?, ¿los recuerdos y los olvidos no cambian con el paso del tiempo?, ¿la memoria no da prioridad a recuerdos diferentes en distintas situaciones?, ¿en qué contextos funciona dicha memoria?

En su estudio La memoria, la historia, el olvido, Paul Ricouer da respuesta a estas preguntas mediante una profunda investigación que abarca desde las teorías de Aristóteles y Platón, pasando por San Agustín o John Locke, hasta llegar a críticos más recientes como Maurice Halbwachs. El crítico francés afirma: "La memoria es del pasado" (34). Esta frase, en un principio simple y obvia, es el origen de la controversia existente en torno a dicho tema. Para tener memoria, el tiempo ha de transcurrir. Según el diccionario de la RAE, la memoria es la "facultad psíquica por medio de la cual se retiene y recuerda el pasado". Sin embargo, la distancia temporal existente entre ese pasado que 
se quiere recordar y el momento presente en el que se pretende recurrir a dicho recuerdo implica una transformación del pasado, por lo que, como ya se dijo anteriormente al hablar de la autobiografía, el pasado es algo irrecuperable y la memoria no recuerda el pasado, sino que elabora un nuevo pasado. Para describir la elaboración de dicho pasado, Ricoeur recurre a dos términos que provienen de la filosofía helénica: mneme y anamnesis. El primero de ellos trata del recuerdo que "sobreviene a la manera de una afección” mientras que el segundo "consiste en una búsqueda activa” (La memoria 3637). Veamos dos ejemplos de estas dos formas de recordar en las obras de los escritores exiliados de la segunda generación del exilio. En La escritura o la vida, Jorge Semprún escribe así: "Ese cuento de La paloma se me ha ocurrido así, de improviso. Pero me recuerda algo de lo que no me acuerdo. Me recuerda que debería acordarme de algo, por lo menos. Que podría recordar, buscando un poco. ¿La paloma? El principio de la canción me vuelve a la memoria. Por extraño que parezca, ese principio me vuelve en alemán” (44). Una determinada situación, en este caso, estar un paraje natural espiando a los enemigos, le recuerda la canción de la paloma, una canción que, como más adelante se puede ver, está relacionada con su infancia. De ese modo, el recuerdo sucede de forma imprevista provocado por las circunstancias, es decir, por el otro, algo a lo que se hará mención más adelante. En el segundo de los casos, la rememoración, la búsqueda activa es un proceso por el que pasan casi todos los exiliados en el momento que se produce el primer viaje de regreso a España para recordar y ver lo que queda de aquella España que sólo existe ya en su memoria.

Ahora bien, hasta ahora se ha hecho mención únicamente a la memoria, pero se ha pasado por alto la diferencia existente entre los siguientes conceptos: memoria y 
recuerdos. Según Ricoeur, cuando hablamos de la memoria lo hacemos siempre en singular, mientras que los recuerdos son múltiples. De esta forma, la memoria se entiende como un almacén de recuerdos que salen a la luz en distintas circunstancias. Y en función de las mismas, el mismo recuerdo puede variar de una vez a otra. Por ejemplo, en Tiempo de llorar y otros relatos de María Luisa Elío Bernal, la narradora relata su propia toma de conciencia del inicio de la guerra civil a través de la visión de la huida de un soldado rojo por los tejados desde el balcón de su casa. En este recuerdo, ella se encontraba sola, probablemente, como reflejo del aislamiento que supone el conflicto civil respecto a su patria. Sin embargo, este mismo hecho, documentado por los otros habitantes de esa casa, se nos presenta de forma distinta: en ningún momento ella estaba sola en ese instante, sino que se encontraba acompañada por sus dos hermanas y cada una de ellas relata el mismo episodio de forma diferente. La perspectiva individual de cada una, el recuerdo de cada una, aflora a partir de una memoria, en este caso, común a las tres hermanas.

Si acudimos a Henri Bergson podemos ver también la distinción que este autor hace de la memoria como hábito y de la memoria como recuerdo. En la primera de ellas, el pasado está incorporado al presente, es decir, se trata de dos espacios temporales que no se han desconectado, sino que el pasado aún pervive en el presente. Se trata de un tipo de memoria especialmente presente en las personalidades traumáticas por no superar episodios difíciles del pasado. Según Tzvetan Todorov, los recuerdos deben ser recuperados para que se pueda producir una sanación completa. Es decir, la neurosis es fruto de una represión, de atribuirle a los recuerdos del pasado un lugar dominante, lo que provoca que dichos recuerdos se conviertan en ofensivos e incontrolables (26). A partir de esta lectura de Todorov, podría entenderse la obra de María Luisa Elío Bernal como 
reflejo de dicha memoria-hábito. La superación de dichos recuerdos daría lugar a lo que el escritor búlgaro-francés ha denominado como memoria-ejemplar, es decir, la utilización de esta para aprender de las situaciones del pasado y afrentar los nuevos problemas que se presentan en el presente. Así esta se opondría a la memoria-lineal, basada en la sucesión de recuerdos intransitivos que impiden el progreso. Volviendo a las teorías de Bergson, la memoria como recuerdo predispone la representación porque el sujeto es consciente de la diferencia temporal entre el ayer y el hoy.

En toda esta fenomenología de la memoria, los recuerdos, y los distintos procesos memorísticos, juega un papel importante el olvido. Recordar significa no olvidar. Sin embargo, olvidar también significa recordar, es decir, el hecho de saber que se ha olvidado implica recordar algo que no se recuerda. Esto influye también en el carácter temporal o permanente del olvido y este, a su vez, está influido por la presencia del otro. En relación al fenómeno temporal del olvido, es necesario matizar su problemática. Por un lado, hay un olvido de los primeros años de vida a los que la memoria no tiene acceso por la falta de conciencia del sujeto como tal. Además, en determinados episodios traumáticos y desde un punto de vista freudiano, la conciencia crea una barrera que imposibilita el acceso a determinados recursos como medida protectora del sujeto. También dentro de dicha problemática, hay que recurrir al otro. Ciertos episodios han pasado a la esfera del olvido y sólo son recuperados a través de la rememoración del otro. De este modo, ese recuerdo recuperado del olvido pasa a dejar de ser del sujeto para ser del sujeto y del otro, es decir, se produce una recreación de ese recuerdo contaminado por el otro ente. 
Una vez mencionado el papel del otro y la contaminación del recuerdo por su presencia, es importante mencionar el debate existente sobre la dicotomía entre memoria individual y memoria colectiva. La crítica está de acuerdo en el carácter subjetivo de los recuerdos y la incapacidad de transferir dichos recuerdos a otros (Jellin, Ricoeur, entre otros). No obstante, según Maurice Halbwachs, las memorias individuales están siempre enmarcadas socialmente, es decir, necesitan del otro. Una persona recuerda a través de una serie de códigos culturales compartidos. Cabría preguntarse posteriormente, en el caso de los escritores exiliados, ¿por quién están compartidos dichos códigos? Según el teórico padre de Los marcos sociales de la memoria, los primeros recuerdos rememorados son los comunes, los compartidos con el otro. En cuanto miembros de un grupo, los recuerdos, gradualmente, son afectados por la rememoración de otro. Esto permite el acceso a unos acontecimientos que han sido reconstruidos para nosotros por otros distintos de nosotros, pero con quienes compartimos un lugar. Póngase como ejemplo a la generación de finales del siglo XX. Esta generación no sufrió ni la guerra civil ni la dictadura franquista y, sin embargo, tienen recuerdos de la misma a partir de los recuerdos que les han creado sus familiares, los medios de comunicación, el sistema educativo, etc.

Ahora bien, en relación a esta teoría social de Halbwachs, Ricoeur desarrolla un planteamiento doble y opuesto. Por un lado, el hecho de no formar parte de un grupo en cuya memoria se conserva tal recuerdo provoca que nuestra propia memoria se debilite por falta de apoyos exteriores. Esto justifica, en alguna medida, el empeño de muchos exiliados por crear círculos en los países de acogida que favorezcan la conservación de ese recuerdo que no es otro que su imagen de España. Por otro lado, para acordarse, 
según Ricoeur, es necesario entonces colocarse en el punto de vista de uno o varios grupos y situarse en una o varias corrientes de pensamiento (La memoria 158-59). En definitiva, "uno no recuerda solo" (Bou "Construcción" 23).

Tras este resumido debate en la medida de lo posible, Ricouer llega a la conclusión de que los recuerdos son individuales, aunque necesiten de una colectividad para salir a la luz. Sin embargo, es muy interesante la aportación que hace Enric Bou cuando, hablando de exiliados, habla de la existencia de un plano intermedio entre la memoria individual y la colectiva. Se trata del plano formado por ese otro que vive cerca del sujeto. Pero, una vez más, ¿quién forma parte de ese círculo cercano en el exilio? En el siguiente capítulo me baso en la teoría de Bou para reflexionar sobre la importancia que tiene la formación de círculos de exiliados, especialmente en México, en la construcción de la identidad, pues funcionan, en ocasiones, como obstáculos para la integración del exiliado. 


\section{Capítulo II}

\section{España fuera de España (I). Niños convertidos en escritores: narrativas reconstructivas de la identidad}

Alicia Alted Vigil, una de las historiadoras más prestigiosas que trata el tema de los niños de la guerra, cuantifica el número de los evacuados durante la guerra civil en más de 33.000: 20.000 en Francia, 4.000 en Inglaterra, 5.000 en Bélgica, 2.900 en la Unión Soviética, 455 en México, 800 en Suiza y 100 en Dinamarca (“El exilio”). No obstante, estas cifras hacen referencia únicamente a aquellos que marcharon, sin sus padres, en expediciones organizadas por numerosos partidos, sindicatos y asociaciones de izquierda para salvaguardar sus vidas. Junto a ellos, muchos otros salieron junto a sus familiares y amigos para escapar de las represiones del ejército franquista.

Posteriormente, muchos de estos trasterrados recurrieron a la escritura para transmitir, de alguna forma, la influencia de la experiencia del exilio en sus vidas. Entre estos nombres encontramos a: Fernando Aínsa (37/51/URU-FR), Federico Álvarez (27/40/CU-ME), María Álvarez del Vayo (29/36/FR), Manuel Arce Porres (29/37/UR), Isabel Argentina Álvarez (23/37/UR), Fernando Barral (28/39/AR), Néstor Basterretxea (24/36/ARG), Ángel Belza (26/37/UR), Carlos Blanco Aguinaga (26/39/ME-US), Inocencio Burgos (28/39/ME), María Casares (22/37/FR), Carmen Castellote (32/37/URSS), Michel del

Castillo (33/36/AR-MA), Aurora Correa (30/37/ME), Nieves Cuesta (25/39/UR), José de la Colina (34/37/ME), Amadeu Cuito (36/36/FR), Gerardo Deniz, (pseudónimo de Juan Almela), (34/36/ME), Edmundo Domínguez Aragonés (38/39/ME), Manuel Durán (25/39/ME), María Luisa Elío Bernal (26/39/ME), Juan Espinasa (27/36/CU-ME), Ángel Fernández (28-29/39/FR), Isabel Fernández (37/39/FR), María L. Fernández 
(27/37/URSS), Manuel Fernández Montesinos (32/40/US), Áurea Matilde Fernández Muñiz (29/37/CU), José Fernández Sánchez (25/37/RU), Jacques Folch-Ribas (28/39/FR), Jomí García Ascot (27TU/39/ME), Carles Gerhard i Hortet (28/39/FR), Francisco González Aramburu (27/37/ME), Teresa Gracia (32/39/FR-VN), Montserrat Julio i Nonell (29/39/CH), Emilia Labajos (31/39/BE), Virgilio de los Llanos (25/38/UR), Roberto López Albo (24/37/CU-ME), Miguel Martínez (31/39/AR), Tere Medina (24/39/ME), Carmen Mieza (31/40C/ME), Pedro F. Miret (32/39/ME), Aurélia MoyàFreire (25/39/FR), Angelina Muñiz-Huberman (36FR/ME), Natura Olivé (27/37/ME), Nuria Parés (25/38/ME), José Pascual Buxó (31/39/ME), Federico Patán (37/39/ME), Emesterio Payá (28/37/ME), Tatiana Pérez (pseudónimo de Josefina Pérez Sacristán), (30/37/UR), Francisca Perujo (34/39/ME), Conchita Ramírez (23/39/FR), Josep Ribera i Salvans (32/47/ME), Francisco Rico Galán (29/40/ME), Víctor Rico Galán (27/40/ME), Luis Ríus (30/39/ME), Enrique de Rivas (31/39/ME-IT), César Rodríguez Chicharro (30/40/ME), Roberto Ruiz (25/39/ME), Jaime Salinas (25AR/37/US), Luis Santamaría (26/37/RU), Tomás Segovia (27/36/ME), Carlos Semprún (26/36/FR), Jorge Semprún (23/36/FR), Conchita Simarro (27/38/FR), Martí Soler i Vinyes (34/44/ME), Arturo Souto (30/38/ME), Maruxa Villalta (32/36/ME), Manuel del Villar (23/36/RC-FR), Ramón Xirau (24/38/ME). ${ }^{16}$ No se ha incluido en esta lista a Michelle Alban a pesar de

\footnotetext{
${ }^{16}$ Junto a cada nombre de los escritores de esta segunda generación se encuentran tres datos autobiográficos. El primero de ellos corresponde a la fecha de nacimiento (en algún caso puede ir acompañado de las iniciales de su país de nacimiento si este no se trata de España, como es el caso de Jomí García Ascot y Angelina Muñiz-Huberman); posteriormente, se encuentra la fecha de su partida al exilio, lo que permite ver la edad con la que abandonaron su país de origen; y, en tercer lugar, el país en el que se instalaron (aunque algunos de ellos pasaron por varios países, solo se han puesto las iniciales del país en el que pasaron la mayor parte de su vida, salvo en excepciones como
} 
haber escrito poesía en los dos números de la revista Hoja, en la que participaron principalmente escritores de la segunda generación del exilio de 1939, por el desconocimiento de su fecha de nacimiento y su país de origen. Del mismo modo, se han excluido de dicha lista a Isidoro Calzada y a Alberto Oliart ya que su obra no está relacionada con el exilio. Tampoco ha sido incluido José Carmona Blanco, ya que, a pesar de nacer en 1926, no marcha al exilio hasta 1947, con 21 años. Caso similar es el de Juan Manuel Polo, nacido en 1928 y exiliado en 1952. También han sido dejados fuera de esta clasificación Claudio Guillén (24/39/US) y Juan Marichal (22/28/ME), puesto que su obra está enfocada en el estudio y la crítica literaria y no en la creación artística o testimonial del fenómeno del exilio. Por la misma razón se ha dejado fuera de estudio a Manuel Bonilla, miembro de la revista Clavileño. Adriana Merino marcha al exilio en 1939, con 17 años, por lo que no ha sido considerada como miembro de esta generación, aunque algunas investigadoras como Katia Irina Ibarra y Mariana Masea la consideren miembro de la generación hispanomexicana (127).

Por otro lado, Maryse Bertrand de Muñoz ha situado a José Luis de Villalonga y Agustín Gómez-Arcos dentro de la segunda generación de escritores exiliados, pero creo que dicha afirmación no es correcta. En el caso del primero de los escritores mencionados, porque nace en 1920, lucha al lado de Franco y no marcha al exilio hasta

la de Carlos Blanco Aguinaga, quien pasó largas temporadas tanto en México como en Estados Unidos, o Enrique de Rivas quien, siendo adulto ya, se trasladó a Italia). En el caso de los países, las iniciales corresponden a los siguientes países: $\mathrm{AR}=$ Argelia, $\mathrm{BE}=$ Bélgica, $\mathrm{CH}=$ Chile, $\mathrm{CU}=\mathrm{Cuba}, \mathrm{FR}=$ Francia, $\mathrm{IT}=$ Italia, $\mathrm{MA}=$ Marruecos, $\mathrm{ME}=$ México, RC = República Checa, RU = Reino Unido, UR = URSS, URU = Uruguay, US $=$ Estados Unidos, $\mathrm{VN}=$ Venezuela. 
los años 50 del siglo $\mathrm{XX}$, tras su desencanto político, por lo que ya no era un niño como el resto de miembros de la segunda generación. En cuanto a Agustín Gómez Arcos, y a pesar de haber nacido en 1939, su partida al exilio no se produce hasta 1966, tal y como afirma el crítico francés, y no durante la guerra civil española, por lo que tampoco puede incluirse en dicho grupo ("El esperpento" 528). Pongo en duda la fecha de nacimiento del último autor pues Encarnación García afirma que nació en 1933 y me ha sido imposible corroborar cuál de los dos autores se equivoca ("La voz de la memoria" 548). Tampoco se han incluido en esta lista los siguientes nombres que aparecen bajo el rótulo de "Voces de la segunda generación" en la obra El exilio literario de 1939 y la segunda generación por diversas razones: Aitana Alberti por haber nacido en 1941 ya en pleno exilio de sus padres; Margarita Carbó Darnaculleta y Ángel Gutiérrez por no conocerse obra de ellos más que el testimonio que dejan en dicho libro; Enrique Cerdán Tato, ya que nunca llegó a salir de España pues fue detenido junto a su familia en el intento; y José Ramón Enríquez, por haber nacido en 1945.

En una conferencia impartida en el Ateneo Español de México, Max Aub hacía ya referencia a parte de esta generación al referirse a ellos como "una nueva generación": Hace once años que nos dejaron en cueros, en pelota, como se dice, a las puertas de nuestra casa, y desde entonces andamos rondando, sin querer dar nuestro brazo a torcer, volviendo constantemente la vista atrás. Once años no son, tal vez, gran cosa para gentes de cierta edad incierta; lo son todo para quienes tenían entonces de ocho, diez o doce. Quien dijo que somos de allí donde estudiamos el bachillerato enunció una gran verdad. De los doce a los dieciocho años es cuando empieza el hombre a darse 
cuenta de su prolijidad, y se desbasta y lima y descubre sus propias facciones; cada quien, como dice Cervantes, "forja su ventura". Con los recuerdos de ese tiempo planta el ser los fundamentos de su monumento. Estos jóvenes españoles que llegan hoy a la orilla de su hombría, empezaron a aprender en España, muchos de ellos continuaron sus estudios en Francia y los han terminado o los están acabado en México [o en cualquier otro país, añado yo], al azar de los destinos patrios y paternos. Es un caso nuevo, en cuanto al número. (12-13)

Aunque la crítica se ha puesto de acuerdo en usar el término de "segunda generación" - también denominada generación nepantla ${ }^{17}$ o generación fronteriza ${ }^{18}$ para hacer referencia a aquellos escritores que, siendo niños o adolescentes, marcharon al exilio huyendo de la Guerra Civil española, nunca antes se había usado este vocablo para reunir a una nómina tan extensa de autores. ${ }^{19}$ Hasta ahora los estudios que intentaban abarcar a la segunda generación de escritores exiliados se habían sido dedicado, principalmente, a lo que los críticos han denominado el grupo hispano-mexicano, ${ }^{20}$

\footnotetext{
${ }^{17}$ Término acuñado por Francisco de la Maza, proveniente del náhuatl, que significa "en medio" (cit. en Eduardo Tasis Moratinos pos. 333).

18 Término proveniente de un poema de Nuria Parés que, posteriormente, popularizó Luis Rius en su artículo "Los españoles en México: Historia de una doble personalidad".

${ }^{19}$ La excepción es el congreso "El exilio republicano de 1939 y la segunda generación" a la que se hacía referencia en la introducción. No obstante, en las actas de dicho congreso no se hace mención en ningún momento a la generación en su totalidad pues la mayoría de estos escritores ni siquiera aparecen, sino que estas recogen estudios individuales sobre determinados autores y temas, con la limitación que esto supone en cuanto a una perspectiva panorámica se refiere.

${ }^{20}$ Término utilizado por primera vez por Arturo Souto en 1987 en El exilio español y la $U N A M(133)$.
} 
término que hace referencia al grupo de escritores arraigados -si en algún momento consiguieron arraigarse- en México. ${ }^{21}$ No obstante, estos estudios dejaban fuera a otros niños o adolescentes que, al igual que ellos, habían marchado al exilio huyendo por decisión de sus padres, pero a los que el destino llevó a otros países: Francia, la URSS, Bélgica, Reino Unido, Argelia, Marruecos, Cuba, Venezuela, Chile, la República Dominicana, EEUU, Argentina, etc. Fernando Larranz reclama, por primera vez, la necesidad de unir a todos estos autores bajo un mismo grupo generacional partiendo de la misma hipótesis que toma este trabajo: "la circunstancia experiencial que comparten" que, al mismo tiempo, en todos ellos viene derivada de la voluntad de sus padres, no de su propia elección ("Memoria y autorrepresentación" 584). No obstante, hay dos diferencias significativas entre la propuesta de Larranz y la aquí presentada. Por un lado, el trabajo de este aún deja a una gran lista de autores fuera de la nómina, tales como: Jaime Salinas, Manuel Fernández Montesinos o Miguel Martínez. Por otro lado, centra su atención principalmente en las obras de ficción, dejando en un segundo plano los textos autobiográficos, género del que se encarga, principalmente, este trabajo. No obstante, profundiza - en la medida de lo posible- en obras como Tiempo de llorar, de María Luisa Elío Bernal, analizada en el cuarto capítulo de esta tesis y de un contenido autobiográfico predominante, así como en Último exilio, de Federico Patán, también con una significante carga autobiográfica. Aun así, es justo mencionar que hace alusión a la

${ }^{21}$ Recuérdense los trabajos citados en la introducción de Eduardo Mateo Gambarte, Susana Rivero, Bernard Sicot y Angelina Muñiz-Huberman. Cabe añadir la tesis de Eduardo Tasis Moratinos sobre el exilio en la poesía de Tomás Segovia y Angelina Muñiz-Huberman que dedica los dos primeros capítulos a un estudio preliminar de la generación hispano-mexicana. 
difícil distinción entre autoficciones y novelas autobiográficas, en lo cual también profundizaré a su debido momento.

A pesar de que se ha cuestionado el uso del término "generación", considero que su utilización es totalmente necesaria para el estudio. Julián Marías, atendiendo a los preceptos de su maestro Ortega y Gasset, apunta que la generación se establece como un sistema de ideas y formas de un determinado momento para interpretar la realidad y que esta cambia una vez que cambia el mundo (85-107). El estallido de la Guerra Civil española provocó un tremendo impacto, no sólo a nivel español, sino a nivel mundial. Las creencias izquierdistas de los familiares de los niños de la guerra y la defensa de la libertad de estos marcaron profundamente a esta generación de jóvenes cuyo sistema mental para interpretar la realidad fue, en parte, heredado de sus padres y, en parte, cimentado en las bases del exilio y en una maduración demasiado temprana. De hecho, Angelina Muñiz-Huberman afirma que "los caracteres del exilio fueron transmitidos de padres a hijos. Como si la genética funcionara aquí en sentido cultural y social, y no sólo biológico" (El canto 156). El hecho de que todos los autores y obras aquí recogidas tengan como tema motriz el exilio es prueba irrefutable de que su interpretación de la realidad viene marcada por este. El exilio se convierte así en el principal elemento interpretativo para entender su obra como consecuencia directa de un acontecimiento histórico. La necesidad de entender el exilio como el elemento clave para penetrar en el sistema mental de esta generación entronca con lo expuesto por Pierre Milza, el cual apoyándose en su interpretación de Wilhelm Dilthey, afirma que una generación "se structure autour d'un «grand événement», disons d'un évenement fondateur" (13). En relación con esto, cabe resaltar la "razón histórica" a la que también había apelado el 
propio Ortega Gasset al pronunciar su célebre frase "yo soy yo y mis circunstancias", extrapolable al de una colectividad, en este caso, a los niños de la guerra (Marías 83). Por otro lado, Julián Marías señala un intervalo de quince años, puesto que divide la vida en cinco periodos de quince años y los primeros quince años corresponden a la infancia, periodo en el que, como se ve a continuación, encajan los escritores aquí mencionados (97). En definidas cuentas, según Marías, el concepto de generación no implica más que: “tener la misma edad y tener algún contacto vital" $(98) .{ }^{22}$

Al hablar de las características de la segunda generación de escritores exiliados en México, Eduardo Mateo Gambarte, así como otros críticos tales como Susana Rivera, Bernard Sicot o Angelina Muñiz-Huberman, están de acuerdo en afirmar que es el hecho de marchar al exilio acompañando a sus padres sin haber cumplido la mayoría de edad, estar en proceso de formación y haber nacido en España lo que nos permite reunir a todos esos escritores bajo dicho término (Los niños de la guerra 63). No hay razones, por lo tanto, para dejar fuera de dicha categoría a los otros autores ya mencionados que marcharon a otros países. Por otro lado, Susana Rivera se encarga de recoger algunas de las características que se pueden atribuir a dicho grupo. En primer lugar, hace referencia a "la educación de marcado tono humanístico", una educación basada en los ideales de la Institución Libre de Enseñanza (ILE), metodología que se empleó en México al crear los colegios del exilio como el Colegio Madrid, el Instituto Luis Vives o la Academia Hispano-Mexicana (Última voz 31). Aunque bien es cierto que muchos de los niños que llegaron a otros países, como la URSS o el Reino Unido, también disfrutaron, durante el

\footnotetext{
${ }^{22}$ El concepto "tener la misma edad" no hace referencia a una edad biológica, sino a tener la misma vivencia de un acontecimiento (98-100).
} 
desarrollo de la guerra civil española, de una educación basada en los principios de la ILE, esta llegó a su fin con la derrota de la República. Tanto es así que fue únicamente en México donde se llevó a cabo la implementación de este sistema educativo de forma plena en la época posterior al conflicto bélico, tal y como demuestra la creación de los institutos ya mencionados. Es esta, sin duda, una de las razones que ha llevado a Angelina Muñiz-Huberman a afirmar que "una generación como la hispanomexicana no se ha dado en ningún otro país al que llegaron refugiados de la guerra civil española" ( $E l$ canto 162). Los textos de aquellos que marcharon a la URSS recuerdan, en muchas ocasiones, que fueron acompañados de profesores y maestros educados bajo las indicaciones de la Institución Libre de Enseñanza. Trinidad Barbero recoge la anécdota en la que, en una de las casas infantiles de Estalingrado, los profesores y educadores españoles seguían dando clase mientras que los niños estaban arropados en la cama (245). José Fernández Sánchez, en sus memorias Diario de un niño en Moscú, recuerda con cariño las clases de Rubén Landa, quien había sido instruido en la Institución libre de Enseñanza. Sin embargo, es también el mismo José Fernández Sánchez el que afirma que este y casi todos los demás profesores españoles —Carmen Jiménez, Magdalena, Cebrián - marcharon a México una vez terminada la guerra española ya que la escuela soviética no les permitía una pedagogía tan liberal. De hecho, asegura que los lotes de libros españoles que recibían por parte de la República dejaron de estar a su alcance y que tuvieron que estudiar a través de manuales soviéticos (435-441). Por otro lado, Manuel Arce también recuerda con cariño la figura de Vicente Eugenio Pertegaz, profesor en la URSS educado en la Facultad de Filosofía y Letras de la Universidad Central (112-133). 
Por otro lado, en el caso de Reino Unido, José Estruch, quien había trabajado en España con Federico García Lorca y Luis Sáenz de la Calzada, creó un grupo de teatro con José García Lorca para unir y mitigar "la ausencia de puntos de referencia cultural e ideológica de aquellos jóvenes" (Luis Monferrer 216). Junto al grupo de teatro surgieron otros grupos folclóricos, como el creado por el profesor Martínez Torner y el profesor Lázaro, así como el grupo Juventud Española. Aunque estos grupos sí se prolongaron más allá del conflicto bélico, su impacto no puede compararse al de las instituciones creadas en México ni a la huella que dejaron los numerosos profesores e intelectuales de la primera generación que pasaron por estos colegios. Aún más llamativa es la situación de aquellos niños que marcharon a Bélgica. Emilia Labajos Pérez explica que casi todos los niños asistieron a la escuela de la localidad junto a los niños belgas, lo que facilitó su adaptación e integración en el país de acogida (59). Esto se debió, probablemente, a que, frente a los centros creados por republicanos o exiliados en México, Francia o la URSS, en Bélgica los niños fueron distribuidos en hogares individuales, en los que las familias se comprometían a cuidar de ellos hasta que la guerra civil hubiese acabado, lo que provocó una mayor separación entre los miembros de la comunidad exiliada.

Por otro lado, Pascual Buxó, poeta de la segunda generación de escritores exiliados en México, establece cuatro características para definir a la segunda generación de escritores exiliados en México (cit. Rivera 33). En primer lugar, la predominancia de la inseguridad causada por las primeras experiencias de vida durante la guerra y el destierro. Rastros de esta inseguridad puede encontrarse también en los relatos de Jaime Salinas, Isabel Argentina Álvarez o Manuel Fernández Montesinos quien afirma "en la primavera de 1941, a los seis o siete meses de nuestra llegada al nuevo mundo, 
empezaron los titubeos identitarios y los vaivenes entre el pasado y el presente (...). Era el inicio de una disyuntiva que se me presentaba, sin darme cuenta, entre lo que había sido y lo que estaba empezando a ser" (41). Por otro lado, el poeta hispano-mexicano argumenta la presencia de una España idealizada como rasgo de su generación. Álvarez del Vayo, refugiada en Francia, escribía en sus memorias:

El grito del destierro se extiende a la patria entera. No a una calle, ni a un pueblo, ni a una ciudad. A España toda, sus ríos y sus fuentes, sus rugosas planicies y sus bravas cordilleras, sus frondosos montes y sus soleados arenales, a la patria toda que encierra nuestra identidad, nuestra inquebrantable unión con el pasado y alienta, desde el día que nos alejamos, el ansia del regreso. (Los últimos 98)

También Jorge Semprún, exiliado en Francia junto a su familia, muestra una visión idealizada de la España de su infancia:

Tan sólo tengo recuerdos de mi infancia en los que subsidiariamente entre en juego la manduca. Los pasteles de merengue de los domingos, en Madrid. Los churros del desayuno, los días festivos, después de la misa de San Jerónimo. O también, cosa que deja maravillado a Ferdinand, el recuerdo enternecido de los garbanzos de un cocido familiar y sistemáticamente semanal. (Aquel domingo pos. 763)

En relación con esta idealización, Fernando Aínsa, exiliado en Uruguay, recoge en su obra Travesias la opinión de Ana Vázquez, quien "ha distinguido entre niños que han llegado siendo muy pequeños o que han nacido aquí y niños que, al ser mayores, recuerdan el país de origen y, por lo tanto, lo idealizan, especialmente: 'cuando deben 
hacer frente a obligaciones sociales y escolares muy diferentes de las que conocían antes'” (35). Sirva esta leve referencia para hacer ver que dicha idealización no es exclusiva de México, lo cual se desarrollará más en profundidad a continuación.

Asimismo, Buxó argumenta la influencia mayoritaria en la obra de su generación de la literatura española, especialmente de la generación noventayochista. Debido al carácter "poco literario" de algunas de las memorias o diarios de esta generación, es difícil rastrear la influencia de dicha literatura en algunos de los escritores. Sin embargo, es fácil rastrear el conocimiento de los escritores españoles en muchos de los autores exiliados de esta generación en otros países que no sean México. Manuel FernándezMontesinos reconoce haber visto en Nueva York las representaciones de El alcalde de Zalamea, producida por sociedades de emigrados y exiliados españoles, y de Fuenteovejuna (50). ${ }^{23}$ También Jaime Salinas, por la influencia de su padre, Pedro Salinas, era buen conocedor de la literatura española. José Fernández Sánchez confiesa haber sido lector de libros en español - aunque no especifica qué tipo de libros- antes de que estos fueran retirados por la URSS (435). También María Casares expone su conocimiento sobre los clásicos españoles a los que llegó a través de su padre (33).

En último lugar, Buxó afirma el desligamiento espiritual de México y sus problemas. Del mismo desligamiento puede hablarse en el caso de estos otros escritores, especialmente en los primeros años de su existencia en dichos territorios. Además, este desligamiento viene causado, en muchas ocasiones, por el sentimiento de extranjería que poseen a pesar de haberse adaptado totalmente al país de acogida, tal y como afirma Luis

${ }^{23}$ Casa de Galicia, el Ateneo Español y el Centro Asturiano. 
Santamaría: "En Inglaterra somos extranjeros, a pesar de todo el tiempo que llevamos viviendo aquí, pero cuando volvemos a nuestra tierra nos convertimos en ingleses" $(186) \cdot{ }^{24}$

Otro miembro de la generación, Roberto Ruiz, también delimita algunos rasgos comunes de dicho grupo. En primer lugar, defiende la seriedad artística, el odio al mal gusto y el respeto por la cultura. Asimismo, señala la independencia ideológica y preceptiva-la cual criticará Max Aub-, puesto que, a pesar de confesar ser conocedores de las diferentes tendencias ideológicas del momento (catolicismo liberal, marxismo crítico, etc.) declaran un profundo deseo de libertad, a la que todos sus miembros podían acogerse ("La segunda generación" 151).

A la hora de hablar de generación, un factor importante a tener en cuenta es la fecha de nacimiento de los autores. Mateo Gambarte ha señalado las fechas de 1924 y 1939 como parámetros para delimitar a dicha generación (Los niños 9). Por otro lado, Angelina Muñiz-Huberman establece las fechas de 1924 y 1937 (El canto 157). Estas son las mismas que establece Enrique de Rivas ("De éxodos, exilios" 30). También coinciden con las propuestas por Bernard Sicot al hablar del grupo poético de los hispanomexicanos (Ecos 15). Susana Rivera comparte la misma fecha para delimitar el fin de la generación, aunque establece su inicio en 1925 (Última voz 33). También Roberto Ruiz establece unos límites temporales para hacer referencia a este grupo, concretamente, los de 1920 y 1930 (“La segunda generación” 149). Es Fernando Larraz el crítico que ofrece un abanico

\footnotetext{
${ }^{24}$ No pretendo desarrollar este punto ahora porque lo retomaré al afrontar la conflictiva identidad nacional de esta generación en el siguiente capítulo.
} 
temporal más amplio, pues data a dicha generación desde 1920 a 1942 ("Memoria" 584). No obstante, creo que ninguna de las fechas propuestas recoge la esencia de esta generación: haber marchado al exilio por decisión de sus padres y familiares y sin una plena conciencia de lo que estaba sucediendo. Por esta razón propongo una nueva clasificación que no esté basada en el momento de nacimiento, sino en la edad con la que estos niños partieron al exilio. No tiene sentido dejar fuera de dicha generación a autores como Jorge Semprún (parte al exilio en 1936 con 13 años) o Conchita Ramírez (parte al exilio en 1939 con 16 años) que, a pesar de haber nacido en 1923, marcharon al exilio con la misma edad -o incluso siendo más jóvenes- que otros autores normalmente incluidos en dicho grupo como Ramón Xirau, Carlos Blanco Aguinaga, Manuel Durán, Roberto Ruiz o Tere Medina. De este modo, desde mi punto de vista, deben incluirse en esta generación todos aquellos niños que marcharon al exilio con 16 años o menos. Ahora bien, varios críticos se han encargado, de forma acertada, de establecer una división dentro de la generación entre aquellos que marcharon al exilio siendo adolescentes y aquellos que eran aún muy niños. De hecho, Mateo Gambarte, en relación a los establecidos en México, expone que aquellos que llegaron de adolescentes se manifestaron, principalmente, en la revista Presencia, mientras que los llegaron de niños crearon las revistas Clavileño y Segrel ("El exilio, los exiliados" 68). También hace referencia a dicha división Juan Rodríguez ("Españoles en casa” 304). Por otro lado, Enrique de Rivas señala incluso la existencia de tres grupos: aquellos que llegaron siendo adolescentes - Ramón Xirau, Manuel Durán, Nuria Parés, Carlos Blanco Aguinaga, Jomí García Ascot y Tomás Segovia-; los que llegaron teniendo entre 8 y 10 años -César Rodríguez Chicharro, José Pascual Buxó, Luis Rius y Enrique de Rivas-; y los que 
llegaron siendo párvulos -Gerardo Deniz, Francisca Perujo, Angelina Muñiz-Huberman y Federico Patán- (“De éxodos, exilios” 30-31). No cabe olvidar que dichas clasificaciones se han limitado únicamente a los establecidos en México, pues no se había tenido en cuenta a los escritores asentados en los otros países.

Una vez justificada la necesidad de ampliar el término de "segunda generación" a todos aquellos escritores que marcharon al exilio con dieciséis años o menos sin importar el país de acogida, es necesario delimitar el área de análisis de este trabajo. Aunque queda pendiente un estudio completo que recoja toda la obra de estos autores sin diferencia de género, este proyecto se centra únicamente en aquellas obras narrativas que pueden situarse dentro de la literatura del yo - memorias, autobiografías, confesiones, cartas, diarios, cuadernos de apuntes - y que tienen una relación con el exilio. De este modo, la nómina de autores expuesta al principio queda más reducida, aunque, aun así, es muy extensa: Fernando Aínsa, Federico Álvarez, María Álvarez del Vayo, Isabel Argentina Álvarez Morán, Manuel Arce Porres, Fernando Barral, Néstor Basterretxea, Ángel Belza, Carlos Blanco Aguinaga, María Casares, Michel del Castillo, Aurora Correa, Nieves Cuesta, Amadeu Cuito, Gerardo Deniz, María Luisa Elío Bernal, Ángel Fernández, Isabel Fernández, María L. Fernández, Manuel Fernández Montesinos, Áurea Matilde Fernández Muñiz, José Fernández Sánchez, Jacques Folch-Ribas, Carles Gerhard i Hortet, Emilia Labajos, Virgilio de los Llanos Más, Miguel Martínez, Tere Medina, Aurélia Moyà-Freire, Angelina Muñiz-Huberman, Federico Patán, Tatiana Pérez, 
Conchita Ramírez, Enrique de Rivas, Jaime Salinas, Luis de Santamaría, Jorge Semprún

y Conchita Simarro. ${ }^{25}$

${ }^{25}$ Fernando Aínsa: Con acento extranjero (1985) y Travesías: juegos a la distancia (2000); Federico Álvarez: Una vida. Infancia y juventud (2013); María Álvarez del Vayo: Los últimos días: recuerdos y reflexiones de una niña del exilio (2003) y Patria mía ¿Dónde estás? (2014); Isabel Argentina Álvarez Morán: Memorias de una niña de la guerra (2003); Manuel Arce Porres: Memorias de Rusia: vivencias de un "niño de la guerra" (2009); Fernando Barral: Mis vidas sucesivas: recuerdos y destino de un niño de la guerra (2010); Néstor Basterretxea: Crónica errante y una miscelánea (2006); Ángel Belza: Memorias de un niño en Rusia 1937-1957 (2013); Carlos Blanco Aguinaga: Un tiempo tuyo (1988), Por el mundo: infancia, guerra y principio de un exilio afortunado (2007) y De mal asiento (2010); María Casares: Résidente privilégiée (2003); Michel del Castillo: Tanguy. Historie d'un enfant d'aujourd'hui (1978); Aurora Correa: Te beso, buenas noches (2000) y Cerezas (2008); Nieves Cuesta: Simplemente mi vida (2009); Amadeu Cuito: Memòries d'un somni (2011); Gerardo Deniz: Paños menores (2002); María Luisa Elío Bernal: Tiempo de llorar (1988), Cuaderno para apuntes (1995) y Voz de Nadie (2017); Ángel Fernández: Rebelde (tomo 1, 2000, y tomo II, 2009); Isabel Fernández: Pauline ou l histoire d'une intégration. De Madrid à Mazamet (1997); María L. Fernández: Memorias de una máquina de escribir de una niña de la guerra (2011); Manuel Fernández Montesinos: Lo que en nosotros vive (2008); Áurea Matilde Fernández Muñiz: José y Consuelo: amor, guerra y exilio en mi memoria (2007); José Fernández Sánchez: Memorias de un niño en Moscú (1999); Carles Gerhard i Hortet: Dues guerres i un exili (2013); Emilia Labajos: La casa de los geranios (2003); Virgilio de los Llanos Más: ¿Te acuerdas Tovarisch? (2002); Miguel Martínez: Casbah d'oubli. L'exil des refugies politiques espagnols en Algerie 1939-1962 (2004); Tere Medina: Sobre mis escombros: estampas de la guerra civil española (1971) y Memorias del exilio (2007); Aurélia Moyà-Freire: Vinc d'Arbeca. Una infantesa travessada per la guerra $i$ l'exili (2014) y Ma vie en France: Cahier d'exil d'une adolescente espagnole, 1939-1943 (2017); Angelina Muñiz-Huberman: Dulcinea encantada (1992), Castillos en la tierra (1995) y Molinos sin viento (2001); Federico Patán: De cuerpo entero (1991), Último exilio (2009) y Una infancia llamada exilio (2010); Tatiana Pérez: Memorias de Lara (1977); Conchita Ramírez: Diario de una niña exiliada (2006); Enrique de Rivas:

Quando finirá la guerra (1992); Jaime Salinas: Travesías: memorias (1925-1955) (2003); Luis Santamaría: Agur Euskadi, hasta mañana (2008); Jorge Semprún: El largo viaje (1965), El desvanecimiento (1967), Autobiografia de Federico Sánchez (1977), Aquel domingo (1981), Federico Sánchez se despide de ustedes (1993), La escritura o la vida (1995), Adiós, luz de los veranos (1998), Vivirá con su nombre, morirá con el mío (2001) y Veinte años y un día (2003); y Conchita Simarro: Diario de una niña en tiempos de guerra y exilio (1938-1944) (2016).

No se incluye a Roberto Ruiz pues, a pesar de ser uno de los mejores escritores de esta generación, sus obras han sido clasificadas dentro del género novelístico, aunque en estas aparecen ciertos rasos autobiográficos y tienen como tema de fondo la condición de 
El análisis de las obras de estos escritores tiene varios objetivos. En primer lugar, establecer los nexos de unión en la construcción identitaria, fruto de la disparidad causada entre su país de origen y su país de acogida, sin establecer barreras geográficas entre los miembros de la generación refugiados en los diferentes países. Asimismo, me propongo explorar las relaciones temporales que surgen por la parálisis cronológica causada por la Guerra Civil, la dualidad entre el pasado y el presente y la incertidumbre ante el futuro. En tercer lugar, es preciso profundizar en las técnicas narrativas empleadas por esta generación para indagar en el pasado a través de la memoria, así como las desarrolladas para expresar su situación limítrofe o fronteriza. En relación con la memoria, es necesario también rastrear las huellas del trauma y de la memoria individual/colectiva en la construcción de una identidad personal. En último lugar, explorar las dinámicas surgidas dentro de la literatura autobiográfica y las relaciones de esta con el lenguaje, la cultura y la identidad, así como el surgimiento de textos híbridos como consecuencias de la intersección lingüística en la que se encuentra el sujeto subalterno en oposición al otro dominante.

exiliado. Véase el breve, pero interesante, artículo de Gerardo Piña Rosales "El exilio como condición humana: la obra narrativa de Roberto Ruiz". 


\section{El exilio involuntario de la segunda generación}

Con motivo del congreso El exilio de las Españas de 1939 en las Américas: ¿adónde fue la canción?, Roberto Ruiz afirma:

De radical importancia fue nuestra conciencia del exilio, diametralmente opuesta a la de nuestros padres. Ellos se habían desterrado de un ambiente vivido y percibido; nosotros, de un ambiente difuso, alterado por las incertidumbres de la infancia y los estragos de la guerra. Si queríamos ocuparnos de España, teníamos que volverla a inventar; para hablar de la nueva residencia nos faltaban recursos y conocimientos; además, al país de adopción le sobraban cronistas mejor situados. Esta fue la corriente vital que impulsó a muchos a la poesía: la reflexión lírica podía prescindir de referencias exteriores, y la materia del exilio, más accesibles que los recuerdos y los proyectos, se adaptaba perfectamente a la vía poética. En cambio los aprendices de narrador, nos vimos obligados a un esfuerzo titánico de memoria y de imaginación, y al riesgo de que nos acusaran, como me acusó a mí más de un ingenuo, de «falsear la realidad». (151)

Esta cita es indicativa de los rasgos que van a marcar profundamente la peculiar situación de esta generación: una conciencia del exilio configurada en oposición a la de sus padres, la formación en un contexto confuso por los continuos cambios de residencia sin aparente motivo, la ausencia de una imagen de España en sus mentes y, por consiguiente, el uso de la imaginación para indagar en los recuerdos, así como la necesidad de crear una narrativa fruto de la convivencia entre la memoria y el ingenio. 
En el capítulo anterior, anuncié que ser exiliado no es sólo renunciar a tu país de acogida, de forma temporal o permanente, por miedo a las represalias políticas, sino que la palabra exilio conlleva unas implicaciones mucho más profundas y cuyas huellas perduran incluso después del deseado regreso. Exiliarse significa abandonar el hogar en el que se nace, romper los lazos familiares y comunitarios; implica una pausa temporal en la configuración identitaria del ser, el miedo a quedar colgado en un limbo sin referentes. Al mismo tiempo, indica una lucha entre el deseo de un pronto regreso, la necesidad de adaptarse al nuevo lugar de acogida y el aferramiento a una imagen del país de origen que no es real, sino creada por la nostalgia y los recuerdos. En definitiva, supone asumir un nuevo rasgo identitario, la condición de exiliado, que antes nunca habían considerado como elemento clave de su ser. No obstante, hay un hecho que agrava aún más el proceso de asimilación en el caso de la segunda generación de escritores exiliados. Frente a la primera generación, conscientes de que su circunstancia de exiliado venía marcada por su creencia en una ideología contraria a la establecida en el poder en España, la segunda generación de escritores no tenía ningún elemento que les ayudara a entender su situación y, por lo tanto, les facilitase una más temprana aceptación de su nueva circunstancia vital. Tal es así que muchos de estos autores recogen, en sus obras narrativas, su desconcierto ante el desarrollo de los acontecimientos. María Álvarez del Vayo, al comienzo de su autobiografía, apunta: “Sé dónde vamos pero no sé por qué...” (Los últimos 10). ${ }^{26}$ También en el relato de Manuel Fernández Montesinos puede vislumbrarse cierta incomprensión ante las circunstancias:

\footnotetext{
${ }^{26}$ Similar sentimiento se describe en las obras de María Luisa Elío Bernal, Emilia Labajos Pérez, Tere Medina y Jaime Salinas, entre otros.
} 
Fue la voz de mi abuelo, a mi lado, la que apartó bruscamente de mí la sensación de triunfo y de aventura cuando le oí decir, erguido contra la barandilla:

- No quiero volver a este jodío país en mi vida.

(...) A mis ochos años, también yo desperté del mío con una voz, la de mi abuelo, porque el efecto que produjo en mí esa frase que masculló entre dientes fue exactamente como el que se siente a veces al despertar, es decir, al pasar de un estado a otro en un instante. (...) Se iluminaron, por un segundo nada más, las zonas más oscuras de todo lo que nos había pasado y comprendí de pronto que estábamos huyendo. Fue como un fogonazo. (15-16)

Los niños pasan a formar parte del conflicto civil de forma forzada, se les asigna un bando y, con ello, se les marca el destino, como dan a entender las palabras en francés de Miguel López Martínez, miembro también de esta generación: “C'est donc cela, la guerre: j'appartiens nécessairement à un groupe antagoniste dont la mission consiste à anéantir l'autre, l'ennemi, si possible dans l'oeuf, en massacrant des enfants de mon âge, frères d'infortune à jamais inconnus" (18). No obstante, ni siquiera en el caso de los más mayores que muestran haber desarrollado un cierto tipo de concienciación política puede hablarse de un entendimiento y de una asimilación de las circunstancias que le facilitase asumir su condición, pues las ideas políticas que algunos manifiestan durante el relato de su infancia corresponden a una transmutación ideológica de las de sus padres y no a una adhesión por convicciones reales. Tal es así que Aurea Matilde recuerda las "guerras" que los niños de padres republicanos emprendían contra los hijos de los fascistas: "Mi 
hermano Pepín, junto a otros niños hijos de republicanos como nosotros, organizaban pequeñas guerras contra los hijos de los fascistas. La guerra era a pedrada limpia (...). Nos sentíamos importantes defendiendo a la República y atacando a sus enemigos" (77). Es curioso el uso del posesivo "sus" para hacer referencia a los enemigos de la República en lugar de "nuestros", lo cual evidencia una falta de identificación total con la causa republicana, simplemente por incapacidad de comprensión de la gravedad del asunto a tan corta edad, no porque, posteriormente, en su madurez, no se identificase con esta. Sin embargo, es preciso señalar que junto a Aurea Matilde son muchos otros los niños mayores de la segunda generación que pretenden asumir la ideología de sus padres durante su infancia, probablemente como consecuencia de los problemas sufridos por sus familiares y amigos. Es el caso de Carlos Blanco Aguinaga quien también se identificaba como republicano en los años de infancia: "Por eso, cuando estoy explicando el Mundo a aquel amigo de nuestros tan pocos años, nacido tal vez en Extremadura, entiendo, sé perfectamente, que es de los Nuestros, no un enemigo. Es decir, que tiene que ser republicano, hijo de republicanos" (Por el mundo 26).

En similar situación se encuentra Jaime Salinas quien se identifica como republicano influenciado, entre otros factores, por la muerte de Federico García Lorca: "Desde el primer día de la guerra, nadie tuvo que decirme de qué lado tenía que estar. Estaba con los buenos, con los republicanos (...). La muerte de Federico García Lorca me enseñó el horror de la guerra y también a odiar" (50). Ahora bien, independientemente del grado de conciencia que tuvieran los niños de la guerra en el momento del inicio de su peregrinaje, en su mayoría han mostrado, posteriormente, una simpatía por los valores 
de la República, sintiendo el conflicto bélico como algo propio, pues en numerosos relatos puede observarse que hacen referencia a esta como "nuestra guerra".

Es esta condición de exiliado como nuevo elemento identitario la que ha provocado que sus obras autobiográficas tengan unos rasgos temáticos en común. En relación a estos, Fernando Larranz destaca, principalmente, la recurrencia a la nostalgia, la infancia, el retorno, así como las conflictivas relaciones generales con sus madres y padres ("Memoria" 587-88). La nostalgia y la infancia conllevan un desarrollo paralelo en la narrativa de estos escritores. Tal es así que Larranz afirma que es en el tratamiento de la infancia donde se puede encontrar una mayor similitud entre los dos grupos de la segunda generación, mayores y menores ("Memoria" 587). Puede verse como la infancia ocupa un papel principal en obras como Tiempo de llorar, de María Luisa Elío Bernal, Por el mundo. Infancia, guerra y principio de un exilio afortunado, de Carlos Blanco Aguinaga, Cerezas, de Aurora Correa, o Adiós, luz de veranos..., de Jorge Semprún. La infancia se convierte en símbolo del mundo perdido, un espacio imposible de recuperar a pesar de los intentos imaginarios de muchos de estos escritores. Para hacer referencia a dicho mundo, Isabel Marín Gómez señala la presencia de unos cronotopos que se repiten en las obras de los niños de la guerra (215). Así, la casa donde nacieron, las calles en las que jugaban, la plaza del pueblo, la escuela, los lugares de trabajo de su padre, los huertos familiares o jardines, se convierten en imágenes recurrentes en las obras de estos escritores. Ahora bien, la recurrencia a la infancia debe interpretarse también como una búsqueda de los orígenes de la identidad, lo cual se desarrollará también en el siguiente apartado. 
También son frecuentes los autores que escriben sobre las relaciones familiares. Especialmente interesantes son las obras de Federico Patán, Jaime Salinas y Michel del Castillo. Junto a la experiencia traumática del exilio, Federico Patán vive la desaparición del rol paternal de la familia pues este, probablemente traumatizado también por el conflicto bélico, fue incapaz de asumir los cambios y de adaptarse a la nueva vida. Tanto es así que el escritor hispano-mexicano narra los problemas económicos que tuvo que atravesar durante su infancia por culpa del alcoholismo y los malos negocios de su padre, hecho que provocó que lo borrase de su memoria: "La memoria es selectiva. Repasando mi infancia en Perote, es de preguntarse la causa de tantos vacíos. Uno de los más señalados el de mi padre" (Una infancia 205). Además, esta problemática relación también ocupa un papel relevante en su otra obra De cuerpo entero. Por otro lado, en la obra Travesías de Jaime Salinas, también puede observarse la tensa relación con la figura paterna, causada, en esta ocasión, por la firme autoridad impuesta por Pedro Salinas. En la obra pueden leerse varios enfrentamientos entre padre e hijo, como el que tuvieron en Puerto Rico, cuando Jaime Salinas quiso registrarse en el American Field Service. ${ }^{27}$ El caso de Michel del Castillo ofrece una nueva visión de las relaciones familiares porque, a diferencia de los otros escritores exiliados, este tuvo que enfrentarse al abandono tanto de la madre como del padre. En su obra, Tanguy. Historia de un niño de hoy, relata, por un lado, el abandono de su padre francés por los ideales políticos de su madre y la posterior traición de este ante la posibilidad de ver en riesgo su situación social tras la llegada de

\footnotetext{
${ }^{27}$ Este tema se desarrollará más profundamente en el próximo capítulo a la hora de hablar de identidad nacional, pues es inevitable establecer una conexión entre la figura de su padre y el papel de este en la configuración de dicha identidad.
} 
Michel del Castillo con su madre a Francia escapando de España; y, por otro lado, el ingreso en un orfanato al sur de Francia durante el peregrinaje de su madre por el exilio, lo que provocó su posterior encierro en un campo de concentración nazi.

No obstante, detrás de esta traumática relación, es posible pensar que yace un hecho más importante si se tiene en cuenta la condición de exiliado de ambas generaciones. Muchos de estos choques - no en el caso de Michel de Castillo- pueden considerarse fruto de la falta de comprensión entre esa primera generación - los padresque intentan educar a sus hijos en la cultura española para que estén preparados para la pronta vuelta y la segunda generación — los niños — quienes intentan integrarse, en la medida de lo posible, en el nuevo país de acogida. En relación a esta diferencia de intereses, Carolyn Galerstein señala: "as the fathers attempt to convince their children that the day of return is approaching, the children rebel against the unreality of their fathers' dreams and the ineffectiveness of their mothers' nostalgia, and they prepare for lives of their own in their new countries" ("The Second” 221). De este modo, se produce un enfrentamiento entre padres e hijos, padres que se niegan a comprar muebles nuevos, a hacer amistades que no sean la de españoles exiliados, y niños que viven la realidad de su nuevo país de una forma natural, con deseo de explorar, sin pensar en el futuro. Como ya señala Eduardo Mateo Gambarte al hablar de los niños hispano-mexicanos, los mayores se sienten decepcionados a medida que los adolescentes van creciendo y no van siguiendo las pautas que ellos mismos les habían marcado (Los niños 74). Este distanciamiento no sólo se produjo en los exiliados en México, sino que la situación se repite también con muchos de los otros escritores y sus círculos familiares. Manuel Fernández Montesinos interioriza sobre el desapego que se produce entre la realidad que 
se vive dentro de casa y la educación española por parte de sus padres y la realidad de lo que sucedía fuera de ella (49). José Fernández Sánchez recuerda cómo los mayores lo acusaban con tono de reproche de ser tan ruso como los rusos nativos (223). Esta disonancia entre los deseos de los adultos y los de los niños ha provocado, en cierta medida, que se le acuse a la segunda generación de estar poco politizada. Juan Rodríguez ya señaló el distanciamiento que había asumido Max Aub cuando se dio cuenta de que esta nómina de autores - refiriéndose a los hispanomexicanos- no eran lo que ellos habían deseado: "herederos de la cultura republicana en una futura España liberada" (301). Además, el propio Max Aub califica su posición política de inestable: “El comunismo les repele por lo que de dictado moral contiene, el capitalismo no es hermoso y los liberales, hacia quienes sin duda van sus simpatías, se empeñan en hacerse los muertos" (13). También Susana Rivera y Eduardo Mateo han apuntado la falta de politización en estos autores. Sin embargo, una vez que muchos de estos niños consiguieron distanciarse de sus padres y fueron encontrando, lentamente, su propio espacio personal y su propia identidad, sí podemos afirmar que se produjo un proceso de politización, correspondiente a una etapa ya más madura, que comienza especialmente alrededor de los años 60 y se acentúa tras la muerte de Franco.

En primer lugar, refiriéndonos a la generación hispano-mexicana, cabe hacer referencia al Movimiento Español 1959 (ME/59), estudiado en profundidad por Elena Aub, hija de Max Aub, y por Manuel Aznar Soler. En el manifiesto de dicho movimiento, transcrito parcialmente por el segundo de los estudiosos, se encuentran nombres pertenecientes tanto a la primera como a la segunda generación, entre los que destacan, con motivo de este trabajo, los de Federico Álvarez, Manuel Durán, Arturo Souto y José 
de la Colina, entre otros ("Movimiento” 158). Según la declaración, este movimiento tenía como objetivo la unidad de acción para luchar en contra del franquismo y la organización para poder manifestarse libremente. Entre las acciones que tomaron, se encuentra la manifestación ante la embajada de los Estados Unidos de América en México D.F. el 21 de diciembre de ese año, el acto en solidaridad tras la detención del escritor Luis Goytisolo así como numerosas actividades culturales en teatros, editoriales, radios y cines. ${ }^{28}$

A pesar de lo "tardío" del involucramiento de la generación hispano-mexicana en movimientos, asociaciones y grupos en contra del franquismo, no sucedió lo mismo con aquellos niños que se quedaron en Europa, sufriendo, posteriormente, la Segunda Guerra Mundial, o con aquellos niños que marcharon a países donde el comunismo contaba con gran apoyo, como Cuba. Muchos de ellos tendrían un papel dentro de las organizaciones clandestinas que pretendían restituir la democracia en España, incluso en los primeros años de la década de los cuarenta. Aunque el caso más popular es, sin duda, el de Jorge Semprún, que posteriormente se convirtió en dirigente de la sección de intelectuales del PCE, son muchos los otros autores que participaron dentro de la resistencia exiliada. Su hermano, Carlos Semprún, también tuvo un papel dentro de la clandestinidad como militante de base, colaborando en numerosas pequeñas "organizaciones de masa" ( $E l$ exilio 189-218). Ángel Fernández relata su detención en Sable, junto a otros compañeros, y su posterior traslado a la cárcel de Zaragoza, su sentencia a muerte -y posterior

\footnotetext{
${ }^{28}$ Véase Manuel Aznar Soler: "Movimiento español 1959: Literatura y política de la segunda generación exiliada en México”.
} 
reducción a 30 años - por participar como conductor de un vehículo en una guerrilla clandestina (Rebelde 216-382). También en el caso de los niños que marcharon a Reino Unido, Natalia Benjamín, quien ha recogido numerosos testimonios sobre sus experiencias, afirma que "muchos de ellos estaban muy politizados y habían actuado como cabezas de sus familias al hallarse sus padres ausentes por la guerra, escondidos, en prisión o muertos" (198). Es interesante destacar la politización de Federico Álvarez en Cuba. Con 15 años, ingresó en la JSU (Juventud Sindicalista Universitaria) y, un año más tarde, en el Partido Comunista. Con respecto a este último, escribe que en el momento de su ingreso no era consciente de lo que aquello significaba (225). Además, confiesa que junto a él había otros cincuenta niños de la guerra, de los que, posteriormente, pasarían a conocerse como miembros de la "segunda generación". No obstante, Álvarez señala que, más que tratarse de unos ideales propios a los que había llegado por convicción propia, esta actividad política era fruto de la sociedad del momento y de su origen familiar:

Nos conocíamos todos y todos sabíamos que aquello era lo que me tocaba hacer. Estaba más que claro. Un adolescente, hijo de comunistas, en los años cuarenta, en plena efervescencia antinazi, pendiente todos los días de los triunfos soviéticos en la guerra, y en medio de una actividad intensa, cotidiana, con la vista fija en la caída del franquismo, un adolescente que respira en ese ambiente, no podía ser sino un militante comunista. Y lo fui. (220)

A pesar de ello, era tal su fe en el papel del partido comunista como sistema para derrocar la dictadura franquista, que intentó volver en varias ocasiones a España en la clandestinidad. Con el paso de los años se dio cuenta de que su militancia no fue más que 
un escollo y, a pesar de la firmeza con la que habla en el momento que tomó algunas decisiones dentro del partido en su juventud, podemos intuir que en el momento de la escritura, en cierta medida, se siente víctima de las circunstancias y de los ideales familiares: "De nuevo había sido un tránsito que yo no había elegido" (227).

A estas breves referencias a una politización de forma activa, es necesario sumar el componente más importante como reflejo de dicho fenómeno: su escritura. Aunque en el siguiente apartado se analizará más detenidamente el papel de la escritura en el proceso de construcción identitaria, es necesario destacar, brevemente, la función de esta desde un punto de vista político. Muchas de las obras de los autores de la segunda generación de escritores exiliados comienzan con dedicatorias o explicaciones similares a las de Isabel Argentina Álvarez: "Sirvan estas Memorias para que nuestros hijos y nietos conozcan la verdad histórica y defiendan por siempre la Paz y la justicia social” (23); o las de Emilia Labajos "Perdonad que estemos todavía aquí para recordároslo [se refiere a la Guerra Civil Española], no para clamar venganza, sino para que las generaciones que nos siguen no tengan que volver a vivir una situación semejante" (13). Dejando de lado la polémica entre testimonio histórico y testimonio literario, que también se abordará más adelante, gran parte de estas obras tiene el deseo de servir como testigo de su experiencia, de educar a las generaciones venideras en las consecuencias de un desastre como el vivido por ellos, en robarle espacio al olvido. En relación con esta lucha contra el olvido destaca también la politización en una época madura a la que se hizo referencia de forma breve. Se produce un aumento de publicaciones que dan fe de su experiencia, especialmente, en dos momentos de la historia: por un lado, en los años 80 , época en la que ya se ha instalado la democracia española y los escritores se sienten con la confianza de denunciar 
lo vivido, como es el caso de Tatiana Pérez, Fernando Aínsa, María Luisa Elío Bernal, Jorge Semprún o Carlos Blanco Aguinaga; y, por otro lado, a comienzos del siglo XXI, ya que muchos de estos escritores empiezan a cumplir los sesenta/setenta años y el fantasma de la muerte se aparece lentamente en su camino. En este segundo momento, publican sus obras autores como Federico Álvarez, Isabel Argentina, Aurora Correas, Virgilio de los Llanos, Carles Gerhard y Hortet, Conchita Simarro o Aurea Matilde, entre otros.

En definitiva, en lo que se refiere a la politización de esta segunda generación, queda patente la necesidad de un estudio crítico detallado que ahonde en los parámetros que acabo de apuntar. En primer lugar, aquella ruptura con los ideales de los padres a los que muchos críticos han venido haciendo referencia, especialmente en relación con los niños recalados en México, no puede extenderse a todos los casos, como prueban los testimonios de los hermanos Semprún o el de Federico Álvarez. Del mismo modo, esto evidencia la politización temprana en niños que tuvieron un mayor contacto con los grupos comunistas. En tercer lugar, independientemente del país de acogida, todos ellos llegan a una politización, ya bien a través manifestaciones como el Movimiento español de 1959 en México, o bien a través de la escritura de su experiencia en el exilio. Es, sin duda, esta última la prueba más importante de la politización de esta generación pues todos ellos denuncian, a través de la escritura, las vejaciones, problemas, insultos, maltratos, traumas y desgracias causadas por la guerra civil y el posterior exilio. 
Volviendo a las semejanzas temáticas a las que hacía referencia Fernando Larranz, la más significativa es, sin duda, la presencia del retorno. ${ }^{29}$ María Luisa Elío Bernal empezaba así su obra Tiempo de llorar: "Y AHORA ME DOY CUENTA QUE REGRESAR ES IRSE” (19). Y es que, incluso desde antes de marchar al exilio, padres e hijos ya estaban pensando en el regreso. Todos los críticos e historiadores están de acuerdo en señalar que los exiliados tenían una gran esperanza, primeramente, en la victoria del bando republicano y, una vez perdida la guerra, en la pronta caída del franquismo. Así lo recuerda María L. Fernández en su obra: “¿Por qué no estudiáis más el ruso? ¡Tenéis que aprenderlo! Y algunos le contestaban tan seguros: No nos va a hacer falta. Ya verá, la guerra de España termina pronto y regresaremos para casa" (47). Por esto último, muchos de los exiliados en Europa participaron de forma activa en la Segunda Guerra Mundial apoyando a las fuerzas socialistas, ya que pensaban que la derrota de las fuerzas fascistas alemanas e italianas conllevaría también el fin de la dictadura en España. Sin embargo, esto no fue así y el regreso se hizo cada vez más lejano y, en muchas ocasiones, ni siquiera se produjo. Esta esperanza fue la causante de

${ }^{29}$ Gerardo Deniz escribe que, a diferencia de sus compañeros de generación, él nunca escuchó hablar de un posible regreso:

Jamás escuché a la hora de la comida — donde sólo éramos tres- el tema del retorno, por ejemplo. Lo cual me diferenciaba — y lo agradezco, repito- de muchos de mis compañeros del Instituto Luis Vives, que evidentemente vivían reflejando a sus mayores - al perpetuo borde del regreso, hipotético y siempre diferido, hacia una noción confusa, una entelequia — en la cual me encuentro sentado en este momento, no sin asombro. En mi personal destierro mexicano, las sobremesas caseras no abordaban dicha posibilidad. Mi padre, extrañamente sería la edad, aunque sospecho que las cosas venían de más lejos-, evitaba los cafés donde se relajaban, en buena hora, otros desterrados tan jorobados como él, pero donde asimismo se gestaban mitos, cuentos tártaros poco de fiar (Paños menores 36). 
que padres y niños no tuvieran gran interés en la adaptación al país de acogida en los primeros años. Cecilia Elío Bernal, hermana de la ya citada María Luisa, me confesaba personalmente que, cuando su actual marido, de origen mexicano, se le declaró, ella se negó rotundamente ya que su familia sólo pensaba en regresar a España lo antes posible y tener un novio mexicano iba en contra de esos intereses. Por lo tanto, la idea del regreso se convirtió en un obstáculo que, en un principio, entorpeció la configuración de la identidad de los niños, pero que, a largo plazo, dio origen a una configuración identitaria distinta, tal y como demostraré más adelante. Tanto es así que, en los primeros años, estos se movían, principalmente, en círculos de exiliados. Especial mención merece el caso de México que creó una España republicana dentro de México, aislando así a los niños. Esta España disponía de sus propios cafés en los que se reunían los exiliados, de sus propios centros de reunión y de sus propias escuelas, por las que pasó la mayoría de miembros de la generación hispano-mexicana. ${ }^{30}$ De hecho, Angelina Muñiz-Huberman escribía:

La asistencia de la mayor parte de este grupo a escuelas diferentes a las del medio (escuelas fundadas por padres y profesores con miras a la continuación del sistema educativo español), señaló, desde el principio, la desviación formal que recibió dicho grupo. Esos niños fueron educados como si el retorno a España hubiera de ser inminente y como si vivieran en

\footnotetext{
${ }^{30}$ Entre los cafés destaca el Café París y el Hotel Imperial. Solían reunirse en la Casa de España, creada en 1938 y dirigida por Alfonso Reyes, y en el Ateneo Español. Entre las escuelas que fundaron destaca el Instituto Luis Vives (1939), la Academia HispanoMexicana (1940) y el Colegio Madrid (1942), seguidores de la Institución Libre de Enseñanza de Giner de los Ríos.
} 
una realidad ajena a la mexicana. Esta educación de invernadero les caracterizó y marcó con una fuerte dosis de idealismo. (El canto 156)

También en Cuba se crearon centros de exiliados, como la Casa de Cultura, a la que Federico Álvarez se refería como el "centro de las actividades públicas de los exiliados que se situaba en la izquierda marxista” (220). En el Reino Unido y en la URSS se formaron también casas-hogares o colonias para albergar a los niños, de modo que, al estar todos reunidos, esto dificultaba su integración en los países de acogida. Por un lado, en relación al país británico, Luis de Santamaría narra su periplo por North Stoneham, Swansea, Liverpool, Oxford, Aston y Margate hasta llegar a la colonia de The Oaks y, posteriormente, a The Culvers. No fue hasta su llegada a The Oaks cuando asistió, por primera vez, a una escuela británica, lo que para él fue su primera señal de resignación ante la idea de no poder volver a su patria (153). En el caso de la URSS, Alted Vigil señala la creación de Casas Infantiles que hospedaron a los casi 3000 niños que habían marchado a tierras soviéticas y en las que se educaba a los niños españoles como tal (Los niños de la guerra 97). ${ }^{31}$ Además, José Fernández Sánchez afirma que también se crearon centros del exilio español en Moscú, como el vestíbulo del Vetoshny, aunque era más frecuente encontrar en este a los mayores de la generación, ya que, en rara ocasión, se dejaban caer los pertenecientes a la segunda generación (444). Diferente era el caso de los niños enviados a Bélgica, país en el que se crearon hogares de forma temporal hasta que se reubicaron a los niños en familias de acogida. Esto hizo que la inserción fuese

\footnotetext{
${ }^{31}$ Para más detalles véase el capítulo noveno del libro Los niños de la guerra de España en la Unión Soviética. De la evacuación al retorno (1937-1999), de Alicia Alted Vigil.
} 
mucho más rápida, tal y como demuestran las palabras de Emilia Labajos: "Tres meses después de nuestra llegada ya hablábamos muy bien francés. Incluso nos olvidábamos de hablar español con nuestra madre cuando venía a vernos" (76). No obstante, si bien es cierto que, una vez que terminó la Segunda Guerra Mundial y comprendieron que la caída de Franco no era un hecho inminente, muchos de estos centros de exiliados, especialmente aquellos destinados a acoger a los niños que contaban con apoyo económico de la República, empezaron a cerrarse -a excepción de México y de algunos otros puntos clave como Moscú o La Habana-, lo que hizo que estos niños, o bien regresaran con sus familias que estaban exiliadas en algún país, fuesen repatriados a España o bien se integrasen al país de acogida. ${ }^{32}$

La aceptación de que el regreso no era algo inmediato le dio a este un valor más acentuado si cabe. El retorno alcanzó así un sentido más profundo pues la pérdida de esperanza hizo que fueran más conscientes de lo que habían dejado atrás. De esta forma, volver al país de origen era una búsqueda de la infancia que le habían arrebatado y de la identidad española en el caso de la segunda generación, y es que, como ya dijo Fernando Aínsa emulando a Ernst Bloch, "el viaje es la búsqueda de un espejo para la identidad humana" (Travesías 9). No obstante, muchos de ellos empiezan a comprender que el regreso ya nunca será completo, puesto que el paso del tiempo hacía que cada vez se sintiesen menos identificados con lo que dejaron, que los recuerdos fuesen cada vez más débiles y que se aferrasen a una imagen idealizada de su tierra que poco se correspondría

\footnotetext{
${ }^{32}$ Puede encontrarse más información sobre las repatriaciones en el capítulo octavo del libro de Alicia Alted Vigil, La voz de los vencidos: el exilio republicano de 1939.
} 
con el momento de la verdadera vuelta. Tal es así que Mateo Gambarte apunta que "la dificultad del regreso es directamente proporcional al tiempo transcurrido, tanto por los problemas que acarrea el desexilio personal como por los derivados de los cambios ocurridos en el país de origen mientras el exiliado está fuera" ("La vuelta a un vacío" 64). Por lo tanto, a medida que pasaba el tiempo y el gobierno de Franco se asentaba en el poder, se hacía cada vez más difícil el posible regreso de la segunda generación por varias razones. En primer lugar, Mateo Gambarte afirma que temían que la vuelta fuese entendida como traición o deserción (Los niños de la guerra 181). ${ }^{33}$ De hecho, María Luisa Elío Bernal confiesa que, por respeto a sus padres, no pudo regresar a España hasta después que murieron. En segundo lugar, les angustiaba que se asociase cierta debilidad a dicho regreso. Y, finalmente, este se concibió como un problema personal, el cual se complicaba por las condiciones personales de cada individuo, ya fuesen sociales, económicas o profesionales. Conchita Ramírez había decidido regresar a España por primera vez en 1948 para encontrarse con su hermana en Sevilla pero posteriormente tuvo que cancelar el viaje por miedo a la policía franquista (152). En el caso de José Fernández Sánchez, el retorno se produjo después de 34 años, pues, según sus propias palabras, Rusia lo había encerrado como si de una prisión se tratase y no lo había dejado salir al denegarle los permisos correspondientes (507). No todos los niños de la URSS corrieron la misma suerte, puesto que Tatiana Pérez — Lara en su autobiografía— formó parte del grupo de 400 personas, todos ellos intelectuales, que conformaron la primera

\footnotetext{
${ }^{33}$ En la entrevista que Juan Cruz le realiza a Jaime Salinas y que publica en el libro bajo el rótulo Jaime Salinas. El oficio de editor, este comenta también los miedos a los que se enfrentaban los que decidían regresar por ser considerados traidores o, simplemente, débiles (158-162).
} 
expedición de repatriación aprobada por la Cruz Roja (164). Por otro lado, Jaime Salinas tardó 18 años en regresar porque, con la muerte de su padre, ponía fin a cualquier vínculo que lo uniese a España ya que él había dejado de ser español en 1939, llegando hasta el punto de odiar a este país como consecuencia del encarcelamiento y la muerte de numerosos seres queridos.

No obstante, en la mayoría de los casos, se trata de un retorno temporal. Fueron pocos aquellos que regresaron para quedarse definitivamente - a excepción de Manuel Fernández Montesinos, Tatiana Pérez, José Fernández Sánchez, Nieves Cuesta y algún otro-. En otros casos, el retorno resultó en un intento fallido, como ya dejaba ver la cita anterior con la que empezó su obra María Luisa Elío Bernal o los breves meses que pasó en España Emilia Labajos tras darse cuenta de que en su país de origen ya no había sitio para ella (93). De hecho, en relación a este retorno fallido, Enrique de Rivas, miembro también de esta generación, escribió:

Constata que el tiempo se sigue desarrollando como de hecho se ha desarrollado su pasado, pero estando ligado este pasado a un espacio vital concreto, su conciencia de exilado tenderá a ver ese pasado como un espacio firme que es el que querrá alcanzar en el futuro, y, en consecuencia, fatalmente pondrá la medida de su tiempo personal, es decir, de su nuevo reloj mental, en la hora que constató que marcaba al producirse su nuevo estado. (“Los durmientes" 86)

Es decir, la falta de correspondencia entre el presente y la imagen asociada al tiempo pasado que espera recuperar en el futuro a través del regreso es la causante del desajuste temporal del exiliado, al que haré referencia en el próximo apartado. 


\section{Recordar y escribir. Narrativas reconstructivas de la identidad}

Ya en el primer capítulo se hizo un breve repaso de los grandes teóricos de la autobiografía partiendo de George Gusdorf, quien proyectaba el enfoque de los estudios hacia el reconocimiento del autos por encima del bios. En la misma dirección, Lejeune desarrolla su concepto de la autobiografía, basado en la coincidencia entre autor, narrador y protagonista de la enunciación. En cuanto a los problemas de la mímesis y su capacidad referencial a través del lenguaje, así como el papel de la retórica dentro de esta, Eakin lleva a cabo un estudio de la relación entre el lenguaje y la formulación del yo, enfrentando las teorías de De Man y Olney, y concluye que la autobiografía era el recurso narrativo para la invención de un yo que accede a su identidad a través del lenguaje (223). Asimismo, habíamos señalado las teorías de Sidonie Smith que argumenta que la creación del discurso identitario autobiográfico parte como discurso alternativo a las voces hegemónicas de la sociedad. En la actualidad, Alicia Molero de la Iglesia señala que la crítica define el género autobiográfico como una aceptación de la construcción del yo a través del texto, haciendo así de forma entendible el sujeto a partir del lenguaje y el conocimiento simbólico (La autoficción 172). De este modo, a partir de las teorías de Ricouer, destaca el concepto de identidad narrativa como modo de recuperar la identidad ya que, debido a la imposibilidad de aprehensión de la identidad, es la propia narración la que da coherencia a la configuración de esta (La autoficción 171).

Ahora bien, es importante destacar también la necesidad de entender el discurso autobiográfico y la identidad narrativa que surge en este como una creación estética determinada por las estructuras socio-culturales que la definen, ya que la autobiografía se basa en una clave de lectura entre el emisor y el receptor. De hecho, Molero de la Iglesia 
señala que es en aquellos momentos en el que estas estructuras sufren más mutaciones cuando se produce un aumento de las manifestaciones autobiográficas, lo que ha llevado a críticos como Romera Castillo y Rolf Eberenz a hablar del boom memorialístico que se produjo tras la muerte de Franco. ${ }^{34} \mathrm{Y}$, al mismo tiempo, Molero de la Iglesia ha señalado que es muy frecuente la adhesión a este tipo de escritura de escritores con crisis de identidad situados en los márgenes sociales (“La autoficción 174). Es, por lo tanto, de suma importancia analizar de qué forma se ha llevado a cabo la reconstrucción del yo a través de una identidad narrativa en el caso de los escritores de la segunda generación de escritores exiliados. Con este propósito es necesario prestar atención a dos elementos: por un lado, la utilización de los diferentes subgéneros del discurso autobiográfico o literatura del yo, así como la difuminación de los límites de estos y, por consiguiente, su hibridez como consecuencia del carácter fronterizo de los autores; y, por otro lado, las técnicas narrativas y otros fenómenos textuales empleados por dichos escritores como mecanismos para construir su identidad narrativa.

No obstante, antes de llevar a cabo dicho estudio, es necesario aclarar una cuestión que también va a afectar al análisis posterior, cuando se exploren las relaciones

\footnotetext{
${ }^{34}$ Molero de la Iglesia señala el resurgimiento de la individualidad en la segunda mitad del siglo XX, el decepcionante fracaso de los sistemas colectivos, el terror derivado de la carrera armamentística, el vacío vital de la sociedad del progreso y su propuesta de emancipación, así como la reacción artística al dominio de la ciencia y la deshumanización tecnológica como algunos de los cambios en las estructuras socioculturales que favorecieron el auge de la autobiografía a favor de los años sesenta y setenta (La autoficción 38). Por otro lado, Romera Castillo explica dicho auge como consecuencia de la libertad de expresión ganada tras la muerte de Franco, el hecho de ser un campo aún novedoso dentro de la literatura y el mercado editorial de la época (De primera 170). Rolf Eberenz también apunta a la falta de información tras la muerte de Franco y el interés por las grandes figuras del exilio como dos de los motivos del éxito del género autobiográfico (44).
} 
entre los conceptos de nación, lenguaje y tiempo y el impacto de estos en la construcción de la identidad de la segunda generación de exiliados. Esta cuestión no es otra que la oposición literario-no literario que podemos encontrar en el género autobiográfico y que Mercedes Arriaga relaciona con la dicotomía público-privado (18). Aunque es cierto que algunas de estas obras, en el momento de su escritura, no fueron pensadas para ser publicadas, como es el caso de Diario de una niña exiliada de Concha Ramírez o el de Ma vie en France: Cahier d'exil d'une adolescente espagnole, 1939-1943, es más oportuno atender a la relación entre literario-no literario y los conceptos de testimonio o finalidad. ¿Por qué escribieron estas obras? Y como ya se preguntó Francisco Ayala, ¿para quién? Bien es cierto que es incuestionable el carácter literario de gran parte de estas obras, como las escritas por Carlos Blanco Aguinaga, Federico Patán, Michel del Castillo, Jaime Salinas o Emilia Labajos. No obstante, frente a estos autores, podemos encontrar a otro grupo importante de autores que están más cerca del mero testimonio histórico que del relato literario, como es el caso de Manuel Arce, quien, bajo el rótulo de "palabras al lector", escribía: "No soy escritor y no pretendo hacer literatura con estas memorias. (...) Tal vez lo que cuento guste a unos y disguste a otros, pero yo no escribo por complacer ni disgustar a nadie. Lo hago porque quiero que estas vivencias, mías y de mis compañeros de exilio, no se pierdan en el olvido" (9). Similar es la situación de Isabel Argentina Álvarez quien confesaba en la dedicatoria de sus memorias que la escritura de dicha obra tenía como fin el conocimiento por parte de hijos y nietos de la verdad histórica (23). En relación a esta distinción, cabe mencionar la diferenciación que hace Molero de la Iglesia entre los aspectos intencionales de los géneros autobiográfico y autoficcional, puesto que señala que 
mientras que el autor de una autobiografía no es necesariamente alguien a quien se conoce como escritor, la autoficción corre a cargo de profesionales de la novela, dispuestos a ignorar los límites entre los planos de la ficción y la realidad. En este sentido, los textos autobiográficos pretenden ante todo la asimilación intelectual de sus contenidos, en cambio las ficciones no tienen otro objetivo más importante que su esteticismo. (La autoficción 33)

Aunque mi análisis no contrapone el género autobiográfico al género autoficcional, sino aquellas obras que están más unidas al modelo tradicional de la autobiografía y aquellas otras que experimentan con los límites de esta, es útil realizar un símil y aplicar la oposición entre escritores no profesionales y escritores profesionales, realizada por Molero de la Iglesia, a la hora de clasificar las obras autobiográficas de esta generación. De este modo, en el primer grupo - escritores no profesionales- sitúo a aquellos autores pegados a la concepción clásica de la autobiografía, mientras que en el segundo - escritores profesionales - cabe analizar a los "experimentadores" del género. De hecho, podemos ver que muchos de los autores del primer grupo - Manuel Arce, Isabel Argentina, Manuel Fernández Montesinos, José Fernández Sánchez, etc.— han escrito únicamente una obra, mientras que los del segundo -Carlos Blanco Aguinaga, Angelina Muñiz-Huberman, Jorge Semprún, Michel del Castilo, Fernnado Aínsa, etc.tienen una trayectoria literaria basada no sólo en el relato de su vida, sino en cómo llevar a cabo dicho relato desde un punto de vista estético. Ahora bien, se podría señalar un pequeño tercer grupo de autores que, a pesar de no tener una gran trayectoria literaria, 
pues esta no reside más que en dos o tres obras, estas contienen un gran valor estético, como es el caso de María Luisa Elío Bernal o María Álvarez del Vayo.

Esta diferenciación no descarta ni menosprecia al grupo de escritores no profesionales ni los opone al de escritores profesionales, sino que pretende justificar una doble vertiente dentro de la literatura autobiográfica: por un lado, aquellas obras que son más fieles a la clasificación clásica de los subgéneros autobiográficos (confesiones, memorias, diarios, cuadernos de apuntes, cartas), más cercanas al testimonio histórico; y, por otro lado, aquellas obras que borran los límites de dichos subgéneros para dar lugar a un nuevo tipo de literatura, tales como autobiografías ficticias, autobiografías noveladas o novelas autobiográficas, autoficciones, docuficciones, etc., que han generado un mayor interés desde un punto de vista literario y que proporcionan una mayor información en cuanto al discurrir de sus autores. Tanto es así que más tarde analizaré el surgimiento de estos nuevos subgéneros literarios mixtos y la relación entre estos y la identidad fragmentada o fronteriza de muchos de los escritores de la segunda generación de exiliados. No obstante, tanto uno como otro grupo son dignos de atención ya que, en palabras de la propia Molero de la Iglesia, "autobiográfico es todo testimonio sobre la propia vida, desde los escritores por los mejores literatos hasta los procedentes de personas dedicadas a cualquier otra actividad" (La autoficción 36).

Dentro de los géneros clásicos del yo podemos encontrar, como ya adelantaba, a la autobiografía clásica, las memorias, las confesiones, los diarios, las cartas o epistolarios y los cuadernos de apuntes. La cercanía de estos géneros literarios a la historia ha provocado, probablemente, que hayan proliferado de forma abundante entre los niños de la guerra que eran testigos de cómo la historia olvidaba poco a poco la 
Guerra Civil Española y el sufrimiento de los exiliados. De hecho, Anna Caballé, hablando de las memorias, afirma que el "objeto de las memorias coincide, aparentemente, con el objeto de la Historia, esto es, dar cuenta de los hechos de cierta relevancia" (Narcisos 41). Una simple ojeada a los títulos de las obras de esta generación basta para afirmar que los géneros con más éxito han sido las autobiografías y las memorias. Los únicos diarios, según la concepción clásica de este, son el de Conchita Ramírez, Diario de una niña exiliada (1936-1947), el de Conchita Simarro, Diario de una niña en tiempos de guerra y exilio (1938-1944) y el de Aurélia Moyà-Freire, Ma vie en France: Cahier d'exil d'une adolescente espagnole, 1939-1943, que, a diferencia de las otras obras, no ofrecen una visión retrospectiva. La escasa presencia de este último subgénero está vinculada al carácter especialmente íntimo de este género, lo que provocó que, en muchas ocasiones, los diarios no sobrevivieran con el paso de los años. De hecho, estos dos últimos diarios se publican en 2016 y 2017 como resultado del empeño de investigadores que pretenden ofrecer una nueva visión del transcurso de la historia. Según la división que hace Mercedes Arriaga entre diario íntimo, diario de abordo y diario de viajes, estas obras se tratan de diarios de abordo por el uso constante de la primera persona y de los tiempos en pretérito perfecto (39). No obstante, también comparte algunos rasgos con el diario de viajes, pues son muchas las ocasiones en las que usan la primera persona del plural, rasgo de este tipo de diario según la ya citada crítica. ${ }^{35}$

\footnotetext{
${ }^{35}$ Para más información sobre los diarios, véase: Enric Bou: "El diario: periferia y literatura"; Anna Caballé: "Aspectos de la literatura autobiográfica en España"; Amelia Cano Calderón: "El diario en la Literatura. Estudio de su tipología"; Angélica González Otero: "El diario: la escritura autobiográfica en su dimensión sociocultural y sus posibilidades cognoscitivas y creativas". Es especialmente interesante el capítulo que
} 
Dentro de esta categoría no puede situarse la obra de Francisca Perujo, Pasar las líneas. Cartas a un comandante, que, aunque aparece escrita bajo las premisas de dicho género, pues su relato no es más que el diario íntimo de una mujer enamorada que le escribe cada día o cada cierto tiempo a su enamorado, esto no es más que el recurso literario de una escritora para escribir una obra totalmente ficticia y sin ningún rastro de escritura autobiográfica en ella.

Tampoco forma parte de esta categoría la obra del exiliado Manuel Durán, Diario de un aprendiz de filósofo: notas sobre magia, religión y ciencia, ya que no tiene de diario más que su nombre en el título y, al igual que en la obra de Perujo, lo autobiográfico no forma parte de ella. En cuanto al género del cuaderno de apuntes, este no aparece como tal más allá de la obra de Maria Luisa Elío Bernal, Cuaderno para apuntes, que comentaré más adelante en el capítulo dedicado a esta escritora. Es, por lo tanto, la división entre autobiografía y memorias la que presenta un mayor campo de estudio para el análisis literario. No obstante, antes de empezar a desarrollar el tema, cabe advertir al lector que también dentro de estas obras se incorporan rasgos de otros subgéneros del yo, pues en ocasiones aparecen recursos propios de estos como la incorporación de cartas enviadas o recibidas durante su infancia, tal y como hace Luis Santamaría en Agur Euskadi, hasta nunca o Ángel Belza en Memorias de un niño en Rusia 1937-1957.

La ya citada Anna Caballé anticipaba en su estudio sobre la literatura autobiográfica en lengua castellana de los siglos XIX y XX la problemática

\footnotetext{
Virgilio Tortosa le dedica a este género dentro de su obra Escrituras ensimismadas. La autobiografía literaria en la democracia española.
} 
diferenciación entre la autobiografía y el libro de memorias. En un intento de establecer una línea divisoria entre ambos géneros, la crítica catalana explica que "si el eje histórico, los recuerdos, el relato de los acontecimientos vividos vertebra la literatura memorialista, en la autobiografía, por el contrario, los recuerdos están sometidos a la tentativa del individuo de interpretarse a sí mismo" (Narcisos 44). Asimismo, argumenta que la autobiografía concede al escritor una mayor libertad para el uso de la imaginación que, según ella, pueden llevar al escritor a perder su honestidad (Narcisos 45). Es quizá el nivel de exigencia y compromiso, propio de la autobiografía lo que ha llevado a muchos autores a usar el término "memorias" en lugar de "autobiografía", según Caballé (Narcisos 42). De hecho, si miramos nuevamente los títulos de las obras de los escritores exiliados de la segunda generación sólo en el caso de Autobiografia de Federico Sánchez de Jorge Semprún, probablemente el autor con una carrera literaria más sólida de todos ellos, aparece el término "autobiografía" mientras que el de memorias aparece hasta en siete ocasiones: Memorias de un niño en Moscú, Memorias de Rusia. Vivencias de un niño de la guerra, Memorias de una niña de la guerra, Dues guerres $i$ un exili. Memòries, Memorias del exilio. La vida cotidiana de los primeros refugiados españoles en México y Memòries d'un somni, Memorias de un niño en Rusia $1937-1957 .{ }^{36} \mathrm{Si}$ tenemos en cuenta el hecho de que muchos de estos autores no se dedicaban a escribir de forma profesional, es aún más compresible su acercamiento hacia el género de las memorias, un género que se dibuja, de entrada, como menos exigente. Ahora bien, ¿qué

\footnotetext{
${ }^{36}$ Es curioso el caso de esta última obra, Memorias de un niño en Rusia 1937-1957, de Ángel Belza, ya que en su portada aparece el término "memorias" mientras que en la contraportada podemos encontrar el rótulo "autobiografía de un superviviente".
} 
pasa con el resto de obras (¿Te acuerdas, Tovarisch...?, Una vida. Infancia y juventud, José y Consuelo, Amor, guerra y exilio en mi memoria, etcétera) en cuyos títulos no aparece ninguno de ambos términos? O yendo más allá, ¿es suficiente el hecho de que una obra aparezca bajo el rótulo de autobiografía o memoria para que sea considerada así?

Aunque es de enorme dificultad y complejidad responder a estas preguntas de forma tajante debido al gran campo de estudio que tenemos por delante, hay ciertas conclusiones o ideas que parecen repetirse con cierta frecuencia y que pretendo argumentar en las siguientes líneas. En primer lugar, es significativo el hecho de que las obras que están más cercanas a la búsqueda personal del individuo, es decir, a la autobiografía y que, por lo tanto, se alejan más de la historia y la colectividad presentan títulos más literarios o, dicho de otra forma, están más alejados del uso de términos como "memoria", "vida" o cualquier otro término que tenga una referencia inmediata a la literatura del yo como parte de él. Este es el caso de Lo que en nosotros vive, de Manuel Fernández Montesinos, Con acento extranjero, de Fernando Aínsa, Rebelde, de Ángel Fernández o Paños menores, de Gerardo Deniz. Aunque estas obras estén más cerca de la autobiografía, en muchas de ellas hay ciertos momentos en los que la colectividad está muy presente como es el caso de Lo que en nosotros vive y su relato sobre las reuniones de exiliados españoles de Estados Unidos en Provincetown en el verano de 1946. En segundo lugar, estas obras son más proclives a una mayor profundización en la individualidad del autor, concretamente, en la construcción de su identidad y el cuestionamiento de sus relaciones con su país de origen, tal y como prueban muchos de los estractos de su obra que pueden leerse en el siguiente apartado cuando estudie los 
conceptos de nación, espacio y tiempo. No obstante, una vez más, hay excepciones pues también las obras de Federico Patán, María Álvarez del Vayo o Jaime Salinas ofrecen un referente directo a la literatura del yo. En tercer lugar, las obras categorizadas dentro de la autobiografía suelen pertenecer a escritores con una carrera profesional-literaria más sólida, como el ya citado Federico Patán, Fernando Aínsa, Carlos Blanco Aguinaga o Federico Álvarez. Sin embargo, no es este, por ejemplo, el caso del recién mencionado Ángel Fernández y su obra Rebelde, que puede denominarse como una autobiografía, aunque su autor no es escritor profesional y la obra carece de un gran estilo literario. Por lo tanto, en el otro lado, cabe relacionar las memorias con aquellos autores que tienen como objeto primario su deseo de testimoniar su experiencia más allá de la búsqueda personal de su ser o su identidad, como es el caso de Manuel Arce, Nieves Medina o Aurea Matilde. En estas obras se puede observar que prestan gran atención no sólo a sus personas, sino a sus compañeros o amigos durante el exilio y el destino que les deparó a muchos de ellos posteriormente. Además, en muchos de estos casos, sus memorias son su única obra publicada.

Parece inevitable, de este modo, hacer alusión a la oposición entre memoria individual y memoria colectiva a la hora de hablar sobre las autobiografías y memorias de la segunda generación de escritores exiliados. Aunque es imposible hacer un estudio completo, resulta necesario tener presentes varios aspectos que ya destaqué en el primer capítulo y que conviene traer a la mente del lector nuevamente. Señalé ya la teoría de Maurice Halbwachs, según la cual no hay memoria individual sin colectividad, ya que esta surge una vez que el individuo se siente parte de una comunidad. Sin embargo, parece difícil esclarecer cuál es esa comunidad de la que se siente parte la segunda 
generación de exiliados. Muchos tienen que luchar entre esa comunidad a las que sus padres quieren que pertenezcan, la comunidad española en el exilio, y la sociedad de acogida que les espera fuera de casa. José Fernández Sánchez cuenta cómo era atacado por los adultos españoles, quienes lo acusaban de ser ruso:

Los mayores solían decirnos con reproche:

-Vosotros ya sois rusos.

Los soviéticos también recelaban de la influencia o mediación de los españoles mayores. Los soviéticos nos consideraban de su vivero y no deseaban que entráramos en otras aguas.

Nuestra inmersión en el mundo ruso era inevitable, pero cada uno tenía que medir la profundidad. (...) Aquel de nosotros al que el destino alejaba de la influencia española debía decidir en qué grado iba a asimilar las costumbres y tradiciones rusas. (223)

Similar situación narra Manuel Fernández Montesinos, quien confesaba encontrarse en una encrucijada entre el mundo exterior, la vida americana, y el mundo de exiliados que se respiraba dentro de su casa: "Pero qué incomodidad me produjo empezar a notar que la vida de mi casa no tenía nada que ver con la que sucedía fuera. Desde dentro, lo de fuera parecía irreal; desde fuera, lo de dentro, incomprensible. Era un paseo por la cuerda floja acoplar los dos mundos" (45). Esta difícil situación de determinar el grupo al que pertenece esta generación ha llevado a Enric Bou a hablar de un espacio intermedio entre la memoria individual y la memoria colectiva en el que se sitúa la memoria de la gente que vive cerca de ellos. A este plano pertenece "la gente que está a medio camino entre el yo aislado y los otros, que son completamente desconocidos. Son 
'personajes cercanos' a los que corresponde el campo de la amistad, o de la familia, aquella philia celebrada por los antiguos a medio camino entre el individuo solitario y el ciudadano definido por su contribución a la acción de la polis" (“Construcción” 24). De esta forma, pueden entenderse las numerosas correlaciones que existen en muchos de los relatos del yo de esta generación en las que los escritores hacen referencia a los otros niños que viven con ellos la experiencia del exilio y cuyo destino también reflejan en muchas ocasiones. Especialmente significativo es el caso de los niños mandados a la URSS quienes, prácticamente en su mayoría, relatan en los primeros capítulos de sus memorias o autobiografías tanto sus hazañas durante su infancia como la de sus compañeros. Estas van desapareciendo a medida que los niños van creciendo y eligiendo caminos separados, aunque, muchos de ellos también al final de sus obras hacen referencia al destino de sus compañeros de exilio durante los primeros años. Ahora bien, en su madurez muchos de estos escritores toman una mayor conciencia de su pertenencia a la comunidad exiliada. A raíz de la muerte de Franco en 1975, la transición a la democracia y la posterior Ley de Memoria Histórica en 2006 se cuestiona la versión oficial de los hechos y muchos de ellos sienten la necesidad de reconstruir una memoria colectiva como individuos pertenecientes a España, pensando, en muchas ocasiones, en sus sucesores, tal y como ya señalé anteriormente.

Frente a este primer grupo de obras que, a pesar del uso de algunos rasgos narrativos innovadores, ofrecen una más fácil categorización dentro del concepto clásico de autobiografía y sus subgéneros, existe un grupo de obras que plantean serios problemas para determinar a qué género autobiográfico pertenecen - si es que pueden situarse dentro de dicho género- $y$, además, tampoco ese es el fin de este trabajo. Mi 
interés consiste en explicar esta difícil categorización como respuesta a la dificultad que estos escritores experimentan al definir su identidad como miembros de una comunidad asociada a una única nación. Es decir, establecer un paralelismo entre la supresión de las barreras entre los géneros autobiográficos y la hibridez identitaria que muchos de estos escritores van a desarrollar a lo largo de sus vidas. Con este motivo, he seleccionado tres obras: la primera de ellas corresponde a Angelina Muñiz Huberman, Dulcinea Encantada. Esta obra fue publicada en 1992 en la editorial de Joaquín Mortiz antes de que viesen la luz Castillos en la tierra y Molinos sin viento, que salieron al mercado editorial en 1995 y 2001 respectivamente, y a las que ella misma subtituló "pseudomemorias". Aunque también merecen ser objeto de análisis por su difícil categorización, las he dejado en un segundo plano por dos motivos: por un lado, por la limitada extensión de este trabajo y, en segundo lugar, porque la obra elegida presenta una mayor difusión de las fronteras genéricas que estos otros dos relatos. ${ }^{37}$ La segunda de las obras elegidas es Un tiempo tuyo, de Carlos Blanco Aguinaga, que vio la luz en 1988. Posteriormente, ya a una edad madura, publicó su autobiografía en dos volúmenes. En 2007 salió al mercado Por el mundo: infancia, guerra y principio de un exilio afortunado y tres años más tarde lo hizo De mal asiento. La tercera obra elegida para este análisis es la publicada en francés por Michel del Castillo en 1956 bajo el título Tanguy. Histoire d'un enfant d'aujourd'hui que, debido a su temprana escritura, sólo abarca hasta el final de su adolescencia. También debería situar junto a estos escritores a Jorge Semprún ya

\footnotetext{
${ }^{37}$ Veáse el artículo de Diana Castilleja, "Angelina Muñiz-Huberman: construcción de un yo fragmentado", en el que analiza la construcción de la identidad en estas dos pseudomemorias.
} 
que su obra es sumamente conocida por jugar con los límites de la ficción y la autobiografía. No obstante, su ausencia en este apartado se debe a que me ocuparé de ello en el capítulo que dedico en exclusividad al que fue ministro de Cultura.

En relación a la fluctuación de recursos entre el género autobiográfico y el novelístico, Molero de la Iglesia afirma:

el protagonismo personal, el autoanálisis y el placer de la evocación son la respuesta a la búsqueda de una escritura más libre de expresión, tanto por lo que de conocimiento de la historia ofrece como por la posibilidad de inventarla. La intimidad y el subjetivismo que invaden a la narrativa, por un lado, la compresión inmanente del yo textual y la gran asimilación que la autobiografía ha hecho de los recursos de la novela, por otro, aproximan ambos géneros narrativos. (La autoficción 27)

¿En qué medida el protagonismo personal y el autoanálisis son también la respuesta a la búsqueda de entender una identidad fragmentada? Y, del mismo modo, ¿cómo afecta la intimidad, lo subjetivo y la compresión del yo textual a la construcción del sujeto?

Angelina Muñiz Huberman, de origen judío, nació en 1936, en el exilio, en Hyéres, Francia, cuando su familia huía de la dictadura franquista. Tras pasar unos años en este país, marchó en 1939 a Cuba donde residiría hasta 1942, momento en que se trasladó definitivamente a México D.F. Allí estudió en colegios mexicanos hasta que en su adolescencia mostró su deseo de ir a un colegio español y los padres la inscribieron en la Academia Hispano-Mexicana donde entró en contacto con los demás miembros de la segunda generación establecidos en este país. Desde entonces, Muñiz-Huberman dedicó 
su vida profesional a los estudios de literatura convirtiéndose el exilio, no sólo el provocado por la Guerra Civil española, sino también el éxodo judío y los estudios cabalísticos en un tema central de su carrera. En su obra El canto del peregrino. Hacia una poética del exilio, hace dos declaraciones que resultan de especial interés para interpretar su posición en cuanto a la escritura del destierro. En primer lugar, haciendo referencia a los hijos del exilio, concretamente a la generación hispano-mexicana, confiesa: "Grupo de escritores que, según avanza el tiempo, se empeñan en la patria del lenguaje. En la recolección y trasmisión de la memoria. Que, por fin, hallan nacionalidad en el quehacer de la escritura rigurosa, amplia, plena de imaginación y de sabiduría. Libre, ante todo" (160). Con estas palabras destaca el papel del lenguaje como vehículo de transmisión de la memoria, así como el deber del escritor de llevar a cabo dicha transmisión sin ataduras, haciendo pleno uso de la imaginación, puesto que es a través de esta de la única forma que puede encontrar su nación y, por lo tanto, parte de su identidad. En la otra declaración a la que hacía referencia previamente, apunta: “el exilio (...) ofrece la compensación de la palabra artística porque la palabra histórica ha sido traicionada" (175). Una vez que el testimonio desde un punto de vista simplemente histórico es insuficiente, la compresión del exilio permite a la escritora hacer de este un elemento artístico que le ayude a recuperar el único mundo verdadero para ella y para algunos otros de su generación: la escritura. Teniendo en consideración ambas afirmaciones, Dulcinea encantada debe entenderse como un sistema superior de escritura, que permite la exploración de una identidad narrativa, en la que la autora mezcla la transmisión de su memoria y la de su generación —elemento que también analizaré más tarde- con la imaginación, a través del cual realiza un primer intento por 
liberarse de las garras constrictoras de la experiencia del exilio como un elemento negativo.

En su libro The Usable Past. The Imagination of History in Recent Fiction of the Americas, Lois Parkinson Zamora sitúa Dulcinea encantada dentro de lo que ella denomina "fragmentary fictions", ya que "in her mind [Dulcinea's mind], historical and fictional texts and contexts fuse and diffuse and proliferate" (159). No obstante, catalogar esta obra bajo el término "ficción" es, desde mi punto de vista, no del todo acertado por varias razones: en primer lugar, por relegar, a un segundo plano, lo que de autobiográfico contiene el texto; y, en segundo lugar, por infravalorar el uso de la ficción o autoficción como elemento constitutivo de la identidad narrativa de la autora. Debe matizarse el significado de lo autobiográfico en esta obra porque muchos de los acontecimientos en los que se ve inmerso el yo protagonista -Dulcinea- no corresponden con los del nombre que aparece en la portada -Angelina Muñiz Huberman-. Angelina Muñiz Huberman no vivió la Guerra Civil española en primera persona, ni fue enviada a Rusia junto a su hermano, ni llegó a México en 1948, todos ellos hechos que forman parte de la vida de Dulcinea según el propio relato. Sin embargo, cuando se aplica el concepto de autobiográfico en esta obra no debe entenderse en relación a un sujeto único, individualizador, protagonista de un relato cuyos acontecimientos corresponden únicamente con el escritor real de la obra, sino que entronca con un sujeto símbolo, el "niño de la guerra", como ente representativo de una colectividad. No se trata de la autobiografía de Angelina Muñiz-Huberman, sino de la autobiografía de los "niños de la guerra". Tanto es así que la propia escritora escribe en su obra "Para mí el título de mi único libro era Corazón. Diario de un niño, es decir, el latir diario del corazón de un 
niño. Yo no sabía lo que era un diario; sí sabía lo que es el corazón de cada día” (48). De esta forma, la escritora no sólo afirma su intención de huir de los parámetros tradicionales de un género como el diario, sino que, al mismo tiempo, destaca su deseo de hablar del corazón de un niño, en este caso, de un niño de la guerra, llamado Dulcinea, creado a partir de las experiencias y relatos de dicha generación, tal y como ella señala también: "Yo soy tantas historias que a veces es difícil elegir con cuál me quedo" (26). Durante todo el relato, se hace eco de la voz de esta generación. En un estudio sobre la hispanidad fragmentada en la obra de la escritora, Malva E. Filler ya había señalado que una de las características principales de la narrativa de Muñiz-Huberman era la peregrinación por la memoria individual y la memoria colectiva (234). No obstante, no por ello se puede decir que se traten de unas memorias porque no profundiza en los hechos históricos por los que pasan los niños de la guerra, sino en el intimismo y en los procesos de transculturación a los que se enfrentan como elemento constitutivo de su identidad. Por esta razón, es necesario recuperar nuevamente su ya citada obra El canto del peregrino. Hacia una poética del exilio, pues ofrece un marco clave para entender la autobiografía del niño de la guerra. Aquí, al hablar de los hijos del exilio, Muñiz-Huberman afirma que el exilio derivó en la generación más joven en una pérdida de nacionalidad, elemento que se discute en el próximo apartado, pero que, en la voz de Dulcinea, nos permite corroborar el concepto de autobiografía de niño de la guerra de esta obra: "Dulcinea siente que sus pies se elevan del terreno. Flora y llega a otras regiones. Vive en otras regiones. Regiones que no se comprueban. Sin llave y sin acceso. Que se atraviesan. Que se transparentan. Que se absorben. En las que. O se está. O no se está” (153). Del mismo modo, MuñizHuberman destaca en El canto del peregino su educación en el tránsito permanente y en 
la idea del pronto regreso a casa, lo cual también aparece en Dulcinea encantada: "Sin deseos de arraigarme porque algún día sería el retorno. Vivía en casas rentadas (nunca se le ocurrió a mis padres la idea de comprar una casa, nunca) y cambiaba de domicilio por cualquier pretexto" (58). A esto cabe sumar la transmisión de los caracteres del exilio de padres a hijos, el papel de los pocos recuerdos que tenían de España, la pasividad de dicha generación, el punto de partida de la Guerra Civil como nuevo elemento organizador del tiempo, la hibridización, la necesidad, en muchos casos, de convertir, en palabras de Dulcinea, "el arte de la memoria en arte de escribir", la batalla con el tiempo y con el olvido, la necesidad de redefinirse como exiliados tras la muerte de Franco, todos ellos elementos que la escritora ha explicado detenidamente en El canto del peregrino y a los cuales hace referencia también a través del personaje de Dulcinea. ${ }^{38}$ De esta forma, es fácil deducir que lo autobiográfico tiene un papel mucho más relevante de lo que sugería la denominación de "fragmentary fictions" pues la experiencia del exilio es, junto al elemento de la ficción que ahora explicaré, el componente motriz del relato.

Una vez que ha quedado demostrado el elemento autobiográfico de la obra, es necesario también estudiar cuánto de ficción hay en ella. No se puede menospreciar el papel de esta porque Angelina Muñiz-Huberman dedica, aproximadamente, la mitad de la obra a la ficción entre Dulcinea y Amadís, a la señora Frances Calderón de la Barca y a

\footnotetext{
${ }^{38}$ Con respecto a la relación entre el arte de la memoria y el arte de la escritura, el artículo de Judith Payne, "Writing and Reconciling Exile: The Novels of Angelina Muñiz-Huberman", aborda la escritura del exilio como un sistema de reconciliación.
} 
otras historias. ${ }^{39}$ Sin embargo, para entender el papel de la ficción o, dicho de otra forma, de la imaginación, es necesario partir del título de la obra y, una vez más, del análisis de la segunda generación que Muñiz-Huberman hace en El canto del peregrino. ¿Qué quiere transmitir Angelina Muñiz-Huberman a través del título Dulcinea encantada? Dulcinea es, probablemente, uno de los personajes femeninos más conocidos de la literatura hispánica, por lo que resulta probable pensar que Muñiz-Huberman recurre a él como símbolo de su hispanidad. Además, aunque la elección de Dulcinea en lugar de Don Quijote, quien es, sin lugar a duda, el personaje más famoso de la hispanidad, pueda ser provocada por una cuestión de género, dicha selección también puede conducir a una segunda interpretación. La elección de Dulcinea viene marcada por la búsqueda de una voz nueva dentro de la tradición. Angelina Muñiz-Huberman, como miembro perteneciente de ese canon minoritario al que hacía referencia en el capítulo 1 -no occidentales, mujeres, clase baja, homosexuales, no blancos y exiliados-, busca una voz que representa su tradición hispánica pero que, al mismo tiempo, se salga de los cánones tradicionales establecidos por esta. Por lo tanto, la elección de un personaje ficticio como Dulcinea también conlleva un elemento autobiográfico como sujeto exiliado sin voz. Al igual que Dulcinea, sin voz y con una identidad tergiversada por la imaginación del propio Alonso Quijano, los miembros de la segunda generación de escritores exiliados se han visto silenciados y desterritorializados por las fuerzas imperantes dentro de las fronteras españolas. El segundo elemento del título, "encantada", también puede

\footnotetext{
${ }^{39}$ Para profundizar en la intertextualidad y la referencia a las otras ficciones presentes en la obra, consúltese el trabajo de Luz Elena Zamudio Rodríguez, "El exilio como motivo generador en la obra de Angelina Muñiz-Huberman”.
} 
interpretarse como una referencia clara a la segunda generación de exiliados de la Guerra Civil española. La propia escritora había señalado en El canto del peregrino la utilización de la imaginación como elemento clave en el quehacer de la escritura rigurosa de dicha generación (160). Tan es así que, al igual que hará Jorge Semprún -véase el capítulo V-, Muñiz-Humerban defiende la utilización de la imaginación como herramienta para entender la situación del exiliado y como elemento característico de la identidad literaria de dicha generación. De hecho, ella misma escribe en Dulcinea encantada: "Pero la verdad, nada de eso lo recuerdo. Todo lo invento. Todo es ficción. La única realidad. ¿La única realidad? ¿Cuál es la única realidad? ¿Cuál? ¿Es? ¿La? ¿Única? ¿Realidad? La que invento. La. Que. Invento" (110). De esta forma, la utilización de la ficción también viene justificada como elemento autobiográfico de una segunda generación que ha vivido una idea de España basada en la imaginación de unos recuerdos a partir del relato de sus familiares y del propio re-hacer de su memoria. Los niños de la guerra se han visto abocados al empleo de la imaginación como parte de sus relatos para convertir en material artístico lo vivido. De esta forma, cabe entender la mezcla entre ficción y realidad en Dulcinea encantada como un juego narrativo que sirve como artificio para buscar un nuevo método literario-artístico en el que reflejar los conflictos de identidad a los que está sometida la segunda generación de escritores de exiliados, una segunda generación que, como atestigua el final de la obra, está avocada a la fragmentaridad, al igual que el relato de Dulcinea encantada:

¿Puede un arqueólogo reconstruir? No, creo que no. Pega las piezas. Las fisuras quedan. Podría volver a salirse el agua por ahí. Pero yo ni siquiera encuentro las piezas. Ni siquiera puedo dar la apariencia de un ser 
remendado. Soy un ser despedazado. La cabeza se me escapa hacia lo alto. El corazón lo he perdido. Un pie se apoya en la tierra y el otro vacila en el aire. Los brazos, desarmónicos. Los ojos, dando vueltas. La cámara lenta en velocidades dispares. No encuentro la unidad: sólo el silencio me consuela. Caen las uñas y la sombra de las pestañas. (186)

Tal es el caso de este juego narrativo que Eugenia Helena Houvenaghel ha señalado, con referencia a la obra de la escritora hispano-mexicana, la ruptura entre la concepción tradicional del género autobiográfico y el género narrativo ficticio como sistema que le permite "no sólo una mayor libertad creativa sino también la construcción de una identidad propia en clave imaginativa" (“Angelina” 17).

Una vez puesto en evidencia el juego entre la ficción y lo autobiográfico como rasgo identitario en el caso de Angelina Muñiz-Huberman, es necesario prestar atención a la segunda de las obras propuestas, Un tiempo tuyo, de Carlos Blanco Aguinaga. Nacido en 1926, Blanco Aguinaga huye a México junto a su familia a finales de agosto de 1939. A partir de 1953 se instala definitivamente en los Estados Unidos donde desarrollará su carrera como profesor universitario e iniciará una larga trayectoria literaria que le llevará a publicar otras obras como Carretera de Cuernavaca, En voz continua o Esperando la lluvia de la tarde, en las que, al igual que en la obra a comentar propuesta, están latentes temas como la crisis de identidad, el destierro y la memoria. Maryse Bertrand de Muñoz no duda en calificar a Un tiempo tuyo como novela en su estudio sobre la autobiografía y la novela de la guerra civil española (“Autobiografía y novela” 187). Del mismo modo, María Teresa González de Garay, quien hace un extraordinario análisis de la obra, la sitúa 
dentro del género novelístico y la califica como su novela "más densa y compleja" ("Memoria y exilio" 104). Además, dice sobre ella:

La novela proyecta una reflexión filosófica y poética muy profunda sobre temas habitualmente tratados desde la óptica trágica y dramática. Un tiempo tuyo es una novela poco tradicional, innovadora y audaz. Se estructura a través de una serie de voces diferentes que hablan (y recuerdan), en capítulos separados, de sucesos divergentes que siempre convergen, sin embargo, en temas como el exilio y la guerra civil española, la memoria -individual y colectiva-, el destino y la muerte. ("Memoria y exilio" 104)

Más allá de la consideración de "novela" según ambos autores, me interesa la estructura de la obra a través de una serie de voces diferentes y el juego entre autobiografía y ficción que establece Blanco Aguinaga. La obra está organizada en torno a siete capítulos organizados a través de diferentes voces, a excepción del primero y el último que cuentan con el mismo personaje, el alter ego del escritor desdoblado, además, en distintas formas gramaticales. Sin embargo, desde un punto de vista estructural, es necesario dividir la obra en dos bloques: por un lado, únicamente los capítulos uno y siete, por estar enunciados en primera o en segunda persona y tener como protagonista al personaje-narrador que identificamos con Carlos Blanco Aguinaga; y, por otro lado, del capítulo segundo al sexto, en la que los protagonistas son personajes fuera del yo: dos niñas españolas también exiliadas, dos brigadistas internacionales y el cantante argentino Carlos Gardel. La primera parte se trata de un diálogo del narrador-protagonista, que se entiende que es el alter ego de Carlos Blanco Aguinaga, entre sus dos yo-es: un yo-joven 
y un yo-anciano. Aunque María Teresa González de Garay destaque que no hay demasiados datos autobiográficos, considero que se equivoca al señalar que no hay demasiada confesión personal porque es precisamente esta la que suple la escasez de estos datos autobiográficos y la que permite al lector establecer el pacto de autenticidad con el narrador-escritor del relato.

En el capítulo uno vemos que, entre otros detalles, el yo-anciano le recuerda al yojoven su llegada a Antofagasta, una ciudad portuaria al norte de Chile en la que los cambios de estaciones están bastante marcados. Sin embargo, Carlos Blanco Aguinaga nunca llegó a este lugar. Pero a este tipo de detalles, a pesar de que, en un primer momento, podrían impedir la identificación entre el protagonista y el escritor de forma estricta y, por lo tanto, podría ser utilizado para negar la clasificación de esta obra como autobiografía, resultan indiferentes para el lector ya que el hecho de la ciudad de acogida sea Antofagasta, México D.F. o Buenos Aires no afecta al pacto que se establece entre emisor y el receptor al confesar los problemas a los que se enfrenta un niño que llega exiliado a un nuevo país. Es decir, en este nuevo tipo de literatura, el lector ya no necesita datos autobiográficos exactos que le lleven a establecer una referencia entre el escritor, el narrador y el protagonista, sino que dicha referencialidad se lleva a cabo a través de otros procedimientos. Y dicho pacto se establece a través de extractos como el siguiente: "De ahí sus aciertos cuando te dice que no podrás volver al país al que ahora crees que has vuelto. Y de ahí los fantasmas que llevamos dentro según día con día nos damos a nosotros mismos cuerpo de Historia, como si amanecer y echar a andar fuese la cosa más natural del mundo" (16). En este caso, el narrador actúa como intermediario entre el yojoven y el yo-anciano y da a conocer al lector el trauma sufrido por Carlos Blanco 
Aguinaga debido al desarraigo provocado por su temprano exilio. De esta forma, rompe con la clásica coincidiencia establecida por Lejeune entre los tres sujetos (escritor, narrador y protagonista). Al lector le interesa el trauma que se percibe detrás del apunte del narrador, la imposibilidad del retorno, la suspensión en un espacio imaginario, la presencia del pasado en el presente y el hecho de convertirse en sujetos de la Historia en primera persona. Son estos otros datos autobiográficos los que sitúan al lector ante la persona de Carlos Blanco Aguinaga. A estos datos autobiográficos se le suma la difícil concepción del tiempo a la que se ve sometida dicha generación y que resulta ser el auténtico protagonista en palabras de la propia González de Garay ("Memoria” 109), que refuerza, una vez más, la autenticidad de la experiencia del escritor: "Entiende que no es posible que hayas caído un día cualquiera, diecinueve o veinte de julio (¿quién se acuerda exactamente?), cuando viste por el aire azul las bombas. Sin embargo, te dices, tiene que haber sido de golpe, porque crees recordar perfectamente que antes no existía el Tiempo" (28). De este modo, y aunque es bien cierto que no se puede hablar de una autobiografía, sí es cierto que lo autobiográfico parece tener un peso mayor de lo que hasta ahora algunos críticos han venido considerando al clasificarla simplemente como una novela.

Ahora bien, al igual que hicimos con el análisis de Dulcinea encantada, reparemos en cómo la ficción del relato establece un diálogo con lo autobiográfico como recurso identitario de esta generación. De los siete capítulos de la obra, cinco podríamos decir que son puramente ficcionales, pero ¿lo son realmente en su totalidad o existen algún tipo de vinculación con el yo narrador del primero y del último capítulo? En el caso de los capítulos dedicados a Carmen y Rocío, podemos encontrar ciertas similitudes entre las vivencias de estos personajes y del propio Carlos Blanco Aguinaga, puesto que ellas 
también fueron niñas de la guerra y puede entenderse este como un recurso para dar voz a otros miembros de su generación y hacer más comprensible el trauma o las dificultades a las que él mismo tuvo que enfrentarse. De hecho, en voz de Carmen, podemos leer las siguientes palabras: "la verdad es que hay días en que quisiera poder olvidarme de mí para evitar esas fracturas de los cimientos en los que todo tendría que tener su propio sitio, donde todo sería indestructible como en una película permanente” (53). Este desarraigo y fragmentaridad es compartido por muchos de los miembros de la segunda generación, por lo que se puede establecer una conexión entre la memoria individual del autor y la memoria colectiva de su generación.

Los capítulos tres y cinco también tienen una profunda relación con el autor, ya que ambos narran las historias de dos brigadistas internacionales, uno ruso y otro alemán, que defienden la misma causa que su familia. Además, junto al relato de estos brigadistas, incorpora reflexiones sobre su destino, tal como el hecho de ser víctima de las creencias políticas de sus padres: “¿Muerte a los padres que nos condenan? En mi caso no hizo realmente falta" (59). Finalmente, el capítulo cuarto, el capítulo central y dedicado a la figura de Carlos -Charles en la obra-también tiene una resonancia autobiográfica importante. Como bien ha estudiado González de Garay, la música de Carlos Gardel simboliza un viaje a su infancia, ya que esta forma parte de la memoria sentimental a través de su madre, su abuelo y su tía ("Memoria" 107). De hecho, la canción es una metáfora de la creación verbal, elemento que ya habíamos anticipado en el apartado anterior como rasgo identitario de la patria de esta generación, el cual se desarrollará detenidamente en el próximo apartado ("Memoria" 108). 
De esta forma, a través de esta breve explicación, queda claro cómo el uso de la ficción puede interpretarse también como un recurso dentro de lo autobiográfico de la obra que forma parte de la identidad narrativa del autor. Por lo tanto, también el uso de la ficción permite al lector establecer una referencialidad entre el personaje de los capítulos uno y siete y el narrador y el autor sin que aparezcan elementos paratextuales, como los denomina Gerard Genette. Evidentemente, esto no es suficiente para hablar de autobiografía, entre otras razones porque no aparece la referencia onomástica, totalmente necesaria según Lejeune y también Manuel Alberca -elemento cuestionable a mi entender-, pero sí nos permite situar dicha obra dentro de las novelas del yo, siguiendo la terminología también de Manuel Alberca. Esta se caracteriza por ser fruto de un pacto ambiguo que se encuentra a medio camino entre el pacto autobiográfico y el pacto novelesco, un pacto en el que puede ser que ocurra o que no la referencialidad y en el que la relación entre ficción y factualidad se encuentra a partes iguales (pos. 1012). De este modo, si en el pacto novelesco el autor parece distanciarse del narrador y de los personajes de la novela, ha quedado demostrado como este distanciamiento no sucede en Un tiempo tuyo, sino que existe un vínculo de unión con todos ellos. Así cobran relevancia las palabras de Michel Ugarte, según el cual es imposible dividir la ficción y lo que él denomina "historiografía", que, teniendo en cuenta el enfoque de este trabajo, podría considerar como sinónimo de autobiografía:

Many of exile writers are faced with the dilema of re-creating their own exile both as a response to their banishment and as a work of fiction. The initial break from the land gives rise to a need to recover a lost identity and thus re-create the former self in a frustrated struggle against oblivion. 
Their texts must, therefore, remain in the middle ground between real events and created ones without ever losing sight of either. (108)

De este modo, Ugarte está también reafirmado la importancia de la novela del yo como género especialmente significativo de los escritores exiliados y, en nuestro caso, más concretamente de la segunda generación de autores exiliados.

En tercer lugar, Michel del Castillo, nacido en 1933 en Madrid y exiliado a Francia junto a su madre poco antes de la caída de la capital española, publicó, en 1957, Tanguy. Histoire d'un enfant d'aujourd'hui. En esta obra y a través de una voz en tercera persona, Michel del Castillo expone un relato lleno de tintes autobiográficos: su huida de España, la difícil relación entre sus padres, su peregrinaje por diferentes ciudades francesas, el abandono de su madre, su internamiento en dos campos de concentración, uno francés y otro alemán, el maltrato sufrido en un asilo para jóvenes sin familia en Barcelona, su posterior ingreso en un colegio jesuita de Úbeda en el que pudo estudiar y tener una vida tranquila, su trabajo en una cantera en Barcelona, así como el posterior reencuentro con su padre y con su madre, por separado, en Francia. No obstante, al igual que pasaba con el caso de Un tiempo tuyo de Carlos Blanco Aguinaga, autores como Antonio Álvarez de la Rosa han calificado esta obra de Del Castillo directamente como una novela (9). Por otro lado, otros autores como Nieves Ibeas son más cautos al considerar el papel de la ficción y la autobiografía y sitúan a la obra dentro de la ficción autobiográfica (351). ¿Es realmente una novela o una ficción autobiográfica? ¿Encaja dentro de lo que Alberca denomina "novelas del yo?"

Para responder a estas preguntas, acudamos al prefacio que el propio Michel del Castillo escribe con motivo de la reedición de Tanguy y en el que habla sobre cómo la 
crítica ha recibido su obra y en qué medida ha encajado esta las relaciones entre autobiografía y ficción. De esta forma, a lo largo de las páginas de este prefacio comentaba el escritor:

Tanguy, mi primera novela publicada, ¿fue también la primera que concebí como texto literario? (...). Así pues, ese sentimiento de urgencia que tantos lectores y críticos señalaron en el momento de su publicación, concebían el libro como una liberación, no correspondía a la realidad. (...) Tanguy no es el fruto de la necesidad biográfica, proviene ante todo de la escritura. No es un testimonio, ni siquiera indirecto. (...) ¿Cómo no ver entonces una autobiografía más o menos novelada? Así es como una mayoría de lectores recibió el libro en el momento de su publicación. (...) No hubiera podido, por lo tanto, aunque hubiera tenido la intención, novelar una autobiografía de la que estaba totalmente desprovisto. Dudaba de quién era y si Yo existía verdaderamente. En cuanto al segundo término que forma la palabra autobiografía, es decir, la vida, la mía era todavía más incierta. (...) La novela precedía a la vida, la ordenaba proporcionándole un marco, constituía un modelo en el que podía deslizar, no una biografía, sino experiencias y recuerdos. Yo no novelaba mi vida, sino que biografiaba la novela. (...) Ni tema estable ni vida decible: ¿qué quedaba entonces de una posible autobiografía, sino su último término, la grafía? Simplemente para existir, estaba condenado a escribir, e incluso a volver a escribirlo todo sin fin. (13-22) 
Este conjunto de fragmentos yuxtapuestos podría generar un intenso debate sobre todos aquellos elementos que discutimos en el capítulo 1 en torno a las relaciones entre autobiografía y ficción y el nacimiento de la autoficción o la novela del yo como un nuevo género. Obviamente, al igual que sucedía con Dulcinea o con el protagonista de Un tiempo tuyo, no puede clasificarse como una autobiografía según la concepción clásica de esta puesto que no cumple con el criterio indispensable por el que debe producirse el reconocimiento del nombre propio y la asunción de este por el sujeto de la enunciación, como ya señalaba Molero de la Iglesia (La autoficción 24). Ahora bien, esta falta de identificación explícita y el hecho de otorgar al protagonista del relato un nombre diferente al del autor no impide al lector establecer un pacto de autenticidad, criterio también clave al hablar de autobiografía. Tanto es así que el propio Michel del Castillo reconoce que dicho pacto con el lector se ha producido al confesar en el prefacio la recepción de la obra como autobiografía. El establecimiento de dicho pacto y la falta de referencialidad entre autor, narrador y protagonista me llevan a considerar esta obra también dentro de la novela del yo.

Al igual que veremos en el capítulo cuarto al analizar la obra de Jorge Semprún, podemos observar en el caso de Michel del Castillo, como el propio autor explica, la necesidad de hacer literatura con sus propios recuerdos como recurso para superar lo vivido y para que la gente pueda entender lo que su generación sufrió. En relación a ello escribía: "Tanguy necesitaba hablar con alguien, contar lo que le sucedía. Pero nadie le hubiera creído. Le hubiesen tomado por un $<<$ sablista $>>$ o por un extravagante. Aquellos hombres que lo rodeaban sin duda habían olvidado y no hubieran querido oír una historia tan inverosímil" (217). De esta forma, Michel del Castillo reivindica la necesidad de 
ficcionalizar los recuerdos y las experiencias vividas para hacer el relato más creíble al lector. De hecho, ya Angelina Muñiz-Huberman había definido esto como un rasgo identitario de la segunda generación de escritores exiliados al afirmar que el uso de la palabra artística conllevaba la compensación por la traición que había sufrido la palabra histórica de esta generación (El canto del peregrino 175). No obstante, habiendo dicho esto, creo que es especialmente interesante tener en cuenta el nacimiento de un nuevo género, el cual no aparece dentro de las variedades posibles dentro de las novelas del yo según Alberca, pero que, sin lugar a duda, reclama un lugar dentro de dicha categoría. Se trata de lo que Encarnación García de Léon ha denominado “docuficción”, término que, según ella, amplía la perspectiva de la autoficción y bajo el que ha clasificado Tanguy. Histoire d'un enfant d'aujourd'hui. García de León afirma que se trata de un género en el que el yo biográfico se establece como núcleo generador de la historia, ya que "el autor está en el texto presente no necesariamente en la persona verbal, sino a través de su criterio subjetivo y como sujeto activo de la memoria histórica" (554). Además, explica que en este tipo de narraciones el narrador reproduce la realidad ficcionalizándola e incluso ficcionalizándose a sí mismo, incorporando datos autobiográficos comprobables -ya señalamos estos anteriormente-, por lo que destacaría su carácter "experiencial" (544). Entre otras características del género destaca la estructura propia de la narración, el hecho de que se trata de relatos socialmente interesantes y el relato de un narrador que cuenta una verdad vivida (544).

La acertada elaboración del término de docuficción para hacer referencia a la obra de Del Castillo no hace más que corroborar lo que he desarrollado en estas páginas a través de los ejemplos de Dulcinea encantada, Un tiempo tuyo y, en último lugar, con 
Tanguy. Histoire d'un enfant d'aujourd'hui. Es decir, la necesidad de revisar con detenimiento muchas de estas obras de los autores de la segunda generación de exiliados que muchos críticos han clasificado como novelas. Ha quedado patente que, a través de un estudio en profundidad, podemos dilucidar que las relaciones entre autobiografía y ficción no son más que el reflejo de un rasgo de la identidad narrativa de esta generación, en la que los límites entre los géneros han desaparecido en muchas ocasiones como consecuencia también de la desaparición de sus propias fronteras nacionales, tal y como abordaremos en el siguiente apartado. De este modo, estas tres obras son un claro ejemplo de la necesidad de hablar de novelas del yo, obras situadas a medio camino entre la concepción clásica de la autobiografía y la novela y cuyo "pacto ambiguo" ofrece una mayor libertad a una generación que había sido anulada por un régimen dictatorial y en el que las relaciones entre ambos géneros son muchos más profundas. 


\section{Capítulo III}

\section{España fuera de España (II). Niños convertidos en escritores: una identidad en lucha con los conceptos de nación, tiempo y lenguaje}

En sus reflexiones sobre el exilio, Angelina Muñiz-Huberman recapacita sobre el significado del mismo y concluye que este es "un salto afuera" que conlleva la caída en un vacío tanto espacial como temporal y que, al mismo tiempo, origina la necesidad de buscar nuevos márgenes que permitan al sujeto echar nuevas raíces (El canto 174). No obstante, es este salto afuera el causante de una profunda y compleja red de traumas e intentos fallidos para establecerse como individuo de una comunidad. Como ya adelanté en el primer capítulo, el ser humano se aferra al concepto de nación para sentirse parte de un grupo de personas con las que cree compartir unos rasgos o elementos identitarios. De hecho, tal y como comenté también en los dos apartados anteriores, fue el deseo de no perder el contacto con esos rasgos que consideraban parte de una identidad colectiva lo que llevó a los exiliados a crear esos centros y escuelas de exiliados en los países de acogida, de modo que les permitiera establecer una continuidad con la identidad nacional que habían establecido previamente en sus países de origen, llevándoles así a crear lo que Juan Carlos Pérez Guerrero ha denominado una "burbuja cultural" ("Franquismo" 668). Sin embargo, también planteé ya que la segunda generación de exiliados no podía establecer dicha continuidad por carecer, debido a su temprana edad, de una identidad nacional propia. Esto nos lleva a plantearnos, por tanto, varias cuestiones: ¿son entes carentes de una identidad nacional?, ¿qué papel juega la identidad nacional de sus padres y la identidad nacional de la comunidad que los ha acogido?, ¿es posible crear una identidad nacional basada en la combinación de ambas o, por el contrario, crean una 
identidad nacional alejada de la confrontación de estas? Y, en último lugar, ¿existe una identidad nacional propia de la comunidad del exiliado?

Ya en el capítulo anterior había apuntado a las teorías de Ugarte quien señala que, en un primer momento, fue el propio hecho de estar fuera de la nación lo que llevó a muchos de estos autores a crear una identidad nacional arraigada en su país de origen (18). Obviamente tuvo mucho que ver con esto la creación de esas escuelas y refugios de exiliados que ya mencioné, así como el pronto regreso que sus padres y profesores les prometían. No obstante, no es este el caso de todos lo escritores, sino que hay otros, como Federico Patán, Angelina Muñiz-Huberman, Carlos Blanco Aguinaga, Jaime Salinas, Gerardo Deniz o María Casares, cuya identidad nacional empezó a cambiar sin poner resistencia, al menos de forma consciente, a ello, precisamente en el momento en el que cruzaron la frontera. Tan es así que el primero de estos autores decía:

Nosotros, en edades moldeables como la bustiña (cierto tipo de arcilla), nos íbamos necesariamente haciendo a un mundo en el que jugábamos cada vez más con los hendayeses según la escuela nos iba afrancesando. Yo, por ejemplo, seguía — como todos— jugando al frontón, pero ahora, además de eso y de dar patadas a una pelota redonda, empezaba ya a jugar al rugby. (...) Aunque lenta y conflictiva, tan segura era aquella asimilación que alguna vez he llegado a pensar que el pueblo en el que empecé a ser quien esto escribe es Hendaya. (Por el mundo 68-69)

Son estos autores quizá los que presentan un proceso de formación identitaria menos complejo ya que estos parecen haber asumido los cambios de forma más receptiva, aunque no por ello sus relatos dejan de mostrar los dilemas y dubitaciones 
propios de su "salto afuera". En cuanto a aquellos que, en un primer momento, sí se mostraron más cercanos a esa identidad nacional española a la que hacía referencia Ugarte, a medida que fueron creciendo, esta sufrió un doble proceso: por un lado, en muchos casos perdió fuerza dando lugar a otro tipo de identidad nacional más compleja y amplia, como es el caso de Enrique de Rivas, Jorge Semprún o Tere Medina; y, por el otro lado, algunos de estos niños se aferraron a una discurso identitario nacional basada en una imagen de España hecha a partir de su imaginación y con la que se produce un profundo conflicto en el momento del regreso ya que se enfrentan a una realidad distinta a la existente en su mente, como es el caso de María Luisa Elío Bernal, Emilia Labajos o Fernando Aínsa. Esta última también derivó, por lo tanto, en el surgimiento de nuevas identidades nacionales que, en la mayoría de los casos, llegan a coincidir con aquellas surgidas por los escritores del primer grupo, aunque en diferentes niveles.

También podemos hablar de un pequeño subgrupo integrado por Tatiana Pérez, Aurea Matilde y Manuel Fernández Montesinos quienes tuvieron que esperar al regreso para poder afianzar su propio discurso identitario nacional en el país de origen el cual se habían cuestionado ellos mismos durante muchos años por la falta de contacto con la realidad de este país. Existe también un tercer grupo de escritores que desarrollaron, desde el primer momento, dicha identidad arraigada en su país de origen y que no cambió profundamente con el paso de los años, aunque sí afloran en ellos ciertos matices que la diferencian de la establecida dentro de España. Es este el caso de escritores como Virgilio de los Llanos, Federico Álvarez, José Fernández Sánchez o María Álvarez del Vayo. En último lugar encontramos un significativo conjunto de escritores de literatura del yo, como es el caso de Luis de Santamaría, Aurora Correa o Manuel Arce, cuyo relato no 
conlleva una reflexión sobre su identificación nacional lo que impide la clasificación de estos bajo ninguna de las categorías aquí propuestas. Ahora bien, la principal diferencia entre estos autores reside en los discursos narrativos que no son más que el reflejo de un proceso que funciona como constructor de una identidad. Es necesario entender la identidad no como un elemento estable y fijo, sino como algo en constante movimiento y en proceso de formación, tal y como afirma Juan Carlos Pérez Guerrero:

Se introduce así un nuevo elemento que rompe con la idea sustantivizada de identidad como un todo de notas constitutivas fundamentalmente estáticas, e introduce el dinamismo, la procesualidad como elemento intrínseco del discurso identitario, remitiéndonos a un sistema informacionalmente abierto al medio social en el que el yo esencialista se convierte en un yo devenir que interpreta la información procedente de su interioridad y exterioridad para generar un discurso social de identidad en constante construcción. ("Franquismo" 664) 40

Es decir, la identidad es una producción que nunca está completa, sino que forma parte de un proceso constitutivo a través de la representación (Hall 222). Dentro de este proceso son muchos los factores que afectan a la segunda generación de escritores exiliados: por un lado, la constante insistencia de los mayores en la necesidad de conservar su identidad española; en segundo lugar, los países de acogida de estos niños, así como también la educación recibida en dichos países y el contacto con otros exiliados. También afecta a dicho proceso el momento en el que se empiezan a asimilar los cambios

${ }^{40}$ La cursiva es mía. 
provocados por el exilio; es decir, si el niño asume estos cambios como algo natural y parte de su ser o si bien estos conforman un trauma o un obstáculo que se ve reforzado por la constante presencia de la nostalgia, la infancia perdida, la España idealizada y la creencia en el pronto regreso. De hecho, también Pérez Guerrero se encarga de destacar la importancia del regreso como elemento fundamental en la construcción de un discurso identitario en relación con los exiliados en México pero que, indiscutiblemente, puede expandirse al resto de miembros de esta generación:

La construcción de un proyecto de vida centrado en el regreso o la permanencia, en la transitoriedad o definitividad del exilio, perfilará un discurso identitario basado en su necesidad de distinguibilidad y reafirmación, o por el contrario, en su difuminación, que nunca anulación, bajo la finalidad clara de una integración social al medio mexicano. ("Franquismo" 666)

Por lo tanto, en las siguientes líneas, pretendo trazar un esquema completo, en la medida de lo posible debido a la multiplicidad de géneros literarios y autores, de los procesos y los resultados a los que llegaron estos autores en cuanto a la formación de una identidad nacional.

Susana Rivera, aunque sin aclarar su fuente, recoge unas palabras de Arturo Souto, miembro de la segunda generación, en las que afirma que, en relación con el exilio, muchos, con su madurez, llegaron a comprender que este no era una opción sino que era una nueva calidad de vida cuya aceptación confortaba la creación de su ser (25). Parece ser que esta maduración llegó bien temprana a ese primer grupo de autores que entendieron el exilio como parte de ellos mismos sin oponer mucha resistencia. Más 
adelante veremos que muchos otros autores llegan a esta misma conclusión aunque el camino hacia esta sea mucho más tortuoso y complicado. No obstante, a pesar de que todos los escritores de este grupo llevaron a cabo una asimilación temprana de este fenómeno, el resultado no fue el mismo en todos los casos, sino que podemos encontrar dos vertientes diferentes en cuanto al impacto de esta asimilación en la formación de su identidad nacional, aunque una goza de mayor popularidad que la otra: por un lado, de este grupo de escritores sólo Federico Patán asume el biculturalismo o la existencia de una doble patria como consecuencia de este exilio; por otro lado, Jaime Salinas, Gerardo Deniz, Angelina Muñiz-Huberman, María Casares y Carlos Blanco Aguinaga configuran una identidad nacional desterritorializada. No obstante, existe un matiz peculiar en cuanto a estos dos primeros. A Salinas y a Deniz los conduce a la desterritorialización el profundo rechazo que sienten hacia España y todo lo que esta representa a diferencia de Muñiz-Huberman, Casares y Blanco Aguinaga quienes otorgan un papel diferente a su país de origen dentro de esa desvinculación geográfica a la que hago referencia.

A modo de anécdota, Federico Patán explicaba que los personajes de sus obras raramente tomaban licores, sino que lo suyo era el café. ${ }^{41}$ Sin embargo, en una conversación con un amigo, Ignacio Martín, este le había sugerido que, aunque fuese por romper la monotonía, pusiese en manos de sus personas una copa de tequila ("Invitación" 221). En resumidas cuentas, el café era símbolo de España mientras que el tequila, obviamente, representaba a México. Sin darse cuenta y a través de un símbolo tan

\footnotetext{
${ }^{41}$ Véase su ensayo sobre su carrera personal y profesional que escribió con motivo del primer número de la revista Migraciones y exilio: Cuadernos de la Asociación para el estudio de los exilios y migraciones ibéricos contemporáneos.
} 
insignificante aparentemente, Patán tomaba conciencia del doble mundo en el que vivía: aquel que había aprendido en casa, el de España, y aquel que había aprendido fuera de ella, el de México. Y es que así se encuentra Patán, dueño de dos mundos. A lo largo de sus dos obras autobiográficas, afirma encontrarse en una dialéctica cultural basada en el enfrentamiento de ambos mundos, no como opuestos, sino complementarios. Tanto el uno como el otro construyen una identidad cultural fruto de la unión entre la identidad nacional de su país de origen (España) y la de su país de acogida (México). Él mismo confesaba en la primera de las obras autobiográficas:

En ese primer contacto hubo en el interior de mi persona un amago de reconocimiento: algo de aquella cotidianeidad española coincidía con oscuros puntos de mi ayer. Al parecer, toda la vida seré un hombre de dos mundos. Pero siento que una condición humana es la de pertenecer a núcleos existentes contradictorios, que en mi caso se reflejan en un claro biculturalismo, de escasas manifestaciones externas y diversas raíces culturales. (De cuerpo 56)

Sin embargo, a tal asunción no llega sin un previo cuestionamiento de su relación con España y México, así como de la identidad que le intentaban imponer sus padres, tal y como se refleja también en este apartado:

Nosotros, y se me quedó muy grabado aquel nosotros, no somos gachupines, somos refugiados (término por entonces el empleado) y estamos viviendo en México mientras derrotan a Franco. (...) Me habré preguntado en ese momento, echando un vistazo alrededor, ¿entonces ésta no es mi casa? Rechacé la idea, pues por alguna razón Perote se levantaba 
más como mi hogar de aquel otro tan abstracto definido por mi padre, meramente hecho de fragmentos escuchados de los mayores y que sólo a los mayores pertenecían. (Una infancia 137)

Aunque Susana Rivera afirme que "se trata de una generación situada entre dos mundos, en tierra de nadie", Patán sí encuentra su tierra. Su tierra es la mexicana, en la que desarrolla su vida diaria y en la que, al mismo tiempo, conserva y está orgulloso de sus rasgos españoles (18). Reflejo de este biculturalismo es el uso peculiar del lenguaje que lleva a cabo Patán y sobre el que existen numerosos estudios que abordaré más adelante cuando profundice en el papel de este en la construcción del discurso identitario. De esta forma, Patán, tal y como sugiere Mateo Gambarte al hablar de la segunda generación de escritores, es un ser binacionalizado pero ubicado y referenciado en México ("Los escritores de la segunda" 209).

Por otro lado, encontramos al resto de autores que ya mencioné anteriormente: Jaime Salinas, Gerardo Deniz, Angelina Muñiz-Huberman, María Casares y Carlos Blanco Aguinaga. Gerardo Deniz y Jaime Salinas forman un pequeño subgrupo ya que, en el caso de estos escritores, como ya destaqué también, su proceso identitario había estado marcado por el rechazo hacia su país de origen, España, como voy a ejemplificar únicamente a través de la obra de Salinas por cuestiones de espacio. En el caso del hijo de Pedro Salinas, la repulsa hacia España viene motivada por dos razones principalmente: por un lado, por los problemas que su condición de refugiado español supusieron en su intento de integrarse en la sociedad americana; y, por otro lado, por el rechazo que sentía hacia su padre. Para Salinas, la figura paterna representaba una España que él conocía ligeramente, lo cual aumentó el distanciamiento entre ambos. Asimismo, este se vio 
incrementado por la relación conflictiva que mantuvieron ambos durante años debido al férreo control que Pedro Salinas ejercía sobre su hijo. Jaime Salinas ha asumido el hecho de que sus memorias puedan considerarse un ajuste de cuentas con su padre (Marchamalo 123). Pedro Salinas siempre había anhelado el retorno a su patria de origen y, como el propio Jaime Salinas escribió, esto significaba perder "las pocas libertades que había conseguido" (440). Su padre y, en general, su familia lo unían a un pasado del que no se sentía parte. De hecho, en la entrevista a la que hacía referencia en unas líneas más arriba confiesa que:

De alguna manera mis padres representaban la vida española mientras que yo lo que intentaba era incorporarme, precisamente por lo que hablábamos, al estilo de vida americano, al american way of life, y claro, me encontraba con que, por ejemplo, mi padre prohibía beber Coca Cola en casa. Imagínese lo que significaba llegar con un amigo a casa y decirle que en casa no bebíamos Coca Cola. Ese tipo de roces fue lo que me fue alejando de mis padres, creando conflictos. Cuento lo más trivial, pero eso se fue multiplicando a lo que estudiaba, a mis amigos, a todo lo que hacía. (Marchamalo 123)

También contribuyó a esto el origen francés de su familia y su tiempo refugiado en Argelia. Desde su infancia, su vida estuvo marcada por los continuos viajes a Argel, donde residía gran parte de la familia de su madre, Margarita Bonmatí, la cual adquiere un papel protagonista en la primera de las cinco partes de la obra. Además, Estados Unidos le había permitido también aceptar su homosexualidad, pues así lo narraba en su obra: "Estaba descubriendo la atracción del cuerpo masculino y, sin que pudiera evitarlo, 
noté como mi pene cobraba vida y quedaba encarcelado en mis calzoncillos. Yo acababa de cumplir doce años, el tendría unos dieciséis" (106). La muerte de Lorca, al que recuerda al principio de la obra, se había convertido en él en un símbolo de la represión sexual. Es la suma de todos estos factores lo que le lleva a desarrollar un rechazo hacia su país de origen con el que confiesa poner fin el día de la muerte de su padre:

Con su muerte se truncó mi identidad nacional, el compromiso o la obligación de estar pensando siempre en volver. (...) Para sobrevivir tenía que dejar de ser español. La verdad es que había dejado de serlo en 1939, cuando nuestros pasaportes sólo servían para ir a México. Era, pues apátrida, lo que me llevaba a reafirmarme en una diferencia que me enorgullecía. Descartaba naturalizarme americano o reivindicar la nacionalidad francesa, a la que tenía derecho por haber nacido en Argelia. (...) me sentí liberado, libre del peso de una patria. La causa, la causa justa permaneció, se consolidó al empalmar una guerra con otra. No era de ningún sitio: las amarras se habían roto. Jamás volví a pensar en España, en ser español como lo había sentido y sido hasta entonces. (506-507)

El rechazo a su país de origen lleva a Salinas a considerarse un ser apátrida a pesar de que, durante su juventud y fruto probablemente de su inmadurez, llegara a autodenominarse yankee (203). Además, es significativo señalar que su obra termina con la llegada a las oficinas de la editorial Seix Barral en la que ha desarrollado su carrera profesional convirtiéndose, en su tiempo, en uno de los editores más influyentes de España. Sin embargo, la última frase de su obra es: “¡Y precisamente en España, país del que siempre había querido huir!’. Igualmente significativo es el hecho de que, a pesar de 
este rechazo, sea el único de la familia que conserve la nacionalidad española ya que sus padres y, posteriormente, su hermana pidieron la nacionalidad americana. No obstante, esto no indica un espíritu patriótico: "No sé si se trataba exactamente de desarraigo, pero sí de ir perdiendo la identidad. Algo que tampoco valoro como negativo. Me alegro de no ser de ningún sitio. Cuando digo que soy antinacionalista no tiene que ver sólo con los nacionalismos de España, sino en general con todo lo que significan las banderas y los himnos" (Marchamalo 122). Ahora bien, de esta forma, Salinas, al igual que el resto de los autores de este grupo y de algún otro que más adelante comentaré, rompe con el concepto de patria como rasgo constitutivo de su identidad. Jaime Salinas se ha convertido en un ser desterritorializado como consecuencia del exilio que heredó de su familia. Es decir, se trata de una resolución en la que el individuo, debido a su falta de arraigo a una tierra pues en ninguna de ellas encuentra suficientes elementos con los que identificarse, ha decidido buscar otros rasgos que lo identifiquen. De este modo, es el mismo hecho de no tener una vinculación única a un espacio geográfico lo que constituye su identidad. Deleuze y Guattari identifican la figura del nómada con el héroe posmoderno, aunque no creo que, en el caso de la segunda generación de exiliados, pueda llevarse a cabo tal identificación, puesto que la experiencia del exilio no dignifica, sino simplemente fuerza al individuo a buscar un nuevo esquema identitario. Fernando Aínsa, miembro de esta generación y gran teórico de la cartografía de la pertenencia, afirma que "se exalta así la 'condición nomádica' y la figura del 'fugitivo cultural' como componentes de una identidad que ya no es unívoca -territorio, lengua y menos aún étnica- sino múltiple, capaz de esgrimir, según qué circunstancia o conveniencia, uno u 
otro pasaporte" (Palabras nómadas 80$).{ }^{42}$ De este modo, cuando Salinas aclara no tener la necesidad de hacerse ciudadano americano ni de reivindicar la nacionalidad francesa está reafirmándose como ser nómada, pero, al mismo tiempo, transnacional. Como aclara Sophia McClennen, el transnacionalismo y el posmodernismo goza de gran aceptación en la última parte del siglo XX como resultado del cambio físico y conceptual que sufre el término "nación", que se ha visto debilitado al cuestionarse la relación entre nación y estado (Dialectics 35). No sólo Jaime Salinas, quien publica su obra en 2003, sino gran parte de los autores de esta generación que publican a partir de los años 80 del siglo XX, son testigos del nacimiento de un transnacionalismo que parece resolver el enfrentamiento identitario con el que muchos de ellos llevaban conviviendo durante años. De hecho, al igual que las obras de Goytisolo, Dorfman y Peri Rossi, la narrativa de Salinas sugiere que el transnacionalismo "may be liberating to the subject because nationalism always implies the repression of difference" (McClennen 36). Además, Braidotti también señala la importancia del nomadismo como estado definido por la "subversión de las convenciones sociales" (31). No obstante, desde la perspectiva de Braidotti, el sujeto nómada puede entenderse como un proceso más elevado al desterritorializado. Es decir, la figuración de su sujeto nómada, o "nómade" como ella misma escribe, debe entenderse como un sujeto que ha buscado en el desplazamiento y en la transición una forma de resistencia a la asimilación y homologación con las formas dominantes de representación del yo (62). Es decir, no es tan importante el viaje sino la

${ }^{42}$ Recomiendo el libro homenaje a Fernando Aínsa, El escritor y el intelectual entre dos mundos. Lugares y figuras del desplazamiento, pues incluye una visión global de la obra del autor. 
oposición del individuo en contra del dogmatismo imperante por la fuerza dominante en el poder. A pesar de ello, y a diferencia de la figura del exiliado, la cual ella misma vincula principalmente a la condición de extranjería, Jaime Salinas, así como otros escritores que abordaré más adelante, han pasado de ser sujetos exiliados, desterritorializados y extranjeros a sujetos nómadas. Es decir, se han valido de su forzado exilio para asimilarlo y formar, a partir de él, una poética nómada como si de un arma de combate subversiva se tratase en términos de Pierre Joris (26). Salinas utiliza su identidad movible, políglota e intelectual para crear un discurso identitario alternativo a la identidad española única que lo había exiliado.

Ahora bien, como ya adelanté, esta condición de nómada, extranjero o individuo transnacional también surge en los casos de Muñiz-Huberman, Casares, Blanco Aguinaga y algunos otros escritores aunque el proceso haya sido diferente. La primera de estas escritoras, quien curiosamente nace en Hyéres ya en el camino del exilio de sus padres, titula su poética del exilio "el canto del peregrino". Utilizando la metáfora del peregrino que "camina de tierra en tierra", se refiere al exilio eterno, es decir, a su posición como nómada que se va a convertir en el motor de su escritura (El canto 178). Y es que MuñizHuberman afirma sobre esta generación que es un "grupo de escritores que, según avanza el tiempo, se empeñan en la patria del lenguaje" (El canto 160). Sus dos obras autobiográficas, a las que ella misma denomina pseudomemorias, incluyen un constante simbolismo de la figura del nómada. Al inicio de Castillos en la tierra, la narradora pone en boca de Alberina, su alter ego, las siguientes palabras:

Los días del hotel Gillow pasaron. Alberina volverá una y otra vez a recordarlos. Ha nacido su gusto por los hoteles: su deseo intermitente de 
vivir en ellos. Su idea de que estar en un hotel es una aventura calculada: un escape: un desdoblamiento. Un elegir lo extraño y lo inesperado. Una proposición fragmentada de vidas, propias y ajenas. Una relación de historias: una gran mentira: o una sencilla verdad. (25)

De esta forma, y especialmente en esta sociedad transnacional y global que predomina a finales del siglo XX, el hotel se convierte en símbolo del transeúnte sin hogar, sin arraigo a una tierra en particular. El hotel se configura como espacio por antonomasia del extranjero, como espacio no sujeto a las limitaciones geográficas de un país, lugar de encuentro de culturas, de mestizajes, espacio en el que el hecho de ser extranjero se convierte en la norma entre ciudadanos de ese microcosmos, en su principal rasgo definitorio. El hotel se erige en metáfora del exilio, pues esta generación vive permanentemente en el viaje. A través de este símbolo Muñiz-Huberman pretender crear un espacio en el que predomine "la idea de una transgresión de fronteras y de una fertilización cruzada entre culturas más allá de las fronteras nacionales y más allá de distancias geográficas", tal y como afirma Eugenia Helena Houvenaghel al analizar el espacio y la identidad en su obra ensayística ("Cruzando" 96). También Braidotti, quien se autodefine como sujeto nómada, se encarga de destacar su afecto por los lugares de tránsito: salas de las estaciones y aeropuertos, tranvías, autobuses de servicio continuo, etcétera. De hecho, se refiere a ellos como "zonas intermedias en las que todos los vínculos quedan suspendidos y el tiempo se extiende a una especie de presente continuo; oasis de no pertenencia, espacios de desapego" (52).

Otro elemento recurrente es la presencia de la fábula. Normalmente el cuento ha sido asociado a la memoria oral y a los niños y, al mismo tiempo, es el refugio de la 
cultura popular, de las raíces y las tradiciones más folclóricas de un pueblo, al igual que lo eran los cantares de los juglares en la época medieval. La conversión de los recuerdos en cuentos que acompañan al individuo durante su madurez refleja la asimilación del pasado, de su herencia cultural, como parte constructora del presente del escritor del mismo modo que un niño empieza a construir su futuro a partir de las narraciones orales provenientes de sus padres. De esta forma, Muñiz-Huberman aboga por la asimilación de la herencia española como una parte más de su identidad, pero sin establecer una relación de unicidad respecto a esta. Ya en el apartado anterior, al analizar los límites entre la autobiografía tradicional y las autoficciones, hacía alusión a su obra Dulcinea encantada que, a pesar de no ser denominada pseudomemorias, contiene una gran carga identitaria de la autora. En el primer sello de la obra leemos:

Yo soy yo. Yo soy yo. Yo soy yo. Y si no, me pongo a leer. Que es lo mismo. Mejor dicho, lo opuesto. Yo no soy yo. Yo soy Penélope. Yo soy Orlando. Yo soy Rodrigo Díaz de Vivar (no doña Jimena, muy aburrida dama), soy Dulcinea, soy Santa Teresa, soy una de las hermanas Bronte, probablemente, Emily. Ah, también soy Elizabeth Browning, por intermedio de Virginia Woolf. Pero podría ser también algún cabalista hispanohebreo del siglo XVII: algún marino famoso del siglo XVI. O algún personaje de Walter Scott (creo que Rob Roy), o de Joseph Conrad (¿Lord Jim?). (22) 43

\footnotetext{
${ }^{43}$ La obra está dividida en sellos, no en capítulos.
} 
Penélope es uno de los personajes más destacados de la literatura griega, Orlando de la italiana, Rodrigo Díaz Vivar de la española, al igual que Dulcinea y Santa Teresa, Emily Brontë una de las novelistas inglesas de mayor resonancia, Elizabeth Browning poeta inglesa a la que llega a través de Virginia Woolf, otra inglesa, al igual que lo son los personajes Rob Roy y Lord Jim también, pero todos ellos conforman lo que es Angelina Muñiz-Huberman, es decir, un sujeto sin frontera, un sujeto desterritorializado que no necesita de una nación que la defina, sino que es la lectura, es decir, su pasión hacia la literatura su rasgo identitario más significativo. No obstante, si después de esto a algún lector aún le queda alguna duda, la propia escritora aborda el tema de una forma directa al escribir:

¿Que si disfruté ser exiliada? Pues sí. No lo puedo negar. Yo sé que hubo quienes sufrieron, lloraron y se lamentaron. Es cierto, les tocaba hacerlo. ¿Pero a mí? ¿Qué me tocaba o qué se esperaba de mí? Por lo pronto, me definí en la indefinición. No era nada: ni española ni mexicana. Porque la posición cómoda, la de la mayoría, era la hibidrización: somos hispanomexicanos. (59)

De esta forma, Muñiz-Huberman rechaza una vinculación única al país de origen y al país de acogida, como lo había hecho Federico Patán, y simplemente acepta la indefinición como un estado permanente. Además, también reflexiona sobre la posibilidad de haberse definido como exiliada pero incluso esta opción le pareció inadecuada posteriormente pues también habría dejado de serlo tras la muerte de Franco en 1975 (60). Ante esta resolución, una vez más, asume "ese deseo de borrar fronteras: de dejar de ser una, para ser el otro. Ambicionar la pluralidad" como parte de su ser (65). Al 
igual que Salinas, Muñiz-Huberman ha optado por ser un sujeto nómada y desterritorializado.

Por otro lado, Sharon Keefe Ugalde, en su estudio sobre las configuraciones nómadas de la poeta de medio siglo Julia Uceda, afirma que son hasta tres las diferentes manifestaciones del nomadismo que sobresalen en la poesía de la escritora. En primer lugar, habla de "una conciencia acéntrica que no acepta ninguna identidad permanente y que insiste en seguir transgrediendo límites”. En segundo lugar, hace alunsión a una condición de extranjería permanente; y, finalmente, menciona "la fluidez y la heterogeneidad como procedimientos poéticos" (814-815). ${ }^{44}$ Del mismo modo, son también numerosas las manifestaciones que podemos encontrar si nos centramos en la siguiente autora de ese grupo, María Casares, autora de Residente privilegiada. ${ }^{45}$ Aunque estas aparecen dispersas en numerosos apartados de la obra, todas ellas pueden resumirse en el siguiente fragmento:

${ }^{44}$ Julia Uceda, nacida en Sevilla en 1925, marcha a Estados Unidos en 1965 para ser profesora en Michigan State University durante ocho años. Posteriormente pone rumbo a Irlanda y regresa a España definitivamente en 1976.

${ }^{45}$ María Casares, nacida en 1922, es hija de uno de los políticos más importantes de la II República, Santiago Casares Quiroga, quien, como afirma Manuel Aznar Soler, "se convirtió en uno de los nuevos héroes de la España tricolor" tras la proclamación de la II República española ("Materiales" 1078). Una biografía completa de la autora puede encontrarse en Maria Casarès, l'ètrangère, obra de Javier Figuero y Marie-Helène Carbonel. Para más información bibligráfica sobre la autora recomiendo el trabajo de Aznar Soler "Materiales para la memoria de un mito: María Casares y el exilio republicano de 1939", cuyos datos bibliográficos puede encontrar al final del trabajo. Es recomendable la lectura de la biografía de su padre escrita por Carlos Fernández, Casares Quiroga, una pasión republicana, para entender los orígenes de la relación entre María Casares y la España refugiada. 
Estoy obligada a representar lo mejor posible lo que me ha sido confiado, es decir, al mundo en el teatro y, a través de los teatros del mundo, a Francia fuera de España, a la España errante en Francia y al exilio en todas partes. En dos lenguas. Pues, aunque de acuerdo con mi tarjeta de residencia he nacido en Galicia -esa punta de tierra por la que España tiende la punta de su nariz hacia el Océano-, soy una actriz francesa, hecha enteramente por Francia, que aceptó la materia bruta que le vino de España y que me modeló a su gusto y según sus criterios. Pero, aunque hija de Francia, en mi nueva patria el teatro, mi nacionalidad -lo mismo que mis orígenes- sigue siendo española o, para decirlo mejor, refugiada española en Francia. (351)

En primer lugar, destaca su posicionamiento como representante del mundo, más allá de las fronteras establecidas por las diferentes naciones. De hecho, asume el teatro como la única patria posible pues este se dibuja en su imaginario como la única forma posible de acceder y, al mismo tiempo, representar a otros mundos, ya sea a Francia fuera de España, a la España errante en Francia o a la comunidad exiliada en cualquier otra parte. Aznar Soler afirma que desde 1942 "el teatro, la escena, el lugar de la representación" se había convertido en la patria para la actriz francesa de origen gallego ("Materiales" 1087). ${ }^{46}$ Del mismo modo, es interesante su vinculación no con la España en la que nació, pues para ella la tierra no tiene más importancia que la de ser el lugar de

\footnotetext{
${ }^{46}$ Entiéndase que al decir "actriz francesa" estoy haciendo referencia al juego de palabras que hace la propia autora dentro de la obra al decir que, aunque ella nace en Galicia, su yo-actriz nace en Francia.
} 
origen, sino con la España refugiada, la España peregrina, sin tierra. Aznar Soler se encarga de estudiar cómo María Casares se convirtió en un mito representativo del exilio republicano español de 1939, del cual se muestra profundamente orgullosa:

Ahora bien, para ser digna de la Francia que me acogió y me hizo y a todos estos documentos que me representan, estoy obligada en primer lugar a seguir siendo fiel, si no a la España que se halla más allá de los Pirineos y que es mi tierra de nacimiento, sí por lo menos a la España errante, sin tierra, que coloniza poco a poco tantos países de Europa y de América; y también a sus súbditos, mis hermanos -los refugiados primero, los emigrantes después- de los que, por mi nacimiento, mi afiliación y mi profesión pública, estoy considerada como uno de los emblemas -una diminuta bandera , pero aún así...- y a los que estoy obligada a representar fielmente a fin de merecer también representar a Francia. ¿Y cómo manifestar la adhesión a mis hermanos de exilio -yo, que he de quemar mi tiempo y mis energías en el teatro- si no es compartiendo su condición? ¿Es decir, conservando al menos su mismo estatuto de refugiado español? Y esperando, para solicitar la nacionalidad francesa - la que quiero adoptar para dar testimonio de mi fidelidad al país que me acogió y que me hizo y a mis nuevos hermanos de adopción- el día en que pueda volver a España, para instalarme en ella quizá y vivir entonces allí representando a Francia-. El día que no haya ya en Francia, ni en ninguna otra parte del mundo, refugiados españoles. (Casares 351-352) 
Su vinculación a la identidad de refugiada española sin tierra fija y, al mismo tiempo, su deseo de adoptar la nacionalidad francesa se perciben como rasgos de un ser que está desterritorializado, puesto que no está unido a una tierra, sino a unos ideales que, como ella misma afirma, "coloniza(n) poco a poco tantos países de Europa y de América". Ahora bien, es esta subversión de las convenciones establecidas, en términos de Braidotti, lo que la lleva a ser un sujeto nómada, es decir, es su rebeldía contra las imposiciones ideológicas imperantes en España la que reafirma esta condición nómada. El hecho de tener una vinculación principalmente con Francia y la España errante no impide clasificarla como un sujeto nómada, pues no se convierte en ello por el acto literal de viajar sino por su posición intelectual. A esta última contribuye su condición de extranjería a la que hace referencia en varias ocasiones en su obra (73).

Al mismo tiempo, Carlos Blanco Aguinaga, al igual que María Casares y Angelina Muñiz-Huberman, también ha evolucionado hacia una identidad cosmopolita e internacionalista, tal y como afirma María Teresa González de Garay (“Exilios, identidades” 261). Reside en España hasta la edad de 9 años y después de dos años y medio en Francia marcha a México con la edad de 12 años. A partir de los dieciséis comienza sus visitas a Estados Unidos, a Ohio y después a Harvard, y posteriormente establecerá su residencia en California donde trabaja en numerosas universidades como profesor. Son estos múltiples destinos los que han llevado a González de Garay a señalar a Blanco Aguinaga como un "vasco-español-americano universal” ((“Exilios, identidades" 278). Esta afirmación se basa, según la escritora, en una "mexicaneidad" muy acusada que va a desarrollar, posteriormente, al dedicarse a los estudios chicanos en Estados Unidos y que está combinada con un estrecho interés por sus identidades vasca y 
española. De forma similar lo clasifica Francisco Rico al referirse a él como "vasco, mexicano, español, norteamericano" (700). En su primera obra autobiográfica, Por el mundo. Infancia, guerra y principio de un exilio afortunado, Blanco Aguinaga recorre los lugares de su infancia hasta el estallido de la Guerra Civil Española, a la que él mismo denomina "guerra nuestra" (54). El uso el adjetivo posesivo "nuestra" denota la vinculación de este autor con una guerra que él vivió cuando apenas tenía nueve años pero que marcó toda su vida. Posteriormente, a medida que avanza el relato, encontramos rasgos de su asimilación, primero, a la cultura francesa -“el pueblo en el que empecé a ser quien esto escribe es Hendaya" (14)- y, posteriormente, a la cultura mexicana al admitir su nacionalización como mexicano ya en su segunda obra autobiográfica, De mal asiento. No obstante, al final de la obra, vemos su autodefinición como ser internacional que abraza el nomadismo como elemento de su ser y de su familia: "¿por qué no pensar que nuestro mundo sería la relación entre dos, tres, varios mundos, y que yo, como Iris, y con nosotros los hijos, seríamos internacionales?" (150). Su residencia en cuatro países, su vida profesional rodeada en un mundo intelectual marcado por extranjeros y por la reivindicación de la cultura chicana en Estados Unidos, sus constantes viajes a España desde finales de los sesenta, su compromiso político tanto con España como con Estados Unidos y su compromiso con las minorías y los diferentes movimientos de liberación latinoamericanos habían hecho de él un autor nómada, un escritor cuya posición intelectual le llevaba a luchar contra las convenciones sociales. De hecho, María Paz Balibrea, en el Diccionario bibliográfico de los escritores, editoriales y revistas del exilio republicano de 1939, afirma que "el ir y venir vital y profesional entre continentes responde a -al tiempo que conforma- una identidad diaspórica que condiciona tanto la 
diversidad de intereses intelectuales como la particular visión del mundo de Blanco Aguinaga (pos. 16356-16362).

En segundo lugar, es necesario recuperar a ese segundo grupo de escritores que se aferraron a su identidad española en el primer momento. En el caso de estos narradores, el paso del tiempo provocó el surgimiento de diferentes procesos identitarios que terminaron de tres formas diferentes: por un lado, la pérdida de ese arraigamiento a una única identidad española sugiriendo otro tipos de identidades (Enrique de Rivas, Tere Medina y Jorge Semprún); por otro lado, aquellos que se mantienen firmes a su identidad española hasta el momento del regreso (María Luisa Elío Bernal, Emilia Labajos y Fernando Aínsa) que también van a derivar en la configuración de una identidad diferente; y, en tercer lugar, un grupo de autores que, a pesar de haberse cuestionado su identidad española, se reafirman en ella una vez que vuelven a España (Tatiana Pérez, Aurea Matilde y Manuel Fernández Montesinos). No obstante, en los dos primeros subgrupos, el resultado identitario es muy similar en todos sus integrantes: la desterritorialización, la identidad múltiple y el nomadismo. La primordial diferencia consiste en que en el segundo de estos subgrupos el trauma ha ocupado un lugar predominante durante gran parte de su proceso identitario y asumieron la escritura narrativa como mecanismo para procesar dicho trauma, tal y como queda demostrado en el capítulo dedicado a María Luisa Elío Bernal. Dejando de lado los casos de Jorge Semprún y María Luisa Elío Bernal, pues abordo a cada uno de ellos en su capítulo correspondiente, es interesante destacar como ambos subgrupos se enfrentan hasta llegar a ese resultado en común. Frente a Enrique de Rivas, quien afirmaba que "la idea de 
patria como un suelo necesario para crecer se demostraba en parte falsa" (Cuando acabe 211), encontramos a Emilia Labajos o Fernando Aínsa.

Emilia Labajos, emigrada primero en Francia y luego en Bélgica, había crecido pensando en el regreso a su patria. Al igual que María Luisa Elío Bernal, se había aferrado a unos recuerdos que dejaron de tener importancia tras el viaje de retorno y la posterior concienciación de que no quedaba nada de aquella imagen guardada en su memoria:

Mi primer regreso a España había precipitado en la nada todos mis recuerdos de infancia, todo en lo que formaba parte de mi jardín secreto, todo el universo feliz de mi tierna infancia en el que me había refugiado tantas veces cuando, en la tormenta, los momentos por vivir eran demasiado duros para poder soportarlos. No había encontrado nada, absolutamente nada de lo que me hubiese podido ayudar a establecer un vínculo entre el presente y el pasado que yo no quería olvidar, aquel pasado que yo necesitaba para abrirme el futuro. Había que sobrellevar todo aquello, no rechazar nada, ni siquiera lo que ya no existía, esto último aún menos. (95)

A partir de la constatación de la no existencia de esa España este subgrupo reconfigura su identidad. De ahí la importancia del retorno al que he hecho referencia en numerosas ocasiones. Ese lugar imaginario, al que hacía referencia Vicente Llorens, en el que se había convertido la patria para la segunda generación de exiliados desaparece y deja el camino despejado a un grupo de escritores que deben reestructurarse como sujetos. Aunque Labajos nunca enuncia su posición nómada o desterritorializada como 
tal, probablemente debido a la escasa introspección presente en su obra, sí podemos interferirla a partir de algunas de sus palabras. Tras haberse dado cuenta de la imposibilidad de ser española, como el resto de ciudadanos que se quedaron viviendo dentro del territorio nacional tras la victoria de Franco, tampoco se siente orgullosa de la nacionalidad belga que asume al casarse con un ciudadano de este país. De hecho, es en este momento cuando, a través de la frase "la territorialidad triunfa sobre todo lo demás", denuncia la limitación que suponen las fronteras (106). Por lo tanto, esta denuncia me lleva a pensar que, al igual que María Luisa Elío Bernal o que aquellos del primer subgrupo, Labajos ha asumido la desterritorialización como elemento identitario. A esta misma conclusión había llegado ya Enrique de Rivas aunque para él esta había sido fruto del paso del tiempo y no del retorno. Tan es así que él mismo escribía: “Como entre nieblas el concepto de «patria» buscaba ensancharse y explayarse más allá de fronteras que se me hacían antojo o casualidad de la historia, para escapar a la negatividad presente que mis ojos descubrían en ella. Me parece que era un concepto superable en lo que tenía de mezquino y de limitador" (Cuando acabe 212). De esta forma, a través de estos dos escritores como representes de cada subgrupo, podemos afirmar que tanto unos como los otros han llegado a la misma conclusión, al igual que ya que lo habían hecho los del grupo anterior, aunque el proceso haya sido diferente. De esta forma, parece surgir una nueva concepción de la identidad en cuanto a su relación con el término patria o nación, pues esta supera los límites geográficos para situarse como parte de una comunidad más amplia, desterritorializada, que se caracteriza por ir en contra de los cánones establecidos. No obstante, esto no es común en todos ellos. Si atendemos a este tercer subgrupo al que hacía referencia en las páginas anteriores (Tatiana Pérez, Manuel Fernández 
Montesinos y Aurea Matilde), observamos que no fue este su resultado. Aunque sí es cierto que su identidad unida a la nación española fue debilitándose durante muchos momentos de su exilio, esta se reafirmó tras entrar en contacto de nuevo con la geografía española. Veamos, en primer lugar, el caso de Tatiana Pérez (pseudónimo de Josefina Sacristán).

Nacida en 1930, tuvo que abandonar España con tan sólo 7 años para regresar a ella 18 años más tarde, ya que formó parte de esa primera expedición de niños refugiados en la URSS que decidió volver a España tras la autorización del general Franco en 1955. Durante su tiempo en la URSS, Tatiana fue víctima del trauma causado por la dicotomía entre su presente en Rusia y su pasado en España. Tan es así que ya en el prólogo, la autora escribe: "Lo más significativo de mi novela es Lara, (...), sus dos personalidades: rusa y española, sus dos patrias" (16). ${ }^{47} \mathrm{Al}$ inicio de su marcha al exilio, son numerosos los fragmentos en los que la autora se reafirma en su nacionalidad española: “Ante todo eran españoles y se consideraban españoles, como sus padres y todos sus antepasados, y querían a España como se quiere un imposible, como se sueña un ideal, como se idealiza una ilusión, como se persigue un fin y se anhela una meta" (34). Sin embargo, esta actitud parece tambalearse a medida que avanza su estancia en el país de acogida. Así, a mitad de la obra, afirmaba ya un equilibro entre sus dos identidades, la española y la rusa, en la que una o la otra sobresalían dependiendo de las circunstancias: "Y así, paulatinamente, iban desarrollándose en Lara dos personalidades: la rusa y la española.

\footnotetext{
${ }^{47}$ A pesar de que se refiere a su obra como una novela, no lo es, pues es una autobiografía. Del mismo modo, Lara no es otra persona que ella misma.
} 
¿Cuál de las dos prevalecía? Imposible precisarlo. Todo dependía del momento, de la ocasión, del lugar, del estado de ánimo, de los otros seres que la rodeaban, de los caprichos del corazón” (104). Además, más adelante, también se reafirma en la imposibilidad de echar raíces en el país de acogida dando así al nacimiento de una condición de extranjería, situación que se acentúa tras la muerte de su marido que era soviético (168). Sin embargo, la posibilidad de volver a España tras la mejora en las relaciones entre España y la URSS hace que se reavive en ella su identidad española y que esto la lleve a afirmar al final del libro que es únicamente en este lugar donde puede encontrar su patria: "No me parece difícil acostumbrarme a España y llegar a amarla más que a nada en el mundo. No me parece imposible conseguir al fin un equilibrio y decir con convicción, después de un largo peregrinaje: Aquí me quedo. Por fin me quedo. Este es mi suelo. Aquí está mi casa. Por fin, un sitio, un suelo y una casa" (174). Caso similar es el de Manuel Fernández Montesinos, así como el de Aurea Matilde quien, a pesar de no profundizar mucho en su obra sobre esta cuestión, afirma al volver a España desde Cuba después de más de 45 años que sintió una "impactante sensación de identidad con la gente que caminaba por las calles" (174).

Por último, encontramos a aquellos autores que se refugiaron en la nostalgia, en la imagen de España de su infancia y en la búsqueda del regreso para mantener intacta su identidad nacional española. Este grupo de autores coincide con aquellos escritores a los que hacía mención Miguel Ugarte al afirmar que fue el hecho de estar fuera de su tierra lo que les llevó a ser aún más nacionalistas (18). En este grupo encontramos a Virgilio de los Llanos, José Fernández Sánchez, Nieves Cuesta o María Álvarez del Vayo. Tanto De los Llanos como Fernández Sánchez y Cuesta consiguieron regresar a su país de origen. 
El primero de ellos lo hizo después de 54 años de vida en la URSS, el 19 de septiembre de 1992. Fernández Sánchez consiguió regresar en 1971 y Cuesta lo logró en 1957. En el caso de María Álvarez del Vayo, aunque enuncia su deseo de querer morir en España -"Si mi vida estuvo en París, su término está en Madrid"- no aclara si llegó a regresar de forma definitiva a este y me ha sido imposible conseguir este dato (Los últimos recuerdos 169). Ahora bien, es significativo el hecho que tres de los cuatro autores que han mantenido una fuerte identidad nacional española hacia un país que apenas conocían hayan sido niños refugiados en la URSS teniendo en cuenta el amplio espectro de países a los que estos niños y niñas fueron a parar. Esto invita a explorar, en la medida de lo posible, la imagen que proyectó sobre ellos la URSS para que nunca dejaran atrás esa nostalgia y esa afinidad a la España de su infancia. En el caso de Cuesta, esta no ofrece gran detalle de su relación íntima con la URSS más allá de las posibilidades educativas que le ofreció su país de acogida. No obstante, sí aclara que para ella el tiempo en este país fue en todo momento algo temporal ya que, usando una expresión rusa que ella misma utiliza, "chemadannoe nastroenie", ella tuvo siempre las maletas listas para el regreso a España (183).

A estas mismas oportunidades educativas se refiere Virgilio de los Llanos cuando destaca que, de los primeros 45 ingenieros hidroenergéticos que preparó la Unión Soviética en la Universidad Energética de Moscú, 23 eran españoles (63). Virgilio de los Llanos confiesa pensar en ruso, haber ingresado en el PCUS en 1953, haber marchado a Cuba en 1961 como parte del equipo de expertos que la URSS mandó a Cuba debido a las afinidades políticas entre ambas naciones, ¿qué es, entonces, lo que lleva a Virgilio de los Llanos a volver a España a la edad de 67 años, con una esposa rusa y tres hijos? Una 
lectura atenta de la obra de José Fernández Sánchez quizá ayude a entender el por qué del deseo de estos escritores de volver a España y de haber mantenido su identidad nacional bien aferrada a su país de origen. Según Fernández Sánchez, desde muy joven sintió el interés de la URSS por borrar de estos niños cualquier rastro de identidad española, lo que podemos pensar que fue más que suficiente para que esta se acrecentara aún más en muchos de ellos. Confiesa el hecho de que los apartaron de los libros en español, obligándolos a usar los manuales de la escuela soviética, hecho que, con el paso del tiempo, consideró como una "homologación ideológica" (439). Posteriormente, los problemas de movilidad en el país, de inflexibilidad laboral y los impedimentos burocráticos por parte del partido comunista soviético contribuyeron a la creación de una atmósfera complicada para estos niños de la guerra que, además, no habían marchado allí voluntariamente. De este modo, Fernández Sánchez describió su estancia en Rusia como un encierro: "Rusia nos encerró. Rusia, el país que nos dio su lengua, su cultura, su corazón, pero nos encerró, cuando Moscú no tenía por qué ser menos acogedora que Nueva York" (507). Es esta situación la que nos invita a entender el hecho de que perviviera en estos autores una identidad nacional arraigada en España y que imposibilitara el nacimiento de nuevos procesos identitarios que asumieran el movimiento espacial como parte de ellos.

En definitiva, un exilio heredado, la promesa de un pronto regreso, la creación de una burbuja cultural, el surgimiento de una España imaginaria a partir del relato de padres, familiares y de sus "propios" recuerdos, la asunción de su pertenencia a la España refugiada (en su mayoría), así como la realización del viaje de regreso, bien temporal o bien permanente, han resultado en la configuración de una identidad nacional a través de 
la literatura del yo que puede clasificarse, de forma concisa, en dos formas predominantes con la excepción de Federico Patán. Por un lado, encontramos a Carlos Blanco Aguinaga, Angelina Muñiz-Huberman, Jaime Salinas, Gerardo Deniz, María Casares, Enrique de Rivas, Jorge Semprún, Tere Medina, María Luisa Elío Bernal, Emilia Labajos y Fernando Aínsa, quienes han recurrido a la literatura del yo para reflejar su identidad desterritorializada. La experiencia del exilio y la escasez de recuerdos les ha llevado a configurar una identidad sin fronteras espaciales o geográficas que, posteriormente, han decidido abrazar en aras de la multiculturalidad y el rechazo hacia la imposiciones ideológicas como elementos definitorios de su discurso identitario. De este modo, y parafraseando a Sharon Keefe Ugalde, la fluidez, la movilidad, el movimiento a la deriva, el cruzar fronteras sin llegar a ningún sitio se ha convertido en su "nación" (814). Como dice John Durham Peters, "for nomads, home is always mobile. Hence there is a subtle doubleness here: being at home everywhere, but lacking any fixed ground" (21). En oposición a ellos, Tatiana Pérez, Aurea Matilde, Manuel Fernández Montesinos, Virgilio de los Llanos, José Fernández Sánchez, Nieves Cuesta y María Álvarez del Vayo conforman el otro grupo. Estos autores han utilizado su recuerdo de España y el viaje de regreso como elementos a los que agarrarse para permanecer anclados a una identidad nacional española. No obstante, hay espacio para una última reflexión. Mientras que son aquellos que tienen una carrera profesional como escritores más desarrollados los que han llevado a desarrollar una identidad desterritorializada, son, al contrario, esos otros escritores que han recurrido a la pluma en menos ocasiones los que han permanecido firmes a su país de origen. También es curioso que gran parte de estos últimos escritores 
vivieron su exilio bajo dictaduras también, pero de tendencias políticas totalmente opuestas a la que reinó en España durante casi cuarenta años.

En Señas de Identidad, Juan Goytisolo, escritor que pertenecería hoy a la segunda generación de escritores exiliados si su padre, de tendencia franquista, lo hubiese enviado también a otro país para mantenerlo alejado de las bombas y que marchó, por decisión propia, posteriormente al exilio a finales de los años 50, escribe en un diálogo consigo mismo: "suspendido como estabas en un presente incierto, exento de pasado como de porvenir, con la desolada e íntima certeza de saber que habías vuelto no porque las cosas hubieran cambiado y tu expatriación hubiese tenido sentido" (15). De este modo, el ganador del premio Cervantes en 2014 reflejaba otro de los grandes conflictos a los que deben enfrentarse los exiliados y, por lo tanto, los niños de la guerra: la relación temporal tanto con el presente como con el pasado y con el futuro. Y es que, como ya afirmó Mateo Gambarte, el exilio no sólo significó su expulsión del espacio físico, sino también del tiempo histórico: "el tiempo personal y biográfico desaparece para establecerse un tiempo ajeno como referente de la propia personalidad" ("La vuelta" 64).

En el capítulo introductorio había hecho un repaso por los principales estudios teóricos en cuanto a la concepción del tiempo por parte de los exiliados. Por un lado, autores como Tabori o Wittlin afirmaban la existencia de una doble temporalidad. Por otro lado, numerosos críticos habían destacado, o bien el pasado como el único tiempo possible, o bien la integración en el presente del país de acogida. También Claudio Guillén crea el término de "destiempo" para hacer referencia a "ese décalage o desfase en los ritmos históricos de desenvolvimientos que habrá significado, para muchos, el peor de los castigos: la expulsión del presente y por lo tanto del futuro -lingüístico, cultural, 
político- del país de origen" (Múltiples 83). Al mismo tiempo, había explicado, brevemente, el esquema temporal propuesto por Sophia McClennen que tenía como base de análisis la ruptura de una cronología lineal, la existencia de tropos temporales que se repetían en las obras, la presencia de la nostalgia y la infancia como temas recurrentes, así como la existencia de ciclos repetitivos temporales fruto del trauma y los problemas identitarios. También Alicia Alted Vigil establece similares márgenes temporales a los que el exiliado debía acostumbrarse cuando escribe que el reloj temporal se detuvo en el momento de la salida y que la geografia y el marco temporal del país de acogida así como el posible retorno real o imaginario cambió la fisionomía del país de origen que "el exiliado ya no conoce ni se reconoce" (“Exilio, identidad" 246).

De esta forma, si Mateo Gambarte afirmaba que es el tiempo más que el espacio "la gran condena del exilio", es necesario profundizar en la multiplicidad de formas que la segunda generación de escritores explora a través de la literatura del yo para insertarse en el tiempo histórico y poner fin a esa condena, así como en los leitmotiv temporales que se repiten con frecuencia (Los niños 72).

Muñiz-Huberman, en su reflexión sobre la poética del exilio, escribe:

La batalla del poeta con el exilio es con el tiempo. Gusta de guardarlo, de atesorarlo, de crear un ambiguo juego en el que el pasado se vuelve presente y es, a la vez, futuro. Quizá no sepa con certeza en dónde está el transcurrir de su infancia. Tiene dificultades para continuar en la historia. Piensa que la ha perdido y que sólo podrá recuperarla por la escritura. (El canto 179) 
Si hablamos de guardar o atesorar el tiempo, es imposible no señalar a los padres de estos niños como los responsables de ese gusto. Durante mucho tiempo, los padres les prometieron un pronto regreso a España, lo que hizo que el niño viviera un continuo viaje imaginario a ese pasado al que esperaba volver pronto, como si estuviera en una máquina del tiempo, y a partir del cual pudiera empezar a construir su presente encerrando así en una especie de clápsula ese periodo de tiempo fuera de su país de origen que, en un principio, iba a ser breve.

Sin lugar a duda, es Enrique de Rivas uno de los que ha concedido mayor importancia a la configuración del tiempo tanto en su obra de ficción como en sus estudios críticos. Nacido en Madrid en 1931 y tras una doble salida al exilio, primero en 1936 y luego a principios de 1939, publica sus memorias en italiano en 1992, ya que se había mudado a Italia de forma definitiva en 1967. Ahora bien, el motivo de traer a colación aquí a Enrique de Rivas y no a otro escritor de esta generación reside en el título de sus memorias: Cuando acabe la guerra.$^{48}$ De este modo, el hijo de Cipriano de RivasCheriff señala el 1 de abril de 1939 como un punto de inflexión en la cronología de sus memorias. Y es que, hasta entonces, llevaba tres años escuchando esa frase constantemente, tal y como recuerda en su obra: "En mi mundo privado, la guerra era el marco que encuadraba lo transitorio de nuestro estado: «Cuando acabe la guerra ...»»" (Cuando acabe 152). Por lo tanto, los niños de la guerra habían vivido en un limbo temporal durante tres años esperando a que el conflicto terminase y ellos pudieran volver

\footnotetext{
${ }^{48}$ Véase el artículo de Juan Rodríguez, "El mito del retorno en la obra de Enrique de Rivas" para una mayor profundización en la importancia de ese prometido regreso por parte de sus padres en la obra del escritor de origen madrileño.
} 
a casa. Así, es ese 1 de abril de 1939 una fecha clave en la esquematización temporal de este grupo:

Como ellos [sus trece años] parecía acercarse a su término la guerra. Con ella había acabado por desarrollar una relación especial. Por una parte, los sucesos bélicos eran como un reloj que se adelantaba o se atrasaba con respecto a un cenit de tiempo que era esplendorosamente irremediable; por otra, sus manecillas me marcaban por dentro la medida del crecimiento o de su parálisis. Obscuramente presentía yo que el final de la guerra y el principio de mi edad adulta eran una sola cosa. Aunque el deseo de verla acabar era intensísimo, se asomaba ya la sospecha de que acabando, se perdía la forma de vida que yo había conocido, la única verdaderamente, y que por lo tanto le sucedería una especie de vacío amorfo que no lograba imaginar. (Cuando acabe 18)

Ahora bien, no es Enrique de Rivas el único que sitúa el fin de la guerra civil española como momento clave en su concepción del tiempo, tanto personal como histórico, sino que este se repite en muchos otros relatos. Federico Patán afirmaba ser fruto de la guerra civil española: "Después de todo, nazco en una guerra civil y soy producto de ella" (Una infancia 66). También Angelina Muñiz-Huberman toma el conflicto bélico como momento determinante en la concepción del eje temporal: "El tiempo se le hizo presente a Alberina. Lo dividió en 'antes', 'después' y 'durante'" (Castillos 74). El fin de la guerra civil y la victoria de Franco conllevaba, por un lado, la necesidad de buscar unas nuevas referencias temporales en las que insertarse y, por otro lado, la paralización de una línea temporal que tuvo múltiples y profundas consecuencias 
para esta generación. Sin embargo, no es esta la única fecha que aparece constantemente en el relato de los escritores de la segunda generación, sino que, incluso de forma más constante, podemos encontrar la fecha en la que cruzan la frontera, es decir, la fecha de inicio del exilio. Giuliana di Febo se encarga de señalar la importancia de este momento en la formación de la identidad de los niños de la guerra ya que atravesar las fronteras del país de origen marcaba la ruptura con el cordón umbilical materno ("Un espacio" 468). De este modo, este momento determina la muerte del niño y el nacimiento del adulto. Así se refería a ello Manuel Fernández Montesinos; “A mis ocho años, también yo desperté del mío con una voz, la de mi abuelo (...), comprendí que despertaba de la simpleza en que como niño dormido había estado" (15-16). ${ }^{49}$

Otra de las fechas que se repite en muchas obras es, como es obvio, la muerte de Franco. Y es que, aunque a partir de entonces fuera posible el regreso permanente a España, tal y como lo hicieron Rafael Alberti y, posteriormente, María Zambrano, para esta generación la situación se complicó aún más pues, como bien narra Juan Rodríguez, “el exilio que retorna se aferrará, como los durmientes de la cueva, a unos $<<$ signos de identidad $>>$ que ya no serán reconocidos como vigentes" ("El mito del retorno" 116). Y no serán reconocidos como vigentes porque esta generación, como también mencioné ya en la introducción, había dormido en una cueva imaginaria. Por lo tanto, es el retorno, ya sea este de forma temporal o, por el contrario, se trate de un regreso permanente la otra fecha de especial relevancia en la configuración del imaginario temporal de esta

${ }^{49}$ De forma similar lo enunció Tere Medina: "Madrid. Mis once años. El adiós a la niña. El adiós a la paz. El comienzo" (Sobre mis escombros 12). 
generación. Así, María Luisa Elío Bernal comienza su obra con su llegada a Pamplona después de una ausencia de más de treinta años (Tiempo 19). Como apunta Mónica Jato, "el regreso al supuesto hogar introduce, así, pues, un cambio sustancial: altera, inicialmente, la dinámica de esta nostalgia fruto de permanentes rupturas o discontinuidades dentro del tiempo y del espacio por las que se define la condición del exiliado" ("Hacia una imposible" 149). El regreso suponía un enfrentamiento con un momento histórico muy distinto al de su salida. Ahora bien, el regreso no tuvo el mismo impacto en todos los autores de la generación. Este varió según el grado de nostalgia hacia la tierra de origen, hacia la infancia, según lo traumático de la experiencia en cada caso y según la capacidad de cada uno para incorporarse al nuevo país y comenzar una nueva vida. De este modo, mientras que para muchos el viaje de regreso significó lo que ellos ya sabían, es decir, la desaparición de la España que ellos conocían y, por lo tanto, la imposibilidad de su retorno permanente, para muchos otros esto conllevó una lucha interna pues aún tenían la esperanza de reencontrar esa España que abandonaron. Este grupo tenía que asumir así que perdieron su país de origen. Como dice la uruguayaespañola Cristina Peri Rossi: "El país donde quisiéramos volver / ya no existe; / lo perdimos en el intento / de construir el país / donde queríamos vivir" (150). Fue el hecho de que no existiera lo que provocó un fuerte impacto en su identidad y la necesidad de buscar alternativas. Muchos de estos exiliados buscaban en el viaje de regreso a España su infancia. Sin embargo, esta había desaparecido. Esta constatación los empujaba a plantearse un nuevo esquema no sólo en el espacio, como ya abordé anteriormente, sino también en el tiempo. Por lo tanto, veamos cuáles son las múltiples formas de conceptualización temporal que ha provocado la condición de exiliado: 
The condition of exile creates a number of temporal conflicts-a focus on the past prior to exile (i.e., nostalgia), a sense that the exiled person has been removed from the present time of his of her country (but is able to live in the present elsewhere), a feeling of being a part of the cyclical repetition of banishment and exile, and the sense that the exile has been removed from history, and therefore, time altogether (destiempo), floating in an eternal void. (Dialectis 64)

McClannen defiende la coexistencia de todas estas formas en la narrativa del exilio como un rasgo característico, pues "the exile's time is cyclical, mythological, monumental, linear, and historical” (64-65). Esta dialéctica entre las diferentes formas temporales se debe a la propia condición del exilio que es cíclica y eterna y, además, está determinada históricamente. Ahora bien, cabe plantearse si esta definición temporal puede aplicarse también a la segunda generación de escritores, si es cierto que estas formas alternan en las mismas obras de dichos autores, si hay algunos que se decantan por unas o por otras, así como si se establece una jerarquía entre ellas. A esto, cabe sumar que es necesario explorar cómo esta multiplicidad temporal afecta a la construcción identitaria del sujeto. Partamos de un ejemplo de María Álvarez del Vayo que resume la problemática concepción del tiempo en múltiples formas para, posteriormente, poder entender la dialéctica existente entre ellas en otros autores de la generación:

Andando el tiempo, nos íbamos acordando del tiempo de Matusalén, del tiempo de Maricastaña, tiempos todos remotos. No podíamos dar tiempo al tiempo, tan solo a mal tiempo buena cara. Capear el tiempo, ganar tiempo, somos ases en no perder tiempo, sí, a veces tomamos el tiempo como 
viene. El tiempo era para nosotros clave de vida en aquellos aciagos tiempos. Mamá con la solfa, mi padre con el ser y el estar a cuestas, de una clase a otra, (...) Mirándolos bien, dominábamos el tiempo, el tiempo presente. Pero nos fallaba el tiempo indefinido al desconocer el tiempo futuro. ¿Cuánto tiempo nos faltaba para salir de ese tiempo indeterminado que nos hacía polvo? No conocía yo en aquel entonces el tiempo muerto. Ni pensaba en el tiempo perdido. Eso vendría andando el tiempo. Cuando empecé a decir "en mis tiempos". Me di cuenta entonces de que el tiempo había pasado; que el tiempo destrozó un porvenir trazado antes de que los tiempos revueltos nos hicieran cambiar de ruta; que el tiempo se había llevado a los que, desde los primeros tiempos, estuvieron a mi lado. ¡Maldito tiempo! Pensé entonces. No tardé en reparar que el tiempo no se había portado tan mal. Que lo podía hacer mío. ¿Qué era yo sino futuro paso del tiempo? (Los últimos 105)

De la imposibilidad de conectar con el pasado histórico de su país, representado a través de "tiempo de Matusalén” y “tiempo de Maricastaña”, Álvarez del Vayo da paso a la inseguridad por la sensación de un vacío temporal, seguido por la lamentación y la culpa por este tiempo que se escapa hasta la posterior superación de la nostalgia y la búsqueda de un futuro basado en su propia concepción del tiempo.

Junto a María Álvarez del Vayo, también María Casares, Emilia Labajos, Federico Álvarez, Carlos Blanco Aguinaga, Federico Patán o Angelina Muñiz-Huberman son magníficos ejemplos de la convivencia de esa multiplicidad de formas temporales como reflejo de su condición de exiliada. Este abanico de representaciones del 
tiempo-nostalgia, sentimiento de exclusión del tiempo del país de acogida e inserción en el presente de otro lugar, la repetición así como el destiempo- aparece en muchas de las obras de estos autores. Para María Casares, el exilio no empezó el día que cruzó la frontera que la alejaba de España, sino que este comenzó con su marcha de Galicia a Madrid donde su padre asumía sus responsabilidades como ministro de Marina y después ministro de Gobernación de la II República. En este momento María Casares ya inició una difícil identificación temporal que pasaba a ser tiempo contado y no tiempo vivido:

¿Cuánto tiempo pasó entre aquella memorable jornada y nuestra instalación en Madrid? No lo sé. Podría informarme, preguntar, calcular, pero no creo que el número de días, de semanas, de meses, tenga aquí la menor importancia. Sé que a partir de ese momento, La Coruña, Montrove, la calle Panaderas, el océano, el sol, la lluvia y yo, ya no éramos los mismos. Ya sabía yo que a partir de aquel momento no podría seguir con ellos el curso de las estaciones de un cabo del año al otro, que el tiempo de ese país en lo sucesivo me sería contado, y de resultas de ello, mis relaciones con él estaban profundamente perturbadas. (21)

De esta forma, Casares ya se identifica como un sujeto fuera del tiempo histórico de su tierra, pasando a ser un sujeto en Madrid carente de lazos temporales. La escritora gallega ya se sentía "exiliada" en Madrid, por lo que el presente de este tampoco era su tiempo. El abandono de Galicia había significado para ella el fin de su infancia con tan sólo nueve años. Similar sentimiento comparte Emilia Labajos al afirmar en varios momentos que el tiempo ya no cuenta $(33,61)$. Aún de forma más tajante se define Federico Álvarez como un sujeto que "empezaba a vivir entre paréntesis” (163). Además, 
este sentimiento cobra aún más importancia tras la muerte de Franco pues con ello el exilio se hacía eterno al no recuperarse la República por la que ellos habían sido exiliados: "Y fue al cerrarse el paréntesis, en los años setenta, cuando cristalizó la estafa, cuando de verdad empezó el exilio, el definitivo. Nosotros no lo sabíamos pero España, la República, desaparecía” (163). Este sentimiento de estar fuera del tiempo histórico del país de origen puede establecer, en cierta medida, una relación con esa otra esquematización temporal que describía McClennen como repetición cíclica de destierro y exilio, a la que hace referencia tanto Federico Patán como Emilia Labajos. Esta última escribe:

No había encontrado nada, absolutamente nada de lo que me hubiese podido ayudar a establecer un vínculo entre el presente y el pasado que yo no quería olvidar, aquel pasado que yo necesitaba para abrirme el futuro. Había que sobrellevar todo aquello, no rechazar nada, ni siquiera lo que ya no existía, esto último aún menos.

Mis visitas a España consistirían, pues, en descubrimientos de un país que se construía sin mí y que yo debía aprender a recorrer paso a paso. (95) Más adelante, María Casares confiesa haberse creado un propio tiempo que no hacía referencia más que a ella, es decir, hacía referencia al destiempo como elemento característico de su identidad:

Las imágenes precisas y vivas que se presentan a mi memoria permanecen en todo caso vírgenes de toda aportación posterior que pudiera metamorfosearlas, como fotografías fijadas en el tiempo que ninguna nueva visión ha venido a enturbiar, para remodelar solapadamente sus 
contornos, en el recuerdo. A excepción de mi tiempo y de mis propias metamorfosis. (70)

También Federico Patán habla de la creación de un tiempo propio como consecuencia de ese destiempo al que vengo haciendo referencia: "Pero las manos, con sus cinco semilunas cada una, cauterizaban el tiempo, un tiempo triste, calmoso, diminuto, lento; mi tiempo, sólo mi tiempo, para yo decidirlo, para yo conquistarlo, para yo soslayarlo, para yo darle límites ciertos, para que nadie me lo arrebate. Ya no, nadie, nunca" (Último 10). Y referente a Angelina Muñiz-Huberman, Eugenia Helena Houvenaghel afirma que esta, en su prosa, “opta por 'borrar el tiempo' para crear un mundo que carece de tiempo, un mundo que se sitúa 'fuera del tiempo'” (“Angelina Muñiz” 17).

No obstante, el tiempo de la infancia también aparece de forma repetitiva, cíclica en forma de nostalgia que provoca en estos autores el revivir de las heridas de la guerra, Por su lado, María Casares afirma:

La nostalgia del tiempo pleno de mi infancia horada en el centro mismo de mis días, de mis noches, de cada una de mis actividades, una terrible exigencia de lentos recorridos y me sorprendo continuamente rechazando, hasta lo más hondo del espacio interior, el vencimiento. Es como una herida que llevase en el costado -pequeño Amfortas-, siempre cerrada por el impulso vital y desgarrada por la urgencia. (106)

Sin embargo, es especialmente interesante la relación con el pasado que narra Muñiz-Huberman en su obra Dulcinea encantada. Aunque sí aparece la nostalgia de su pasado, la cual aparece reflejada a través del uso del imperfecto, como parte de su 
esquema temporal, muestra un total rechazo hacia el pasado como lugar de refugio o de lamento, representado este a través del pretérito pluscuamperfecto de subjuntivo. Es decir, aunque podemos ver una constante referencia a la infancia y a la nostalgia por esta, la autora no le concede un lugar primordial, sino que asume su pérdida a través de la aceptación y huyendo así de una relación traumática con esta:

Hay un tiempo verbal que no soporto. El pretérito de subjuntivo. Si no hubiera estallado la Guerra Civil. Si mis padres no me hubieran embarcado a Rusia. Si no hubiera llegado a México. Si no viajara, en este momento por el Periférico si no hubiera nacido. Si ya me hubiera muerto.

Tiempo de hipótesis imposible. Tiempo de deseo negado. Tiempo de la más inoportuna melancolía. Tiempo de lo que pudo haber sido y no fue. Tiempo de la acción que no sucedió. De todas las desesperanzas del hombre: si hubiera. De todos los errores: si hubiera. De todas las desmemorias: si hubiera. (...)

Desde entonces no existe ese tiempo. Tiempo inútil y quejumbroso. Tiempo inmoral. Borrado.

¿Y el imperfecto, Dulcinea? El imperfecto sí me gusta. Tan imperfecto. Tan habitual. Tan cotidiano. Tan sedoso. Solía. Hacía. Escribía. Nevaba. Escuchaba. Caminaba.

Tiempo de la costumbre. Tiempo de la chimenea. Tiempo cálido en noche de invierno. De preparar el samovar y de beber el té. (...) Érase que se era. Las memorias de la infancia. Mi madre me decía.

Buen tiempo y buena cara. (95-96) 
Este rechazo hacia el subjuntivo es también un rechazo del aspecto negativo del exilio y es que, como Mateo Gambarte había señalado también, el gran número de exiliados llevó a muchos de ellos a aferrarse a un profundo sentimiento de victimización ("El exilio, los exiliados hispanomexicanos" 73). De hecho, Arturo Souto, escritor de la segunda generación, se quejaba también del hecho de que los exiliados se hubieran enfocado en la negatividad del fenómeno, lo cual había impedido, durante mucho tiempo, la aceptación de este como la ventana hacia un nuevo mundo: "Lo que más sorprende, sin embargo, es que no se haya visto sino el aspecto negativo del problema. Porque esta dualidad tiene también un indudable lado de luz, es decir, la conciencia y aceptación de una realidad, una realidad quizá más rica por su doble perspectiva” (332). ${ }^{50}$

Asimismo, Casares también muestra su desvinculación con el pasado/presente de su país de origen y su inserción en el presente del país de acogida. La muerte de una forma de ser en España había dado origen al nacimiento de otro yo:

${ }^{50}$ María Teresa González Garay también aborda la doble forma de entender el exilio, tanto la positiva como la negativa, al abordar el estudio de la obra de Carlos Blanco Aguinaga, Un tiempo tuyo, a partir de los estudios de Claudio Guillén sobre Ovidio y Plutarco:

El fenómeno del exilio está en el origen de la historia del hombre. No sólo en las versiones bíblicas de la expulsión del Paraíso. El desplazamiento y las migraciones son universales y difíciles de clasificar, pero hay respuestas que históricamente se han dado al tema del exilio, muy eficaces, en la literatura clásica. Una es la llamada por Claudio Guillén actitud ovidiana y representa una sensibilidad negativa, centrada en la protesta, en la lamentación y en la nostalgia. (..)

La otra actitud es la ya mencionada en los escritos de consolación frente a las penas del destierro. Llamada plutarquesca, presenta el destierro como una posibilidad de fortalecer al individuo con una nueva vida. Plutarco explica que el ser humano tiene más posibilidades de comprender lo que comparte con los demás hombres según se muda de sociedad y lugares ("Memoria" 112). 
De lo que hubiera podido ser si nada hubiera sucedido, no sé más de lo que sé sobre lo que yo era antes de mi nacimiento o de lo que seré después de mi muerte, y la sola certeza que me queda es que a la edad que tenía y en la situación en que me encontraba cuando estalló, fue para mí fin y muerte de un modo de ida, pero también comienzo y renacimiento. (111)

Por otro lado, Carlos Blanco Aguinaga corrobora su sensación de exilio del presente de su país de origen, pero en su capacidad para reinsertarse en otro tiempo histórico cuando se reafirma en la continuidad que establece entre su pasado en España y su nuevo presente histórico:

Termina, pues, aquí una manera de vivir la niñez y de recordarla casi como quien recuerda la desaparición de un paraíso perdido y empieza otra etapa en la que, por supuesto, se repiten comportamientos infantiles y la continuidad es —para mí— clara, según recuerdo cómo iba creciendo. Pero ya en otro contexto, con un algo oscuro por dentro, la ausencia de Irún y de mi calle, lo que, quiéralo o no, me marca por siempre de varias y diversas maneras. Tal vez esa calle Santiago sea el mito que me hace creer en mi continuidad. (Por el mundo 55)

También en la obra de Federico Álvarez aparece una referencia a esa doble temporalidad a la que hacía referencia Tabori cuando escribe: "Eugenio fue corriendo a buscar sus patines. El tiempo se detuvo un instante mientras yo subía las escaleras. Y, en seguida, otro tiempo empezó. Un tiempo doble: ¿se pueden vivir dos vidas al mismo tiempo?" (162). 
A través de estos múltiples ejemplos queda en evidencia la teoría de McClennen que señala al exilio como el causante de la confluencia de una multitud de esquemas temporales. Y, al igual que en el análisis que hace McClennen en el caso de Goytisolo, Peri Rossi y Dorfman, tampoco en el caso de ninguno de estos escritores puede afirmarse que estos enfaticen una visión sobre la otra, sino que navegan entre ellas haciendo muy difícil afirmar qué organización temporal prevalece (71). Ahora bien, es a partir de las teorías feministas de Kristeva que McClennen sugiere que esta combinación temporal es una forma de enfrentarse al discurso identitario temporal proyectado desde los círculos de poder y que la construcción de una relación temporal basada en la suma de múltiples organizaciones temporales es la herramienta desarrollada para mostrar su rechazo hacia cualquier rasgo de complicidad con las bases ideológicas del autoritarismo (72). De esta forma, este discurso identitario-temporal no es fruto únicamente de la condición de exiliado sino también una respuesta hacia las ideologías fascistas de sus países de origen. Por lo tanto, si recuperamos la idea de sujeto nómada de Braidotti que entendía el nomadismo como una forma de oponerse a las convenciones sociales, podemos afirmar que este discurso identitario-temporal es una faceta de ese sujeto nómada. Es decir, no sólo se enfrenta a los sistemas de poder a través de una nueva identificación con el espacio, sino que también lo lleva a cabo a través de una nueva esquematización temporal basada en la aceptación de múltiples formas o, dicho de otra forma, en la supresión de conflictos entre los diferentes momentos históricos del sujeto que, a su vez, corresponden con diferentes naciones y etapas de su vida.

Ahora bien, sería erróneo afirmar que este discurso temporal es común a toda la generación puesto que, a excepción de los autores mencionados en los ejemplos 
anteriores, así como de María Luisa Elío Bernal y Jorge Semprún, a los cuales me remitiré en sus capítulos correspondientes, y de algún otro escritor de forma menor, es imposible encontrar dicho discurso identitario-temporal en el resto de narradores. Esto se debe principalmente a dos motivos: por un lado, existe un grupo de autores al que pertenecen Nieves Cuesta, Virgilio de los Llanos o José Fernández Sánchez, entre otros, en cuyas obras sí se establece una jerarquía de una de las formas temporales; concretamente muestran un enfoque en el pasado y conceden a la nostalgia un papel protagonista en sus obras. Tal es así que todos estos autores, en su madurez, vuelven de forma definitiva a España. En el caso de los dos diarios, el de Conchita Ramírez y el de Conxita Simarro, la inmediatez del relato impide también una profundización en este tema; por otro lado, existe un grupo de obras tan cercanas al relato testimonial, en el sentido más tradicional del término, que esto impide una profundización en el estudio del discurso identitario-temporal de estos autores, como es el caso de Ángel Fernández, Fernando Barral o Isabel Argentina Álvarez, ya que los autores se aferran a un relato "objetivo" de los acontecimientos impidiendo al lector entrar en la intimidad de estos. ${ }^{51}$ De hecho, Paula Simón, en referencia a esta última escritora, destacaba la ausencia de introspección a favor de los acontecimientos históricos-políticos (312). Algo similar sucede con la obra de Michel del Castillo, a la que había calificado denominado en el capítulo anterior de docuficción.

${ }^{51}$ Mary S. Vázquez se ha encargado de señala que la obra de Ángel Fernández consta de 86 páginas de copias de correspondencia y documentos de archivos, lo que es prueba suficiente del carácter testimonial de esta obra (610). 
En 1949 Francisco Ayala ya se planteaba uno de los grandes problemas del exiliado: “¿Para quién escribimos nosotros? Yo, español en América, ¿para quién escribo" (36). La falta de un público receptor de sus textos y la distancia entre su lenguaje y el del país de acogida dejó a los exiliados en un limbo literario que no sólo afectó a los escritores consagrados, sino también a las futuras promesas. ${ }^{52} \mathrm{Y}$ es que, tal y como afirma Angelika Bammer, el lenguaje es un símbolo de identidad fuertemente vinculado al hogar en el caso de desplazamientos: "For, at once carrier of national and familiar traditions and emblem of cultural and personal identity, language functions equally as an identity-grounding home under conditions of displacement and a means of intervention into identity-fixing cultural agendas" (XVI).

Por lo tanto, detrás de esta pregunta que se hacía Francisco Ayala se esconden dos de los retos a los que tiene que enfrentarse cualquier escritor exiliado: por un lado, cómo utilizar el lenguaje para representar una realidad distinta a la que se relata desde los círculos de poder, teniendo en cuenta que dicha representación no puede ser recibida en el país de origen debido a la censura y que carece de especial trascendencia para el público del país de acogida; y, por otro lado, en qué lengua escribir y cómo crear un lenguaje propio capaz de reflejar su identidad. Es, por lo tanto, necesario dibujar un mapa lingüístico que aclare en qué lengua escriben los autores de esta segunda generación, así como investigar de qué forma se refleja la influencia entre ambos idiomas para, en un segundo nivel, profundizar y analizar dicho lenguaje como resultado de su identidad

52 Para saber más sobre el lugar de la narrativa del exilio, acúdase a Fernando Larranz: "El lugar de la narrativa del exilio en la literatura española" que ofrece un recorrido sobre el lugar de esta a partir de las obras más importantes de la historia de la literatura española. 
transcultural y, al mismo tiempo, entender el uso de este lenguaje como sistema para crear un discurso identitario diferente al propuesto desde las esferas políticas predominantes en España, no sólo durante el régimen de Franco, sino también en los años de democracia tras la muerte de este.

Parece evidente hacer una diferenciación entre aquellos niños que fueron a parar a países en los que se hablaba el mismo idioma que en su país de acogida, tales como México, Cuba o Uruguay, y aquellos que tuvieron que enfrentarse al reto de un nuevo sistema comunicativo durante numerosos años, como es el caso de todos aquellos niños cuyo destino final fue Francia, la URSS, Argelia, Bélgica o Reino Unido. En este segundo grupo, el trauma creado por la confrontación lingüística es, sin duda, más profundo y ocupa un mayor espacio en sus obras autobiográficas. Así tenemos el caso de Jaime Salinas quien sentía rechazo hacia su familia por no hablar la lengua del país de acogida, el inglés: “Creo que llegué a sentir rencor hacia ellos por ser extranjeros, por no hablar la lengua del país, por vivir en un mundo que nada tenía que ver con el de Bobby, con el mío" (151). Contrario a él está el caso de José Fernández Sánchez, quien culpa al país de acogida del empobrecimiento de su lengua de origen que, como él también afirma, era símbolo de su españolidad: “Al llegar a Cuba comprendí las razones de la repulsa de aquel muchacho. Nuestro idioma era torpe y rebuscado, triste despojo de algo que alguna vez había sido vivo. Y no sólo eran las palabras” (317). Virgilio de los Llanos, quien había regresado a España después de 54 años en la URSS, confiesa seguir pensando en ruso a pesar de estar ya en territorio español: “¿En qué lengua pensará mi cerebro aquí? Hasta ahora sigo pensando en ruso, mientras mi mente traduce rápidamente los pensamientos, las preguntas y las respuestas cuando tengo que hablar en español" 
(250). Es significativo el caso de Aurélia Moyà-Freire ya que, a pesar de tener tan sólo 14 años y con el limitado conocimiento que una niña española pudiera haber adquirido del nuevo idioma en la escuela, comienza a escribir su diario en francés, Ma vie en France: Cahier d'exil d'une adolescente espagnole, 1939-1943, y únicamente realiza una copia de este en español cuando se lo aconseja un profesor exiliado. Además, ella misma explica el por qué de su esfuerzo: “Je m'efforce d'apprendre le français, puisque la guerre a détruit tous mes projets d'avenir, ici je profiterai pour apprendre ce que je pourrai, plus tard ça pourra peut- être me servir” (36).

No obstante, tampoco podemos olvidar el hecho de que muchos de estos niños que fueron a parar a países con los que compartían el mismo idioma pasaron largos periodos de tiempo, durante los cuales estuvieron escolarizados en muchos casos, en Francia. Por lo tanto, también se enfrentaron, aunque por un espacio más corto de tiempo, a la necesidad de adquirir un nuevo idioma. Esto conllevó un impacto en su configuración identitaria, tal y como recuerda Gerardo Deniz, cuyo destino final fue México: "Primer año de primaria, felizmente truncado. En castellano, fábulas de Iriarte y Samaniego, un enorme cuento español y casi nada más. En francés, muchos relatos, demasiada condesa de Ségur, mis dos primeros Vernes. Por encima de todo, el diccionario de Larousse" (10). De esta forma, el escritor de origen madrileño y que durante su vida aprendió más de diez idiomas, recuerda la marca que le produjo enfrentarse a un nuevo lenguaje que le permitió acercarse a una nueva cultura, la de la condesa de Ségur y las obras de Vernes. Además, es significativo el hecho de que ubica el diccionario de Larousse "por encima de todo" si entendemos este como un nexo de unión entre dos idiomas, es decir, entre dos culturas. En definitiva, aunque se trate de una 
generación prácticamente políglota en su totalidad, ¿en qué lenguas escribieron los niños de la guerra?

Por un lado, tenemos a un minoritario grupo de autores que escribieron sus obras exclusivamente en el lenguaje que aprendieron más allá de las fronteras españolas. Este es el caso de Miguel Martínez López, Isabel Fernández y María Casares. Todos ellos escribieron sus obras en francés, marcados por el profundo deseo de insertarse cuanto antes en la sociedad de acogida y borrar así cualquier trazo de su identidad española que pudiera hacer que fuese discriminado ${ }^{53}$. Frente a este grupo, encontramos a otro grupo mayoritario de autores que se sirvieron de su lengua de origen para expresar sus experiencias: María Luisa Elío Bernal, Tere Medina, Fernando Aínsa, Carlos Blanco Aguinaga, Gerardo Deniz, Angelina Muñiz-Huberman, Federico Patán, Jaime Salinas, Manuel Fernández Montesinos, José Fernández Sánchez, Ángel Fernández, Virgilio de los Llanos, Luis Santamaría, Aurora Correa, Conchita Ramírez, Conchita Simarro, Manuel Arce, Isabel Argentina Álvarez, Aurea Matilde, Tatiana Pérez y Federico Álvarez. También utilizaron su lengua de origen, aunque no el español, sino el catalán, Carles Gerhard i Hortet y Amadeu Cuito. No obstante, existe un grupo de autores que utilizó tanto la lengua de su país de origen, como la de su país de acogida, entre los que se encuentran Jorge Semprún, María Álvarez del Vayo, Enrique de Rivas, Michel del Castillo y Aurélia Moyà-Freire. Ahora bien, ¿qué implicaciones conllevan estas elecciones en cuanto a su formación como sujeto?

\footnotetext{
${ }^{53}$ Esto no debe interpretarse como un rechazo hacia sus raíces españolas, sino como un deseo de adaptarse a las circunstancias de su nueva situación como sujeto.
} 
Más allá de la lengua que cada escritor decidiera utilizar a la hora de narrar el impacto del exilio en su vida, la mayoría de estas obras muestran unos claros rasgos de transculturación idiomática, puesto que es posible rastrear la existencia de puentes lingüísticos tras los que se esconden conexiones entre los diferentes mundos a los que se han enfrentado estos niños de la guerra. En su trabajo "Exolalia and Dictatorship: The Tongues of Hispanic Exile", Paul Illie crea el concepto de "graphocentrism" para hacer referencia al lenguaje del exiliado como un lenguaje carente de vinculación a ninguna nación en particular, sino que huye de toda clasificación nacional (246). Sin embargo, una lectura atenta a las obras de la segunda generación no demuestra, a mi parecer, esa ausencia de unión a la nación, sino que, contrariamente, permite establecer lazos no solo a una nación, sino a varias. Ahora bien, la diferencia es que estos lazos no son restrictivos ni tampoco es posible establecer una jerarquía entre las naciones a las que se vincula, sino que se trata un lenguaje que, como afirma McClennen, "crosses borders or becomes more nationalistic, at times within the same text" (Dialectics 124). Es decir, sí es posible hablar de un lenguaje sin anclajes a una particular nación, como decía Illie, pero no por ello totalmente desnacionalizado, sino que es la suma de naciones y el discurso entre ellas lo que lo convierte en un lenguaje propio del exiliado.

En su artículo "Invitación a un exilio", Federico Patán hace referencia al constante diálogo existente entre su español de España y su español de México, así como a las interpretaciones que los diferentes críticos han hecho de ello. De esta forma, a lo largo de su discurso encontramos referencias tales como: "donde mis padres son asombrosamente jóvenes, mi rostro demasiado ingenuo y mis caireles (mis chinos pudieran decir en México)” (215); “tanto años más tarde y sólo ante la pantalla de mi ordenador 
(computadora)" (216); "Camino de la escuela gente del pueblo me saludaba: 'Adiós, güero' (es decir, alguien de tez blanca o de pelo claro)" (218); o, "mal había hecho yo en meterme en esos berenjenales (para emplear una expresión poco mexicana)" (223). Todos estos ejemplos, en los que observamos abundantes referencias y aclaraciones tanto respecto al español de México como al de España, no hacen más que reforzar los lazos existentes entre la lengua y, en este caso, las dos naciones a las que Federico Patán estaba vinculado. No cabe olvidar que, al hablar de la construcción identitaria nacionalista, habíamos señalado la doble identidad cultural con la que se reflejaba el escritor residente en México. El autor es consciente de utilizar un lenguaje transcultural. Tal es así que ante el comentario de un amigo suyo quién, tras leer su novela, le dijo "que se había tropezado con un idioma español traducido al mexicano", él afirma que su "condición anfibia en cuanto al idioma" es el resultado de su "condición de biculturalismo" y, por lo tanto, de su "origen en el exilio" (225). Por otro lado, Jaime E. Cortés, al que hace referencia también Patán en el artículo ya mencionado, le confiesa que, para él, su prosa estaba "llena de extranjerismos: aquellos provenientes del español peninsular" (229). Si prestamos atención a la obra de Tatiana Pérez, Memorias de Lara, encontramos la constante presencia de términos rusos en un relato escrito en español. Así, al inicio del capítulo dos encontramos: "Katerina Vasílievna, la educadora de turno del diétsky dom, entró en el dormitorio de las niñas. (...) El dormitorio se hallaba en el segundo piso de una bonita dacha con jardín. (...) Por debajo de la nieve se asoman las alegres florecillas azules de la primavera, vasilki'" (20-21). El uso de estos términos en ruso no viene provocado por la incapacidad de escribir estos términos en español pues ella misma 
incorpora notas a pie de página con una traducción al español, sino que son reflejo de una identidad lingüística transcultural. ${ }^{54}$

Podemos encontrar ejemplos similares en las obras de María Luisa Elío Bernal y Jorge Semprún, cuyo análisis se desarrollará en los próximos dos capítulos. De esta forma, Rosi Braidotti considera la imagen del políglota como una "variación sobre el tema de la conciencia crítica nómade; estar situado entre dos lenguas es estar colocado en un punto ventajoso para deconstruir la identidad" (43). Por lo tanto, a la luz de los ejemplos, ya sean bien dos lenguas diferentes o incluso dos dialectos de la misma, los niños de la guerra se encuentran en un punto ventajoso para formar su identidad, aunque no sea esta la percepción de todos ellos, tal y como quedó demostrado con el ejemplo anterior de José Fernández Sánchez. De hecho, también Braidotti asegura que el carácter sagrado de la lengua materna tiende a aparecer en aquellos individuos que hablan más de un idioma y han estado expuestos a situaciones multiculturales (43).

Ahora bien, estos ejemplos de interferencia lingüística no son más que el resultado de la construcción de un discurso lingüístico identitario diferente al propuesto desde los círculos de poder. Su condición involuntaria de exiliado les hace ser conscientes de pertenecer a un sector social silenciado, enfrentado al sistema imperante en el poder y, por lo tanto, sin capacidad de ser escuchados. Prueba de ello es que la mayoría de estos escritores dan a conocer sus obras tras la muerte de Franco, surgiendo así un boom primero en los años 80 y, posteriormente, ya en el siglo XXI, momento en el

\footnotetext{
${ }^{54}$ Cabe aclarar también que Tatiana Pérez dedicó toda su vida a la traducción entre el ruso y el español, ya que fue profesora de traducción en el Instituto de Traductores y Lenguas Modernas de la Universidad Complutense de Madrid, y se convirtió en una de las traductoras más importantes de Leon Tolstoi e I.S. Turguéniev.
} 
que sus historias se ven amenazadas por un silencio perpetuo debido al poder irrevocable de la muerte. De esta forma, tal y como comenté en el apartado anterior al hablar de los motivos que había llevado a esta generación a escribir sus obras autobiográficas, es un rasgo en común de esta generación el querer construir un discurso identitario cultural diferente al existente a través del lenguaje. El lenguaje se convierte así en una herramienta de resistencia para luchar contra una identidad cultural vinculante únicamente a una nación. Como bien afirma McClennen:

The crisis of language is a constant element in exile texts (...). These texts trace territories as they attempt to narrate an experience in relation to geographical space. They cannot reproduce 'the reality' of this story, but they can trace it, using language as their tool. At the same time, they outline the spatial and historical lines of their experience, they also strike out into new and unmapped territory, making marks in the margins. Now the borders of identity are blurred, not reinforced. Culture becomes a notion that avoids description and escapes location. Therefore, at the same time that these contexts construct visible signs of a former identity characteristic of their national, political, and gendered origins, they also mark the spaces beyond those lines that now represent the instability and incommunicability of their experience and their identity. (Dialectics 130)

María Casares, reflexionando sobre las razones que le llevaron a escribir su autobiografía, aclara que esta es fruto de "la construcción sin cesar recomenzada de un hogar, de una familia, de raíces reinventadas, de amistades y de amores renovados y sostenidos a pulso" (105). De esta forma, el lenguaje funciona como método para 
construir una nueva identidad que difiere de la de aquellos españoles que apoyaron al régimen franquista. Y es que, María Casares, quiere construir a través del lenguaje una obra que represente una identidad silenciada que, como ella misma afirma, es cada vez más frecuente. Se convierte así en la representación de unos ideales y de una identidad que se ha anclado en el desplazamiento:

Pero éstos no son más que contratiempos, más bien divertidos, cuyo único interés reside en el hecho de que siguen representando el singular destino del patito feo del cuento de Andersen, una historia que, poco a poco, se reproducía cada vez con mayor frecuencia en el mundo entero, a fin de llenarlo todo de patos feos, llegados de todos los confines del horizonte para extenderse por todas partes, para aprender un nuevo idioma y una nueva forma de existencia aun intentando permanecer fieles a lo que eran, para convertirse poco a poco en los únicos representantes de esta noción de fidelidad que se va perdiendo y para buscar -nuevos nómadas- un suelo donde poder implantarla; pero cuya verdadera identidad - suceda lo que suceda y hagan lo que hagan - seguirá siendo siempre la de personas desplazadas. (354)

Por consiguiente, y recuperando las teorías de Judith Butler que exponía en el capítulo primero, los escritores exiliados buscan crear un discurso identitario a través del lenguaje que ponga fin a las relaciones entre poder y sujeción, buscando así su propio espacio como sujeto nómada que no necesita de un espacio geográfico para crear su propio discurso identitario con su propio tiempo y su propio lenguaje, un discurso basado en la multiplicidad de formas y en la transculturalidad como elemento base. Es decir, es 
su conocimiento de varias lenguas lo que convierte su escritura en un proceso que anula "la ilusoria estabilidad de identidades fijas, de hacer estallar la burbuja de la seguridad ontológica que proviene de la familiaridad con el sitio lingüístico de cada uno" (Braidotti 47). Y es que como sujetos nómadas, la escritura es siempre "the practice of outside" (Joris 30). Por lo tanto, a pesar de la frágil conexión entre el sujeto y el lenguaje debido a la pérdida de identidad causada por el exiliado y al silencio impuesto por los gobiernos autoritarios, los niños de la guerra consiguen recomponerse y buscan en él un espacio propio donde testimoniar la conexión "between language, the self, and history" (McClennnen, Dialectis 130). 


\section{Capítulo IV}

\section{María Luisa Elío Bernal: "Y Ahora Me Doy Cuenta Que Regresar Es Irse"}

\section{Semblanza biográfica}

A pesar de que Carlos Fuentes o, mejor dicho, su personaje Laura, describiera a María Luisa Elío Bernal como una “mujer frágil, esbelta y elegante que en su casa caminaba descalza, como un gato seguida por otro gato que posaba como el doble de su alma deseada y envidiada a la vez por toda la raza felina a causa de su perfil agresivo y su débil mentón, sus ojos de melancolía y su risa abarcadora, incontenible” (pos. 7555 7558), indagar en su personalidad resulta ser una misión casi imposible de acometer debido a las numerosas facetas de esta en diferentes momentos de su vida. Fue una niña que dejó de serlo demasiado pronto, una mujer que llegó a ser mujer demasiado tarde, una esposa en una relación de fuertes caracteres, una madre a la que le costó ser madre, una fiel cuidadora de la mujer que le dio la vida, una mirada de incomprensión hacia la figura paterna, una eterna hermana, una musa de las letras y una pluma creativa.

No obstante, todos estos elementos son entresijos de una vida marcada por un conflicto bélico y las consecuencias derivadas de este. Para poder analizar posteriormente de qué forma Historia e historia se unen en María Luisa Elío Bernal, es imprescindible investigar sobre su propia historia primero. Cabe aclarar que no es mi objetivo aquí la escritura exhaustiva de su biografía, pues esto ya ha sido acometido por otros investigadores, sino la de esclarecer los momentos claves que arrojen un poco de luz sobre los episodios que marcan la configuración de su identidad. Para llevar a cabo esta tarea, son numerosas las fuentes de información que he utilizado: en primer lugar, su propia obra, tanto la fílmica como la escrita (más adelante se analizará el contenido 
autobiográfico de estas); asimismo, las obras de Eduardo Mateo Gambarte, María Luisa Elío Bernal. La vida como nostalgia y exilio y Exilio, infancia perdida, identidade imposibilidad de retorno. En el balcón vacío de Jomí García Ascot y María Luisa Elio Bernal; no menos importante es la entrevista que su hermana Cecilia me concedía en el año 2014 con motivo de la investigación de mi tesis de máster. Y, finalmente, toda una serie de testimonios y relatos que amigos y conocidos de su entorno han otorgado con motivo de algunas entrevistas e investigaciones realizadas en torno a En el balcón vacío y la figura de María Luisa Elío Bernal.

En una familia bien avenida de Pamplona nació María Luisa Elío Bernal el 17 de agosto de 1926. Ni ella, ni sus padres, Luis Elío Torres y Carmen Bernal López de Lago, ni sus dos hermanas, Carmenchu y Cecilia, podían en aquel entonces sospechar que sólo diez años más tarde, el 18 de julio de 1936, su vida se desmoronaría para siempre.

Sus padres, casados desde 1920, procedían de buenas familias. Por el lado paterno, Luis Elío emparentaba con los Duques de Elío y el Conde de Guendulain, así como con la familia Vidarte. Además, la familia de Luis poseía un patrimonio notable, hasta el punto de ser considerada los segundos propietarios con más terrenos en Navarra. En el momento de la herencia, el padre de María Luisa Elío Bernal recibió numerosas tierras y, entre ellas, el pueblo de Barañáin, siendo este uno de los causantes de la desgracia familiar, como se explicará más adelante. Por el lado materno, Carmen Bernal pertenecía a la clase acomodada de Madrid, llegando a entroncar su padre con la reina de Bélgica, Fabiola de Mora y Aragón, de la que era primo. Don Luis Elío era Juez Municipal de Pamplona desde 1928 y, además, presidente de los Comités Paritarios, mientras que su madre se dedicaba al cuidado de la casa ayudada por el servicio. A pesar 
de proceder ambos de familias conservadoras, con tendencias de derecha, María Luisa Elío vivió en una familia profundamente religiosa, con ideas republicanas y liberales. Fueron estas ideas las que llevaron a Don Elío a repartir las tierras de Barañaín entre los trabajadores del pueblo. Así relataría este acontecimiento María Luisa Elío a su hijo durante el viaje de regreso: "Hay algo que me gustaría que recordaras de mayor, y es que el abuelo regaló todas las casas del pueblo a quienes vivían en ellas, con una parte de tierras" (Tiempo 33). Este hecho altruista fue el detonante de su detención en el momento de la sublevación, ya que debido a esto se le consideró comunista, tal y como relata el propio Elío en una conversación con el comisario recogida en su libro: "A usted, que es el primer terrateniente de este término, le ha dado últimamente por repartir entre sus colonos sus casas y sus tierras. ¡Si esto no es comunismo, dígame qué cosa es!” (Tiempo 37). Sin embargo, tras ser detenido, consiguió escapar con la ayuda del capitán requeté Generoso Huarte. Este consiguió que Blas Inza, que había sido administrador de las tierras de su padre, lo ocultase en su casa durante tres años hasta que, a finales de agosto de 1939, consiguió cruzar la frontera francesa, momento en el que se entregó a la policía francesa y fue ingresado en el campo de concentración de Gurs.

Mientras que D. Luis permanecía escondido de las tropas sublevadas, Carmen escapó con sus tres hijas hacia Elizondo con la intención de cruzar la frontera y reunirse con su marido en tierras francesas en algún momento. En aquel entonces tenían indicios de que Luis Elío podía haber escapado, aunque en el trayecto les llegó la noticia de su muerte. Sin embargo, el camino no fue fácil y fueron detenidas por las tropas falangistas durante tres meses. Es en este tiempo cuando María Luisa presenció la desaparición de un preso republicano, "el rojo", episodio que afectaría profundamente a la memoria de una 
niña: "Tomar el mismo autobús, llegar al mismo lugar y, sobre todo, tratar de enterarme quién era aquel preso — mi preso—, cómo se llamaba, dónde está enterrado, ¡en fin!, estar con él” (Tiempo 61). Tras salir de la cárcel, consiguieron salir de España con la ayuda de Javier Arvizu, entrar en Barcelona y llegar hasta Valencia donde le esperaba la hermana de Carmen, Cecilia. Durante su estancia en esta ciudad portuaria, las niñas fueron aún más conscientes de la guerra, ya que fueron testigos de los bombardeos en primera fila. Posteriormente, se trasladaron a Barcelona, donde la madre empezó a trabajar en las oficinas de Indalecio Prieto. Finalmente, marcharon a París, ciudad en la que las tres hermanas comenzaron a estudiar francés. Unos meses más tarde, se produjo el anhelado reencuentro: Luis Elío consiguió reunirse con su familia en la capital francesa y, tras unos meses, toda la familia marchó a México con unos billetes financiados por la JARE, a través de un préstamo del señor Mombrison y con algún dinero que aún conservaba la familia. El 14 de febrero de 1940, María Luisa Elío Bernal, junto a su familia, pusieron rumbo hacia un mundo que, desde entonces, debió convertirse en su mundo de manera forzosa.

A pesar de los problemas que tuvieron al entrar en territorio americano por Ellis Island, consiguieron llegar a México D.F. el 19 de marzo de 1940, donde ya disponían de una casa que Indalecio Prieto les había proporcionado a cambio de proteger uno de los mayores tesoros de la República: el tesoro del Vita. ${ }^{55}$

${ }^{55}$ Así se conoce a las joyas y otros objetos de valor pertenecientes al gobierno de la República fuera de España, valorado en más de cincuenta millones de dólares (Domínguez Prats 97). Es a esta historia a la que hace referencia el último libro póstumo de la autora publicado por su hijo y titulado Voz de Nadie. 
A mitad de 1941 sucedió algo que marcó también de manera importante la vida de María Luisa Elío: la separación de sus padres, viéndose obligada a elegir entre uno de ellos. Se quedó, al igual que sus hermanas, con su madre, que tenía graves problemas de salud. Además, a partir de este momento la situación económica de Carmen y sus hijas empeoró y pasaron por toda una serie de estrecheces económicas. No sólo las pasaron Carmen y sus hijas, sino también Luis, en Acapulco, que tuvo que vivir los últimos años de su vida refugiado en casa de su hija Carmen.

María Luisa Elío Bernal estudió en la escuela de Juan Ruiz de Alarcón, en primer lugar, y luego pasaría a una escuela de comercio. ${ }^{56}$ El colegio Juan Ruiz de Alarcón estaba, como otras instituciones creadas en esa época, a cargo de la República para reunir así a los exiliados, lo cual tendrá una importante repercusión cuando, posteriormente, señale los problemas de inserción en el país de acogida. Durante estos años entró en contacto con Inocencio Burgos, Federico Patán, Angelina Muñiz y Magda Donato quien la invitó a trabajar en el teatro infantil que dirigía. De esto nació su pasión por el teatro, lo que la llevó a estudiar en la Academia del profesor Seki Sano, quien estaba dispuesto a cambiar el teatro mexicano. Posteriormente, en los años 50, formó parte del teatro experimental y vanguardista «Poesía en voz alta», donde también colaboraban Octavio Paz, Juan José Arreola, y Leonora Carrington, entre otros. ${ }^{57}$ Actuó en la obra de Paz, La

\footnotetext{
${ }^{56}$ María Luisa Elío disfrutó de beca para estudiar en la escuela Juan Ruiz de Alarcón, como así lo hacían todos los empleados de la JARE según datos de Pilar Domínguez (161).

${ }^{57}$ Proyecto teatral iniciado bajo la dirección de Juan José Arreola y Octavio Paz entre 1956 y 1963. Consta de un total de ocho programas. Se propone recobrar el espíritu original del teatro y su carácter mágico a través de la recreación poética sin delimitaciones o nociones pre-concebidas.
} 
hija de Rapacine. También trabajó en algunas películas de la época; colaboró en distintos medios periodísticos con cuentos y leyó algunos de ellos en el Ateneo Español de México.

En 1952 se casó con Jomí García Ascot, al que conoció trabajando en la oficina de turismo francés. Desde ese momento, ambos formaron a pasar parte de la vida intelectual mexicana, participando así de las actividades en los múltiples cine-clubs. ${ }^{58}$ Allí pasaron a formar parte del círculo de Emilio Prados, Luis Buñuel, José Gaos, José de la Colina, Juan Rulfo o Salvador Elizondo, entre otros.

En 1959 la pareja marchó a Cuba, ya que Alfredo Guevara había invitado a Jomí a colaborar con el ICAIC (Instituto Cubano de Arte e Industria Cinematográfica). Fue durante este tiempo cuando comenzó a escribir las primeras notas de En el balcón vacío: “Allí en Cuba me encontré de nuevo con lo hispano: con los carabineros, la gente con fusiles ... y empecé a sufrir una especie de fiebre nerviosa. Me sentí completamente sumergida en Angustia, hecha un desastre. Pero, curiosamente, logré liberarme escribiendo. Y fue entonces cuando escribí En el balcón vacio" (Ulacia y Valender 352). Fue en el hotel en el que se encontraban donde Alejo Carpentier, con el que habían establecido una buena amistad, leyó sus papeles y la animó a que siguiera adelante con ello. De hecho, Carpentier dijo: "No te conocía absolutamente nada, eres la persona que

${ }^{58}$ Como en otros aspectos de la sociedad, aquí la mujer también encuentra cierto rechazo para su incorporación. En los cafés de la ciudad de México, el Café de París y el Hotel Imperial se producían encuentros entre los intelectuales mexicanos y los españoles. Algunos de los centros culturales más importantes fueron la Casa de España, creada en 1938 y dirigida por Alfonso Reyes, en la que la única mujer que aparece es María Zambrano; y el Ateneo Español, de cuya Junta Directiva participaba Margarita Nelken (Domínguez Prats cap. XII). 
más he desconocido en mi vida" (Ulacia y Valender 353). Allí también conoció, entre otros, a Eliseo Diego, con el que, junto a su mujer, mantendrán una importante relación posteriormente, en México.

A su vuelta de Cuba, conoció a Gabriel García Márquez a través de Álvaro Mutis, otro buen amigo de la pareja. Cien años de soledad será más tarde dedicada a María Luisa y a Jomí en su versión española, y a Álvaro Mutis y a su mujer, Carmen Miracle, en la versión francesa. García Márquez asistió muy interesado al rodaje de En el balcón vacío y es, a través de esta película, como se produjo el primer contacto del colombiano con el cine mexicano. Además, la pareja García-Elío fue testigo del nacimiento de otras obras del ganador del premio Nobel en 1982. Ya en estos momentos Elío Bernal trabajaba como agente literaria.

En toda esta entretenida vida social, la pareja de María Luisa y Jomí pasaba por sus altibajos. En 1964 tuvieron a su hijo Diego pero, finalmente, pusieron fin a su relación en 1968 tras la muerte del padre de la escritora. Después de esto, la autora se sintió con la fuerza necesaria para volver a su tierra natal, Pamplona, y comenzó el viaje de regreso: "Debía de haber vuelto a España mucho antes, pero un cierto respeto por mi padre me lo impidió. Muerto él, tardé poco en hacerlo" (Ulacia y Valender 93). Este viaje se produjo en 1970 cuando su hijo tenía tan solo seis años.

A su vuelta de Pamplona, ingresó en un sanatorio debido a un problema que tuvo con los somníferos: "Estoy en una casa de salud —así llaman a los manicomios, Maison de Santé-, no comprendo nada, no sé por qué estoy aquí tirada sobre una cama" (Tiempo 105). No obstante, esto provocó una mejoría en ella y logró salir de allí bastante 
recuperada. Entró a trabajar en Televisa, donde colaboró hasta finales de los noventa. Posteriormente volvió en varias ocasiones a España, una de ellas con sus hermanas.

El 14 de febrero de 2007 se le concedió la Orden de Isabel la Católica y murió el 17 de julio de 2009 en México D.F., dejando como testigo de su vida En el balcón vacio (1962), Tiempo de llorar (1988) y Cuaderno para apuntes (1995).${ }^{59}$ Estas dos últimas aparecieron en España, en 2002, en una edición compuesta por ambas, bajo el título Tiempo de llorar y otros relatos. Recientemente, en 2017, su hijo, Diego García Elio, ha publicado una obra póstuma: Voz de Nadie. Esta última obra recoge, según explica García Elío en la introducción de la misma, el guion de lo que sería una nueva película que iba a grabar junto a Alejandro Rossi sobre la leyenda del tesoro del Vita. Sin embargo, esta obra tiene un valor histórico más que literario y por ello no será objeto del estudio de este trabajo. Además, carece de información relevante al tema de análisis.

\section{La escritura como proceso reparador: el retorno a los orígenes}

“Y AHORA ME DOY CUENTA QUE REGRESAR ES IRSE. Es decir, que volver a

Pamplona es irse de Pamplona. Al fin voy a volver donde las cosas no están ya. He vivido en el mundo de mi propia cabeza, el verdadero mundo quizá, y contando poco con el mundo exterior" (Tiempo 19). Con estas palabras María Luisa Elío Bernal sumerge al lector en el relato de su viaje hacia el pasado, un viaje en busca de respuestas: ¿quién soy, cuál es mi lugar, qué sucedió, qué queda de aquello? Aunque la escritora pamplonesa había pasado la mayor parte de su vida en su país de acogida, México, la obra narra la

${ }^{59}$ A pesar de que son dos obras independientes y como tal me referiré a ellas, las citas procederán de la edición conjunta que se publicó en España en 2002 por la editorial Turner bajo el título Tiempo de llorar y otros relatos. 
problemática relación entre ella y su país de origen, España, entre su pasado y su presente, su infancia y su madurez. Para ella, España era la única realidad posible. Sin embargo, esa realidad no existía más que en su cabeza y el viaje de regreso se dibujaba como la única salida posible para rastrear las huellas de dicha realidad después de algunos intentos fallidos llevados a cabo por su imaginación. De ahí que, una vez muerto su padre, decidiese volver a Pamplona para comprobar con sus propios ojos aquella imagen que se había configurado a base de acumular recuerdos que, en ocasiones, ni siquiera pertenecían a ella, sino al relato de familiares u otros compañeros de exilio. No obstante, entre el momento de su partida y el de su regreso hay un lapso temporal de más de treinta años. Esto provoca una lucha titánica entre el pasado y el presente, entre la memoria y los recuerdos, entre su yo infantil y su yo adulto. Como afirma Mónica Jato, “el relato constituye además una meditación sobre el ejercicio de la memoria como estrategia de compensación ante la ausencia de todo lo amado y perdido, estrategia que pone de manifiesto, por supuesto, la presencia latente en la mujer adulta de una serie de traumas infantiles no superados" (147). El viaje tiene lugar en 1970 y Tiempo de llorar se publica en 1988, pero ¿cuándo se escribe realmente?, ¿qué papel juega la escritura de la obra en la vida de la protagonista?

María Luisa Elío Bernal cruzó la frontera entre Francia y España a mediados de 1938. En ese momento, se activó lo que Guiliana di Febo ha señalado como el binomio memoria-identidad ya que destaca que el hecho de traspasar los límites geográficos del país de origen implica la ruptura con el cordón umbilical de la madre, en este contexto, de la patria ("Un espacio" 468). Por consiguiente, la niña, fuera ya de España, empieza a crear en su memoria una imagen de España que, a medida que crece, va a configurar 
como parte de su identidad. Es en este instante cuando se produce la primera ruptura en la identidad de la escritora pamplonesa, quedando su yo, así, dividido en dos: el yo-infantil, anclado a España y al tiempo previo a la guerra civil española, y el yo-adulto, que va a desarrollarse en México y que se asocia con el presente. ${ }^{60}$ Tal es así que dicho momento también implica una nueva concepción del tiempo que, en términos de Mateo Gambarte, pasa de ser "tiempo contando a tiempo que pasa. El primero es tiempo asumido, es conciencia y memoria formantes de la propia personalidad; el segundo, el tiempo que pasa, anula al sujeto activo y lo convierte en ilusión pasiva, en padecer desencializado en puros recuerdos" (María Luisa Elío Bernal 176). Es decir, mientras que el yo-infantil corresponde a "tiempo contado", el otro, el yo-adulto se asocia a "tiempo que pasa", que se convierte en un sujeto pasivo, sometido a la memoria. Podríamos decir que, aunque el cuerpo de la narradora de este relato consiguió escapar de España y establecerse en México, el alma de la escritora niña quedó atrapado entre las rejas de la España previa a la Guerra Civil. Como diría Rafael Alberti, "mi cuerpo anduvo sin nadie". A través de la escritura podemos ver como María Luisa Elío Bernal empieza a comprender que el viaje de regreso funciona como sistema para acabar con su yo-infantil: "Creo que podría volver en este instante a México, y creo saber por qué. Me estoy quitando a mí misma mi motivo de ser, mi excusa, y el miedo vuelve a aparecer cuando pienso en quedarme vacía” (Tiempo 27). Dicha comprensión puede interpretarse a través de varios elementos: por un

${ }^{60}$ Van der Kolk y Van der Hart afirman que "many traumatized persons, however, experience long periods of time in which they live, as it were, in two different worlds: the realm of the trauma and the realm of their current, ordinary life. Very often, it is imposible to bridge these worlds" (448). 
lado, la toma de conciencia de su propia división de yoes; por otro lado, la reflexión sobre el poder de los recuerdos y la memoria; $y$, en tercer lugar, el viaje de retorno como punto de partida para convertir la memoria traumática en memoria narrativa.

Hasta ahora he hablado de la existencia de dos yoes: uno identificado con la infancia, que sobrevive en la memoria; y otro que hace referencia a la madurez de la autora y que está sometido al primero. No obstante, la escritora no es consciente de ello hasta que, al inicio de la obra y haciendo alusión al viaje del regreso, señala: "Y AHORA ME DOY CUENTA QUE REGRESAR ES IRSE. Es decir, que volver a Pamplona es irse de Pamplona. Al fin voy a volver donde las cosas no están ya. He vivido en el mundo de mi propia cabeza, el verdadero mundo quizá, y contando poco con el mundo exterior" (Tiempo 19). Estas palabras que, según Mateo Gambarte, fueron las últimas en ser escritas dejan ver al lector que la escritora ha tomado consciencia de su propio aferramiento al "mundo de su propia cabeza", es decir, a sus recuerdos, a su memoria y, por lo tanto, a su yo-infantil (María Luisa Elío Bernal 114). Aunque Aleksandra Hadzelek afirma que el resultado de la autobiografía es permitir al yo presente ver y recrear el yo anterior para hacerlo nacer de nuevo, sucede todo lo contrario en este caso (310). Recrear el yo anterior permite ver a la autora que no queda nada de él en la actualidad y que es el momento de dejar nacer al yo- adulto. Es por ello que puede interpretarse que más de treinta años más tarde volvería a España para buscar ese yo que aún sentía que era ella. Tiempo de llorar es, por lo tanto, el relato de una contienda entre los diferentes yoes que configuran su identidad.

Según la ya citada Hadzelek, la autobiografía se entiende como la "necesidad de autodefinirse frente a la imposibilidad de definir la realidad" (309). Atrapada en un 
mundo de recuerdos y traumas del pasado, María Luisa Elío es incapaz de entender su posición ante la sociedad y su relación con la realidad española. Dar respuesta a esta situación es el objetivo tanto del viaje como de la posterior plasmación de éste en unas cuantas páginas en blanco. En su libro The Ethics of Autobiography. Replacing the Subject in Modern Spain, Ángel Loureiro afirma a modo de conclusión que, debido a que los exiliados han sido obligados a reemplazarse a ellos mismos y a sus yoes, no es sorprendente que sus historias sean narrativas de reparación. Dichas narrativas ofrecen dos vertientes para ser llevadas a cabo: por un lado, la reparación como restauración y renovación del yo y, por otro lado, la reparación del yo como compensación por su pérdida (181). En la misma línea se encuentran las teorías de Van der Kolk y Van der Hart que van a hablar de memoria traumática y memoria narrativa que desarrollaré más adelante. Tiempo de Llorar y Cuaderno para apuntes parecen ser testigos fieles de la restauración y renovación de un yo. Aun así, debe entenderse en este caso el término renovación como sinónimo de sustitución. El relato apunta al nacimiento de un nuevo yo a partir de la aceptación de la muerte del otro yo. ${ }^{61}$

Ya anticipaba anteriormente que María Luisa Elío Bernal había muerto por primera vez a mediados de 1938 cuando cruzó la frontera francesa. En ese momento, la niña pamplonesa quedó atrapada en España, puesto que esta se dibujaba como la única realidad posible para ella. Su recuerdo y su memoria quedaban ancladas en su vida en Pamplona mientras que, de repente, se vio obligada a convertirse en una mujer demasiado

\footnotetext{
${ }^{61}$ No todos los críticos están de acuerdo con el nacimiento de este yo, sino que lo califican como un intento fallido. Sin embargo, se discutirá sobre este tema en el próximo apartado cuando se discuta la configuración de la identidad.
} 
pronto en un mundo totalmente nuevo, afrontando situaciones que no le correspondían a un ser humano de 12 años. En Francia tuvo que enfrentarse a sus nuevas compañeras del orfanato y al hecho de no ver a su madre que, a pesar de no haber trabajado antes de que llegase el conflicto, se había vista forzada a insertarse en el mundo laboral con largas jornadas para poder mantener a sus hijas. A esto hay que sumarle el trauma que supuso enfrentarse a un nuevo idioma, a la ausencia de su padre y, posteriormente, a un nuevo viaje hacia México, ya que las tropas nazis se acercaban y Francia había dejado de ser un lugar seguro. De repente, de la noche a la mañana, el yo de esta niña tuvo que esconderse en algún lugar de su interior para convertirse en una mujer, madurar y así poder asimilar todos los cambios repentinos que ella y su núcleo familiar estaban sufriendo. Sin embargo, la asimilación de estos cambios no tuvo éxito y se convirtió en un trauma que llevó a María Luisa Elío Bernal a vivir hasta el momento del regreso aferrada al pasado, al momento antes de la Guerra Civil, como ella afirma: "Creo que podría volver en este instante a México, y creo saber por qué. Me estoy quitando a mí misma mi motivo de ser, mi excusa, y el miedo vuelve a aparecer cuando pienso en quedarme vacía" (Tiempo 27).

Hasta ese momento, María Luisa había vivido anclada al recuerdo del pasado, a la imagen que había configurado de España en su propia cabeza. No obstante, como bien apunta Mónica Jato, volver conlleva la producción de unos nuevos recuerdos de España que acaben con los existentes (149). Prueba de ello es el siguiente fragmento que narra el regreso de María Luisa Elío Bernal y su hijo al pueblo de Barañáin, propiedad de su padre hasta el momento del alzamiento:

Lo que me asombra es cómo ha cambiado. Aquí está la ciudad universitaria y una que otra fábrica, pero al parecer el campo ha 
desaparecido. [...] Le pregunto al chófer si ya no queda nada del pueblo. [...] En unos minutos estábamos ya en lo que yo llamaba 'el pueblo'. Parecía que lo hubiesen barrido. Sólo quedaban en pie dos casas, un granero y la iglesia, que difícilmente se reconocía. (Tiempo 33)

De esta forma, el viaje a España y la reescritura de este acababan con el pasado tal y como había sido grabado en la memoria de la escritora. Poner punto y final a ese pasado significaba también acabar con su yo anterior a la guerra. La España existente en su cabeza era sustituida por la nueva imagen creada tras el regreso con su hijo y esto provocó que rechazase aquella idea que había mantenido durante tantos años según la cual la verdadera María Luisa era la María Luisa niña:

Ahora que tenía decidido irme, me parecía que en realidad no había hecho nada y que mi infancia era menos importante de lo que yo creía, puesto que ella tomaba toda su relevancia con el inicio de la guerra, y que era ese preciso instante, esa circunstancia, la que me había hecho también perderla. Posiblemente treinta años de angustias en mi vida se habían concretado a mi idea de haber abandonado a esa niña que no era otra sino yo. (Tiempo 73)

Volver a España y, posteriormente, transcribir el trastorno que había padecido durante su estancia en México funciona como mecanismo para matar a su yo infantil. Este proceso consistía en la búsqueda activa de los restos del mundo de aquel yo — su casa de Roncesvalles, el pueblo de Barañáin, el preso de Elizondo - con el objetivo de entender en qué medida su recuerdo había impedido el nacimiento y el desarrollo de un yo adulto arraigado en la nueva sociedad. Penetrar en el trauma causado a esa niña era un 
paso necesario para dejar surgir a la adulta que llevaba intentando nacer durante más de treinta años. De hecho, Bessel A. van der Kolk y Onno Van der Hart definen los recuerdos traumáticos como "unassimilated scraps of overwhelming experiences, which need to be integrated with existing mental schemes, and be transformed into narrative language. It appears that, in order for this to occur succesfully, the traumatized person has to return to the memory often in order to complete it" (447). Por lo tanto, es la escritura el sistema que Elío Bernal utilizar para transformar esas experiencias sobrecogedoras en "narrative language". El regreso se había producido en la mente de la escritora numerosas veces. Sin embargo, este debía realizarse también de forma física. De este modo, completar el recuerdo supuso el inicio de una muerte lenta, dolorosa y necesaria, que iba acompañada del nacimiento de un nuevo yo, no fruto del viaje, sino de la escritura, puesto que "the reparation continues in the act of telling itself" (Loureiro 181). Siguiendo la terminología de Van der Kolk y Van der Hart, la escritura de este regreso es un intento de convertir la memoria traumática en memoria narrativa. La primera de ellas se refiere a un sujeto que es incapaz de enfrentar el recuerdo de un evento con el cual aún se encuentra enfrentado - la Guerra Civil española y la salida de España en el caso de María Luisa Elío Bernal-puesto que su adaptación en referencia a este episodio no ha sido satisfactoria y aún continúa haciendo esfuerzos para adecuarse. La segunda de ella, la memoria narrativa, se trata de una construcción mental que el sujeto utiliza para hacer que los eventos de los que es protagonista cobren sentido (427-28). Por lo tanto, el viaje representó el enfrentamiento con la realidad, la aceptación de que la realidad no era como ella la había concebido. Asimismo, supuso la fecundación de un nuevo yo, de un ente que fue creciendo poco a poco en el interior de la escritora para nacer en el momento en el 
que María Luisa asumió la escritura de Tiempo de llorar. De esta forma, verbalizaba la lucha interior por la que había atravesado. La escritura y, junto a ella, el lenguaje era el medio organizador del conflicto entre sus yoes, pues ella misma escribió posteriormente en Cuaderno para apuntes:

En el principio existía la Palabra, y la palabra estaba con Dios, y la palabra era Dios.

Ella estaba en el principio con Dios, todo se hizo por ella, y sin ella no se hizo nada de cuanto existe. (Tiempo 114)

Ahora bien, cabe plantearse cuál es el papel de la memoria y los recuerdos en todo este entramado de lucha de yoes autobiográficos. Giuliana di Febo, en un intento de encontrar puntos en común entre los textos autobiográficos femeninos del exilio, afirma que la memoria funciona "como código ordenador de la experiencia que distribuye prioridades y relevancias, que silencia y recrea precisamente en la medida en que sea traduce en autoimagen" ("Memoria" 308). Por lo tanto, es significativo analizar en qué medida la presencia de los recuerdos en la mente de la escritora y la liberación de estos a través de la escritura afectan a la función de la autobiografía como recurso paliativo del dolor. Si se presta atención a las teorías del crítico francés Paul Ricoeur, existe una importante fenomenología a tener en cuenta dentro del área de la memoria y los recuerdos. En primer lugar, Ricoeur define la memoria como un elemento único y singular. La memoria es la aseveración de que existe un pasado. Sin embargo, sólo es posible acceder a dicha memoria y, por lo tanto, al pasado, a través del testimonio que se 
dibuja así como nexo de unión entre la memoria y la historia. El problema está en la fiabilidad del testimonio y la capacidad rememorativa de este. Por eso, frente a la singularidad de la memoria, Ricoeur señala la importancia de los recuerdos y la multiplicidad de estos (La memoria 40-42). Entiéndase así la memoria como concepto abstracto al que nunca se puede tener acceso de una forma completa, puesto que dicho acceso es llevado a cabo por el recuerdo cuya fiabilidad puede estar condicionada por numerosos factores externos: circunstancias personales del individuo que recuerda, distancia temporal con el momento que se pretende recordar, postura social-ideológica o sentimental en relación al hecho en sí, etc. Es, en parte, esta casuística en torno al recuerdo lo que ha llevado también a Ricouer a hablar de dos tipos de recuerdos: por un lado, el simple recuerdo (mneme), que surge de forma espontánea, deliberada, fruto de la afección; frente a este, se encuentra la anamnesis, conocida también como "búsqueda". Este es fruto de un auténtico deseo de luchar contra el olvido, pues consiste en la acción intencionada de rememorar sucesos del pasado (46-48). Sin embargo, dicha rememoración puede resultar en un éxito o en un fracaso y son muchos los mecanismos que el ser humano ha desarrollado para evitar que resulte en la última de las opciones. Dejando a un lado las constantes luchas con el recuerdo que Elío Bernal pudo llevar a cabo desde el momento en el que dejó España por primera vez, ella se sirvió de dos mecanismos artísticos para llevar a cabo esa anamnesis.

El primero de ellos es la escritura, y posterior grabación, del guion de la película En el balcón vacio.$^{62}$ La única película del exilio español hecha por exiliados —así se

\footnotetext{
${ }^{62}$ Véanse, entre otros, los siguientes trabajos sobre En el balcón vacio para un estudio completo de la obra: Francie Cate-Arries “«War Through a Girl”s Eyes, Exile in a
} 
refiere a ella en numerosas ocasiones la crítica—es el intento fallido de un imaginario retorno al país de origen. A pesar de que la propia María Luisa Elío Bernal confesara a James Valender y Paula Ulacia que la escritura de En el balcón vacio fue fruto del encuentro con lo hispano en un viaje a Cuba con su marido en 1960, realmente no fue así (352). En aquel entonces sólo escribiría unos breves fragmentos que curiosamente leería Alejo Carpentier, pero que no dejaron de ser un simple recuerdo a modo de afección, en términos de Ricoeur. Sin embargo, convertir lo que en principio parecía ser un simple recuerdo en una búsqueda constante de los recuerdos que le ayudasen a entender la lucha entre Gabriela — pues así se llama María Luisa en la película — niña y Gabriela-adulta es el resultado de una búsqueda activa en el baúl de los recuerdos. La escritura de los guiones de En el balcón vacio nace de numerosas horas de trabajo entre Jomí García Ascot, María Luisa Elío Bernal y Emilio García Riera, acompañados de numerosas llamadas de apoyo del poeta Emilio Prados. Además, para hacer posible su grabación, contaron con la ayuda de todo el círculo exiliado. Los actores no fueron actores profesionales, sino que eran también refugiados o hijos de refugiados españoles, como explica Charo Alonso (144). Pintores como Vicente Rojo, Juan Soriano y Souza donaron tres cuadros con cuya venta se recaudó dinero para comprar la cámara y material necesario para la grabación. Esto desemboca en otra pregunta: ¿es esta película, por lo

Woman's Voice: Cinematic Images of Memory's Hiding Places in En el balcón vacío (1963)»; el proyecto de investigación AEMIC, dirigido por Javier Lluch-Prats, En el balcón vacío. La segunda generación del exilio republicano en México, en el que se reedita la película, se realiza un documental sobre ella y se recopilan numerosos trabajos y entrevistas en torno a la obra fílmica; Eduardo Mateo Gambarte, Exilio, infancia perdida, identidad e imposibilidad de retorno: En el balcón vacío de Jomí García Ascot y María Luisa Elío Bernal. 
tanto, una exploración en los recuerdos de un individuo, en este caso María Luisa Elío, o en los recuerdos de una colectividad, los exiliados españoles en México? Se responderá a esta pregunta más tarde cuando se aborde la problemática entre memoria individual y memoria colectiva. Sin desviarnos más del tema, cabe explicar por qué la grabación de esta película resulta ser una búsqueda activa de los recuerdos en el baúl de la memoria.

A medida que pasan los años, muchos de los recuerdos se van debilitando y pasando al plano del olvido. La mente es consciente de que existió un recuerdo, pues sólo se puede entender el olvido si se sabe de la existencia de un recuerdo que no se recuerda, valga la redundancia. Olvidar implica recordar un suceso en el pasado. Sin embargo, en el caso de María Luisa Elío Bernal estaban funcionando, entre otros, dos fenómenos importantes en la configuración de dicho olvido. Por un lado, la poca cuantía de esos recuerdos que iban desapareciendo con el paso de los años. Manuel Durán, miembro también de la segunda generación de escritores exiliados, afirma, en primera persona, que "los niños de la guerra" no habían acumulado suficientes recuerdos o experiencias que les permitiese vivir ajenos al tiempo (cit. Rivera 20). Por otro lado, críticos como Elizabeth Jellin o el ya citado Paul Ricoeur están de acuerdo en afirmar que el olvido ocupa un lugar importante en aquellas narraciones "donde la represión y la disociación actúan como mecanismos psíquicos que provocan interrupciones y dramatizaciones traumáticas" (Jellin 29). Son estos hechos traumáticos los que generan unos vacíos en la memoria que María Luisa Elío Bernal intenta rellenar llevando a cabo una semi-reconstrucción de su huida de España a través de la película de En el balcón vacio. A lo largo de la película, María Luisa intenta recrear las escenas que vivió en su camino a México: la huida del preso rojo por los tejados, el reencuentro con el preso de Elizondo, su viaje en el coche 
para escapar donde vio las cabezas de los hombres muertos colgando, la entrada a la que fue su casa en la calle Roncesvalles, etc. Además, como afirma Isabelle Steffen Prat, "el hecho de que María Luisa se interprete a sí misma se puede percibir como un deseo de convocación directa de la memoria mediante la palabra, de unificación ontológica” (56). Sin embargo, esta búsqueda activa, que tiene como objetivo entender las relaciones entre pasado y presente, su infancia y su situación actual, la lucha entre sus yoes, no tiene un final feliz. En la última escena de la película, Gabriela-niña se cruza con Gabriela-adulta en las escaleras de la que se suponía que era su casa, pero, sin embargo, no se produce el reconocimiento entre ambos yoes. ${ }^{63}$ La película trata únicamente de una reconstrucción de la imaginación en los escenarios de México. La autora no se enfrenta a la verdad de la realidad española de ese momento ya que dicha reconstrucción no se había llevado a cabo en España, sino que se enfrenta a sus recuerdos de esta, por lo que no se produce una total asimilación de los recuerdos, del pasado en contraste con los cambios del presente provocando que sea así imposible la realización de un presente y futuro, asimilación a la que conduciría el bueno de uso de la memoria ejemplar, según Todorov (34). Entiéndase que Todorov concibe "la memoria ejemplar" como aquella que permite indagar en el pasado con el objetivo de aceptar la realidad e incorporarla como forma de aprendizaje en el presente. No obstante, para poder llevar a cabo dicha incorporación, era necesario la confrontación con la verdadera imagen de España del momento, ya que el mundo creado a través de sus recuerdos no era suficiente para que se produjera la catarsis tan necesitada

${ }^{63}$ José María Naharro-Calderón realiza un estudio en profundidad de la anagnórisis en esta película en su artículo: "En el balcón vacio de la memoria y la memoria de En el balcón vacio". Archivos de la Filmoteca: Revista de estudios históricos sobre la imagen 33 (Octubre 1990): 150-161. 
por parte de María Luisa Elío Bernal. Por lo tanto, esta situación provoca la realización del segundo mecanismo de búsqueda activa del recuerdo al que se hacía mención anteriormente: el verdadero viaje de regreso a España y su posterior escritura en Tiempo de llorar.

Elío Bernal, en la ya mencionada entrevista a Paloma Ulacia y James Valender, afirma sobre Tiempo de llorar: "Voy, todo lo que pasó lo voy a ir deshaciendo, borrándolo, para que no haya pasado" (359). De esta forma, volver a España significaba buscar en el pasado las respuestas a las preguntas que aquella niña llevaba haciéndose en su cabeza por más de treinta años para poder crear unos nuevos recuerdos que facilitasen su inserción en el presente. No obstante, este ejercicio de la memoria no resulta en un mecanismo de reafirmación de la imagen utópica e idealizada de una España vista a través de los ojos de una niña anclada en el momento de su salida en 1938, como quizá hubiera esperado María Luisa, sino todo lo contrario. Supone una constatación de la realidad imaginaria en la que ella misma había vivido, es decir, de la realidad formada en su mente a partir de sus propios recuerdos. De esta forma, se produce una aceptación de la no-existencia ya de aquella España y, por lo tanto, la reafirmación en el poder del recuerdo como sistema para crear una realidad más importante que la realidad misma en determinadas situaciones traumáticas. Asimismo, la escritora pamplonesa explica: "En realidad el recuerdo de uno es lo verdadero. El recuerdo no es algo que uno inventa o cambia, es algo mucho más exacto que la realidad, dispuesta siempre a ser cambiada" (Tiempo 22). María Luisa había hecho de sus recuerdos de España su excusa de ser pues, como afirma en la obra, había otorgado una importancia a su infancia y a la guerra civil que, tras el regreso, había comprendido que no tenían para ella. A pesar de ello, esta 
supuesta apacible comprensión de su error sobre la verdadera realidad y el poder de los recuerdos con vistas a un presente fracasa con el fin del libro: “'No llores, María Luisa, anda. Mira aquí están tus hermanas.' 'María Luisa, ¿qué pasa?' 'Pero, ¿por qué lloras? Di algo.' '¡Anda!, deja de llorar.' 'Pero di algo, ¿qué te pasa?' '¡Mamá!, ¡Mamá! ¿Por qué te has muerto?"' (Tiempo 98). El viaje a España había funcionado para aceptar que la realidad no era tal y como ella había pensado. Ahora, de vuelta en México, debía aceptar los cambios que se habían producido en México y que tampoco había asimilado completamente por estar viviendo en el mundo del pasado. Es entonces cuando entra en función la segunda obra escrita: Cuaderno para apuntes. Por lo tanto, Tiempo de llorar, por sí sola, no consigue llevar a cabo ese transición de memoria traumática a memoria narrativa, sino que esta obra es el inicio de un proceso que busca una segunda parte en Cuaderno para apuntes para finalizar con dicha tarea.

Entre Tiempo de llorar y Cuaderno para apuntes han pasado siete años. Durante este tiempo, Elío Bernal ha estado un breve período de tiempo en un centro de salud, en parte, fruto del trabajo memorístico que había hecho a través del viaje de España y de la aceptación de la realidad imaginaria en la que había vivido. El momento del viaje supuso la ruptura total con ella misma, una fragmentación entre lo que ella había sido y lo que debía ser a partir de entonces. Esto provocó otra crisis de identidad que resultó en una nueva búsqueda activa en el baúl de la memoria. No obstante, dicha búsqueda ya no se remonta únicamente al pasado en España, sino también a sus años en México. Hasta este momento la lucha entre el yo-adulto y el yo-infantil había dado a luz a una técnica narrativa basada en el desdoblamiento. Durante Tiempo de llorar, las voces de estos dos yoes se alternan, aunque no de forma simultánea ni equilibrada, para reflejar la dualidad 
traumática surgida en su propia personalidad. Véase el siguiente ejemplo: “«Os escondéis las tres y yo os busco.» Corremos cada una para un lado, chocando con todo. A mí debía serle muy fácil encontrarme ya que siempre me escondía en los mismos lugares" (Tiempo 30). La voz infantil habla en presente de lo que pasó hace más de treinta años. En oposición, la voz adulta reflexiona sobe el juego con la familia. Pero, con Cuaderno de apuntes, este recurso alcanza un nivel superior dando lugar a una triplicación del yo, por lo que se puede encontrar no sólo la lucha entre María Luisa niña y María Luisa adulta, sino también entre una María Luisa adulta, en México, serena y sin rastro de sus traumas, es decir, recuperada tras el viaje, y María Luisa adulta, afectada aún por la contusión traumática provocada por el viaje:

“¿Pasó tiempo? Sí pasó, no sé cuánto tiempo, pero un largo tiempo. Y ahí estaba yo —al fin caritativa, ¡ah pobre de ti caritativa! —, con una bolsa de caramelos y un paquete de cigarros. Ve, anda, ve, sí y ahí fui, y me abrieron las rejas y entré: ahí estaba, la que lloraba y cantaba ahí, derecha, dignamente derecha en toda su locura, dando un paso hacia mí. Me alarga la mano, '¿cómo estás?', me pregunta, 'te veo muy bien', 'me alegro', y pronuncia mi nombre. '¿Por qué sabes mi nombre?', quisiera decirle, si yo nunca me atreví a mirarte a la cara, si estás loca, si tú no sabes y me voy.

'Doctor, ¿se curó verdad?' '¿De quién me habla? 'Ah, no, no, imposible de diagnosticar, es un caso incurable'.

Pero yo sé, ahora yo sé bien, que ella sabe" (Tiempo 112). 
En este caso la escritora no se reconoce a sí misma durante su estancia en el centro psiquiátrico. En esta última frase, María Luisa Elío Bernal reconoce el proceso de curación iniciado tras la realización del viaje. Su yo-adulto mexicano es conocedor del trabajo mental que ha supuesto la confrontación con la realidad española y acepta la lucha que su otro yo-adulto aún está llevando a cabo a través de la terapia en el centro de salud. Se trata del inicio de un proceso de unificación de los dos yoes adulto que afloran en Cuaderno para apuntes. Todo esto resulta especialmente curioso si se tienen en cuenta las palabras de Alicia Alted Vigil, según la cual "el lugar de origen y el tiempo 'detenido' en el momento de la partida" sólo afecta a aquellos que han vivido el exilio siendo adultos ("Exilio, identidad" 247-248). Sin embargo, este no es el caso de María Luisa Elío Bernal. De esta forma, Cuaderno de apuntes resulta ser su último trabajo conocido en el que aborda las relaciones entre memoria e identidad con el fin de poder incorporarse al presente. Para llevar a cabo dicha incorporación, era imprescindible afrontar los traumas que habían coexistido con ella durante toda su vida. Esta obra trata de una serie de mini-relatos, en los que desafía desde su locura hasta la propia muerte pasando por la confrontación con la propia Guerra Civil, el poder del recuerdo, su infancia y la propia escritura. De esta forma, volvemos al inicio en el que había explicado el poder de la autobiografía, de la escritura, de lenguaje como proceso catalizador. A través de este mecanismo, había conseguido darle al pasado el lugar que le correspondía, resolver la lucha entre sus yoes y, finalmente, incorporarse al presente. Puede entenderse que la escritura funciona como proceso curativo, es decir, relatar sus vivencias le ha permitido enfrentarse a la realidad de su pasado y de su presente para poder configurar una nueva identidad. De hecho, aunque no nos interese con objeto de este trabajo su obra Voz de 
Nadie, es significativo que no aparezca en esta el relato traumático de su desdoblamiento entre el pasado y el presente, entre su infancia y su madurez. Es, por lo tanto, necesario sacar a la luz, por última vez, las teorías de Van der Kolk y Van der Hort, según los cuales: "In the case of a complete recovery, the person does not suffer anymore from the reappearance of traumatic memories in the form of flashbacks, behavioral re- enactments, etc. Instead the story can be told, the person can look back at what happened; he has given it a place in his life history, his autobiography, and thereby in the whole of his personality" (447-448). Es decir, Elío Bernal ya ha integrado la experiencia del exilio como parte de su memoria narrativa, por lo que no siguen apareciendo esos recuerdos traumáticos. Además, el hecho de que también haya hablado posteriormente de esta experiencia en varios medios de comunicación, así como en la entrevista ya mencionada a Paloma Ulacia y James Valender también demuestra la capacidad de la autora por integrar, finalmente, dicha experiencia como parte de su memoria narrativa.

Antes de finalizar este apartado, es necesario prestar atención a una cuestión que ya salió a la luz anteriormente y a cuya pregunta es más fácil dar respuesta si se entiende la narrativa de Elío Bernal como un proceso de reparación identitaria. ¿Memoria individual o memoria colectiva? Según el gran teórico francés Maurice Halbwachs, el individuo no recuerda sólo, sino que necesita siempre del otro y de los códigos culturales compartidos para poder llevar a cabo dicha rememoración. Isabelle Steffen-Prat afirma en relación con En el balcón vacio que las imágenes de esta "sugieren la progresiva desaparición de la memoria individual y su sustitución por imágenes colectivas" (50). Por su parte, Tomás Segovia, en una entrevista concedida en torno a la reedición que estaba realizando el grupo AEMIC de esta película, confesaba: "Yo creo que la película, a casi 
todos nosotros, cuando la vimos ya terminada, nos pareció que, efectivamente, era un documento sobre el exilio, sobre la segunda generación, sobre la experiencia infantil del exilio" (365). Sin embargo, el papel de la memoria colectiva a la que gran parte de la crítica hace referencia al hablar de la película no cobra la misma importancia cuando se habla de sus obras escritas. ${ }^{64} \mathrm{Si}$ se presta atención únicamente a la propia representación de una memoria colectiva, la respuesta es sencilla: no, no existe tal en su obra escrita. Tanto una como otra giran en torno a la problemática personal e individualizada de María Luisa Elío Bernal, sin poder rastrear huella que permita extender su labor memorística al resto de los miembros de la segunda generación. Si como bien afirma Paul Ricoeur, "la memoria colectiva consiste en el conjunto de huellas dejadas por los acontecimientos que han afectado al curso de la historia de los grupos implicados que tienen la capacidad de poner en escena esos recuerdos comunes con motivo de las fiestas, los ritos y las celebraciones públicas", sin lugar a duda, en su obra escrita no hay lugar para dichos recuerdos comunes (La lectura del tiempo 19). Sin embargo, cabe recapacitar sobre las palabras de Halbwachs que mencionaba al principio de este párrafo. ¿Quién es el otro y cuáles son los códigos culturales compartidos? Ya en el segundo capítulo, expliqué la situación de muchos de los miembros de esta generación que, a pesar de estar en un nuevo país de acogida, carecían de contacto con la realidad de este debido a la formación de núcleos de exiliados en los que se movían con la esperanza de un pronto regreso. En el caso de María Luisa Elío, esto no fue diferente, pues acudió a los institutos creados por la

\footnotetext{
${ }^{64}$ Resulta interesante leer el artículo de Eduardo Matero Gambarte, "En el balcón vacío: guiones, realización y represión", pues expone una laboriosa tarea de hemeroteca en la que recopila los comentarios de los críticos del momento sobre la película, muchos de los cuales se mostraban de acuerdo en hablar de una memoria colectiva en el film.
} 
República en México. Además, en el momento de la realización de la película, fueron los otros exiliados los que colaboraron en la creación de la película, pues su historia interesaba a ellos, pero no a la mayoría de los mexicanos. ${ }^{65}$ De esta forma, el otro constituía, en gran medida, España, lo que contribuyó a la mitificación de una imagen basada en los recuerdos y el relato de los amigos y compañeros del exilio. En cuanto a los códigos culturales, sucedía algo similar. Sus costumbres y tradiciones procedían del ámbito español y los puntos en común con la cultura mexicana eran escasos, lo que contribuyó también a su aislamiento. De este modo, el viaje a España era también un intento por buscar un conjunto de códigos culturales que ella creía que compartía aunque no fuese así- para poder entender en qué medida la memoria colectiva había influido en su propia memoria. Sin embargo, darse cuenta de que tampoco compartía dichos códigos culturales con España pues, de una forma o de otra, con el paso del tiempo se había ido mexicanizando la ayudó a entender que sólo podría tener acceso al otro desde su posición privilegiada establecida más allá de las fronteras de una u otra sociedad. Y es la escritura y el lenguaje el medio que María Luisa Elío Bernal va a utilizar para alcanzar ese status quo.

En definitiva, la imposibilidad de reinserción o reformulación identitaria por parte de María Luisa Elío Bernal genera un trauma anclado en el momento de partida de España en 1938. La beligerante discrepancia entre el pasado y el presente reclama una resolución que armonice la lucha de egos interiores. Como ha quedado demostrado, En el

\footnotetext{
${ }^{65}$ Por cuestión de espacio no abordo la cuestión de para quién escribe, pero remito al artículo de Francisco Pérez de Ayala “¿Para quién escribimos?”, cuyos datos podrán encontrar en la bibliografía.
} 
balcón vacio se dibuja como un primer intento fallido de confrontación con el mundo de los recuerdos, ya que dicho enfrentamiento no tiene una constatación con la realidad de España que le ayude a aceptar su situación real, sino que esta se basa en una simple recreación imaginaria de la escritora junto a su marido y Emilio García Riera. Sin embargo, el posterior viaje de regreso en 1970 supone un choque, por vez primera, entre la realidad de España y la existente en la mente de María Luisa Elío Bernal que no corresponde más que a la mirada de una niña de 12 años. Además, este viaje supone también el paso de esa memoria colectiva que puede interpretarse en la obra fílmica a una memoria individualizada en la figura de la narradora pamplonesa. Así, la reflexión identitaria en torno al papel de la memoria y el recuerdo y las relaciones de esta con su ubicación en el país de acogida que tiene lugar en Tiempo de llorar y Cuaderno para apuntes concede a la escritura un papel relevante en la estructuración de yoes de la escritora pamplonesa. Es la redacción del relato de su experiencia del viaje de regreso a España la que le permite ver con mayor claridad el lugar que había ocupado hasta ese momento el pasado en su vida y la que le otorga la oportunidad para comenzar una vida más allá de la cárcel de recuerdos infantiles en la que ella misma se había encerrado.

\section{La formación de la identidad: de una niña española a una mujer ¿mexicana?}

En Shifting Ground: Spanish Civil War Exile Literature, Michael Ugarte expone que es la experiencia particular del exilio la que lleva al autor, quizá de forma inconsciente, a establecer un diálogo consigo mismo sobre el propio proceso de la escritura y los problemas derivados de su intención de captar la realidad (19-20). Sin embargo, esa experiencia particular del exilio a la que hacía referencia el escritor americano implica una serie de fenómenos a los que ya se hacía mención en los primeros 
capítulos y que pretendo retomar aquí con el objetivo de entender la configuración de la identidad de María Luisa Elío Bernal a través de su obra artística. En primer lugar, el exilio conlleva un desplazamiento espacial, que obliga al exiliado a repensar y revalorizar el concepto de nación y de frontera. Al mismo tiempo, se produce un trastorno en la esquematización del eje temporal, que va más allá de la clásica concepción de este basado en presente-pasado-futuro, dando lugar así a un nuevo entramado de relaciones. Y, en último lugar, los exiliados se enfrentan a uno de los rasgos más identificativos de la identidad: el lenguaje, no sólo como elemento identificador de un grupo social, sino también como herramienta para proyectar una identidad nacional diferente a la propuesta desde dentro de España. La diferenciación semántica propia del español entre los verbos "ser" y "estar" funciona como punto de partida para la representación del sujeto en el exilio. En un mundo de vacíos, la escritura, es decir, el lenguaje se convierte en su única medida para visibilizarse y reafirmar unos códigos ocultos por el poder dominante. En este caso, no se trata de un cambio de idioma, más que el breve tiempo que María Luisa Elío vivió en Francia, sino un cambio de registro social-dialectal. Además, el lenguaje tiene el poder de crear una identidad como una producción en constante proceso de formación que se construye a través de la representación, según las teorías de Stuart Hall (222). Es a través del lenguaje que puede llevar a cabo dicha construcción cultural e identitaria a la que haré mención más adelante. Por lo tanto, en este apartado exploraré en qué medida la guerra civil y el posterior exilio perturbó a María Luisa Elío Bernal a la hora de autodefinirse como miembro de un grupo social. Para ello, es necesario recurrir a las relaciones existentes entre nación-espacio, tiempo y lenguaje, a las que ya hacía referencia también en el tercer capítulo. 
Estar sin estar y ser sin ser. Con estas poéticas palabras podría resumirse, de forma simplista, la obra de María Luisa Elío Bernal. Anteriormente, había definido Tiempo de llorar y Cuaderno para apuntes como un ejercicio memorístico de la autora que enfrentaba la infancia y la madurez, el pasado y el presente, España y México en un intento de configurar su identidad. La escritora pamplonesa se encuentra en una encrucijada consigo misma en su intento por avanzar hacia el futuro pero teniendo en mente que, para ello, era necesario regresar a su pasado. Con el viaje de regreso a España, María Luisa pretendía unir "ser" y "estar" en un mismo concepto, acabar con ese desdoblamiento de egos al que había hecho referencia anteriormente.

Ahora bien, como ya adelanté en el capítulo anterior, el término nación tiene como origen el sentimiento compartido de un grupo de personas como pertenecientes a un mismo territorio. De esta forma, María Luisa, junto a muchos otros exiliados, sintió durante muchos años que pertenecía a España a pesar de no estar en él. Ya desde su película En el balcón vacío es evidente el apego a su lugar de origen, pues el yo-infantil de María Luisa Elío Bernal, interpretado por Nuri Peña, recorre los lugares más significativos de su infancia así como algunos de los pueblos que tuvo que recorrer durante el camino al exilio. Sin embargo, mientras que los exiliados de la primera generación sí habían desarrollado una vida plena en el país de origen que les permitiera encontrar unas raíces firmes que sustentaran esta idea, no era así en el caso de María Luisa que había marchado de España con apenas doce años. A pesar de su intento personal — y el de otros miembros de la comunidad exiliada — por mantener viva la imagen de España durante su infancia, la verdad era que se había configurado una identidad influenciada, en gran medida, por su vida en México. Fue tal su intento por 
mantener esa imagen de España intacta que, en Tiempo de llorar, diría las siguientes palabras: "Sé que no volveré a verla y que trataré de no ver, desde este momento, a nadie que haya conocido a mis padres. Nadie volverá a decirme en pasado cuánto los quería. Aquí, en España, no están muertos. Lo están en México. El recuerdo de ellos en Pamplona es de ellos vivos y nadie me lo cambiará” (41). Pero esta dualidad, sus padres vivos en España, muertos en México, su oposición entre el país de origen y el país de llegada tenía como origen una identidad nacional desestructurada causada por el exilio. Fue el propio hecho de estar lejos de su país lo que provocó, en un primer momento, el arraigamiento más fuerte en su nacionalidad española, no sólo en el caso de María Luisa, sino en el de muchos otros exiliados. De hecho, este arraigamiento ha provocado una idealización de la tierra natal en muchos casos como ya han destacado el propio Mateo Gambarte (Los niños 71). También Susana Rivero habla de un "pasado imaginario que irrumpía incesantemente en el presente" (21). María Luisa Elío Bernal, a través del viaje de regreso y la posterior escritura de este, empieza a aceptar la problemática identidad a la que se había aferrado durante toda su vida, una identidad aprisionada en España. Ella misma afirma en la obra que ese vínculo con la España del pasado era lo único que la mantenía con vida: "Creo que podría volver en este instante a México, y creo saber por qué. Me estoy quitando a mí misma mi motivo de ser, mi excusa, y el miedo vuelve a aparecer cuando pienso en quedarme vacía" (Tiempo 27). De esta forma, el viaje a España y la reescritura de este acababan con la imagen de España tal y como había sido recogido en la memoria de la escritora. Poner punto y final a ese pasado significaba también acabar con su yo anterior a la guerra. La España imperante en su cabeza era sustituida por la nueva imagen creada tras el regreso con su hijo y esto provocó que 
rechazase aquella idea que había mantenido durante tantos años según la cual la verdadera María Luisa era la María Luisa niña, la María Luisa de España:

Ahora que tenía decidido irme, me parecía que en realidad no había hecho nada y que mi infancia era menos importante de lo que yo creía, puesto que ella tomaba toda su relevancia con el inicio de la guerra, y que era ese preciso instante, esa circunstancia, la que me había hecho también perderla. Posiblemente treinta años de angustias en mi vida se habían concretado a mi idea de haber abandonado a esa niña que no era otra sino yo. (Tiempo 73)

Volver a España y, posteriormente, transcribir el trastorno que había padecido durante su estancia en México, funciona como mecanismo para iniciar una nueva relación identitaria en torno a su nación de origen. A pesar de ello, las últimas páginas de Tiempo de llorar que, aunque en un principio, parecían conducir hacia una reconciliación consigo mismo y hacia la aceptación de México como lugar de origen, resultan ser un final abrupto en el que, llorando, invoca a la madre, lo que invita a pensar que puede ser un llanto debido a la incomprensión de una identidad cultural que no sabe asimilar. El viaje ha funcionado para que sea consciente de que su vínculo con España no es tan fuerte como ella pensaba, pero la vuelta a México tampoco le ha proporcionado la paz que ella esperaba tras su viaje de regreso a este país. Es en Cuaderno de apuntes donde se produce el encuentro con su yo mexicano para, en última estancia, poder entender la particularidad de su caso, de su generación:

Es extraño convencerse de eso, puesto que no pertenece al recuerdo, sino a una absoluta realidad - ahora empiezo a recordarlo como una 
realidad fuera del tiempo- - En todas las historias hay un punto en que aparece lo imposible, y ese punto logra hacer que el resto se rompa. Calculo que la realidad es saber notar la diferencia, y que ése es el motivo por el cual puedo estar ahora escribiéndolo. (Tiempo 111)

De este modo, María Luisa asume esa percepción diferente de su realidad en la que el desplazamiento espacial prolongado en el tiempo ha provocado que no exista una identidad nacional con la que reflejarse totalmente, más que la que ella misma crea. A pesar de que ella misma, en la entrevista a Paloma Ulacia y James Valender, afirme sentirse mexicana en el periodo final de su vida, no creo que en realidad fuese así puesto que en la misma entrevista responde de la siguiente forma cuando la entrevistadora le pregunta si no siente ninguna identificación con España: "Si me dices España, siento una cosa que surge por dentro ¡uuuurrrggg..!” (358). Sin ser consciente de ello y, por lo tanto, sin materializarlo de forma concreta en su obra, se había convertido en un ser desterritorializado, término establecido por Deleuze y Guattari, que debe entenderse como "unchaining of both material production and desire from socially restricting forces" (cit. Best and Kellner 88). Es decir, sentía lazos con México y con España, marcados por las relaciones personales-afectivas desarrolladas durante toda su vida, pero no existía una lucha entre ambos países ni una necesidad de definir su identidad vinculada a una de estas naciones. Elío Bernal había conseguido desprenderse de los recuerdos y lazos que la mantenían unida a un concepto de nación aferrado a la España previa a la guerra el cual no la dejaba progresar y, al mismo tiempo, había conseguido asumir que México, sin ser su lugar de origen, era el lugar que le ofrecía la oportunidad para desarrollar una vida feliz, para configurar una identidad. No obstante, en la configuración de dicha identidad, 
la palabra nación carecía de sentido, no pretendía buscar una nación pues se había convertido en un ser nómada desvinculado de la tierra. Sophia McClennen rechaza tanto el concepto de deterritorialization como el de nomadism afirmando que conlleva una glorificación de la experiencia del exilio. Sin embargo, no creo que en el caso de María Luisa Elío Bernal se trate de una glorificación de la experiencia, sino de una asimilación y aceptación de ella. Este fenómeno no se refleja como un hecho positivo que le haya permitido liberarse de vínculos opresivos, sino simplemente como un hecho que le ha conducido a buscar una identidad ligada a otros elementos que no sean los de patriaespacio. En terminología de Sohpia McClennen sería más correcto usar el término transnationalism como opuesto al de nación en el que la identidad cultural no tiene ninguna conexión con un espacio geográfico. Pero insisto en que no se trata de un transnacionalismo entendido como globalización o universalidad, sino como un rechazo a la necesidad de establecer una nación como rasgo identitario, como un hecho un elemento liberador de las garras del concepto de "patria". De esta forma, la dialéctica existente entre los conceptos de nación y trasnacionalismo desarrollada por Sophia McClennen al analizar el trabajo de los exiliados en los años 50 y 60 - concretamente Juan Goytisolo, Ariel Dorfman y Cristina Peri Rossi - puede aplicarse, en cierta medida, también al caso de María Luisa Elío Bernal y a otros miembros de la segunda generación de escritores exiliados. La particular posición de María Luisa Elío Bernal de estar entre dos mundos le ha permitido, en último lugar, liberarse de los conceptos opresivos de la categorización nacionalista para llevar a cabo una configuración transnacional de su identidad en la que no es necesario establecer una nación fija, sino un sentimiento nacionalista discursivo entre dos vasos comunicantes, España y México. De hecho, como la propia Sophia 
McClennen afirma, el exilio se ha convertido en un rasgo de la identidad nacionalcultural más al igual que el de clase, género o sexualidad, aunque, en mi opinión, es la inclusión de este como nuevo elemento caracterizador la que conlleva también la desvinculación a una única patria y la que convierte al exiliado de la segunda generación en un ser desterritorializado (42).

No obstante, la narrativa de María Luisa Elío Bernal no se puede entender como un intento de crear un discurso nacionalista distinto, ya que la problemática existente en torno a la configuración de una narrativa de este tipo se esconde tras un relato individualista explícitamente basado en la nostalgia y el trauma causado por la guerra civil, dejando el elemento político en un segundo nivel. Con la escritura de su experiencia ha mostrado su rechazo al nacionalismo cultural existente en su país, un nacionalismo conservador, de derechas contra el que, de forma simple, se dirige así:

"Me di cuenta al ver cómo perseguían a aquel hombre por los tejados, me di cuenta cuando se escondió y una mujer gritó diciendo en dónde estaba. (...) ¿Matar a papá? Entonces en mi cabeza de niña se hizo claro quiénes eran los buenos y quiénes los malos. Todo se me iba haciendo claro, aunque sólo en mí misma, pues no me atrevía a hablar con nadie". (Tiempo 62)

Sin embargo, no ha propuesto una nueva narrativa nacional-cultural desde fuera de las fronteras, pues su escritura tenía como fin último la reparación de su identidad cultural, identidad que comienza a surgir tras la desaparición del término patria como elemento restrictivo y vinculante de esta. 
El desplazamiento espacial al que se ha hecho referencia hasta ahora tuvo un fuerte impacto también en la configuración del eje temporal en el exiliado. Del mismo modo que el desterrado no encuentra correspondencia con el nuevo espacio ofrecido por el país de acogida, tampoco así la encuentra en el aspecto temporal. Generalmente, el exiliado no se identifica con el momento histórico por el que atraviesa la realidad del país de acogida, ya que no la siente como algo propio. Sin embargo, el reloj ha seguido avanzado, por lo que tampoco puede encontrar una identificación con el momento histórico de su país cuando este lo dejó. ¿Podría decirse que se convierte así en un ser ahistórico, fuera de la historia?

Mateo Gambarte, en relación a la relación de esta generación con el tiempo, señala: "Se trata de un exilio de espacio, pero a su vez ellos son exiliados doblemente en el tiempo. El tiempo personal y biográficos desaparece para establecerse un tiempo ajeno como referente de la propia personalidad" ("La vuelta" 64). A lo largo de los años, en la escritura de los discursos nacionales, y, en concreto, de la historia de España, el tiempo tiende a mantener una estructura lineal, concatenando los hechos en el espectro causaconsecuencia. Sin embargo, el fenómeno del exilio tiene el poder de romper cualquier concepción pre-existente del tiempo. María Luisa Elío Bernal escribe:

Es increíble cómo pasa el tiempo... cuántas veces había oído decir esta frase y ahora estaba ahí, conmigo, era yo quien la repetía: “es increíble cómo pasa el tiempo”. ¿Por qué no me habían dicho antes lo que era el tiempo? ¿Por qué no me lo habíais puesto entre las manos y me lo habíais enseñado? "Mira niña, esto es el tiempo". El tiempo son diez días para contarlo, tengo siete años, cinco de la mano derecha y dos de la izquierda. 
Y después el tiempo es Navidades, "la otra Navidad y la Navidad próxim". Y después deja de ser tiempo y se hace fecha, mi santo, mi cumpleaños y el día de mi primera comunión. Y después el tiempo se hace distancia, cinco años después de la guerra, nueve años después de la guerra, quince años después de la guerra... Y después no hay, ya no hay tiempo contado, sólo hay tiempo que pasa: seis años...siete años.. o una tarde agradable, pasada en casa. (Tiempo 25)

Críticos como Jozef Wittlin hablan de una doble temporalidad que conduce al individuo a vivir en dos momentos históricos: el pasado de su país de origen y el presente de su país de acogida. Sin embargo, la obra de María Luisa Elío Bernal, entre muchas otras, demuestra que no siempre es así. El aferramiento al pasado, durante gran parte de su vida, imposibilitó la aceptación del presente. No era posible afrontar un nuevo presente hasta que llevara a cabo una aceptación del pasado, a lo que ya hice referencia anteriormente al hablar de la lucha entre los egos. De esta forma lo expresaba en Tiempo de llorar la propia escritora pamplonesa: "Me habían quitado el pasado. Ahora me quitaban el recuerdo del pasado, del que yo hacía el presente, y sin tener ninguno de los dos me era imposible en el futuro. ¿Cómo puede haber un futuro sin pasado ni presente? No había nada" (Tiempo 22). La nostalgia se convierte así en un mecanismo para acercarse al único "tiempo" posible durante gran parte de la vida del exiliado según algunos críticos. Pero esta nostalgia lleva, simultáneamente, una fosilización del tiempo en el caso de María Luisa Elío Bernal. Rechaza los sucesos históricos ocurridos en su país de origen posteriores a su salida. El único tiempo posible es el de su infancia y como tal se introduce frecuentemente en el relato en oposición al tiempo presente del viaje de 
retorno que amenaza con borrarlo: "Si mi intención al volver a Pamplona era borrar el pasado para poder vivir el presente, lo estaba logrando, pero se iba borrando solo, sin el menor esfuerzo, aunque no dejaba nada a cambio" (Tiempo 51). La confrontación con el presente queda profundamente marcada por el constante uso del adverbio temporal “ahora" que acompaña a gran parte de las reflexiones sobre dicha problemática en la obra. No puede olvidarse que así inicia la obra "Y AHORA ME DOY CUENTA ..." (Tiempo 19).

Sin embargo, Sophia McClennen, tras hacer un repaso de algunos de los estudios más importantes sobre el tiempo del exilio — Tabori, Wittlin, Guillén, Paul Illie_elabora una nueva esquematización del tiempo del exiliado sintetizada en cuatro conflictos temporales a los que ya hacía referencia en el tercer capítulo capítulo. De todos ellos, nos interesa el primero de ellos con motivo del análisis de la obra de María Luisa Elío Bernal. La rememoración del momento histórico antes del exilio se configura como un rasgo característico de la obra de esta escritora. Dicha repetición se lleva a cabo a través del uso continuo de la técnica narrativa del flashback. La escritora recuerda aquellas tardes en las que se escondía en un baúl para que su padre la encontrase y en las que iba al parque de la Media Luna acompañada de sus hermanas y sus niñeras. Sin embargo, junto a los conflictos temporales sintetizados por McClennen referentes a la esquematización del eje temporal, es necesario incorporar otros dos fenómenos a la luz de la obra de esta narradora. El primero de ellos es el inicio de una nueva estructuración del tiempo que tiene como punto de partida la guerra civil, rasgo que aparece en las obras de otros escritores de la generación, tal y como demostré también en el capítulo previo. María Luisa Elío Bernal en uno de los relatos de Cuaderno para apuntes que forma parte 
de la serie "En el balcón vacío" divide el orden cronológico temporal en dos partes, el antes y el después del conflicto bélico: "Y después el tiempo se hace distancia, cinco años después de la guerra, quince años después de la guerra..." (Tiempo 125). Considera, durante mucho tiempo, la guerra civil como el elemento histórico clave en el desarrollo de su vida y, por ello, se convierte en eje organizador del tiempo. Así, la guerra civil es el punto detonante que separa su infancia de su madurez y, por lo tanto, se establece como punto de partida de un nuevo discurrir temporal.

En segundo lugar, hay que hacer referencia al fenómeno de la concepción del viaje de regreso al país de origen como elemento que da razón de ser a un nuevo orden temporal para el exiliado. El hecho de que el viaje funcione como mecanismo para borrar las huellas del pasado permite así romper los lazos del exiliado con la nostalgia y su incorporación al presente. No obstante, aunque este viaje pueda entenderse como un instrumento para reconectar al exiliado con el presente, no se trata del presente de su país de acogida ni del presente de su país de origen, sino que, desde mi perspectiva, se trata de un presente individual y propio, fuera de la necesidad de elegir un momento histórico del que sentirse parte. Así, del mismo modo que hablábamos de transnacionalismo, cabría hablar de "transtemporalidad". María Luisa Elío ha escapado de las garras tiránicas de la historia como elemento opresivo. Puesto que la historia está asociada, intrínsecamente, a una nación y los exiliados han sido borrados de la de su país durante el régimen franquista, es lógico pensar que ellos no pertenecen a esa historia narrada por la nación propuesta desde el otro lado de su océano. No obstante, si la aceptación de su situación especial en el espacio como exiliada se configura como elemento característico de dicha generación, puede pensarse también que María Luisa, a través del viaje, ha entendido su 
particular posición en la configuración de un tiempo histórico, lo que le ha llevado a aceptar el propio exilio como un momento histórico con un tiempo propio, fuera de cualquier otra nación: "Ahora yo estoy a punto de cerrar el círculo" (Tiempo 26). No debe confundirse el término "transtemporalidad" aquí propuesto con el que crearon Witlin y Claudio Guillán al hablar de "destiempo". A pesar de que los dos comparten el hecho de haber sido expulsados del tiempo presente y del futuro del país de origen, el término de "transtemporalidad" conlleva la identificación de un tiempo individual como ser humano, desligado del de una colectividad de origen ligada a un país único. Cerrar el círculo del pasado implicaba así poder incorporarse al presente propio del exiliado, un tiempo transtemporal, desligado de una historia en concreto más que la del exiliado propia, una historia universal.

El último de los rasgos identitarios a debate sobre la obra de María Luisa Elío Bernal es el lenguaje. En el capítulo anterior, ya se atendió a la doble vertiente de este: lenguaje como forma de representación, por un lado, y lenguaje como sistema de comunicación por otro. No obstante, ahora es preciso prestar atención a la segunda acepción puesto que, respecto a la primera de ella, no hay gran diferencia con el resto de miembros de la segunda generación, lo cual ya ha sido expuesto en dicho apartado. Ser de un lugar implica compartir un mismo idioma con el resto de miembros de dicha comunidad. Ser expulsado de un lugar, por lo tanto, puede conllevar el abandono de tu lengua materna para tener que adoptar la del país de origen. Frente a esto, el lenguaje ha sido y será el medio a través del cual el ser humano ha podido manifestar su experiencia de vida con el otro. A quién le pertenece ese lenguaje y la capacidad de este para traducir un suceso como el exilio son también cuestiones a resolver. 
Las relaciones entre lenguaje y cultura parecen ser evidentes, aunque no por ello excluyentes. Es decir, una cultura puede tener varios lenguajes y un lenguaje puede tener, al mismo tiempo, varias culturas. Sin embargo, como Edward Sapir afirma, el lenguaje no existe fuera de la cultura, es decir, más allá del ensamblaje socialmente heredado de costumbres y pensamientos que determinan el funcionamiento de nuestras vidas (207). En el caso de María Luisa Elio Bernal, son muchos los elementos que influyen en las relaciones entre ambos elementos. En primer lugar, María Luisa Elío Bernal, como muchos otros exiliados, antes de marchar a México, tuvo que afrontar los problemas que el desconocimiento del francés le suponía, ya que Francia se convirtió en su primer país de acogida alrededor de dos años. Así, la lengua que hasta ahora había utilizado como elemento comunicativo de su sociedad dejó de serle útil. De hecho, ella misma lo recordaba en la obra de la siguiente forma: "Recordé a la niña del internado quien, el primer día que llegamos, me tiró la pelota a los pies gritándome: 'Et toi, la nouvelle, passe moi la balle'. Nunca olvidaría el nombre de pelota en francés” (Tiempo 23). La necesidad de aprender un nuevo idioma se oponía, en cierta medida, al deseo de los exiliados de preservar su idioma materno, uno de los pocos elementos que aún conservaban de la que había sido su patria desde su nacimiento. A este choque cultural que supuso la confrontación con otra lengua cabe añadir, posteriormente, el choque con el español de México. A pesar de compartir un mismo lenguaje, no así una misma forma de utilización de este. Aunque la comunicación era posible, son notables las diferencias entre los dialectos. Prueba de ello es el diálogo entre madre e hijo en Tiempo de llorar: “Mamá, ¿por qué va vestido así y llama al elevador ascensor, como tú?” (23). Esto influyó en la crisis de identidad de la segunda generación de escritores, la cual se vio 
acrecentada por esa educación en colegios y escuelas creados por el grupo de exiliados que los mantenía, en cierta medida, al margen del español de México. No obstante, el lenguaje de María Luisa poco a poco fue evolucionado para crear un lenguaje que ya no hacía referencia ni al habla de España ni al de México, sino al lenguaje del exilio. Así, Pual Illie describe la lengua del exilio como "graphocentrism", puesto que este "denationalizes Spanish and encourage language to float unanchored to any particular nation” (Exolalia 246). Sin embargo, Sophia McClennen no afirma estar totalmente de acuerdo con la existencia de este fenómeno. El hecho de que el lenguaje flote sin estar vinculado a ninguna patria resultaría en un elemento liberador y, por lo tanto, positivo de la experiencia; es decir, sería una idealización de dicha experiencia. Sin embargo, según mi opinion, el hecho de que el exiliado haya conseguido crear un lenguaje, mezcla del de su país de origen y del de país de acogida, no lo sitúa como un elemento liberador, mejor o peor que los otros lenguajes, sino como un elemento diferente, un nuevo rasgo identitario de este grupo social. El hecho de haber creado un nuevo sistema de comunicación no implica que, en determinadas ocasiones, no surja la disyuntiva social al enfrentar su lengua con los otros miembros de dicha comunidad cuya forma de "moldear" el lenguaje difiere. En definitiva, si decíamos que el exiliado había configurado una identidad alejada de la necesidad de identificarse con una nación y que el tiempo había pasado a tener una conceptualización vinculada a su propia historia, individual y universal a la vez, es sensato pensar que se ha producido también la creación de un nuevo lenguaje, de alguna forma "a-nacional”, en respuesta al desplazamiento producido con el exilio. 
Para concluir, quiero volver a llamar la atención sobre el elemento que ha funcionado como común denominador en la formación de una identidad en el exilio: el primer viaje de regreso a la patria. A pesar de los numerosos estudios en torno a este, creo que no se le ha dado el lugar correspondiente como elemento organizador de la traumática experiencia del exilio. A lo largo de todo este relato en busca de una identidad fundamentada en conceptos de nación-espacio, tiempo y lenguaje, ha sido el viaje y, por lo tanto, la constancia de la no-existencia de una realidad imaginaria el elemento que ha provocado la ruptura definitiva con el lugar de origen para poder llevar a cabo la configuración de dicha identidad. Así, el viaje de retorno es el punto de inflexión en una escritora que, hasta entonces, había vivido atrapada en la España de antes de 1936, una España que se mantuvo vigente en su mente durante más de 30 años y que es transformada, borrada, asesinada el día que aterriza por primera vez en España: "Y AHORA ME DOY CUENTA QUE REGRESAR ES IRSE. Es decir, que volver a Pamplona es irse de Pamplona. Al fin voy a volver donde las cosas no están ya. He vivido en el mundo de mi propia cabeza, el verdadero mundo quizá, y contando poco con el mundo exterior. Ahora al fin me atrevo a regresar donde la gente ha muerto. Por eso sé que regresar es irse, irme. Irme de una vida, casi de toda una vida (y sigo hablando en el orden del pensamiento), porque sé que ahora la mirada tan sólo va a servir para borrar. Lo sé, lo sabía, y en ese saber tiene una importancia total el verificar. Pamplona, tan sólo un lugar". (Tiempo 19)

En definitiva, el viaje de regreso y su posterior escritura asume una función restauradora en la figura de María Luisa Elío Bernal. A través de este, la escritora 
pamplonesa consigue acabar con su pasado, borrarlo, para poder dar lugar a un nuevo presente. Dicho presente se caracteriza por la instauración de una identidad aferrada a unos patrones distintos de los de aquellos seres humanos que no han sufrido la experiencia del exilio, unos patrones alejados de una específica sociedad vinculada al espacio, al tiempo y al lenguaje de una nación, de un país, en concreto. Así, María Luisa Elío Bernal pasa a pertenecer a la sociedad del exilio, una sociedad única cuyo principal elemento identificativo es la de que los términos de "espacio", "tiempo" y "lenguaje", hasta ahora utilizados para definir el concepto de identidad nacional, no están vinculados una nación en concreto, sino que se configuran de forma especial en el momento en el que se unen al fenómeno del exilio. Por lo tanto, tras la escritura de Tiempo de llorar y Cuaderno para apuntes, María Luisa configura una identidad desterritorializada o transnacionalista, transtemporal y grafocéntrica, una identidad más allá de las garras de unas fronteras. 


\section{Capítulo V}

\section{Jorge Semprún: "Había Hecho del Exilio una Patria"}

\section{Semblanza biográfica}

Miembro de una de las familias aristocráticas y políticas más importantes del siglo $\mathrm{XX}$; un rojo español, integrante del comité ejecutivo del PCE clandestino y director de la organización intelectual de este en España durante 10 años; ganador del premio Formentor en 1962 con su primera novela, Le Grand Voyage, y, posteriormente, una de las figuras literarias más importantes del siglo XX; ministro de cultura en España durante la segunda presidencia de Felipe González en 1988 con el PSOE; afrancesado hasta el punto de ser nominado para ser miembro de la Real Academia de la Lengua Francesa. Sin embargo, Jorge Semprún tuvo muchas más facetas. Fue un jardinero, Gerard Sorel, durante sus años en la resistencia francesa anti-nazi; fue el preso 44.904 en Buchewald; fue Santiago, el personaje protagonista de su primera obra de teatro inédita, Soledad, y, casi de forma simultánea, fue Georges Falcó, autor de algunos artículos en las revistas comunistas del PCE; también fue Jacques Grador, nombre con el que entraría de forma clandestina, por primera vez, en España en el año 1953; o Federico Sánchez, pseudónimo que utilizaría durante el periodo de trabajo clandestino para el PCE en España; en La Algarabía fue Rafael Artigas y Carlos Bustamente, ambos alter-egos, y en La montaña blanca fue Juan Larrea, heterónimo igualmente, en cierta medida también, de Jorge Semprún; del mismo modo fue Camille Salagnac, uno de los nombres utilizados en el relato de Aquel Domingo.

En todo este entresijo de caracteres, Semprún se movió en multitud de círculos, tanto en los más pobres durante su estancia en Buchenwald y su retorno a París, hasta en 
los más elitistas, rodeado de personas con mucho poder, líderes revolucionarios, embajadores, presidentes, reyes y reinas. Durante su vida participó del panorama intelectual tanto francés como español y conoció a gran parte de las figuras literarias del momento de ambos países. Del mundo francés, entraría en contacto, entre muchos otros, con Maurice Halbwachs, quién había sido profesor suyo y con el que se reencontraría en Buchenwlad, Marguerite Duras y Robert Antelme, compañeros del PCF, o Alais Resnais e Ives Montand. Por la parte española, principalmente durante su tiempo como organizador intelectual clandestino del PCE, conoció a Blas de Otero, Javier Pradera, Carmen Martín Gaite, Rafael Sánchez Ferlosio, Ángel González, Luis Goytisolo y su hermano Juan. Este último, en sus memorias, haría referencia a Semprún de la siguiente forma: "Jorge era culto, seductor, desenvuelto y brillante, se movía en el medio intelectual francés como un pez en el agua y compaginaba su audacia de hombre de acción con una soterrada pasión por la literatura" (4613-4624). Fueron todas estas cualidades las que ayudaron al escritor madrileño a llegar a lo más alto de las esferas de poder. Sin embargo, ¿quién fue Jorge Semprún?

Antes de explorar, en la medida de lo posible, la respuesta a dicha pregunta, es preciso aclarar que esto no pretende ser un desarrollo en profundidad de la vida de Jorge Sempún entre otros motivos porque carece de interés debido a la existencia de varios estudios sobre ello ya escritos. Además, tampoco es el objetivo de esta investigación, como ya expliqué al hablar de María Luisa Elío Bernal. Simplemente, procuro afrontar aquellos episodios más relevantes de su vida para, en los próximos apartados, poder entender, de forma más exacta, en qué medida estos episodios biográficos son reflejados en su obra literaria en aras de la búsqueda de su identidad. Con este propósito, he acudido 
a numerosas fuentes: en primer lugar, la propia obra del autor, aunque hay ciertos pequeños detalles, especialmente en cuanto a fechas, que no son del todo ciertos; en segundo lugar, a las numerosas entrevistas que este ha dado a lo largo de su vida; y, en tercer lugar, tanto al recién publicado Diccionario bibliográfico de los escritores, editoriales y revistas del exilio republicano de 1939, como a los dos monográficos escritos sobre su vida: por un lado, la obra de Felipe Nieto, La aventura comunista de Jorge Semprún. Exilio, clandestinidad y ruptura, un fabuloso trabajo que ofrece, de forma pormenorizada, todos los detalles necesarios desde el comienzo del exilio en 1939 hasta su ruptura definitiva con el PCE en 1964; por el otro lado, el libro de Soledad Fox Maura: Ida y vuelta. La vida de Jorge Semprún.

El 8 de junio de 2011 España se despertaba con la noticia en todos los periódicos de la última despedida de Federico Sánchez. Jorge Semprún había fallecido en París el día anterior a causa de su lucha con el cáncer. El polifacético escritor ponía fin así a una vida que había comenzado el 10 de diciembre de 1923. Hijo de José María de Semprún Guerra y Susana Maura y Gamazo y, por lo tanto, nieto de Antonio Maura, nacía en una de las familias nobiliarias más poderosas y mejor conectadas de la sociedad del momento. Su padre, abogado de profesión, profesor de filosofía del derecho en la Universidad de Madrid, católico devoto y con afanes literarios. Su madre, ama de casa, educada en los colegios católicos femeninos de la élite madrileña y defensora de una educación moderna. Semprún era el cuarto hermano de un total de siete. A su hermana mayor Susana, le seguía María Isabel y Gonzalo. Después de él, vendrían Álvaro, Carlos y Francisco. Los siete hermanos fueron instruidos según los ideales de la Institución Libre de Enseñanza, fundada por Francisco Giner de los Ríos. Su propia madre se encargó de 
enseñar a los niños mayores a leer y a escribir. Desde su nacimiento contaron con institutrices alemanas. Con una de ellas, Annette Litschi, rehizo su vida José María de Semprún Guerra tras la muerte de su esposa Susana en 1932 después de una larga lucha contra una infección contraída unos años antes. Al parecer, la relación de todos los hermanos con la madrastra no fue muy buena.

La infancia en el número 12 de la calle de Alfonso XI de Madrid — que aparece como símbolo de su infancia durante la narración del regreso como ministro de Cultura en Federico Sánchez se despide de ustedes — es recordada como un periodo feliz por parte del escritor madrileño. De hecho, se convierte en un leitmotiv de su obra:

Tan sólo tengo recuerdos de mi infancia en los que subsidiariamente entra juego la manduca. manduca. Los pasteles de merengue de los domingos, en Madrid. Los churros del desayuno, los días festivos, después de la misa en San Jerónimo. O también, cosa que deja maravillado a Fernand, el recuerdo enternecido de los garbanzos de un cocido familiar y sistemáticamente seminal. (Aquel domingo 767-769)

Durante este tiempo, su padre ejerce también como gobernador civil en Toledo y en Santander de la mano de su cuñado Miguel Maura, ministro de gobernación en el primer gobierno provisional republicano. Don José María Semprún introdujo al joven Semprún en el círculo de las tertulias literarias, en las que coincidía con Lorca y Alberti. Durante este tiempo, colaboró también en la Revista de Occidente, fue fundador de la publicación Cruz y Raya e 1933 y representó al grupo de católicos franceses Esprit en España. 
Sin embargo, todo este mundo de riquezas, poder y distinción desapareció con el estallido de la guerra civil. La familia Semprún había marchado a Lequeitio, Vizcaya, el 17 de julio de 1936, a una villa donde veraneaban desde el año 1933. Desde Bilbao, la noche del 22 de septiembre, marcharon a Bayona en un barco, destino al que llegarían al día siguiente, tal y como cuenta Jorge Semprún haciendo referencia a Rafael Artigas en La algarabia: "El 23 de setiembre de 1936 llegaba a Bayona, procedente de Bilbao, tras una noche de navegación a lo largo de las costas del País Vasco, ocupado ya por las tropas franquistas, a bordo de un pesquero bautizado con el predestinado nombre de Galerna" (313). Tras su llegada a tierras francesas, fue Jean-Marie Souto, quien posteriormente se casará con Maribel Semprún, el que se hizo cargo de la familia. Pasaron unos días en Lestelle-Bétharram y a principios de octubre se instalaron en Ginebra. En diciembre de ese mismo año, José María de Semprún fue nombrado secretario de primera clase en la Legación de España en La Haya. Esto fue el inicio del resquebrajamiento familiar, puesto que Jorge y Gonzalo fueron enviados a estudiar al liceo Henri IV y los siete hermanos ya nunca más estarían juntos de nuevo. Jorge terminó el bachillerato en este instituto destacando en la asignatura de filosofía. Mientras que estaban en este instituto, se produjo la victoria del bando sublevado y la familia fue trasladada a Saint-Prix, al norte de París.

Apenas unos meses más tarde, comenzó la II Guerra Mundial. Es curioso el hecho de que, aunque los autores de la entrada de Jorge Semprún en el Diccionario bibliográfico de los escritores, editoriales y revistas del exilio republicano de 1939 mencionen que estudió filosofía en La Sorbona, ninguna de las dos monografías biográficas citadas anteriormente haga mención a este episodio. Parece ser que sí fue así 
puesto que el propio Semprún habla de ello en su libro La escritura o la vida, pero debió dejar los estudios por las penurias económicas y por la invasión de Alemania de París no está muy claro cuál fue la causa primera—. Abandonados los estudios, dedicó su tiempo a participar en la resistencia francesa en contra del nazismo, concretamente se incorporó al grupo Jean-Maria Action, pero fue detenido por la Gestapo en Joigny el 8 de octubre de 1943. Tras ser torturado en la prisión de Auxerre —episodio que sólo aparece reflejado en su obra póstuma Ejercicios de supervivencia — fue trasladado el 27 de enero de 1944 a Buchenwald acompañado de otros 1.583 prisioneros según los datos recogidos por Felipe Nieto (424).

Al llegar al campo de concentración, fue registrado con el número 44.904 como stukateur (estucador), lo que pudo haberle salvado la vida, ya que esto le evitó ser enviado a los campos del exterior más duros, como Dora. A los tres días de entrar en el campo, fue recibido por Falcó, un dirigente del PCE clandestino en Buchenwald. Este le asignó un puesto de trabajo en la administración: la Arbeitsstatistik, lo cual también favoreció la supervivencia del escritor madrileño. Entre los trabajos de Semprún estaba contabilizar las nuevas entradas en el campo, así como las bajas, asignar puestos de trabajo y elaborar las listas de prisioneros que más tarde eran enviados a campos de concentración más duros donde la muerte era prácticamente inevitable. Esto ha suscitado dos debates en los que no pretendo entrar, pero considero que es oportuno enunciarlos para que el lector los conozca: por un lado, Soledad Fox Maura ha especulado sobre las razones que situaron a Semprún en una posición tan ventajosa dentro de la clandestinidad en el campo de concentración (Cap. III); por otro lado, en reuniones de deportados y supervivientes de dichos campos también se cuestionó la responsabilidad moral de estos 
comunistas que colaboraron con los alemanes para elaborar las listas de aquellos que serían mandados a los campos más duros. Dejando a un lado ambas cuestiones, porque considero irrelevante el resultado de ellas en la actualidad, el resultado es que Semprún vivió la liberación del campo el 11 de abril de 1945.

E1 29 de abril de 1945 Jorge Semprún regresó a París, que no a su patria como él mismo insistió en varias de sus obras, y marchó por un tiempo a Saint-Prix, donde estaba su padre, y posteriormente a Berna, a casa de su hermana Maribel y su cuñado JeanMarie Souto. Durante esta época, tuvo un accidente en la estación de tren de Gros NoyerSaint-Prix que fue el punto de partida de su segunda obra El desvanecimiento. A principios de 1946 regresó a París, y a pesar de su penuria económica, comenzó a relacionarse con el mundo intelectual francés (Marguerite Duras, Robert Antelme, Claude Roy, Roger Vaillant, etc.) y formó parte de la célula 722 del PCF. En 1947 fue contratado por la Unesco como traductor y revisor. Durante este tiempo, había dado el salto del PCF al PCE y había conocido a la actriz Loleh Bellon, con la que, el 23 de julio de 1947, tuvo un hijo: Jaime Semprún. La pareja se separó en 1949, después de tres años de convivencia.

Ya en 1947 se había producido el primer encuentro de Semprún con la líder comunista española, Dolores Ibarruri. También en este año escribió en francés su obra de teatro Soledad, cuyo personaje, Santiago, es un alter-ego. Aunque nunca estrenó ni publicó esta obra, Felipe Nieto afirma que ya pueden observarse en él los temas obsesivos de su obra: "La clandestinidad como [...] camino hacia la conquista de una identidad. La política como destino individual (...) La libertad, precisamente, como factor decisivo de todo compromiso político y existencial" (pos. 1971-1974). Desde este 
momento hasta 1953, Semprún desarrolló su tarea dentro del PCE y participó en numerosos actos de este: comisión pro-presos que tiene como fin mejorar las condiciones de los presos franquistas; la creación de la revista Cuadernos de Cultura y posteriormente de Cultura y Democracia, etc.

Sin embargo, en 1952 Jorge Semprún abandonó la Unesco para, poco después, dar el paso que, probablemente, fuera el más importante de su carrera política: su primer viaje clandestino a España en 1953. Así relató este momento en La escritura o la vida: En 1953, cuando regresé a Madrid por primera vez para trabajar en la clandestinidad de la organización comunista, me precipité a la calle Alfonso XI. Apenas había dejado la maleta en el hotel en el que me alojaba con mi pasaporte falso, atravesé Madrid a la carrera hasta la calle Alfonso XI. La ciudad de mi infancia todavía no se había convertido en la metrópoli industrial, tentacular, salvajemente suntuosa y destartalada que es hoy en día. (...)

Sin embargo, aquel atardecer de junio de 1953, pese a la perfecta identificación de los recuerdos y de las imágenes del presente, un desasosiego indistinto, innombrable mejor dicho, me destrozó el corazón nada más llegar a la calle Alfonso XI, nada más contemplar los balcones del último piso de la casa, donde había pasado mi infancia". (160)

El primer viaje lo llevó a cabo con un pasaporte a nombre de Jacques Grador. José Serrán, secretario de Carrillo, ya lo había bautizado entonces con el pseudónimo de Federico para su actividad en el interior de España en relación con los intelectuales y estudiantes. Este viaje se prolongó un mes. Recorrió Barcelona, Valencia, Madrid, 
Salamanca y San Sebastián y se reunió con figuras como Vicente Aleixandre, Celaya y Enrique Múgica. Así comenzó una vida de clandestinidad en España que se prolongó durante diez años. Durante este tiempo, se produjo la celebración del Congreso de Jóvenes Escritores; asistió al V Congreso del Partido, celebrado fuera de España; fue nombrado miembro del comité central; escribió el "Manifiesto a los universitarios españoles", firmado por gran parte de los intelectuales del momento y por el que muchos de ellos —Javier Pradera, Dionisio Ridruejo, Miguél Sánchez Mazas, Enrique Múgica, José Luis Abellán, Fernando Sánchez Dragón, etc.—fueron detenidos, etc. A partir de 1956, Semprún se instaló en Madrid para pasar temporadas más largas. Residió en el número 5 de la calle Concepción Bahamonde, apartamento que el PCE habría comprado a través de una pareja comunista y en el que él "alquiló" una habitación bajo el nombre de Rafael Bustamente. Asimismo, propuso la creación de una nueva revista, Nuestras ideas. Teoría, política, cultura, de la que Fernando Claudín y él estuvieron a cargo. Siguió con sus actividades culturales e intelectuales: homenaje a Antonio Machado, campaña comunista por la amnistía, colaboración en el intento de huelga general promovida por Carillo en 1959, etc. Asistió al VI Congreso del Partido en Praga por el que Carrillo pasó a ser secretario del PCE e Ibarruri fue elegida presidenta. Ya en esta época escribió su primera obra, El largo viaje, lo que significaba la realización de uno de sus sueños: convertirse en escritor. En 1960 también fue amonestado por primera vez por el PCE.

En noviembre de 1962 celebró su último viaje clandestino a España, ya que Carrillo, alegando que era por su seguridad, había decidido sustituirlo de forma repentina por José Sandoval, quien sería detenido en 1964. Tras su regreso a Francia, Semprún fue 
aconsejado que resolviera su situación legal en París y se casó con Colette Leloup, su segunda y última esposa. Recibió el premio Formentor por su novela, cuya ceremonia escribió extensamente en La escritura o la vida. En 1963 se produjo un fuerte enfrentamiento entre dos bandos por la nueva propuesta agrícola: por un lado Semprún y Claudín; en el otro lado, Carrillo y Gallego. Los primeros decidieron escribir sendos artículos, sin autorización previa, explicando su disconformidad con esta situación en la revista del partido Realidad, de la que Semprún era responsable. Esto fue considerado un acto de indisciplina y fue el origen de una nueva crisis en el PCE que, tras algunas reuniones, la expulsión del comité ejecutivo y la negativa a rectificar, acabó con la definitiva expulsión del PCE de Jorge Semprún y Fernando Claudín en 1964. Sobre esto se expresó así Semprún en su obra Autobiografía de Federico Sánchez:

Creo ser perfectamente sincero conmigo mismo si digo que me embargaban en ese momento dos sentimientos contradictorios. Por un lado la certeza de que se terminaba un periodo esencial de mi vida, sin duda el más importante de mi vida, el más rico de aventura y de experiencia. Por otro, la íntima satisfacción de haber sido fiel hasta el fin a mis convicciones más profundas, de no haber traicionado aquella libertad comunista que me llevó al Partido, a los dieciocho años, y que ahora, en función de una idéntica exigencia de rigor y de coherencia, me expulsaba del Partido. (282)

Tras la salida del PCE, Jorge Semprún se dedicó a la escritura, entre otros quehaceres, en Francia. En 1967 escribió El desvanecimiento; en 1969 salió a la luz La segunda muerte de Ramón Mercader, por la que ganó el Premio Fémina; en 1977 el 
Premio Plantea le llegó de la mano de Autobiografía de Federico Sánchez, primer libro escrito en castellano, y en 1980 publicó su obra Aquel domingo, en el que volvió a relatar su experiencia en Buchenwald tomando la conversación de un domingo con Barizon, compañero de su experiencia, como punto de partida. A esta le siguió La algarabía en 1981, La montaña blanca en 1986 y un año más tarde Netchaiev ha vuelto. Cabe señalar que durante este período Semprún también desarrolló una importante carrera en el mundo de la cinematografía. Escribió el guion de las películas La guerra est finie (1966) y Stavisky (1974), ambas dirigidas por Alain Resnais; para Costa Gavras compuso el guión de $Z$ (1968) y L'Áveu (1970) y adaptó la novela Sección Especial (1975). A esto hay que sumar los guiones de L'attentat de Yves Boisset, en 1972, y Les routes de Saud de Joseph Losey en 1978. En 1973 realizó un documental sobre la guerra civil española llamado Les deux memoires.

No obstante, la última gran aparición de Jorge Semprún en el mundo de la política llegó en 1988 de la mano de Felipe González. A este lo había conocido en 1975, cuando Franco ya se encontraba en sus últimos días y desde el principio entablaron una buena amistad. Su madre ya había dicho en su infancia que su hijo sería escritor o presidente de la República. Ya se había convertido en escritor y aunque ya no pudiera ser presidente de la República, el próximo cargo que ostentaría lo situaba en una posición no tan alta, pero cercana:

Javier solaba estaba al teléfono. Su entrada en materia fue desconcertante. «Dime», me soltó a bocajarro, «¿cuál es tu nacionalidad?» (...) Por tanto, respondí inmediatamente a Solana que tenía un pasaporte español. Me pareció que esta noticia le tranquilizaba. 
«Bueno, pues entonces puedo continuar», me dijo. «¿Estás sentado para oír lo que viene a continuación?» Todo aquello comenzaba a intrigarme. Le dije que estaba de pie pero que me mantendría firme. «Siéntate de todas maneras», insistió Solana, y me lanzó el mensaje que estaba encargado de hacerme llegar. Felipe González iba a proceder en los días próximos a una remodelación de su Gabinete y me proponía el Ministerio de Cultura. Tenía la noche para reflexionar, nada más. Necesitaba una respuesta al día siguiente por la mañana. En el caso de aceptar, me enviaría un billete de avión para encontrarme con González en Madrid. Cenaríamos juntos en La Moncloa, el miércoles". (Federico 18-22)

De esta forma, Jorpe Semprún comenzó su aventura como ministro de cultura de España durante tres años, periodo que relata en su libro Federico Sánchez se despide de ustedes. Sin embargo, su identidad de "extranjero" y de "afrancesado" no hizo fácil su trabajo en muchas ocasiones, como así tampoco se lo puso fácil la figura de Alfonso Guerra, con el que estuvo enfrentado durante todo este período y a cuyo hermano no dudó en atacar públicamente cuando fue acusado de corrupción en la sede del partido de Sevilla. Esto provocaría la dimisión de Alfonso Guerra y, un año más tarde, la suya propia en 1991.

De esta forma, Jorge Semprún, a los 68 años, cesaba su carrera en la política española, con la que se había comprometido con su entrada clandestina en el PCE a los 18 años. A partir de ese momento, se dedicó única y exclusivamente a dar conferencias y a escribir sobre los campos de concentración y sobre los problemas sociales y políticos de Europa. Posteriormente, publicó La escritura o la vida (1994), considerada para muchos 
su gran obra; Adiós, luz de los veranos (1998) y Vivirá con su nombre, morirá con el mío (2001), consideradas estas dos últimas como relatos de infancia; y Veinte años y un día, segunda y última obra escrita en castellano (2003) y ganadora del premio José Manuel Lara en 2004. Justo antes de su muerte, en 2010, salió al mercado Pensar en Europa y apenas hace un año, en 2016, se publicó su obra póstuma Ejercicios de supervivencia, con prólogo de Mario Vargas Llosa.

Como decía al principio, Jorge Semprún falleció el 7 de junio de 2011. Antes de hacerlo, había dejado dicho que quería ser enterrado en Biriatour, un pueblo fronterizo entre España y Francia, gesto simbólico que representa la dualidad de un exiliado incapaz de retornar:

En ese lugar fronterizo, patria posible de los apátridas, entre los dos ámbitos a los que pertenezco —el español, que es de nacimiento, con toda la perentoriedad, a veces abrumadora, de lo que cae de su propio peso; el francés, que es electivo, con toda la incertidumbre, a veces angustiosa, de la pasión_-, en la vieja tierra de Euskal Herria. Ese es el lugar, a mi entender, que mejor perpetuaría mi ausencia. (Adiós 203)

A pesar de sus deseos, sus restos se encuentran en Garentreville junto a su mujer Colette en un ataúd envuelto por la bandera republicana, deseo este último que si se le concedió.

\section{La reescritura como búsqueda identitaria}

"Decirlo todo es imposible. No bastaría una vida. Todos los relatos posibles no serán nunca sino fragmentos desperdigados de un relato infinito, literalmente interminable" (Aquel domingo 1467-1468). Con estas palabras, Jorge Semprún ya 
anunciaba la incapacidad de la escritura para aprehender la totalidad de un relato, de una vida, de su vida, y, por lo tanto, la imposibilidad también de conocer quién era él a través de sus obras. Y es que, como afirma Carlos Fernández, el escritor madrileño es autor de un mismo libro "que se escribe sin cesar, con datos nuevos, juicio ponderados por la experiencia, recursos narrativos más complejos" ("Estrategias" 69). Son estos mismos nuevos datos y recursos narrativos empleados los que abren una serie de interrogantes en lo que concierne a la relación del autor con la escritura.

En primer lugar, cabe preguntarse cuál es el objetivo de su narración y de qué forma dicho objetivo entronca con la construcción de una identidad, cuanto menos problemática, tras la salida de España. A la hora de analizar dicho aspecto, es necesario prestar atención al perspectivismo creado en sus obras a través del relato del mismo acontecimiento desde distintos momentos históricos y múltiples puntos de vista. La experiencia del campo de concentración es narrada en El largo viaje, pero también en El desvanecimiento, en Aquel domingo, en La escritura o la vida y en Viviré con su nombre, moriré con el mío. Por otro lado, la infancia es tema recurrente en La algarabia, Adiós, luz de veranos... y Veinte años y un día. Esta recursividad hace necesario plantearnos cómo el cuestionamiento de un mismo tema en determinadas obras apunta a la búsqueda de una identidad. Al mismo tiempo, analizar los mecanismos de aproximación a la realidad o, dicho de otra forma, profundizar en qué medida se produce una dialéctica entre la ficción y la realidad, la verosimilitud y la autenticidad, es inevitable para poder entender el proceso de la reescritura como búsqueda de esa identidad. La presencia de una lucha interna entre estos elementos va a contribuir, además, a que sea necesario indagar en las razones que ha llevado a Jorge Semprún a la elección de una multiplicidad 
de géneros literarios dentro del mundo del yo en los que se inscribe su narrativa. Por último, se lleva a cabo un cuestionamiento del papel de la memoria y el lugar de la individualidad/colectividad en la construcción identitaria de la escritura.

No obstante, antes de comenzar dicha tarea, cabe apuntar un aspecto en cuanto al campo de trabajo que ya se comentó en la introducción de este trabajo. Previamente ya se señaló que algunos críticos como María A. Semilla Durán habían clasificado la obra del escritor madrileño según el establecimiento de las representaciones ficticias del yo con su propia persona. Según esto, Semilla Durán había clasificado su obra en tres grandes categorías: por un lado, aquellas narrativas en las que el "doble legítimo" del autor es el protagonista de una narración ficcionalizada de los eventos que él mismo experimentó, como es el caso de El largo viaje y El desvanecimiento; en segundo lugar, se encuentran aquellos relatos que contiene un "doble legítimo" cuya vida coincide únicamente de forma parcial con la del autor, tal y como ocurre en La montaña blanca; y, finalmente, existe una tercera categoría que incluye obras como La algarabía o La segunda muerte de Ramón Mercader, en las que el protagonista, cuyo nombre es bien ficticio o bien real, y su trayectoria no coincide con la del autor, aunque puedan encontrarse rasgos, conocimientos o comportamientos de rasgos autobiográficos (158). Dicho esto, es necesario recordar que únicamente las obras pertenecientes al primer grupo son objeto de análisis de este trabajo, ya que se considera que la reflexión sobre el establecimiento de la identidad es más propicia en aquellas narraciones que gozan de un mayor acercamiento al componente autobiográfico del autor. Por lo tanto, las obras que, desde mi punto de vista, deben pertenecer a esta categoría son: El largo viaje, El desvanecimiento, Autobiografía de Federico Sánchez, Aquel domingo, Federico Sánchez se despide de ustedes, La 
escritura o la vida, Adiós, luz de los veranos ... y, en menor medida, Viviré con su nombre, morirá con el mío. Esto no quiere decir que no sea posible encontrar citas o referencias a otras obras puesto que, como ya se señaló, en todas ellas hay componentes autobiográficos que, en un determinado momento, pueden ser de utilidad para arrojar un poco de luz sobre la construcción de su identidad, como es el caso de la reflexión sobre la lengua que se lleva en La algarabía o la reconstrucción de la infancia, el exilio y la nostalgia en obras como Veinte años y un día. Ahora bien, la justificación de por qué pueden clasificarse estas obras como pertenecientes al primer grupo debe esperar hasta el final de este apartado, momento en el que se estudian las relaciones entre la ficción y la realidad en el establecimiento de los géneros literarios en la obra de Semprún.

En La escritura o la vida, Jorge Semprún explica el nacimiento de su primera obra, El largo viaje, como una respuesta al discurso desordenado y confuso de Manuel A., superviviente de Mauthasen. Así lo confesaba:

Me desperté sobresaltado, al cabo de una semana de relatos sobre Mauthausen de Manuel A. (...) Todo me parecía claro, a partir de ahora. Sabía cómo escribir el libro que había tenido que abandonar quince años antes. Mejor dicho: sabía que podía escribirlo, a partir de ahora. Pues siempre había sabido cómo escribirlo: me había faltado valor para hacerlo. Valor para afrontar la muerte a través de la escritura. Pero ya no tenía necesidad de este valor. (...) Iba a escribir para mí mismo, por supuesto, sólo para mí. Ni hablar de publicar lo que fuera, en efecto. Resultaba impensable publicar un libro mientras fuera un dirigente clandestino del P.C.E. (259-260) 
Jorge Semprún había luchado, desde su salida del campo de concentración de Buchenwald, con el recuerdo, intentando enterrarlo en lo más profundo de su memoria para poder sobrevivir. Desde 1945, momento en el que Buchenwald es liberado, hasta 1962, fecha de publicación de El largo viaje, había vivido en la encrucijada entre la escritura o la vida, entre el compromiso social y el deseo de libertad. Como ya afirma $\mathrm{M}^{\mathrm{a}}$ Pilar Suárez, El largo viaje es el resultado de una consciencia de lucha contra la violencia, contra el nazismo y, por lo tanto, contra el franquismo también (215). Para muchos de los exiliados, la lucha contra la invasión nazi significaba luchar contra la dictadura franquista ya que, una vez derrotada esta, confiaban en que el gobierno impuesto por la fuerza en España no se prolongase durante mucho más tiempo. No obstante, una vez perdida la fe en la caída de franquismo y tras su salida del PCE, Semprún es capaz de enfrentarse a la muerte tras escuchar, en palabras de su amigo, la incapacidad transmisora de su relato. Por lo tanto, el hecho de "dar cuenta de ello", utilizando palabras del propio Semprún, era el primer objetivo de esta obra, testimoniar y dejar por escrito su experiencia. En algunas de las obras, como la ya citada El largo viaje o La escritura o la vida, así como Aquel domingo o Viviré con su nombre, morirá con el mío, el testimonio entronca en los campos de concentración nazis tras la huida de España. En otras, el eje va a ser la clandestinidad en España, como Autobiografía de Federico Sánchez; su período como ministro de cultura en Federico Sánchez se despide de ustedes; o la experiencia del exilio en Adiós, luz de los veranos ... De este modo, el testimonio como fin de una gran parte de su obra se articula en torno a los tres momentos claves de su vida — el exilio y posterior encierro en Buchenwald, la clandestinidad en España y el ministerio de Cultura-, todos ellos relacionados con el compromiso social del autor que 
ya se mencionaba anteriormente. Este se dibuja así como uno de los rasgos que nos permitían establecer todas esas obras como parte del primer grupo al que hacía referencia anteriormente, ya que el hecho de "dar cuenta de ello" es uno de los ejes motrices del relato, en oposición a los otros dos grupos cuyo objetivo final está más asociado al propósito clásico de la novela: entretener. De este modo, sólo aquellas obras en las que el discurso autobiográfico pesa más que el discurso novelesco son objeto de análisis.

Ahora bien, el compromiso social de Semprún, que se refleja tras la escritura de una parte de su obra, puede entenderse, en cierta medida, como un deseo de libertad, individual y colectiva. Escribir es revivir la memoria, dar salida a los recuerdos de los que ha huido durante casi 20 años y cuya reescritura a lo largo de su vida es el resultado de su enfrentamiento con la batalla al olvido. Y es que, como ya afirma Joseph Brodzky, "a freed man is not a free man, that liberation is just the means of attaining freedom and is not synonymous with it” (20). De este modo, Jorge Semprún, tras su liberación de los campos de concentración en 1945, se convierte en prisionero de la memoria. Hasta el momento de la escritura del primer libro, Jorge Semprún había conseguido imponerse a ella. Era consciente de que no estaba preparado para afrontar el relato de la muerte. Sin embargo, la conversión de este relato de la muerte en testimonio de forma que el lector sea consciente de lo sucedido y así educar a la sociedad del momento es su forma de hacer de la memoria una fuente útil para el compromiso social: "No poseo nada salvo mi muerte, mi experiencia de la muerte, para decir mi vida, para expresarla, para sacarla adelante. Tengo que fabricar vida con tanta muerte. Y la mejor forma de conseguirlo es la escritura. En eso estoy: sólo puedo vivir asumiendo esta muerte mediante la escritura, pero la escritura me prohíbe literalmente vivir" (La escritura 174). De esta forma, la 
escritura y el compromiso social surgen como dos elementos entrelazados característicos de su identidad. El silencio al que se había aferrado durante años era una carga de conciencia que le reclamaba luchar contra el olvido de lo vivido, contra el olvido de los que no lograron sobrevivir para contarlo: “¿Tenía yo derecho a vivir en el olvido? ¿A vivir gracias a este olvido, a expensas suyas? Los ojos azules, la mirada inocente de la joven alemana hacían que este olvido me resultara insoportable. No sólo el mío: el olvido general, masivo, histórico, de toda esta muerte antigua" (La escritura 195).

No obstante, la relación entre el compromiso social, la memoria y la escritura no se reduce a la narrativa que gira en torno a su experiencia en el campo de Buchenwald, sino que se extiende también a las otras obras en las que el primero de los elementos mencionados es el motor discursivo. La Autobiografía de Federico Sánchez, publicada en 1977 en español, resulta ser un ejercicio memorístico de su compromiso social durante su pertenencia al partido comunista español en el exilio como medio para cambiar la realidad de su país. Y es que, como el propio Semprún escribió en esta obra, la clandestinidad no fue sólo una aventura sino que lo consideraba como un "camino hacia la conquista de una verdadera identidad" (100). Su trabajo en la clandestinidad del PCE era un intento de defender su pensamiento político-social, rasgos identificativo de su ser. Pero, además, la escritura de esta obra tenía otros dos objetivos más: en primer lugar, era el punto de partida para una justificación sobre su papel dentro del PCE, en el que había dejado de creer. A sí mismo se define de la siguiente forma: "Hay que asumir lo que uno ha sido (...). Y yo he sido un intelectual estalinizado. Hay que saber lo que he sido y tengo que explicar por qué lo he sido. Sería muy fácil olvidarse del propio pasado" (19). En segundo lugar, era un ajuste de cuentas con el comunismo. Como bien afirma Molero 
de la Iglesia al hablar de las novelas autobiográficas — lo cual se explicará más adelante ya que, según esta escritora, la Autobiografía de Federico Sánchez es la primera tras la muerte de Franco-, muchas de estas novelas surgían en un momento de profunda decepción tras el fracaso de los sistemas colectivos y sus soluciones macrosociales dando lugar así al resurgimiento de la individualidad (La autoficción 38). De esta forma, Jorge Semprún intenta alejarse de la decadencia de un partido, que poco antes de la fecha de publicación del libro, había sido legalizado en España, para dar, una vez más, testimonio; en este caso, la narración tendrá como objetivo explicar la evolución del partido y su distanciamiento hasta el momento en el que la Pasionaria tomó la palabra para expulsarlos a él y a Fernando Claudín del partido, hecho con el que comenzará y terminará la obra: "Pasionaria está hablando. (...) Está fulminando contra vosotros los rayos de su cólera. (...) Está diciendo que sólo sois, Fernando y tú, $<<$ intelectuales con cabeza de chorlito $>>$ " (342). Con este objetivo, la memoria ocupa un lugar central en la obra, memoria a la que Semprún hace referencia constantemente para retar — sin dejar lugar a dudas al lector- el principio de autenticidad discutido por algunos críticos al hablar de él en relación al nuevo discurso autobiográfico creado en el último tercio del siglo XX (Molero, Alberca). Durante la obra, al describir su papel como director del núcleo intelectual clandestino del partido comunista español, reafirma, en numerosas ocasiones, la capacidad de su memoria, pues es esta la que le ha sabido mantener seguro durante más de 10 años en la clandestinidad ya que todas sus citas y encuentros dependían de ella debido a la incapacidad de anotar nada por temor a dejar rastro de sus encuentros. Es el llamamiento a esta memoria tan exacta la que otorga un mayor grado de autenticidad, de hecho, al relato. Es decir, si la memoria no le ha fallado en ningún 
momento durante sus años de relato, tampoco habría de hacerlo en el momento de la escritura, traicionando así el principio de la "verdad".

También en Aquel domingo, Federico Sánchez se despide de ustedes y La escritura o la vida, la relación entre el compromiso social y la memoria se dibuja como eje temático. En Aquel domingo, Jorge Semprún parte de la conversación con su amigo Gerard una tarde de domingo en Buchenwald como elemento estructurador de la obra. Sin embargo, realmente se trata de un juego de la memoria en el que, como ya explicamos en el primer capítulo y también al hablar de la función de la memoria en la obra de María Luisa Eló Bernal, acude a modo de mneme, es decir, la narración como el discurrir de los recuerdos que vienen a la memoria. Y es que, Molero de la Iglesia, afirma que esto es uno de los recursos del nuevo discurso autobiográficos del último tercio del siglo XX al que se hacía alusión anteriormente: “el autobiógrafo de nuestros días piensa que imitar el orden de la vida es una artificiosidad que traiciona el curso de la memoria, a la que concurren los recuerdos de forma inopinada, por lo que pasará de imitar el transcurso vital a imitar el fluir de la memoria" (La autoficción 41). Así, en Aquel domingo utiliza el papel de la memoria como técnica narrativa para ilustrar su compromiso social y dar testimonio. En Federico Sánchez se despide de ustedes la memoria transciende a la última etapa de su compromiso social político activo. Semprún asume su labor para construir una sociedad mejor a través de la dirección del ministerio de Cultura y una verdadera fe en el socialismo que, por aquel entonces, manifestaba el presidente de España, Felipe González. Así, a través del recuerdo que le viene a la memoria tras su llegada a Madrid y el establecimiento justo en frente de la que había sido su casa en la calle Alfonso XI antes de su huida de España, inicia su relato por los 
pasillos de las oficinas de gobierno en el que la memoria, a modo de flashbacks, establece un diálogo entre tres de los momentos claves de su vida: la infancia, Buchenwald y su labor como ministro de cultura. En La escritura o la vida —que, según palabras del propio Semprún, surge como respuesta a la muerte de Primo Levi— la reflexión sobre el papel de la memoria y los recuerdos ocupan también gran parte del relato. De forma irónica, Semprún escribía en La escritura o la vida: "este libro era fruto de una alucinación de mi memoria, el 11 de abril de 1987, el día del aniversario de la liberación de Buchenwald”. Sin embargo, el uso de la memoria y la escritura tenía aún un postrero fin: asumir la muerte de una parte de su yo, como ya lo había hecho María Luisa Elío Bernal con la escritura de Tiempo de llorar: "No poseo nada salvo mi muerte, mi experiencia de la muerte, para decir mi vida, para expresarla, para sacarla adelante, Tengo que fabricar vida con tanta muerte. Y la mejor forma de conseguirlo es la escritura. En eso estoy: sólo puedo vivir asumiendo esta muerte mediante la escritura, pero la escritura me prohíbe literalmente vivir" (180). Enfrentarse a la muerte era, en cierto modo, asumir la pérdida de una parte de su ser, de su libertad.

Ya hicimos alusión en los previos capítulos a la teoría de Ángel Loureiro según la cual "the reparation continues in the act of telling itself" (181). De este modo, la escritura sin fin de Jorge Semprún de la memoria tiene mucho de reparación del yo. A través de la escritura, Jorge se enfrenta a un elemento primordial de su identidad: el compromiso social. Es en la escritura de esta donde afronta la reparación de un yo que, como ya señalamos, había vivido durante años en el silencio, en el olvido, en la clandestinidad. Sin embargo, mientras que en el caso de María Luisa Elío hablamos de reparación como restauración del yo, en el caso de Semprún se trata de una reparación del yo como 
compensación por la pérdida. No se ha producido la muerte de una primera persona para dar lugar al nacimiento de una nueva, sino que la reparación de su yo en el relato consiste en, por un lado, compensar la pérdida de sus "compatriotas", es decir, la de todos aquellos que, como él, se habían unido para luchar por una causa social más allá de las fronteras nacionales, la de aquellos que no consiguieron sobrevivir al holocausto nazi. Por otro lado, también en aquellas obras en la que no se aborda los campos de concentración se produce una compensación por la pérdida, la pérdida de su fe en el comunismo y también la pérdida de fe en la democracia en su sentido más profundo de compromiso social. En definitiva, se trata de una compensación por el fracaso de proyectos a los que él había dedicado su vida. Narrar la experiencia traumática de haber "fallado" o de "no haber conseguido" aquello por lo que había luchado es una forma de afrontar el nuevo presente, de afrontarlo a través de su escritura. De esta forma, Loureiro, siguiendo a Levinas, afirma que en los textos de Semprún debe hablarse de the ethical constitution of the subject haciendo especial hincapié en La escritura o la vida ya que el autor se ve en la obligación ética de hacer frente al otro, origen en la construcción de la autobiografía según este crítico (Capítulo 5). De este modo, no se trata de una memoria literal de los hechos, sino de una memoria ética. Ofelia Ferrán utiliza esta terminología de the ethical constitution of the subject para hacer referencia únicamente a aquellos textos que tratan sobre la experiencia de Buchenwald, especialmente a la obra El largo viaje ("Trauma" 86). Sin embargo, desde mi punto de vista, esta teoría es expansible al resto de su obra cuyo objetivo es relatar su compromiso social. Según la crítica mencionada, se puede hablar de dos elementos fundamentales que constituyen the ethical memory y que caracterizan la escritura de Semprún sobre Buchenwald: por un lado, lo que ella 
denomina je me rends compte, es decir, el hecho de saber la realidad de lo sucedido, enfrentarlo y contarlo; por otro lado, en rendre compte, la búsqueda de una narrativa comprometida para hacer posible la comunicación de dicha experiencia incluso cuando parezca imposible. Por consiguiente, ambos conceptos pueden aplicarse a Autobiografía de Federico Sánchez o Federico Sánchez se despide de ustedes, puesto que, como ya se ha señalado previamente, todas ellas comparten la narración del compromiso social, de lo sucedido en la lucha interna por una misma causa social: la democracia, como parte un proyecto epistemológico. En el caso de la primera de las obras mencionadas, Jorge Semprún se enfrenta al relato de los entresijos de la experiencia clandestina del PCE en España para contar el modus operandi del PCE y de la resistencia franquista. Por lo tanto, existe también una memoria ética de la obra, puesto que hay un diálogo con el otro, con aquellos que cayeron durante su periodo como director del núcleo intelectual clandestino en España. De hecho, invoca su compromiso narrativo para comunicar su experiencia: Y ahora en mi propio nombre quiero hablarte, Con mi voz más profunda y entrañable...

Así decía aquel antiguo poema mío del año 1947, y así digo hoy, en abril de 1964, también hoy quisiera hablarte, en mi propio nombre, con mi voz más profunda y entrañable. (342)

El término "hablarte" no hace referencia solo al propio Semprún, como parte de su técnica de desdoblamiento de yoes, sino que es también un llamamiento al lector con el que ha firmado un pacto durante todo el relato de la obra. Caso similar es el de Federico Sánchez se despide de ustedes, en el que, desde el principio a través del título, está reafirmándose en el acuerdo con el lector con el objetivo de hacerlos partícipe de esa 
memoria ética de un compromiso social a través de su actuación durante los casi tres años en los que ocupa el puesto de ministro de Cultura.

Por otro lado, la reescritura desde El largo viaje en 1962 hasta ya entrado el siglo XXI con Viviré con su nombre, morirá con el mío está profundamente relacionado con la dinámica del trauma. Tal y como señala Ofelia Ferrán: “The dynamics of trauma never come to a point of complete resolution. The traumatic memory recurs inevitably and thus has to be dealt with forever in new contexts, in new situations where we might have thought the problem had been settled (“Jorge Semprún” 92). Este reescribir funciona como mecanismo para superar el trauma que ha tergiversado la formación de su identidad. Son numerosos los episodios traumáticos que se cosifican en un entramado de conexiones que vuelven una y otra vez a la obra de Semprún. La infancia destruida por la guerra civil, la añoranza de su casa en Madrid en la calle Alfonso XI, la relación con su familia, su formación literaria, el vínculo con su lengua materna, el primer viaje de regreso a España, la blanca nieve de Buchenwald, los gritos de "Krematorium, ausmachen!', todos ellos se convierten en tropos de su obra que, a modo de recuerdo traumático, se repiten cada vez que el autor aborda una nueva etapa en su escritura, bien sea su experiencia en Buchenwald, su clandestinidad en España, o su labor como ministro de cultura en Madrid. Incluso aparecen en aquellas obras más cercanas al discurso novelesco que ya señalamos anteriormente. Dicha repetición se corrobora tras la definición de Cathy Caruth del trauma según la cual es "an overwhelming experience of sudden and catastrophics events" cuya incomprensibilidad impide al sujeto la asimilación de estos provocando la traumática repetición que "returns to haunt the survivor later on" (151). Especialmente interesante es el hecho de que algunos de los elementos de esta 
traumática experiencia se convierten en sistemas secundarios organizativos de la memoria, como menciona Kathleen M. Vernan al hablar del lenguaje de la memoria en la narrativa española contemporánea — esta idea se desarrollará al explorar las relaciones entre la identidad y el tiempo- - La presencia de la nieve está presente en todas aquellas obras que, de una forma $\mathrm{u}$ otra, se relacionan con la re-experiencia de los campos de concentración a modo de recuerdo que articula el proceder de la memoria. Del mismo modo, la casa de Madrid de Alfonso XI está omnipresente en aquellos relatos que hablan del regreso a España o de una añoranza de la infancia en España. En relación a esta repetición, Alberto Giordano afirma que esto es fruto de the writing of remembrace en la que se produce coexistencia del pasado y el presente:

The exploration of the past that still insists, that coexists with the present and unsettles it, can only be left in the hands of a writing of remembrance, which is an art of repetition, that is to say, of suspensions and new beginnings, of the unpredictable crosscrossings among heterogeneous realities. Memory repeats the promise as impossible fulfillment because it is, itself, the experience of a time without presents or full presences, a time of exile in which the subject, exiled from the masks that he had constructed throughout its history in order to hide its lack of identity, finds itself in its true homeland, childhood as an absence of origin and desire for its invention. (48)

Estas masks a las que Giordano se refiere pueden relacionarse con estos tropos literarios a los que hacíamos referencia. Detrás de ellos se esconde no sólo su función como eje estructurador del relato, sino que también son mecanismos para ocultar la 
ausencia de una identidad resquebrajada por la imposibilidad de reconciliación entre pasado y presente. No obstante, siguiendo la línea de Ofelia Ferrán en su análisis sobre las relaciones entre memoria y trauma, especialmente en relación a Buchenwald, los textos de Jorge Semprún alcanzan un doble significado. No sólo utilizan el relato repetitivo de la memoria traumática como compensación del yo, sino que existe una metanarratividad sobre el ejercicio de la narración de la memoria y el trauma:

His texts, therefore, do not just make traumatic memory their recurrent theme, but become meta memory texts, self-reflexively exploring the very process by means of which this traumatic memory can, or cannot, be narrated, how it can, or cannot, be received by other. Furthermore, these meta-memory texts recurrently enact a process of working through memory. (“Jorge Semprún”73)

Jorge Semprún reflexiona sobre la posibilidad de narrar lo vivido, especialmente en relación con el holocausto nazi, sobre el poder del lenguaje para representarlo, sobre la necesidad del uso de la ficción en confabulación con la memoria, sobre la existencia de un lector, etc. No obstante, hay elementos metanarrativos de la memoria en otras obras que no tratan sobre Buchenwald como en Autobiografía de Federico Sánchez en la que reflexiona no sólo sobre su propio proceder memorístico, sino también como sobre el del PCE: "Pero te asombra una vez más como funciona la memoria de los comunistas. La desmemoria, mejor dicho. Te asombra una vez más comprobar qué selectiva es la memoria de los comunistas. Se acuerdan de ciertas cosas y otras las olvidan. (...) No es una memoria histórica, testimonial, es una memoria ideológica" (240-41). En definitiva, working through memory está estrechamente relacionado con el rasgo más característico, 
según mi punto de vista, de la identidad sempruniana: el compromiso social. Como afirma Ofelia Ferrán:

by working through the traumatic memory of the camps and recreating its endless breakdowns of meaning and communication, the possibility to change is upheld, and a space of social communication is sought, one that in no way denies or belittles the atrocity of the past, but that puts the memory of that atrocity to work towards potentially improving the present and the future. (“Jorge Semprún” 74)

Ahora bien, han sido también muchos los críticos que han discutido sobre el proceder de la memoria traumática y su relación con la ficción como elemento integrante de esta. Algunos críticos como Elie Wiesel han negado la imposibilidad del elemento ficticio en la narrativa de los campos de concentración ya que esta puede traicionar la experiencia del horror (Cit. en Ferrán “Jorge Semprún” 71). Sin embargo, el propio Semprún afirma: “Solo alcanzarán esta sustancia, esta densidad transparente, aquellos que sepan convertir su testimonio en un objeto artístico, en un espacio de creación. $\mathrm{O}$ de recreación. Únicamente el artificio de un relato dominado conseguirá transmitir parcialmente la verdad del testimonio" (La escritura o la vida 25). Por lo tanto, únicamente a través de la ficción es posible llegar a conocer la verdad de una experiencia tan traumática como la de Buchenwald que, en cierta medida, se podría extrapolar a los horrores vistos por muchos exiliados durante la huida de España.

Ahora bien, si se habla de la memoria traumática y el uso de la ficción como medio para crear un espacio de comunicación social, es necesario estudiar el papel de la memoria colectiva frente a la memoria individual en este tipo de narraciones, más 
concretamente, en Jorge Semprún. En relación con este tema y a propósito de Autobiografía de Federico Sánchez, Enric Bou expone:

El texto de Semprún parte de lo individual para proyectarse en lo colectivo. Nos habla de grandes fechas, hechos, bien conocidos en una historia de la posición al franquismo. Y es de hecho su conocimiento de los entresijos de una cronología pública lo que le concede valor (y valentía, por el momento de publicación) documental y literario. Así, el pacto autobiográfico está marcado por una total sinceridad, con carácter de ajuste de cuentas, puesto que escribe un "relato o memorial en que no pienso callarme nada" (60) o una "autobiografía política" (239), y afirma que quiere hurgar en el pasado "para poner al descubierto sus heridas purulentas, para cauterizarlas con el hierro al rojo vivo de la memoria", puesto que, afirma, los comunistas odian la memoria verídica.

\section{(“Construcción” 29)}

Sin embargo, el hecho de "partir de lo individual para proyectarse en la colectividad" no es sólo material de dicho relato, sino que puede ampliarse a toda la obra de la que es objeto de análisis este trabajo. Ya en los capítulos anteriores se había hecho referencia a las teorías de Ricouer, según el cual uno no recuerda sólo, así como a las teorías de Maurice Halbwachs sobre la toma de conciencia de la memoria individual como análisis de la experiencia particular como parte de un grupo. Jorge Semprún se hace eco de una memoria colectiva perteneciente a todos aquellos que están, de una forma o de otra, en una posición subalterna. En Aquel domingo, se puede leer la siguiente reflexión: 
En Nantua, al escuchar el lío que se armaba Fernand Barizon, me preguntaba por qué siempre son los mismos los que cuentan las historias, los que hacen la historia. ¡Sí! ¡Por supuesto que en Nantua ya sabía que son las masas las que hacen la historia! (...) Volvemos con ello al inicio de esta pregunta más tautológica que metafísica, ¿quién hace la historia real? (...) las masas quizás hagan la historia, pero indudablemente no la cuentan. Son las minorías dominantes — las que la izquierda llama «vanguardias» y la derecha, incluso el centro, «élites naturales»— quienes cuentan la historia. Y quienes la reescriben, si así es menester, si la necesidad así lo requiere, y la necesidad, desde su punto de vista dominante, lo requiere a menudo. Las minorías dominantes hacen su historia como quien hace sus necesidades. (...) Tampoco yo sé cómo salir del paso. También yo me armo un lío. ¿Qué es lo que estoy contando, en realidad? (851-868)

A partir de estas palabras puede entenderse la intención de Semprún de contar la historia de una colectividad, que no de hacerla, ya que el momento de la escritura siempre se produjo cuando carecía del poder dentro de las organizaciones políticas a las que había pertenecido, es decir, cuando ya no pertenecía a ninguna posición dominante y no era más que un espectador de aquellos que sí hacían la historia. Desde esta perspectiva, hay que entender la obra de Jorge Semprún. En el caso de El desvanecimiento parte de un hecho individual, su desvanecimiento en un tren y su traslado a una farmacia, para satisfacer sus "ganas de decirlo todo, de contarlo todo, de testimoniar" (30). Por su parte, en El largo Viaje, Semprún, tomando como excusa su camino en tren desde la cárcel 
hasta Buchenwald, narra la historia de los que le acompañan en la memoria, no sólo durante ese viaje, sino durante la experiencia en el campo de concentración. Él mismo había escrito: "Ya puedo contar la historia de los niños judíos de Polonia, no como una historia que me haya sucedido a mí particularmente, sino que les sucedió ante todo a aquellos niños judíos de Polinia. (...) Debo hablar en nombre de lo que sucedió, no en mi nombre personal" (191-192). Esto se repetirá, posteriormente, en Autobiografia de Federico Sánchez en la que testimonia sobre los cientos de personajes que hicieron posible la actuación del PCE en la clandestinidad española. De hecho, María Pilar Suárez afirma que "es desde esa experiencia de ruptura — se refiere a la expulsión del PCE— como vuelve a evocar en esta obra la idea de colectividad épica que ya había sido planteada en Le Grand Voyage, y que en la Autobiografia se centra en los compañeros que en España, y desde la clandestinidad, luchan por salvaguardar la seguridad de los otros" (218-219).

Volverá a repetirlo en Aquel domingo, en el que hablando con una joven polaca que perdió a su padre en el campo de concentración, se erige como narrador de todos aquellos que fallecieron y no podrán contar jamás ese relato: "Uno no puede contarle nada a su hijo, si es que tiene un hijo. A quienes mejor se les puede contar es a los desconocidos: porque a uno le afecta menos, se siente menos solemne. Pero, en cualquier caso, su padre no hubiera podido contarle su muerte. ¡Y yo sí puedo!” (5919-5920). También Federico Sánchez se despide de ustedes es un intento de contar la historia de una colectividad una vez que es expulsado del gobierno de Felipe González y pertenecía a esa posición subalterna que no tiene voz en la escritura de la historia. Sin embargo, es esta, de entre todas sus obras, una de las que está más aferrada a la memoria individual, 
probablemente por ser el fin de su carrera en el mundo del compromiso social a través de la política de forma activa —realmente nunca terminó dicho compromiso pues su labor como escritor y conferenciante con el mismo objetivo perduró hasta su muerte- .

Finalmente, tanto La escritura o la vida como Viviré su nombre, moriré con el mio, están fuertemente vinculadas a la memoria colectiva también. En la primera de ellas decía así: “el superviviente del Sonderkommando de Auschwitz, aquel judío polaco que no tenía nombre porque podía ser cualquier judío polaco, cualquier judío de cualquier parte, en realidad, el superviviente de Auschwitz, permaneció inmóvil, con las manos descansando en las rodillas: estatua de sal y de desesperanza de la memoria" (65). Jorge Semprún narra así lo sucedido a toda una comunidad torturada por la imposición de un poder dictatorial y elige la figura de un judío polaco como símbolo de toda la colectividad.

Mención especial merece Adiós, luz de veranos... Es probablemente la única obra en la que el plano individual se sobrepone al colectivo. En ella la obra gira en torno a cuatro elementos: el recuerdo de la infancia y la adolescencia; su identificación como extranjero en París; el descubrimiento de la ciudad de las luces a través de la lectura y el mundo de la sexualidad. Es, sin lugar a dudas, su obra más autobiográfica en el sentido clásico del término, ya que todos estos elementos están entrelazados por un rasgo en común: la dislocación del sujeto: "sumido en la tristeza del desarraigo, de la pérdida de todos los puntos de referencia habituales (lengua, costumbres, vida familiar)" nació "el hastío vital que me embarga desde entonces" (58), "la sensación de ausencia de mí mismo en el mundo", la impresión de "radical extrañamiento" (59). Es, en esta obra, donde se lleva a cabo un intento más claro de buscar su identidad. Las técnicas hasta ahora utilizadas, tales como el uso de pseudónimos, el desdoblamiento de sujetos o la 
impostura, son inadecuados para resolver una identidad desterritorializada — sobre este término se discutirá más en el apartado siguiente—. Como afirma Ángel Loureiro en “Jorge Semprún: memorial de ausencias", esta obra es "relato de pérdidas y descubrimientos, de descubrimientos de cómo la perdida conforma la identidad y marca todo relato del pasado" (21). En definitiva, a excepción de esta última obra, la memoria colectiva se impone ante la memoria individual como resultado de esa identidad sempruniana caracterizada por el compromiso social y por sentirse parte de una misma sociedad ahogada y aniquilada por las fuerzas totalitarias de regímenes dictatoriales. De hecho, Ana Ruiz Sánchez interpreta el proyecto literario de Semprún como un intento de construir una "memoria intercultural de la sociedad" (146). Esta crítica sitúa la obra del escritor madrileño en un contento socio-político europeo en el que se produce una “identificación con una ciudadanía políglota y multicultural a la par que leal tanto a la realidad nacional como a la supranacional" (145), elemento que también se abordará de forma detallada al hablar de la relación entre nación e identidad.

Antes de acabar, es necesario volver a uno de los temas que ya se anunció, en cierta medida, anteriormente. Al hablar de la memoria traumática, la repetición de los tropos literarios y de la metanarratividad del discurso memorístico, se llegó a la conclusión de que la ficción era el único medio para aprehender la verdad de una realidad como la de los campos de concentración. Habíamos señalado incluso que esta afirmación se podía extrapolar, de alguna forma, a la experiencia del exilio por lo de que de experiencia del horror había tenido esta para muchas personas. También se había afirmado que el uso de la ficción tenía como propósito buscar un espacio de comunicación social para avanzar hacia el presente. Es en la búsqueda de dicho espacio 
de comunicación social donde cabe señalar, de forma breve, la discusión sobre el género autobiográfico que ha surgido en torno a la obra de Jorge Semprún. Críticos como Ángel Loureiro, José Romera Castillo, Alicia Molero de la Iglesia, Manueal Alberca e Íñigo Amo González, partiendo de los pensadores más importantes de la autobiografía y la teoría de la ficción — Lejeune, Eakin, Paul de Man, Doubrovsky, Colonna, Darrieussecq - han dedicado numerosos estudios a hablar sobre el papel de la ficción dentro de la literatura del yo en relación con la obra de Jorge Semprún. Si partimos del principio básico de la literatura por el cual toda obra literaria es, en cierta medida, ficción y, del mismo modo, entendemos la obra de Jorge Semprún como de gran valor literario, estamos afirmando, por lo tanto, que la narrativa del escritor madrileño es también ficción. Ahora bien, la clave está en determinar qué papel le corresponde a esta en la creación de una narrativa como espacio en el que conformar una identidad.

Ya Philippe Lejeune había establecido el pacto autobiográfico según el cual sólo podía hablarse de autobiografía si se producía el reconocimiento entre el autor del libro, el narrador y el protagonista. Posteriormente, en una segunda elaboración se dio cuenta de la inexactitud de dicha afirmación debido a la consideración de obras narrativas escritas en segunda persona, en tercera, así como a la posibilidad de que el personaje de una novela tuviera el mismo nombre que el autor, dejando así un espacio vacío a la posibilidad de hablar de un pacto novelesco también (123-147). Es esta laguna en su teoría lo que provocó que los críticos ya mencionadas, tras la publicación de Fils en 1977 por Serge Doubrovsky y la denominación del propio autor de su obra como autoficción, establecieran un profundo debate que llega hasta la actualidad sobre los límites entre la autobiografía y la novela. A esta obra le siguió un profundo debate entre Colonna y 
Darrieussecq sobre la definición de la autoficción en el que no nos vamos a detener, pero a la que pueden acercarse a través de los trabajos de Romera Castillo e Íñigo Amo González. Posteriormente, Manuel Alberca, bebiendo de las propuestas y debates de los escritores ya mencionadas, creó el término de "autoficción biográfica", más cercana al pacto autobiográfico, y el de "autobioficción", en el que se produce una mayor ambigüedad, aunque todavía pueda leerse de forma autobiográfica.

Aplicada esta controversia al caso de la literatura española, a la asunción de la autobiografía como "auténtica creación verbal, porque su codificación depende de unas claves de emisión y recepción, aceptadas socialmente" (Molero de la Iglesia, La autoficción 21) y a la necesidad de los escritores del último cuarto del siglo XX por buscar nuevas formas textuales que asumieran las necesidades reflexivas de la identidad autobiográfica, los escritores se vieron en la necesidad, según palabras de Romera Castillo, de crear una nueva forma lingüística para la que utilizaron dos procedimientos: “ficcionalizar lo autobiográfico y autobiografiar lo ficticio (y al hablar de ficción no tenemos más remedio que referirnos a su encarnación más prístina: la novela)" (“Actualidad" 11). De este modo, Romera Castillo sitúa a lo autoficticio dentro de la novela autobiográfica, aunque advierte que los límites de la autoficción no están determinados. A partir de las teorías expuestas por este crítico y de un estudio de las formas discursivas de la escritura autobiográfica en el último periodo del siglo XX, Molero de la Iglesia distingue tres categorías en cuanto al discurso autobiográfico, de las cuales a nosotros nos interesa, con motivo de la obra de Semprún, la segunda: aquellas que buscan una recreación artística de la experiencia vivida. De esta forma, en la actualidad existe un profundo debate sobre la concepción de lo autobiográfico, en el que 
se reflejan múltiples obras de la literatura europea de los años 70 y 80 y en las que se pone en cuestión la intencionalidad del autor, bien autobiográfica o bien novelesca, la fusión del pacto novelesco y el nombre propio del autor, así como la ficcionalización de la historia dentro de un marco autobiográfico.

Por un lado, Olivia Ferrán, tras estudiar la posibilidad de incluir El largo viaje dentro de la tendencia de la novela realista social que surge en España con la obra de Luis Martín Santos, Tiempos de silencio, ya que, al igual que este tipo de obra, mina la construcción épica y mítica de una historia creada por Franco, determina que se trata de una "novela de la memoria", puesto que el pasado está presentado de forma subjetiva a partir de la recreación de una memoria individual (“Jorge Semprún” 94-95). Esta categorización puede compaginarse con la definición de Manuel Alberca de novela del yo. Ferrán afirma que se trata de una novela de la memoria, puesto que se produce una ruptura con el tiempo, el yo, la narración y la ilusión referencial de la verdad y su totalidad. Sin embargo, la ruptura de todos estos elementos puede extrapolarse también a esta nueva concepción de lo autobiográfico y el debate entre este, la novela y el surgimiento de la autoficción. Por eso mismo, creo que es oportuno, para hablar esta obra, así como de otras obras de Semprún, emplear la denominación de Manuel Alberca de "novelas del yo", según la cual, "constituyen un tipo peculiar de autobiografías y/o ficciones. En realidad, como su nombre indica, se trata de novelas que parecen autobiografías, pero también podrían ser verdaderas autobiografías que se presentan como novelas, en cualquier caso las considero como la excepción o el desvío de la regla y una "tierra de nadie" entre el pacto autobiográfico y el novelesco" (pos. 658). El uso de "novela del yo" para referirme a El largo viaje, así como me referiré a otras obras 
posteriormente, viene justificado por la libertad que ofrece esta denominación. Manuel Alberca, al definir esta novela, las caracteriza por ser fruto de un "pacto ambiguo", es decir, un pacto que nada entre las aguas del pacto autobiográfico y del pacto novelesco. Es decir, por un lado, la identificación entre autor, narrador y protagonista puede producirse a distintos niveles (afirmada, sugerida o camuflada) y, por otro lado, la relación entre la ficcionalización y la factualidad también puede producirse en diferentes grados, dando así lugar a hablar novela autobiográfíca, autoficción o autobiografía ficticia. De esta forma, dicha denominación genérica nos permite entender mejor la búsqueda de un nuevo género literario libre que le permitiese construir ese espacio de comunicación social situado entre dos polos: por un lado, contar su testimonio como testigo de lo acontecido en el siglo XX; por otro lado, ficcionalizar dicho testimonio de modo que su narración cumpliera una función social educativa. Y es que, Manuel Alberca, afirma que estas obras en las que se produce una dialéctica entre lo ficticio y lo vivido "representa(n) una manera particular de metabolizar la experiencia propia y ajena en la escritura narrativa y de alumbrar el binomio vida-literatura" (pos. 597). Dentro de esta categorización pueden situarse otras obras como Aquel domingo, La escritura o la vida o Viviré con su nombre, moriré con el mío, porque en ambas se lleva a cabo un pacto ambiguo entre los tres elementos nominales $y$, al mismo tiempo, existe un cierto equilibro entre la ficción y la factualidad, equilibrio que no existe ni en la autobiografía, marcada por la veracidad, ni en aquellas inscritas dentro del pacto novelesco, que se caracterizan por una mayor presencia de la invención. Por su parte, Jaime Céspedes rechaza el término de autoficción, puesto que para él el hecho de que haya invención de ciertos episodios, el uso de pseudónimos o de otros recursos no pone en cuestión la verificación por parte del 
lector de la correspondencia nominal del pacto autobiográfico. No obstante, prefiere usar la denominación "obras autobiográficas" a "autobiografías" para dar cabida a la invención de algunos detalles por parte de Semprún para crear una mayor verosimilitud. De hecho, clasifica la obra de narrativa en tres grandes grupos: en primer lugar, obras autobiográficas concentracionarias para hacer referencias a aquellas obras que están relacionadas con los campos de concentración (El largo viaje, El desvanecimiento, Aquel domingo, La escritura o la vida y Viviré con su nombre, moriré con el mío); posteriormente, destaca la existencia de autobiografías en el sentido más tradicional del término, ya bien de su infancia y adolescencia, como es el caso de Adiós, luz de veranos..., ya bien de su vida política, como es el caso de Autobiografía de Federico Sánchez y Federico Sánchez se despide de ustedes; en tercer lugar, habla de novelas y sitúa aquellas obras a las que ya hacíamos referencia al principio del trabajo y que escapan del objeto de este por pertenecer a dicho grupo, como La algarabía o La montaña blanca (53-58).

Aparte de esas novelas del yo, cabe llamar la atención sobre las obras que se han clasificado tradicionalmente dentro del género de la autobiografía: Autobiografía de Federico Sánchez, Federico se despide de ustedes y Adiós, luz de veranos... La segunda y la tercera de estas narraciones no presentan gran problemática. En el caso de Federico Sánczhez se despide de ustedes, toda la crítica se ha puesto de acuerdo al entenderlas como unas claras memorias políticas que cubren su periodo como Ministro de Cultura con Felipe González a pesar de que use el pseudónimo de Federico en el título. Del mismo modo, unánime es la opinión de los críticos sobre Adiós, luz de veranos... al leerlas como una autobiografía de infancia, como desarrolla Ángel Loureiro en su 
artículo "Jorge Semprún: memorial de ausencias". Sin embargo, la primera de ellas ha generado cierta polémica. Por un lado, Manuel Alberca no duda en denominarla como "memoria política", con el cual estoy de acuerdo, a pesar de su engañosa apariencia con el título. No obstante, reconoce la problemática en cuanto a la presencia de algunos elementos en los que se han basado otros autores para hablar de una diferente categorización (pos. 2868). De hecho, Romera Castillo ha clasificado Autobiografía de Federico Sánchez como una novela (De primera mano 48); Pozuelo Yvancos como una autobiografía (20) y Molero de la Iglesia la ha calificado como autoficción (“Autoficción" 537). Esta última crítica defiende tal posición basada en una lectura autoficticia del pacto establecido a través de la identidad nominal. Para sustentar dicha lectura se basa en el desdoblamiento del narrador - técnica que también había utilizado la otra escritora a investigar en este trabajo, María Luisa Elío Bernal—, una motivación política y el uso de heterónimos. No obstante, creo que ninguno de estos fenómenos ofrece una vacilación al lector sobre la identificación entre el autor, el narrador y el personaje, como afirma Íñigo Amo González (88). Tal es así que propone situar esta obra dentro de la categoría de "autoficción biográfica". Sin embargo, lo que ha quedado claro después de haber estudiado, de forma breve, algunos de los problemas clasificatorios de la obra de Semprún dentro de un género limitado es el hecho de que "en la obra narrativa de Semprún, como en otras muchas, los compartimentos genéricos estancos son en ocasiones vasos comunicantes entre sus contenidos y estrategias" (Alberca pos. 3190).

Dejando un poco de lado toda esta controversia en cuanto a si se trata de enunciado autobiográfico, discurso autoficticio, novela autobiográfica, autoescritura o cualquier otro término relacionado con esta problemática, lo que nos importa en estos 
momentos, teniendo en el horizonte la obra de Jorge Semprún, es el hecho del nacimiento de un nuevo tipo de escritura autobiográfica en la que, como dice Molero de la Iglesia, "el protagonismo personal, el autoanálisis y el placer de la evocación son la respuesta a una búsqueda de una escritura más libre de expresión" y es en esta búsqueda de una escritura más libre de expresión donde adquiere protagonismo la ficción. Es, sin lugar a dudas, La escritura o la vida la obra en la que el elemento reflexivo de este nuevo tipo de literatura autobiográfica adquiere una mayor importancia. En esta obra, no sólo reflexiona sobre la experiencia de la individualidad del sujeto en cuanto a partícipe de una memoria colectiva, sino que existe también una reflexión de índole metanarrativa en la que teoriza sobre el medio más adecuado para llevar a cabo dicha tarea. De este modo, articula la función de la ficción como principio motriz de su relato, ya que es este el único elemento capaz de crear una historia que pueda ser recibida por el otro. Así, el escritor madrileño afirmaba:

Pues no pretendo un mero testimonio. De entrada, quiero evitarlo, evitarme la enumeración de los sufrimientos y de los horrores. De todos modos siempre habrá alguno que lo intente... Por otra parte, me siento incapaz, hoy, de imaginar una estructura novelesca, en tercera persona. Ni siquiera deseo meterme por este camino. Necesito pues un yo de la narración que se haya alimentado de mi vivencia pero que la supere, capaz de insertar en ella lo imaginario, la ficción... Una ficción que sería tan ilustrativa como la verdad, por supuesto. (181-182)

De este modo, la ficción aparece como elemento configurador de la realidad, es decir, es el eje en el que el autor busca el apoyo para convertir en relato una experiencia 
tan traumática como la del exilio y los campos de concentración. No se trata de inventar una historia diferente a la realidad, sino la de crear un relato que el lector sea capaz de asimilar. Es esta la única que le permite crear un espacio "objetivo" y "verosímil” en la que construir un sujeto después de la muerte. Como afirma Alais Robbe-Griller, "the bios of fiction is, ulimately, much more personal than the supposed sincerity of the confession" (cit. Semilla Durán 164).

No obstante, este hecho no se reduce sólo a La escritura o la vida, sino que puede extenderse a todas las obras narrativas objeto de este trabajo y que señalaba anteriormente. Ya en su primera obra, El largo viaje, hablaba de la necesidad de olvidar para poder contar. En el primer capítulo se habló del papel del olvido como sistema de la memoria para recordar algo que no se recuerda, por lo que es necesario olvidar lo sucedido durante su experiencia en el exilio y en Buchenwald para poder contarla, en una segunda fase, a través de la ficcionalización del relato de modo que este sea más creíble para el lector, un lector que, en el momento de lo sucedido, no estaba preparado para oír la verdad y, por lo tanto, el mero testimonio que podría haber transcrito tras la salida de Buchenwald hubiera resultado en una narración fallida de la experiencia. Y en esa lucha entre ese simple testimonio y la necesidad de dejar constancia de lo sucedido para que las próximas generaciones aprendan de los errores de su pasado es donde cobra vital importancia la ficción de la memoria, unas veces más ficcionalizadas como en $E l$ desvanecimiento o en Aquel domingo, otras quizás menos como en Autobiografía de Federico Sánchez, pero siempre como elemento generador del relato. Del mismo modo, la presencia del silencio, a la que tantas veces hacía referencia Semprún en sus obras, se dibuja como un mecanismo para dar cabida a una ficcionalización del relato. Tal es así 
que Î́nigo Amo afirma que el silencio es "precisamente uno de los apoyos sobre las que se sustenta la teoría de la autoficción" (44). Por lo tanto, la ficción es un elemento esencial en la construcción de un espacio de comunicación, espacio que, como veremos en el siguiente apartado, será lo más cercano a una patria que pueda tener este escritor. Es en la búsqueda de dicho espacio a través de la ficción donde cobra también especial importancia su concepción sobre la construcción de un sujeto a partir de una nueva configuración de los elementos de patria, tiempo y lenguaje.

\section{La construcción de la identidad: en búsqueda de nuevos parámetros}

Con motivo del recibimiento del Premio Libertad por parte del gremio de escritores alemanes, en octubre de 1994, Jorge Semprún pronunciaba las siguientes palabras en su discurso:

Du point de vue de la langue littéraite, ou bien je suis apatride —á cause de mon bilinguisme invétéré, de ma schizophrénie lingüistique définitive — ou bien j'ai deux patries. Ce qui, en verité, est impossible... En fin de compte, ma patrie n'est pas la langue, ni la française ni l'espagnole, ma patrie c'es la langage. C'est-á-dire, un espace de communication sociale, $d$ 'invention lingüistique: une posibilité de representation de l'univers. De le modifier aussi, par les oeuvres du language, fut-ce de façon modeste, á la marge" (Mal et modernité 101102).

Jorge Semprún, al igual que muchos otros escritores de su generación, tuvo que construir una identidad más allá de la concepción tradicional de los términos de nación, tiempo y lengua utilizados para hablar de construcción identitaria. Sin embargo, este 
resultado fue fruto de un largo proceso de reflexión cuya evolución y desarrollo ha quedado reflejado en sus obras literarias. $\mathrm{Y}$ es que asumir que la identidad, tal y como afirma Claudio Magris, no es algo rígido e inmutable, sino algo fluido que, en su caso, se alejaba de los orígenes para renovarse en el quehacer del camino del exilio fue una ardua tarea a la que Jorge Semprún se enfrentó a través de la escritura (74). Desde El largo viaje hasta Adiós, luz de veranos... o La escritura o la vida el escritor madrileño ha pasado por varias etapas en la construcción de su identidad en relación al concepto de nación, de cuyo proceso y evolución pretende dejar constancia este trabajo para reflejar así otra de las huellas del exilio en la segunda generación de escritores exiliados tras la Guerra Civil española.

En su obra Aquel domingo, Jorge Semprún reflexiona sobre el exilio como punto de inflexión en su vida. Su salida apresurada del País Vasco con destino a Ginebra, en primer lugar, lo obligaba a reestructurar una identidad que, a sus trece años, se vio forzada a madurar a pasos agigantados:

Me hago cargo de que hubiera debido ocultar aquel episodio y limitarme a describir la conmovedora imagen del niño que descubre las angustias del exilio político, las congojas del desarraigo. Pero se da el caso de que el niño, precisamente, entraba en el desasosiego de la primera adolescencia. El niño estaba a punto de cumplir los trece años y, al mismo tiempo que perdía — quizá para siempre— las señas de identidad de una patria, de una familia, de un universo cultural, descubría, a través de las exigencias del cuerpo, su identidad, su masculinidad, su turbadora y furiosa expresión de su auténtico yo" (pos. 1606). 
De esta forma, sitúa al exilio como culpable de la reorganización de sus señas identitarias a la que tuvo que hacer frente tanto a nivel personal como a nivel social. No obstante, Jorge Semprún debe afrontar el hecho de "exiliarse" no en una ocasión ni en dos, sino en tres. Y es que, como afirma Michael Ugarte, el escritor madrileño debe recomponer su identidad en tres ocasiones por culpa del exilio: en primer lugar, como miembro de una familia de exiliados tras la guerra civil española; en segundo lugar, como superviviente de un campo de concentración alemán; y, en tercer lugar, como víctima de la expulsión de un partido político por cuyos principios había luchado durante más de 20 años (99). A estos tres exilios, cabría sumar un cuarto según mi parecer: su dimisión/expulsión como Ministro de Cultura en España, lo cual significaba, nuevamente, la ruptura con un lazo de unión con la tierra en la que había nacido. De esta forma, Semprún vive en un constante rehacer identitario causado, entre otros motivos, por vivir en un continuo exilio de todo aquello de lo que ha formado parte en alguna ocasión. Dicho rehacer se ha evidenciado también en la obra por la continua reflexión sobre el propio yo y el desdoblamiento de este. La obra de Semprún está cargada de un diálogo consigo mismo en segunda o en tercera persona que invita al lector a reflexionar sobre la experiencia traumática del exilio como elemento trastornador del yo. Así al inicio de El desvanecimiento, escribe: "Ha debido comprender que ya no sabe ni dónde está, ni quién es, ni qué es todo aquello" (16). Semprún se ha visto forzado a reordenar todos los elementos de su yo, un yo que se ha visto además multiplicado en el caso de este escritor por el uso de numerosos pseudónimos como parte de su actividad secreta en contra de las estructuras de poder. Es, por lo tanto, el hecho de estar enfrentado al poder que lo condujo al exilio el elemento que ha roto con las fronteras de un yo estable. Así, en 
Aquel Domingo, expresa su inseguridad o incertidumbre ante la necesidad de definirse ante los demás: “¡Pero tú, muchacho, ya no debes de saber quién eres con tantos cambios de identidad! Tengo ganas de decirle a Fernand que más de una vez se me ocurre no saber quién soy, aun cuando no cambio de identidad. Pero, ¿me ocurre no cambiar de identidad? Cuando recobro la mía, ¿no es la realidad del otro? Pero no digo nada” (pos. 1628). Y es que la formación de su yo evolucionó también a medida que el autor comprendió la incapacidad de construir un yo estable y rígido y asumió la necesidad de aceptar un yo formado a través de distintas experiencias y elementos más allá de los tradicionales, tal y como se afirmaba al principio de este apartado.

Ya en El largo viaje, su primer gran éxito literario, habla del regreso a Francia tras su salida del campo de concentración de Buchenwald y rechaza la aceptación del país de Napoleón como nación o patria:

—Lo que usted quiere es defender su país.

—Pues no — le contesto—, no es mi país.

— ¿Cómo? —exclama—, ¿Qué es lo que no es su país?

—Pues Francia — le respondo-, Francia no es mi país.

—¿Cuál es su país? — pregunta.

-España - le contesto.

—Pero España es nuestra amiga — dice.

_ ¿Usted cree? Antes de hacer esta guerra, ustedes hicieron la guerra de España, que no era su amiga. (50-51)

Jorge Semprún, en un principio, no sólo rechaza la posibilidad de considerar Francia como una patria, ya que es ésta en la que estaba establecido en el momento en el 
que fue capturado por los nazis, sino que afirma su sentimiento nacionalista español. Sin embargo, es interesante ver cómo esta reafirmación patriótica se va modificando a lo largo del relato. Posteriormente, en la misma obra, el escritor madrileño se denomina "refugiado español”. De esta forma, marca distancia con aquellos que quedaron en España, ya bien a favor o en contra del régimen franquista. Esta denominación le permite, en cierta medida, empezar a valorar el elemento de "lucha o subversión" que lleva implícito el hecho de ser refugiado como parte de su identidad. No obstante, dicho sentimiento sigue evolucionado a medida que continúa la narración hasta el punto de distinguirse como “extranjero". Especialmente significativo es el uso de este adjetivo, puesto que mientras que anteriormente se había vinculado de una forma u otra a una tierra en concreto, el hecho de autodenominarse "extranjero" conlleva la supresión del vínculo a un lugar como elemento de su identidad. Es decir, es la primera vez que Jorge Semprún verbaliza la configuración de una identidad nacional más allá de las fronteras de una nación, es decir, fuera de los límites establecidos hasta ahora por la concepción tradicional de dicho concepto. De hecho, Ofelia Ferrán define su inestable relación con el lugar de origen como "the eternal outsider", puesto que su constante sentido de desplazamiento provocado por el exilio y el campo de concentración le lleva a crear un discurso de "homelessness" ("Cuanto más escribo" 269).

Sobre su posición como extranjero, Semprún va a reflexionar a lo largo de toda su obra escrita. El sentimiento de no sentirse en casa en ningún lugar le lleva a eliminar el término "patria" como elemento de su identidad. Tal es así que en Federico Sánchez se despide de ustedes responde a la pregunta de un personaje sobre su nacionalidad de la siguiente forma: "Soy bastante apátrida, le contesté. Bilingüe, por consiguiente 
esquizofrénico, por consiguiente sin raíces. De hecho, mi patria no es ni siquiera la lengua, como para la mayor parte de los escritores, sino el lenguaje" (19). Obviando el hecho de que considera el lenguaje como patria, pues nos ocuparemos de ello más adelante, es importante destacar la ruptura por parte de Semprún con el vínculo a una tierra única. Es el primer paso para convertirse en lo que Deleuze y Guattari habían denominado un ser nómada, desterritorializado. La experiencia del exilio y, probablemente, su actuación en la resistencia nazi con individuos de otras nacionalidades, unidos por una misma causa, ha provocado que Semprún sea capaz de poner fin a los lazos opresores de unas fronteras estáticas para sentirse miembro de una comunidad superior basada en la unión con el ser humano y no con los sujetos de un único país. De ahí que surja la importancia del compromiso social como característica de su identidad, de lo cual habíamos hablado extensamente en el apartado anterior. Semprún es capaz de convertirse en un ser desterritorializado en el que prima su responsabilidad con la justicia social por encima de cualquier frontera o patria.

No obstante, en este camino hacia esa desterritorialización, debe tenerse en cuenta otro aspecto importante y estrechamente relacionado: la consideración del exilio como patria. En Federico Sánchez se despide de ustedes, el escritor madrileño escribió las siguientes palabras:

Yo había sido un rojo español en Francia, un Rostpanier en el campo nazi de Buchenwald. No se puede abandonar esa identidad bajo ningún pretexto, me había dicho siempre. (...) Sobre todo porque ese destino por una parte entrañaba riesgos al tiempo que por otra me inscribía en una 
comunidad sufriente y paternal. Había pues vivido el exilio político español como una especie de patria. (19)

Convertir el exilio en patria significa, en cierta medida también, asumir esa desterritorialización a la que se viene haciendo mención. Asimilar los términos "patria" y "exilio" conlleva identificarse como parte de una comunidad que lucha en contra de la imposición de un poder dictatorial y autoritario, una comunidad que trasciende las fronteras de un país para unirse a individuos con los que comparten un ideario. Es decir, la patria ya no la forma el vínculo a un territorio, sino la proximidad a unos mismos ideales, a un compromiso social. Así, en La escritura o la vida, Semprún afirma: "Mis raíces, de ahora en adelante, siempre estarían en ninguna parte, o en cualquiera" (167).

Así, finalmente, en su obra más autobiográfica en el término más tradicional de la palabra, Adiós, luz de veranos ..., desautomatiza y subvierte, tal y como afirma Gerard Torres, la noción tradicional de identidad estable (141). En su periplo de regreso a Francia tras su liberación de Buchenwald, relata un encuentro en una panadería en la que, rápidamente, se siente identificado como un extranjero por su acento. Esto le llevará a reflexionar sobre la necesidad de perfeccionar su idioma, pero no para ocultar sus orígenes ni buscar una nueva patria, sino para preservar su identidad de extranjero. Como afirma el ya mencionado Gerard Torres,

Lo que quiere conservar no es la esencia irrenunciable de una identidad nacional previa, sino una condición del sujeto como elemento extranjero, capaz de pasar por español, por francés o por alemán en una u otra situación, pero consciente de que su verdadera identidad no es ni ser francés, ni español, ni alemán, sino todo ello y nada de eso al mismo 
tiempo. Adiós, luz de veranos... configura literariamente una identidad que transciende las fronteras nacionales y se articula en una ética de carácter benjamiano fundamentada en la "fraternidad de los humillados y ofendidos, la solidaridad de los pobres. De los vencidos" (íbid, 67). El narrador construye una identidad irónica, múltiple, huidiza, mucho más completa que la marca de cualquier frontera nacional. Toda la obra de Semprún es un reinventar constante de la identidad, un intento de escribir desde nuevas perspectivas, desde una subjetividad que revisita su experiencia y la interpreta desde renovados ángulos hermenéuticos.

En definitiva, su situación como exiliado y su acercamiento a los individuos de los otros países europeos que también se rebelan contra el fascismo y el autoritarismo del nazismo le ha permitido a Semprún crear una conciencia nacional fluida, nómada, desterritorializada, más allá de los límites de las fronteras patrióticas, que tiene como eje central el compromiso social con los subalternos al poder. De esta forma, al igual que María Luisa Elío Bernal, Semprún se ha convertido en un ser transnacional, liberado de las pautas impuestas por la tradición en lo que a nación se refiere. Ahora bien, una vez analizada la problemática en cuanto al término de "nación" en la configuración de la identidad sempruniana, es necesario repensar el papel del lenguaje y el tiempo en la conformación de esta.

Desde el punto de vista del lenguaje, ya adelanté al hablar del concepto de nación que Semprún había afirmado en varias ocasiones que la única patria posible para él era este. Sin embargo, el camino para llegar a esta aseveración ha estado marcado un duro 
camino hacia el bilingüismo y por la aceptación de este como rasgo intrínseco de su identidad.

El exilio a Ginebra, en primer lugar, y, posteriormente, a Francia obligó al autor a reinventar su código de comunicación social. Hasta ahora, el español había sido su idioma materno, seguido muy de cerca por la naturalidad con la que Semprún se desenvolvía con el alemán gracias al papel de las institutrices alemanas con las que él se había criado. Desde el principio de su primera obra, El desvanecimiento, Semprún plantea la doble realidad a la que se ve sometido el exiliado a través de lenguaje: No sin preguntarse si habría dos palabras para cada una de las realidades de este mundo (por supuesto, al volver de su desvanecimiento, en la farmacia en cuestión, no fue tal su visión de las cosas, ya que la idea de mundo, la idea de realidad le resultaban en aquel momento imposibles de concebir, por supuesto, no fue más que una impresión confusa), si habría dos palabras para una sola realidad, la palabra aout, la palabra agosto. (9)

Esto provocó un primer periodo de confusión en la mente del autor. En Aquel domingo, Semprún se refería a este fenómeno como una de las primeras experiencias del exilio. Para integrarse en el nuevo país de acogida, era necesario aprender su lengua y su cultura, a lo cual Semprún parece haber estado dispuesto desde un principio. Ser bilingüe no implicaba un rechazo hacia el español, sino que reafirmaba su deseo de pertenecer a una comunidad superior sin barreras. Ser bilingüe era también una forma de aferrarse a su nueva identidad de extranjero, es decir, de poder pertenecer a cualquier nación: "He tomado la decisión de eliminar cuanto antes todo vestigio de acento de mi francés: nadie volverá a llamarme <español del ejército derrotado> con sólo oírme. Para preservar mi 
identidad en el extranjero, para convertirla en una virtud interior, secreta, fundadora y singularizante, voy a fundirme en el anonimato de una pronunciación correcta" (Adiós 76).

Este deseo de ser bilingüe y asumir su identidad de extranjero está también estrechamente relacionado con la elección del idioma a la hora de escribir sus obras. Es importante destacar que Semprún comienza escribiendo sus obras en francés. $E l$ desvanecimiento y El largo viaje, sus dos primeras obras, son publicadas en la lengua de Rimbaud. Algunos críticos como Tomás Espino Barrera han asumido que esa elección venía dada por la existencia de la censura en España que imposibilitaba su publicación en su país de origen. Tal es así que en La escritura o la vida cuando Semprún narra el momento en el que se le obsequia con una copia de su obra en diferentes idiomas con motivo de la entrega del premio Formentor por El largo viaje, Carlos Barral, en el momento de darle su copia en español, le entrega una copia en blanco como símbolo de la censura. Otros críticos como Giuseppina Notaro han afirmado que la elección del idioma viene en función de la temática de la obra, utilizando así el francés para referirse a los temas del campo de concentración y de la infancia y el español para escribir sobre la vida política clandestina (456). No obstante, creo que hay una razón más que la crítica ha pasado por alto o, al menos, no le ha concedido el lugar que le corresponde. Semprún en El largo viaje ya asumía su identidad de extranjero, tal y como quedó demostrado unas líneas arriba. No obstante, para aceptar dicha realidad el primer obstáculo que debía superar era el uso del idioma. La escritura de dos obras en francés demostraba su bilingüismo y su capacidad para escribir en distintos idiomas, dejando así claro una igualdad en cuanto a las lenguas que manejaba y, por lo tanto, a las naciones que 
representaban estas. Es decir, el hecho de escribir en francés iba más allá de un problema con la censura española o con la temática de la obra, era una forma de definirse él mismo, de romper con una identidad única para definirse como miembro de una comunidad superior, de una comunidad en la que no había fronteras y que se caracterizaba por la aceptación del otro.

En sus obras posteriores, la elección de francés o español tiene otras razones importantes a considerar. En 1977 publica Autobiografía de Federico Sánchez, su primera obra escrita en español. En este caso, sí pesan más las razones temáticas y de censura que se habían mencionado anteriormente. Apenas unos meses antes se había legalizado el Partido Comunista Español en España tras la muerte de Franco hace apenas dos años. Jorge Semprún, que había sido expulsado de este hace ya más de diez años, utiliza el español en este caso para dejar constancia de su realidad dentro del partido y de la actividad de este durante los años de clandestinidad. Este libro tiene como destinatario principal al pueblo español, por lo que es coherente pensar que fuese escrito directamente en este idioma. Por otra parte, Veinte años y un día, su única otra obra escrita en español —a excepción de su propia traducción de Federico Sanchez vous salue bien-, aparece escrita en español por su temática también, ya que en esta novela relata una historia de ficción durante la España franquista.

No obstante, es interesante destacar La algarabía en el plano de lo lingüístico como obra que marca un antes y un después en el empleo del idioma por parte de Semprún. Aunque este libro no es objeto de análisis de este trabajo por alejarse de la autobiografía, como ya se explicó brevemente, es interesante hacer referencia a ella porque en esta obra se puede observar el proceso babélico de las lenguas a las que se 
hacía referencia anteriormente y que se va desarrollando hasta que se produce una fusión total de los dos idiomas. Simboliza el momento de eclosión en la mente de un escritor exiliado que vive entre dos culturas, entre dos idiomas, tal y como ya señala María del Carmen Molina Romero:

Il y a chez Semprun una évolution dans la manière de considérer 1'espagnol dans ses récits. Dans les premier temps 1'espagnol n'apparait jamais. Il se laisse pénétrer par la nouvelle langue et sa littérature. Nancy Houston dit que c'est une reaction normale: $<<$ L'étranger, donc, imite. Il s'applique, s'ameliore, apprend a maîtriser de mieux a mieux la langue d'adoption... >>. (...) Puis l'evolution de son $<<$ conflict schizophréne>> le mène à accepter l'interference et la contamination avec la langue maternelle, il afiche ouvertement sa différence linguistique, l'amplifie exprés. C'est la spécificité du language des immigrés qu'il étale dans L'Algarabie. Aprés ce melange babélique necessaire et cathartique Semprún est disposé à accepter un glissement vers l'espagnol, langue dans laquelle il écrit de plus en plus. (77)

En La algarabia se puede rastrear en todo momento el proceso cognitivo de una mente bilingüe que vive dividida en dos mundos que interfieren entre sí. Ya el título es síntoma de ello pues, como señala Tomas Espino, su título original, L'Algarabie, no existe en francés, sino que se trata de un calco de la palabra española algarabía, que significa alboroto o griterío (264). Junto a esto se pueden observar numerosos otros calcos, principalmente del español al francés, tales como la interferencia de vocablos españoles en el discurso francés, la traducción literal de fraseología española al francés, 
etc. Dicha alternancia de idiomas alcanza un nivel superior cuando se lleva a cabo también con el alemán, lengua que representa su periodo en los campos de concentración y a cuyo conocimiento le debe, en cierta medida, su supervivencia. Este recurso lingüístico que, en algunas ocasiones le lleva a utilizar incluso términos en ruso u otro idioma, le lleva a Semprún a afirmar en una entrevista a Patricia López L. Gay que escribe en dos idiomas, pero vive en tres o cuatro (158).

La elección del idioma en el resto de las obras viene dada por otras razones, quizá editoriales o quizá de gusto personal, que carecen de importancia a la hora de analizar su identidad. A partir de esta obra, Jorge Semprún ya ha dejado claro su relación identitaria con el lenguaje a través de la asunción de todos los idiomas como característica de un individuo bilingüe-plurilingüe, capaz de traspasar las barreras culturales que cada idioma impone para llegar a un público sin límites, para educar a un público en una conciencia supranacional. Por lo tanto, en última instancia, la elección del lenguaje como patria, a la que ya se hizo referencia anteriormente, es asumida como lugar para romper con las relaciones de poder y sujeción que argumentaba Judith Butler, las cuales ya se exponían en el capítulo I. Semprún, a través de la escritura y del lenguaje, pretender subvertir el discurso identitario nacionalista de una Europa sacudida por una serie de movimientos nacionalistas extremistas. El lenguaje le permite crear una identidad superior, cuyo único rasgo esencial es el compromiso social, el compromiso con el mensaje cosmopolita, tal y como afirma también Josep Romaneda en la introducción del libro Pensar en Europa de Semprún: "La identidad de Semprún es la polivalencia. Sí, la lengua es la patria, pero una lengua u otra lengua: la lengua como compromiso del intelectual como palabra y ese es el verdadero mensaje cosmopolita" (10). De esta forma, la escritura le permite construir ese 
mensaje cosmopolita, de aceptación del ser humano libre e igualitario, que conlleva la ruptura de una identidad rígida, a la que ya se ha hecho referencia en numerosas ocasiones. Por lo tanto, el exilo y el enfrentamiento hacia un nuevo contexto lingüístico ha significado para Semprún una reafirmación en la creación de un nuevo discurso nacionalista identitario creado a través de un lenguaje original y transcultural.

El otro elemento que señalé previamente que era necesario analizar en la formación de la identidad era el tiempo. En el capítulo I introduje las teorías de Sophia McClennen, según la cual la relación problemática entre el escritor y el tiempo podía resolverse de diferentes formas: o bien una ruptura del orden cronológico lineal, marcado por la exclusión del tiempo histórico del país de origen, que puede conllevar a una inserción en el presente del país de acogida o un suspense temporal por la imposibilidad de integrarse, o bien un enfoque nostálgico en el pasado, así como la repetición cíclica del tiempo del exilio como castigo. Sin embargo, es especialmente curioso el hecho de que todas estas formas se representen, en mayor o menor medida, en el caso de la narrativa de Semprún.

Cuando estuvimos analizando el papel de la memoria en la obra de Semprún, mencionamos los constantes recursos narrativos que implicaban saltos temporales hacia delante o hacia atrás, así como las prolepsis o paralepsis que invadían las obras del escritor madrileño. El discurso de Jorge Semprún está marcado por una profunda ruptura del orden cronológico lineal, recurso utilizado por gran parte de la segunda generación de escritores exiliados como mecanismo para romper con la narrativa tradicional de la autobiografía con el objetivo de buscar un modo que permitiera expresar de forma más coherente la ruptura que el yo había sufrido durante el exilio. Ofelia Ferrán, haciendo 
referencia a El largo viaje, señalaba la presencia de "narrative breakdowns and shakeups" como consecuencia de la relación que la escritura pretendía establecer con la historia ("Jorge Semprún” 92). Dicha relación estaba marcada por una memoria traumática en la que pasado y presente se alternan. No obstante, va a ser esta memoria traumática la que va a provocar que el tiempo del campo de concentración se convierta en un tiempo cíclico en la narrativa de Semprún, apareciendo así en El desvanecimiento, El largo viaje, Aquel domingo o La escritura o la vida. Esta repetición cíclica va a ir acompañada de la creación de ciertos cronotopos, como la nieve, que se van a repetir en todas las obras en las que se recurren a este pasado, convirtiéndose así en símbolos de ese tiempo incapaz de borrar: "Se pregunta por qué hay tanta nieve en su memoria, masas de nieve crujiente en su insomnio. (...) Era el mes de agosto, y sin embargo hay masas de nieve en su memoria" (El desvanecimiento 7). Esto ha llevado a críticos como Loureiro a hablar de una narratividad atemporal al hablar de estas obras, puesto que la memoria traumática conduce a un presente inhabitable, ya que el revivir del tiempo pasado amenaza la estabilidad de este y, por lo tanto, la de un presente incapaz de olvidarlo ("Radical Evil" 163). Es significativo el hecho de que, en Aquel domingo, introduzca una nueva relación temporal: el inicio de un nuevo orden temporal, tal y como ya había hecho María Luisa Elío Bernal. En Cuaderno para apuntes, Elí Bernal había reflexionado sobre el inicio de un nuevo orden cronológico tras la guerra civil española. En el caso de Semprún, este nuevo sistema no viene marcado por el conflicto bélico mencionado, sino por su liberación en Buchenwald:

“El 11 de abril de 1975. Empieza a ser edad los treinta años. (...) Treinta años que retornaste a la vida, como decíais entonces. ¿Y su no había sido 
el retorno a la vida? Treinta años desde el último día de la muerte, habías pensado. ¿Y su no había sido el último día de tu muerte?, ¿si había sido, por el contrario, el primer día de tu nueva muerte?¿De otro sueño, al menos?" (pos. 5959).

Caso similar se da en La escritura o la vida cuando una mujer afirma que le gustaría ser su primera mujer y Semprún confiesa que sólo puede ser la primera después de su muerte, es decir, de su nueva vida tras su liberación en Buchenwald. Por lo tanto, en ambos casos, se produce una diferente estructuración del tiempo que tiene como punto de partida una experiencia traumática, bien el exilio en sí o bien el campo de concentración, consecuencia del exilio.

No obstante, esta narrativa cíclica del exilio o, más concretamente, de los campos de concentración, también entendida como narrativa atemporal, no se repite en las obras que no tienen como centro temático su experiencia en Buchenwald. En aquellas obras que tienen como eje argumentativo la nostalgia hacia la España de antes de la guerra civil se produce, en algunos casos, una fosilización del tiempo anterior al conflicto bélico que sigue presente hasta la actualidad. Por ejemplo, en Federico Sánchez se despide de ustedes se refleja la presencia de un nuevo tiempo que pertenece únicamente a su yo del pasado y que ha sido erosionado por el transcurso normal de los años: "Pero la imagen infantil ha sido borrada por la pátina del tiempo: la casa de mi infancia ha envejecido como yo, conmigo. Seguimos siendo contemporáneos, seguimos viviendo en el tiempo inmóvil, juntos, el tiempo erosionado por el curso de las cosas” (17). De esta forma, la España antes de la guerra civil tiene una línea temporal ajena a su yo actual, pues solo se corresponde con el yo anterior, aunque estos no escapan del envejecimiento que conlleva 
el transcurrir del tiempo. No obstante, estos nuevos esquemas temporales se reducen a pequeños momentos en los que el autor deja vislumbrar algunos elementos autobiográficos más personales, puesto que tanto en Autobiografía de Federico Sánchez como en Federico Sánchez se despide de ustedes, la estructura temporal está marcada principalmente por el diálogo que se produce entre el momento de escritura y el momento en el que suceden los acontecimientos políticos a los que hace referencia.

Especialmente interesante es el caso de Adiós, luz de veranos... por ser esta su obra más personal. En relación a esta obra, Ángel Loureiro destaca:

La muerte de la madre y el desarraigo causado por la guerra civil es una doble expulsión del espacio de su infancia o, mejor dicho, del tiempo de su infancia: pero esa expulsión fuera del tiempo es la que constituye el tiempo mismo, pues todo tiempo es un destierro, todo discurrir temporal siempre encierra en sí la memoria de un paraíso pretemporal" (“Memorial" 28).

De esta forma, Loureiro destaca el exilio como un tiempo propio. Por lo tanto, si al hablar de María Luisa Elío Bernal había señalado la existencia de una estructura temporal transtemporal, valga la redundancia, puesto que la autora se había liberado tanto del momento cronológico de su país de origen como del país de acogida para crear un tiempo propio, algo similar puede entreverse en dicha obra. El autor ha conseguido establecer su identidad como una identidad más allá de los ejes temporales de una nación en concreto. Si señalaba anteriormente que Semprún abogaba por una nación libre de fronteras, es decir, una identidad transnacional, también es posible pensar que lleve a cabo una configuración temporal que acabe con las barreras impuestas por una nación. Se 
trata de una estructura temporal única del exiliado, puesto que está caracterizado por el destierro, que ya lleva implícito su propio tiempo, como afirmaba Loureiro. No obstante, esta "transtemporalidad" no se ha desarrollado de forma totalmente exitosa en el caso del escritor madrileño, ya que dos obras posteriores, Aquel domingo y Viviré con su nombre, morirá con el mío, obras que tienen como eje temático los campos de concentración, dejan en evidencia que la presencia de este evento traumático es demasiado fuerte en la memoria del escritor y se repite de forma cíclica. Por lo tanto, aunque en Adiós, luz de veranos... pueda entreverse la liberación de las cadenas temporales, con sus siguientes obras el autor demuestra que se trata de un intento fallido. La identidad de Jorge Semprún vive anclada al tiempo del campo de concentración que vuelve de forma constante al presente del autor.

En definitiva, la marcha al exilio de Jorge Semprún supuso la desestabilización de todos los patrones identitarios establecidos hasta el momento de la partida. Mientras que disfrutaba de unas vacaciones con su familia en el norte de España, Semprún debió dejar atrás su infancia y su país de forma repentina para asumir un nuevo papel en una sociedad ajena. Además, el camino hasta dicho papel estuvo marcado por episodios extremos de esfuerzo, dolor y angustia, marcados por la pobreza, los internamientos escolares, los campos de concentración, la actividad clandestina, etc. Es esta situación subversiva frente al poder que comparte con otros individuos europeos durante su adolescencia y primeros años de madurez la que va a provocar en Semprún la elaboración de una identidad alejada del canon tradicional. Por ello mismo, el escritor madrileño se aferra a su identidad de extranjero como punto de encuentro con otras culturas, identificándose como un ser nómada, desterritorializado, transnacional, cuya ideología no entiende más compromiso 
que con la igualdad, la libertad y la justicia social. Rompe así con el corsé de la identidad nacional a favor de una conciencia identitaria supranacional. La única herramienta de la que dispone para llevar a cabo dicha tarea es el lenguaje, de ahí su afirmación en varias ocasiones de este como única patria posible. Su dominio de los idiomas es un arma que utiliza a favor de esa identidad transnacional, ya la escritura y el lenguaje es la mejor forma, según él, que puede utilizar para educar a la sociedad y evitar que se vuelvan a repetir los errores del pasado. Es decir, es esta la que le permite responsabilizarse con el compromiso social que acoge como elemento identitario. Emplea así el lenguaje para desarrollar una memoria ejemplar, según la terminología de Todorov, o sea, asimila su experiencia y la narra para poder educar a las nuevas generaciones. No obstante, Jorge Semprún ha sido incapaz de liberarse de las garras opresoras del tiempo del exilio, más concretamente del tiempo en los campos de concentración. A pesar de que puede vislumbrarse en alguna obra un intento de situarse en el exilio como entidad con un tiempo propio, tal y como había hecho María Luisa Elío Bernal y otros escritores de la segunda generación de exiliados, Jorge Semprún es aún víctima de la memoria traumática causada por su tiempo en Buchenwald. Jorge Semprún es, en este sentido, víctima un tiempo pasado del que no ha conseguido liberarse. 


\section{Conclusiones}

Este proyecto de investigación analiza la obra autobiográfica de todos aquellos niños de la guerra que, siendo víctimas de un mismo momento histórico, la Guerra Civil española, recurrieron, en algún momento a lo largo de su vida, a la escritura para relatar de qué forma dicha experiencia les había impactado como individuos, construyendo así un discurso identitario con muchos elementos comunes. Esta es la primera vez que se estudian, en una sola monografía, los textos autobiográficos/autoficcionales de la segunda generación de escritores exiliados por la Guerra Civil española sin tener en cuenta el país de acogida al que marcharon. No obstante, se trata de un estudio que requiere constante revisión debido a la existencia de numerosos manuscritos y obras autobiográficas que aún no ha sido publicadas y que problablemente vean la luz en los próximos años. De hecho, Diego García Elío, hijo de Jomí García Ascot y María Luisa Elío Bernal, me confesaba la existencia de un manuscrito autobiográfico de su padre que espera sacar a la luz en los próximos meses, así como la existencia de unas memorias inéditas de José de la Colina. A esto cabe sumar la existencia de numerosos fondos personales e institucionales que no han salido a la luz. Gracias una beca de investigación del School of International and Public Affairs de Florida International University, he podido realizar recientemente una breve investigación en el Ateneo Español de México en la que he descubierto grabaciones inéditas de mesas redondas realizadas durante los años 80 en las que los propios escritores de la segunda generación discuten su propia situación identitaria y otros fenómenos relacionados con su generación. Además, actualmente, me encuentro trabajando en los archivos personales de María Luisa Elío Bernal, un fondo rico en textos de ficción inéditos y, asimismo, en cartas con escritores como Gabriel García Márquez, 
Emilio Riera, Alejo Carpentier o Eliseo Diego, las cuales forman parte de un nuevo proyecto de investigación que ya estoy diseñando. Todos estos textos inéditos y documentos sin publicar constatan que se trata de un tema de total actualidad que requiere aún de mayor atención.

No obstante, tras un profundo análisis comparativo, puedo afirmar que son cuantiosos los rasgos que todos ellos tienen en común más allá del país en el que cada uno de ellos recalara. Muchas de las características con las que se había identificado a la generación hispano-mexicana -marchar al exilio sin cumplir la mayoría de edad, estar en proceso de formación, haber nacido en España, una educación de tono humanístico, la predominancia de la inseguridad, la idealización de España, la influencia de la literatura española o el desligamiento del país de acogida y sus problemas- son aplicables al resto de individuos de esta generación que habían llegado a la URSS, Bélgica, Francia, u otros países. Por lo tanto, se confirma la teoría de Julián Marías y Ortega y Gasset, la cual sostiene que las generaciones quedan marcadas por acontecimientos históricos que impactan el sistema de ideas y las formas de pensamiento de todo un grupo. Al mismo tiempo, ello conlleva que desaparezcan las fronteras como rasgo divisor en el caso de este grupo de individuos. Por eso, cobra especial importancia la nueva clasificación que propuse por la cual debe tenerse en cuenta la edad con la que cada sujeto marchó al exilio más allá de su fecha de nacimiento o de su país de destino.

A lo largo de este proyecto he establecido dos áreas principales de investigación: por un lado, el estudio del uso de la literatura del yo como recurso para expresar un evento tan traumático como la salida involuntaria de tu país de origen, así como la utilización de la escritura para configurar una identidad marcada por la memoria y el 
trauma; y, por otro lado, el análisis del discurso identitario de esta generación en relación a los conceptos de nación-espacio, tiempo y lenguaje. Tras el estudio de ambas áreas, surgen algunos interrogantes que abren nuevas líneas de investigación.

En primer lugar, la división entre escritores profesionales y no profesionales invita a una reflexión más profunda sobre qué llevó a todos estos individuos a transcribir su experiencia. En el caso de los escritores profesionales, es evidente que, más allá del relato de su vida, la escritura se ha convertido en un rasgo definitorio de su identidad. No obstante, en el caso de los escritores no profesionales, es necesario replantearse el acercamiento de estos a la escritura como herramienta para contar otra "verdad" que, durante años, ha estado silenciada desde los círculos de poder. De este modo, cabe explorar en qué medida esta literatura testimonial está cubriendo un vacío que desde los círculos de poder aún no se ha revelado abiertamente y de qué forma estas obras invitan a re-escribir la historia de España de los últimos 80 años.

En segundo lugar, argumenté que el uso de la ficción dentro de las obras autobiográficas/autoficcionales de este grupo de escritores es un elemento propio de la identidad de una generación que ha recurrido a la escritura para poder contar el horror y el trauma de su experiencia sin provocar un rechazo en el lector. El uso de la ficción en Dulcinea encantada o Un tiempo tuyo está íntimamente relacionado con lo autobiográfico, puesto que esta tiene como objetivo dar a conocer una nueva identidad. De este modo, la ficción se convierte en una herramienta para reconstruir la imagen de una España que apenas recordaban y para terminar con las secuelas traumáticas de una experiencia como la que ellos vivieron. Para esta generación es inevitable ficcionalizar lo vivido para dar a conocer su historia y que esta no resulte en un relato inverosímil ante 
los ojos del lector. Por lo tanto, esto abre las puertas a una revisión de la narrativa de la segunda generación de escritores exiliados por la Guerra Civil española teniendo en mente que la ficción es un rasgo más de su identidad y que el uso de esta permite un mayor acercamiento a la construcción del sujeto.

Asimismo, la existencia de numerosos elementos comunes en la configuración del discurso identitario nacional entre miembros de esta generación que desarrollaron sus vidas en diferentes países de acogida, evidencia la necesidad de explorar nuevos estudios que vayan más allá de términos como la "generación hispano-mexicana" o "los niños de la guerra en Francia" y establezcan vínculos entre estos niños convertidos en escritores cuya vida estuvo marcada por un mismo momento histórico. Si ellos consiguieron elaborar una narrativa identitaria alejada de las restricciones que pueden ejercer actualmente y que han ejercido a lo largo de la historia las fronteras, es necesario que también nosotros, como críticos, seamos capaces de superarlas para ver no lo que los separa, sino lo que los une.

En relación con la creación de discursos identitarios nacionales diferentes a los propuestos desde dentro de las fronteras españolas, destaqué que es llamativo el hecho de que gran parte de los escritores que vivieron el exilio bajo dictaduras de izquierda no desarrollaran un discurso identitario nacional desterritorializado o nómada como sí hicieron los otros miembros de la generación. Por lo tanto, es necesario seguir profundizando sobre cómo las políticas de los diferentes países de acogida impactaron en la construcción de dichas narrativas y analizar, en qué medida, sufrir también las consecuencias de dictaduras como la de Fidel Castro o la de la URSS condicionó el desarrollo de una nueva identidad. 
Por otro lado, el exilio no es algo exclusivo de la sociedad española. De esta forma, sería interesante analizar los discursos identitarios nacionales de la segunda generación de escritores exiliados por la Guerra Civil española en comparación con aquellos creados por miembros de segundas generaciones de escritores exiliados de otras guerras civiles, tales como las de Chile y Argentina, la revolución cubana o, incluso, otras sociedades no hispanas. Considero interesante reflexionar sobre la forma en que han evolucionado los discursos de los exiliados víctimas de otros regímenes dictatoriales, bien de izquierdas o bien de derechas, y analizar si han creado un discurso identitario nacional similar al observado en los autores aquí estudiados o, por el contrario, proponen otras alternativas. No obstante, esta comparación no tiene por qué limitarse únicamente al discurso identitario nacional, sino que puede extrapolarse al estudio de las esquematizaciones temporales, la interferencia lingüística, el impacto del retorno, así como a la difuminación de las fronteras entre los géneros literarios. Apoyándome en las teorías de McClennen, afirmé que hay un importante grupo de autores - no todos- en el que conviven, de forma simultánea, múltiples sistemas de relacionarse con el tiempo, las cuales aparecen de forma aleatoria en diferentes momentos de su vida. Esto se ha interpretrado como una herramienta de rechazo hacia cualquier rasgo de complicidad con las bases ideológicas del autoritarismo. No obstante, ¿se produce dicha convivencia en otros autores de segunda generación exiliados por otra guerra civil? ¿es también, en su caso, un sistema de resistencia?

En último lugar, el lenguaje debe entenderse no sólo como conjunto de signos que permiten expresar una realidad, sino también como elemento identitario de una comunidad-cultura. Tras hacer un bosquejo de los diferentes idiomas en los que escribe 
esta generación -español y sus variedades dialectales, francés, ruso, catalán-, es interesante señalar la existencia de puentes lingüísticos en gran parte de las obras de esta generación pues son numerosas las referencias, la utilización de algunos giros sintácticos o la inclusión de vocablos en otros idiomas. Esta multiplicidad de rasgos propios de diferentes idiomas o dialectos nos permite entender el grafocentrismo al que hace referencia Illie no como lenguaje carente de vinculación, sino como lenguaje capaz de vincularse a numerosas naciones o culturas sin establecer jerarquías entre ellas. De esta forma, la suma de rasgos lingüísticos provenientes de diferentes culturas convierte al lenguaje del exilio en un lenguaje multicultural. De hecho, también Braidotti ha utilizado la figura del políglota para referirse al sujeto nómada. Ahora bien, este nuevo lenguaje constituye su principal herramienta para construir una realidad diferente a la que durante años se había propagado desde los círculos de poder. Así, intentan poner fin a las relaciones entre poder y sujeción que había explicado Judith Butler y hacen de la escritura el lugar desde el cual, a través del lenguaje, crean un discurso narrativo diferente que, a diferencia del que utiliza el régimen franquista, está basado en la multiplicidad de formas y en la transculturalidad. No obstante, a excepción del estudio comentado en el capítulo tercero sobre el lenguaje en la obra de Federico Patán y de referencias tangenciales en algunos otros artículos, existe un importante vacío en cuanto al estudio del uso del lenguaje en estas obras. Por lo tanto, es necesario acercarse a estas narraciones a partir de un estudio pormenorizado del lenguaje teniendo en cuenta la influencia sintáctica, semántica y léxica entre las diversas lenguas que domina gran parte de los escritores de la segunda generación de escritores exiliados por la Guerra Civil 
española para poder entender mejor las implicaciones identitarias que se derivan del uso del lenguaje multicultural propio de esta generación.

En definitiva, esta tesis analiza, a partir de los textos autobiográficos o autoficcionales, el discurso identitario de los autores pertenecientes a la segunda generación de escritores exiliados que, en muchas ocasiones, ya sea por motivos políticos, ya sea por simple desconocimiento o, incluso, por la falta de calidad literaria en el caso de algunas obras, ha pasado desapercibido por parte de la crítica. No obstante, este mismo silencio demuestra la necesidad de repensar las narrativas sociales y políticas de la Guerra Civil española teniendo en cuenta el estudio de estas obras. De esta forma, invito a los investigadores a acercarse a la obra no sólo autobiográfica, como he hecho yo en este trabajo, sino a toda la literatura de esta generación para poder reescribir una historia cultural y literaria de España que, durante años, fue silenciada y que, afortunadamente, hace muchos años que críticos e investigadores han venido colaborando en su escritura. Y es que, tal y como se recuerda a todos los visitantes del campo de concentración de Auschwitz al entrar al bloque 4, "those who do not remember the past are condemned to repeat it". 
Obras citadas

AA.VV. El exilio español en México, 1939-1982. México: Fondo de Cultura Económica, 1982.

Abellán, José Luis. Cultura y literatura. El exilio español de 1939. Madrid: Taurus, 1977. ---. De la guerra civil al exilio republicano (1936-1977). Madrid: Mezquita, 1983. Adela Kohan, Silvia. De la autobiografía a la ficción. Entre la escritura autobiográfica y la novela. Barcelona: Grafein Ediciones, 2000.

Almet, Margarita y María García Lorenzo y Helena Guzmán y Marina Sanfilippo. Ecos de la memoria. Madrid: UNED, 2001.

Aguirre Herráinz, Pablo. "Hijos del exilio y de la emigración: la segunda generación como problema". Academia.edu

Aínsa, Fernando. Con acento extranjero. Buenos Aires: Nordan, 1985.

---. Travesías. Juegos a la distancia. Málaga: Litoral, 2000.

---. Palabras nómadas. Nueva cartografía de la pertenencia. Madrid:

Iberoamericana-Veuvert, 2012.

Alberca, Manuel. El pacto ambiguo. De la novela autobiográfica a la autoficción. Madrid: Biblioteca Nueva, 2013. Kindle file.

Alonso García, Charo. "Una mirada hacia lo perdido: En el balcón vacio". Archivos de la Filmoteca: Revista de estudios históricos sobre la imagen 3 (octubre 1999): 140149.

Alted Vigil, Alicia. "El exilio republicano español de 1939 desde la perspectiva de las mujeres". Arenal. Revista de historia de las mujeres 4.2 (julio-diciembre 1997): 223-238.

---. “Los niños de la Guerra civil”. Anales de Historia Contemporánea 19 (2003): 43-58.

---. "Exilio, identidad y alteridad". L'autre et soi-meme la identidad y la alteridad en el ámbito francés y francófono. Coord. María Pilar Suárez. Madrid:

Universidad Autónoma de Madrid, 2004, 245-259.

---. La voz de los vencidos. El exilio republicano de 1939. Madrid: Aguilar, 2005. Edición Kindle.

Alted Vigil, Alicia, Encarna Nicolás Marín y Roger González Martell. Los niños de la guerra de España en la Unión Soviética. De la evacuación al retorno (19371999). Madrid: Fundación Largo Caballero, 1999.

Alted Vigil, Alicia y Roger González y María José Millán. El exilio de los niños. Madrid: Fundación Pablo Iglesias, 2003. 
Alted Vigil, Alicia y Manuel Lluisa, eds. La cultura del exilio republicano español de 1939. Actas del Congreso Internacional celebrado en el marco del Congreso Plural: sesenta años después (Madrid - Alcalá - Toledo, diciembre de 1999). Madrid: UNED, 2003.

Álvarez, Federico. Una vida. Infancia y juventud. México D.F.: Memorias Mexicanas, 2013.

Álvarez de la Rosa, Antonio. "Michel del Castillo: ¿autobiografía o veneno?". VII Coloquio APFUE (Asociación de Profesores de Francés de la. Universidad Española): Cádiz, 11-13 de Febrero de 1998. Vol 2. Cádiz: Universidad de Cádiz, 1999, 9-14.

Álvarez del Vayo, María. Los últimos días. Recuerdos y reflexiones de una niña del exilio. Madrid: Fundación Pablo Iglesias, 2003.

---. Patría mía ¿Dónde estás? Oviedo: Universidad de Oviedo, 2014.

Álvarez Morán, Isabel Argentina. Memorias de una niña de la guerra. Gijón: Fundación Municipal de Cultura, Educación y Universidad Popular, 2003.

Amo González, Iñigo. El ciclo de Federico Sánchez de Jorge Semprún entre la autoficción y la memoria política. UNED, 2010. Web. 30 Enero 2018. http://www2.uned.es/centro-investigacion-SELITEN@T/pdf/Inigo_Amo.pdf

Anderson, Benedict. Imagined Communities. New York: Verso, 1983.

Anderson, Linda. Autobiography. London: Routledge, 2001.

Arce, Manuel. Memorias de Rusia. Vivencias de un "niño de la guerra". Madrid: Multipress, 2009.

Arriaga Flórez, Mercedes. Mi amor, mi juez: alteridad autobiográfica femenina. Barcelona: Anthropos, 2001.

Ascunce, José Ángel y María Luisa San Miguel. Los hijos del exilio vasco: arraigo o desarraigo. Donostia: Saturrarán, 2004.

Ashley, Kathleen, and Leigh Gilmore and Gerald Peters. Autobiography and Postmodernism. Boston: The University of Massachusetts Press, 1994.

Aub, Max. “Una nueva generación”. Sala de Espera 21 (junio 1950): 12-15.

Ayala, Francisco. "Para quién escribimos". Guaraguao 25 (autumn 1997): 83-94. 
Aznar Soler, Manuel. El exilio literario español de 1939: Actas del Primer Congreso Internacional (Bellatera, 27 de noviembre - 1 de diciembre de 1995). Sant Cugat del Vallés: GEXEL, 1998.

---. Las literaturas del exilio republicano de 1939. Sant Cugat del Vallés: GEXEL, 2000.

---. "La historia de las literaturas del exilio republicano español de 1939: problemas teóricos y metodológicos". Migraciones y Exilios 3 (2002): 9-22. ---. Escritores, editoriales y revistas del exilio republicano de 1939. Sevilla: Renacimiento, 2006.

---. "Materiales para la memoria de un mito: María Casares y el exilio republicano de 1939". Escritores, editoriales y revistas del exilio republicano de 1939. Ed. Manuel Aznar Soler. Sevilla: Renacimiento, 2006, 1073-1107.

---. "Movimiento Español 1959: literatura y política de la segunda generación exiliada en México". El exilio republicano de 1939 y la segunda generación. Eds. Manuel Aznar Soler y José Ramón López García. Sevilla: Renacimiento, 2011, 143-198.

Aznar Soler, Manuel y Alicia Alted Vigil. Literatura y cultural del exilio español de 1939 en Francia. Salamanca: GEXEL, 1998.

Aznar Soler, Manuel y José Ramón López García. El exilio republicano de 1939 y la segunda generación. Sevilla: Renacimiento, 2011.

---. Diccionario biobibliográfico de los escritores, editoriales y revistas del exilio republicano de 1939. Sevilla: Renacimiento, 2017.

Aznar Soler, Manuel y José Ramón López García, Francisca Montiel Rayo y Juan Rodríguez. El exilio republicano de 1939: viajes y retornos. Sevilla: Renacimiento, 2014.

Balibrea, María Paz. Tiempo de exilio: una mirada crítica a la modernidad española desde el pensamiento republicano en el exilio. Barcelona: Montesinos, 2007.

Balibrea, María Paz y Jaime Concha y Beatrice Pita y Rosaura Sánchez. Encuentros en la diáspora: ensayos en honor de Carlos Blanco Aguinaga. Sant Cugat del Vallés: GEXEL, 2002.

Bammer, Angelika. Displacements. Cultural Identities in Question. Indianapolis: Indiana University Press, 1994.

Barbero, Trinidad. "Josefina Iturrarán: una investigadora tras las huellas de españoles en la Unión Soviética”. El exilio republicano de 1939 y la segunda generación. Eds. Manuel Aznar Soler y José Ramón López García. Sevilla: Renacimiento, 2011, 243-254. 
Barral, Fernando. Mis vidas sucesivas. Recuerdos y destino de un niño de la guerra. La Habana: La Memoria, 2010.

Barriales-Bouce, Alejandra. El reto ético del exilio: La autoescritura del éxodo republicano español. Diss. University of Massachussets, 2003.

Basterretxea Arzadun, Néstor. Crónica errante y una miscelánea. Irún: Alberdania, 2006.

Belza, Ángel. Memorias de un niño en Rusia 1937-1957. España: Paradiso-Gutenberg, 2013.

Benjamín, Natalia. Recuerdos: Basque children refugees in Great Britain. Oxford: Mousehold Press, 2007.

Bergson, Henri. Matiere et memoire. Essai sur la relation du corps a l'esprit. Trad. Pablo Ires. Buenos Aires: Cactus, 2006.

Bertrand de Muñoz, Maryse. "Autobiografía y novela de la Guerra Civil Española. Textos recientes". Actas del XVII Congreso de la Asociación Internacional de Hispanistas: Rumbos del hispanismo en el umbral del Cincuentenario de la AIH (2010). Roma: Bagatto Libri, 2012, 184-190.

---. "El esperpento de tres novelistas exiliados a raíz de la guerra: José Luis de Villalonga, Agustín Gómez-Arcos y Jorge Semprún". El exilio republicano de 1939 y la segunda generación. (Coords.) Manuel Aznar Soler y José Ramón López García. Sevilla: Renacimiento, 2011, 525-532.

Best, Steven, and Douglas Kellner. Postmodern Theory: Critical Interrogations. New York: The Guildorf Press, 1991.

Bhabha, Homi K. "DissemiNation: time, narrative, and the margins of the modern station". Nation and Narration. Ed. Homi K. Bhabha. London: Routledge, 1990.

Blanco Aguinaga, Carlos. Un tiempo tuyo. Madrid: Alfaguara, 1988.

---. "La literatura del exilio en su historia". Migraciones y exilio 2 (2002): 23-42.

---. Por el mundo: infancia, guerra y principio de un exilio afortunado. Irún: Alberdania, 2007.

---. De mal asiento. Madrid: Caballo de Troya, 2010.

Bou, Enric. "El diario: periferia y literatura". Revista de Occidente 182-183 (1996): 121136.

---. "Construcción autobiográfica y exilio: entre la memoria individual y la colectiva". Revista Canadiense de Estudios Hispánicos 301 (2005): 17-32.

Braidotti, Rossi. Sujetos nómades. Corporización y diferencia sexual en la teoría feminista contemporánea. Trad. Alcira Bixio. Buenos Aires: Paidós, 2000. 
Brenneis, Sara J. "Carlos Blanco Aguinaga: The Spanish Other in Mexico". Genre Fusion: A New Approach to History, Fiction, and Memory in Contemporary Spain. Indiana: Purdue University Press, 2014, 131-169.

Brockmeir Jens and Donal A Carbaugh. Narrative and Identity: studies in autobiography, self and culture. Philadelphia: Amsterdam, 2001.

Brodsky, Joseph. "The Condition We Call Exile". The New York Review (21 enero 1988): 16-20.

Brodzi, Bella y Schenck, Celeste. Life/Lines: Theorizing Women's Autobiography. Ithaca: Cornell University Press, 1988.

Bruss, Elizabeth W. Autobiographical Acts. The Changing Situation of a literary genre. London: The Johns Hopkins University Press, 1976.

Butler, Judith. The Psychic Life of Power. Theories in Subjection. California: Stanford University Press, 1997.

Caballé, Anna. “Aspectos de la literatura autobiográfica en España”. Scriptura 2 (1986): 39-50.

---. Narcisos de tinta. Ensayo sobre la literatura autobiográfica en lengua castellana (siglos XIX y XX). Málaga: Megazul, 1995.

Cano, Amelia. "El diario en la Literatura. Estudio de su tipología". Anales de filología hispánica 3 (1987): 53-60.

Caruth, Cathy. Unclaimed experience: Trauma, Narrative, and History. Baltimore: Johns Hopkins University Press, 1996.

Casares, María. Residente privilegiada. Trad. Fabián García-Prieto Buendía y Enrique Sordo. Barcelona: Argos Vergara, 1981.

Castilleja, Diana. “Angelina Muñiz-Huberman: construcción de un 'yo' fragmentado". Anales de Literatura Hispanoamericana 44 (2015): 21-33.

Castillo, Michel del. Tanguy. Historie d'un enfant d'aujourd'hui. Paris: Julliard, 1978.

Cate-Arries, Francie. "War Through a Girl's Eyes in a Woman's Voice: Cinematic Images of Memory's Hiding Places in En el balcón vacio (1963)". Letras Peninsulares 16.1 (2003): 205-13.

Céspedes, Jaime. La obra de Jorge Semprún: Claves de Interpretación Vol. 1: Autobiografía y novela. Bern: Peter Lang, 2012. 
Chantraine-Braillon, Cecile, Norah Giraldi Dei Cas y Fatiha Idmhand. El escritor y el intelectual entre dos mundos: lugares y figuras del desplazamiento. Madrid: Iberoamericana, 2010.

Catelli, Nora. El espacio autobiográfico. Barcelona: Lumen, 1991.

Correa, Aurora. Te beso, buenas noches. México D.F.: Ediciones SM, 1997. ---. Cerezas. Aguascalientes: Instituto Cultural de Aguascalientes, 2008.

Crego, Rosalía y Carmen Heredia y Enrique Zafra. Los niños españoles evacuados a la URSS (1937). Madrid: Ediciones de la Torre, 1989.

Cuder Domínguez, Pilar. Exilios femeninos. Sevilla: Instituto Andaluz de la Mujer, 1999.

Cuesta, Nieves. Simplemente mi vida. Asturias: Ediciones Azucel, 2009.

Cuesta Bustillo, Josefina. “"Las capas de la memoria". Contemporaneidad, sucesión y transmisión generacionales en España (1931-2006)". Hispania Nova: Revista de historia contemporánea 7 (2007). Web.

Cuito, Amadeu. Memòries d'un somni. Barcelona: Quaderns Crema, 2011.

Deleuze, Gilles, and Félix Guattari. Anti-Oedipus. New York: Viking Press, 1977. ---. Nomadology: The War Machine. New York: Semiotext(e), 1986.

De Man, Paul. “Autobiography as De-Facement”. The Rhetoric of Romanticism. New York: Columbia UP, 1984, 67-81.

Deniz, Gerardo. Paños menores. México: Tusquets, 2002.

Domínguez Prats, Pilar. Mujeres españolas exiliadas en México (1939-1950). Madrid: Comunidad de Madrid: Dirección General de la Mujer, 1994.

Durán, Manuel. Diario de un aprendiz de filósofo. Sevilla: Renacimiento, 2007.

Durham Peters, John. "Exile, nomadism, and diaspora. The stakes of mobility". Home, Exile, Homeland. Film, Media and the Politics of Place. New York: Routledge, 1999, 17-41.

Dutrénit Buelous, Silvia. "La marca del exilio y la represión en la segunda generación". Historia y grafia 41 (2013): 205-241.

Eakin, Paul John. Fictions in Autobiography. Studies in the Art of Self-Invention. Princeton: Princeton University Press, 1985. 
Eberenz, Rolf. "Enunciación y estructuras metanarrativas en la autobiografía". $L a$ autobiografía en lengua española en el siglo XX. AA.VV. Lausanne: Hispánica Helvética, 1991, 37-51.

Elío Bernal, María Luisa. Tiempo de llorar y otros relatos. Madrid: Turner, 2002. ---. Voz de Nadie. México: El Equilibrista, 2017.

Elío Bernal, María Luisa y García Ascot, Jomí. En el balcón vacío (México, 1962). Madrid: AEMIC, 2012.

Elío Torres, Luis. Soledad de ausencia. Entre las sombras de la muerte (España, 1936). Pamplona: Pamiela, 2002.

Espino Barrera, Tomás. "Exilios y retornos lingüísticos: Jorge Semprún, entre dos lenguas". El exilio republicano del 1939: viajes y retornos. Coord. Manuel Aznar Soler, José Ramón López García, Francisca Montiel Rayo y Juan Rodríguez. Sevilla: Renacimiento, 2014, 260-67.

Faber, Sebastian. Exile and Cultural Hegemony: Spanish Intellectuals in Mexico, 19391975. Nashville: Vanderblit University Press, 2002.

Febo, Giuliana di. "Un espacio en la memoria: el paso de la frontera francesa de los exiliados españoles. La despedida del presidente Azaña”. Literatura y cultura del exilio español de 1939 en Francia. Coords. Alicia Alted Vigil y Manuel Aznar Soler. Barcelona: Gexel, 1997, 467-483.

---. "Memoria e identidad política en los escritos autobiográficos femeninos del exilio". La cultural del exilio republicano de 1939. Actas del Congreso Internacional celebrado en el marco del Congreso Plural: sesenta años después (Madrid-Alcalá - Toledo, diciembre de 1999). Eds. Alicia Alted Vigil y Manuel Lluisa. Madrid: UNED, 2003, 305-318.

Fernández, Ángel. Rebelde. Tomo I. Toulouse: edición del autor, 2000.

---. Rebelde. Tomo II. Toulouse: edición del autor, 2009.

Fernández, Carlos. Casares Quiroga, una pasión republicana. A Coruña: Edicios do Castro, 2000.

---. "Estrategias de la memoria en la obra de Jorge Semprún". Historia, antropología y fuentes orales 32 (2004): 69-88.

Fernández, Isabel. Pauline ou l histoire d'une intégration. De Madrid à Mazamet. Mazamet: Sud 81, 1997.

Fernández, María L. Memorias de una máquina de escribir de una niña de la guerra. Gijón: Concejalía Memoria Social Ayuntamiento de Gijón, 2011. 
Fernández Martínez, Dolores. "Entrevista a Tomás Segovia: el grupo Nuevo Cine y la película En el balcón vacio". En el balcón vacío. La segunda generación del exilio republicano en México. (Ed.) Javier Lluch-Prats. En el balcón vacío. La segunda generación del exilio republicano en México. Madrid: AEMIC, 2012, 349-374.

Fernández-Montesinos, Manuel. Lo que en nosotros vive. Barcelona: Tusquets, 2008.

Fernández Muñiz, Aurea Matilde. José y Consuelo. Amor, guerra y exilio en mi memoria. La Habana: La Memoria, 2013.

Fernández Sánchez, José. Memorias de un niño en Moscú. Cuando salí de Ablaña. Barcelona: Planeta, 1999.

Ferrán, Ofelia. “'El largo viaje' del exilio: Jorge Semprún”. El exilio literario español de 1939: Actas del Primer Congreso Internacional (Bellatera, 27 de noviembre - 1 de diciembre de 1995). Volumen 2. Ed. Manuel Aznar Soler. Barcelona: Gexel, 1998, 107-116.

---. "Cuanto más escribo, más me queda por decir': Memory, Trauma, and Writing in the Work of Jorge Semprún". MLN 1162 (2001): 266-94.

---. "Jorge Semprún: trauma and memory". Working through memory: writing and remembrance in contemporary Spanish narrative. Lewisburg: Bucknell University Press, 2007.

Figuero, Javier y Marie- Helène Carbonel. Maria Casarès, l'ètrangère. París: Fayard, 2005.

Filler, Malva E. "La integración de una hispanidad fragmentada en la obra de Angelina Muñiz-Huberman”. Silva: studia philologica in honorem Isaías Lerner. Coord. Isabel Lozano Renieblas y Juan Carlos Mercado. Madrid: Castalia, 2001, 233244.

Foucault, Michel. The Care of the Self. New York: Random House, 1986.

Fox Maura, Soledad. Ida y vuelta. La vida de Jorge Semprún. Barcelona: Debate, 2016.

Fuentes. Carlos. Los años con Laura Díaz. México D.F.: Alfaguara, 2016. Kindle file.

Galerstein, Carolyn. "Outside-Inside Views of Exile: Spanish Women Novelists and Younger Generation Writers". Latin America and the Literature of Exile: a Comparative View of the 20th-century European Refugee Writers in the New World 1 (1983): 137-148. 
---. "The Second Generation in Exile". Papers on Language and Literature. A Journal of Scholars and Critics of Language and Literature 212 (Spring 1985): 220-228.

García de León, Encarnación. "La voz de la memoria, perturbada por el drama personal de Miche del Castillo: un caso de docuficción". El exilio republicano de 1939 y la segunda generación. Eds. Manuel Aznar Soler y José Ramón López García. Sevilla: Renacimiento, 2011, 548-555.

Gellner, Ernest. Culture, Identity, and Politics. Cambridge: Cambridge University Press, 1987. ---. Nations and Nationalism. New York: Cornell University Press, 1983.

Gerhard I Hortet, Carles. Dues guerres i un exili. Memòries. Barcelona: L'Avenç, 2013.

Giner de los Ríos, Francisco. Segunda generación de poetas españoles del exilio mexicano. Santander: Institución Cultural de Cantabria, 1980.

Giordano, Alberto. Una posibilidad de vida: Escrituras íntimas. Rosario: Beatriz Viterbo, 2006.

González de Garay, María Teresa. "Memoria, exilio en Un tiempo tuyo de Carlos Blanco Aguinaga". Guerra y memoria en la España contemporánea. (Coords.) Alison Robeiro de Menezes, Roberta Quance y Anne L. Walsh. Madrid: Verbu, 2009, 103-116.

---. "Exilios, identidades y memoria en Carlos Blanco Aguinaga". El exilio vasco: estudios en homenaje al profesor José Ángel Ascunce Arriera. Iker GonzálezAllende (coord.). Bilbao: Universidad de Deusto, 2016, 257-279.

González Otero, Angélica. "El diario: la escritura autobiográfica en su dimensión sociocultural y sus posibilidades cognoscitivas y creativas". La Palabra 30 (2017): 151-167.

Goytisolo, Juan. Señas de identidad. Barcelona: Biblioteca Universal Formentor, 1980. ---. Autobiografía. Barcelona: Galaxia Gutenberg, 2017, Kindle file.

Guillén, Claudio. "On the Literature of Exile and Counter Exile". Books Abroad 50 (1976): 271-80.

--- Múltiples moradas: ensayo de literatura comparada. Barcelona: Tusquets, 1998.

Gusdorf, Georges. "Condiciones y límites de la autobiografía”. Trans. Ángel Loureiro. Suplementos 29 (dic 1991): 9-17. 
Hadzelek, Aleksandra. “¿Por qué la autobiografía? El exilio en la autobiografía o la búsqueda de la identidad perdida”. El exilio literario español de 1939: actas del primer congreso internacional: Bellaterra, 27 de noviembre - 1 de diciembre de 1995. Ed. Manuel Aznar Soler. Barcelona: Gexel, 1998, 309-316.

Halbwachs, Maurice. Los marcos sociales de la memoria. Barcelona: Anthropos, 2004.

Hall, Stuart. "Cultural Identity and Diaspora". Colonial Discourse and Post-Colonial Theory. Eds. Patrick Williams y Laura Chrisman. New York: Columbia University Press, 392-403.

Hogan, Colman y Marta Marín-Domine. Eds. The Camp: Narratives of Internment and Exclusion. Cambridge: Cambridge Scholars Publishing, 2007.

Hopkins, Stephen. "Still a 'Spanish Red"? The Communist Past and National Identity in the writing of Jorge Semprun”. Twentieth Century Communism 33 (Julio 2011): 70-91.

Hoyos Puente, Jorge de. "Las mujeres exiliadas en la configuración de la identidad cultural y política de los refugiados españoles en México". Ubi sunt: Revista de Historia 27, 2012, 28-40.

Houvenaghel, Eugenia Helena. "Angelina Muñiz: hacia la construcción de una identidad más allá de las líneas fronterizas". Anales de la Literatura Hispanoamericana 44 (2015): 15-20.

---. "Cruzando fronteras: espacio e identidad en el ensayo de Angelina Muñiz". Anales de Literatura Hispanoamericana 44 (2015): 87-99.

Ibeas Vuelta, Nieves. "Michel del Castillo: el texto único en permanente reescritura". Intertexto y polifonía. Estudios en homenaje a María Aurora Aragón. Tomo 1. Oviedo: Universidad de Oviedo, 2008, 351-358.

Illie, Paul. Literature and Inner Exile: Authoritarian Spain, 1939-1975. London: The Johns Hopkins University Press, 1980.

---. "Exolalia and Dictatorship: The Tongues of Hispanic Exile". Fascismo y experiencia literaria: reflexiones para una recanonización. Ed. Hernán Vidal. Minneapolis: U of Minnesota Press, 222-254, 1985.

Irina Ibarra Guerrero, Katia y Marian Masera. "Identidad(es) literaria(s): el exilio en las poetas hispanomexicanas". Valenciana 1020 (jul./dic. 2017): 113-136.

Jato, Monica. "Hacia una imposible poética del regreso: Tiempo de llorar de María Luisa Elío Bernal". Mujer, creación y exilio (España, 1939-1975). Eds. Mónica Jato, Sharon Keefe Ugalde y Janet Pérez. Barcelona: Icaria, 2009, 145-163. 
Jato, Mónica, Ascunche, José Angel y San Miguel, María Luisa. España en la Encrucijada de 1939: Exilios, Cultura e Identidades. Bilbao: Universidad de Deusto, 2007.

Jelin, Elizabeth. Los trabajos de la memoria. Madrid: Siglo XXI de España, 2002.

Jelinek, Estelle. Women's Autobiography. Essays in Criticism. Bloomington: Indiana University Press, 1980.

Joris, Pierre. A nomadic poetics. Essays. Middletown: Wesleyan University, 2003.

Kaminsky, Amy K. Reading the Body Politic: Feminist Criticism and Latin American Women Writers. Minneapolis: University of Minnesota Press, 1993. ---. After exile: writing the Latin America diaspora. Minneapolis: University of Minnesota Press, 1999.

Keefe Ugalde, Sharon. "Configuraciones nómadas en la poesía de Julia Uceda”. Anales de la literature Española contemporánea 383 (2013): 813-827.

Labajos, Emilia. La casa de los geranios. Bruselas: Excritos, 2003.

Labajos, Emilia y Fernando Vitoria-García. Los Niños. Histoire d'enfants de la Guerre civile espagnole exilés en Belgique (1936-1939). Erpent: Association Los niños de la Guerra, 1994.

Labanyi, Jo. "Postmodernism and the Problem of Cultural identity". Spanish cultural studies: an introduction: the struggle for modernity. Eds. Helen Graham y Jo Labanyi. Oxford: Oxford University Press, 1995.

Lagos-Pope, María-Inés. Exile in Literature. Toronto: Bucknell University Press, 1988.

Larranz, Fernando. "El segundo exilio. La segunda generación en la narrativa de las exiliadas republicanas". Ernestina de Champourcín. Mujer y Cultura en el siglo $X X$. Eds. Rosa Fernández Urtasun y José Ángel Ascunce. Madrid: Biblioteca Nueva, 2006, 411-416.

---. "La novela testimonial de las exiliadas republicanas en México". Género y géneros: Escritura y escritoras iberoamericanas. Eds. Ángeles Encinar, Eva Löfuist y Carmen Valcárcel. Madrid: Universidad Autónoma de Madrid, 2006, 245-257.

---. "Memoria y representación. La segunda generación del exilio en su escritura narrativa". El exilio republicano de 1939 y la segunda generación. Eds. Manuel Aznar Soler y José Ramón López García. Sevilla: Renacimiento, 2011, 583-589. ---. "El lugar de la narrativa del exilio en la literatura española". Iberoamericana XII 47 (2012): 101-113. 
Leggott, Sarah. The Workings of Memory: Life-Writing by Women in Early TwentiehCentury Spain. Lewisburg: Bucken University Press, 2008.

Lejeune, Philippe. El pacto autobiográfico y otros estudios. Madrid: Megazul-Endymion, 1994.

León-Portilla, Ascensión H. y María Luisa Capella. El exilio español y la UNAM. México: Universidad Nacional Autónoma de México, 1987.

Llanos Más, Virgilio de los. ¿Te acuerdas, Tovarisch ...?: del archivo de un niño de la guerra. Valencia: Institució Alfons el Magnàni, 2002.

Llorens, Vicente. Estudios y ensayos sobre el exilio republicano de 1939. Sevilla: Renacimiento, 2006.

Londero, Eleanor. "Espacio y memoria en la narrativa del exilio español". Historia, espacio e imaginario. Ed. Jacqueline Covo. Paris: Presses Universitaires de Septention, 1997.

López-Aguilar, Enrique. Visita a seis poetas hispanomexicanos. Exilio y memoria. Fuentes Humanisticas 46 (2013): 79-95.

López L.-Gay, Patricia. "Conversación con Jorge Semprún. Sobre autotraducción. De los recuerdos y sus formas de reescritura". Quaderns: Revista de traducción 16 (2009): 157-164.

Loureiro, Angel G. The Ethics of Autobiography: Replacing the Subject in Modern Spain. Nashville: Vanderblit University Press, 2000.

---. "Radical Evil and the Secrets of Fraternity". The Ethics of autobiography: replacing the subject in modern Spain. Autor: Ángel Loureiro. Nashville: Vanderbilt University Press, 2000, 143-181.

---. "Semprún: memorial de ausencias". Cuadernos hispanoamericanos 617 (2001): 21-30.

Lluch-Prats, Javier. En el balcón vacío. La segunda generación del exilio republicano en México. Madrid: AEMIC, 2012.

Magris, Claudio. Utopía y desencanto. Barcelona: Anagrama, 2001.

Mangini, Shirley. Recuerdos de la resistencia. La voz de las mujeres de la guerra civil española. Barcelona: Península, 1997.

Marchamalo, Jesús. "Entrevista con Jaime Salinas". Cuadernos hispanoamericanos 646 (2004): 117-138. 
Marías, Julián. El método histórico de las generaciones. Madrid: Revista de Occidente, 1949.

Marín Gómez, Isabel. "Identidad y representación. La construcción de una memoria común. La infancia desterrada”. El exilio de los niños. Eds. Alicia Alted Vigil, Roger González y María José Millán. Madrid: Fundación Pablo Iglesias, 2003.

Marqués, Pierre. Les enfants espagnols réfugiés en France, 1936-1939. París: P. Marqués, 1993.

Martínez López, Miguel. Casbah D’Oubli. L'Exil des réfugiés politiques espagnols en Algérie (1939-1962). Paris: L’Harmattan, 2004.

Marra-López, José R. Narrativa española fuera de España (1939-1961). Madrid: Guadarrama, 1963.

Masanet, Lydia. La autobiografía española contemporánea. Madrid: Espiral HispanoAmericana, 1998.

Mateo Gambarte, Eduardo. "La identidad del exiliado". Turia 18 (1991): 29-45.

---. "La segunda generación del exilio español en México: ¿españoles o mexicanos?". Eurídice 1 (1991): 175-194.

---. "Segunda generación del exilio español a México: la presencia del exilio en su obra”. Cuadernos para investigación de la literatura hispánica 16 (1992): 79-104. ---. "Dos problemas del exilio: géneros literarios y relación con los escritores del interior". 8-9 (1992): 359-366.

---. Los niños de la Guerra. Literatura del exilio español en México. Lleida: Universitat de Lleida, 1996.

---. Diccionario del exilio español en México. De Carlos Blanco Aguinaga a Ramón Xirau. Pamplona: Eunate, 1997.

---. María Luisa Elío Bernal. La vida como nostalgia y exilio. Logroño:

Universidad de La Rioja, 2009.

---. "El exilio, los exiliados hispanomexicanos, su literatura y la mirada del crítico". El exilio literario de 1939: 70 años después. Eds. María Teresa González de Garay Fernández y José Díaz-Cuesta Galián. La Rioja: Universidad de La Rioja, 2013, 67-98.

---. "La vuelta a un vacío llamado recuerdo: segunda generación del exilio republicano español en México". El exilio republicano de 1939: viajes y retornos. Coords. Manuel Aznar Soler, José Ramón López García, Francisca Montiel Rayo y Juan Rodríguez. Sevilla: Renacimiento, 2014, 63-101.

---. Exilio, infancia perdida, identidad e imposibilidad de retorno: En el balcón vacío de Jomí García Ascot y María Luisa Elío Bernal. Pamplona: Leer-E, 2016.

McClennen, Sophia A. The dialectics of exile: nation, time, language, and space in Hispanic literatures. Indiana: Purdue University Press, 2004. 
Medina, Tere. Sobre mis escombros: estampas de la guerra civil española. México: B. Costa-Amic, 1971.

---. Memorias del exilio: la vida cotidiana de los primeros refugiados españoles en México. México D.F.: Consejo Nacional para la Cultura y las Artes, 2007.

Milza, Pierre. "La notion de génération". Enfants de la guerre civile espagnole: vécus et représentations de la génération née entre 1925 et 1940. Fondation nationale des sciences politiques. Centre d'histoire de l'Europe du vintigième siècle. París: Harmattan, 1999, 9-14.

Molero de la Iglesia, Alicia. La autoficción en España: Jorge Semprún, Carlos Barral, Luis Goytisolo, Enriqueta Antolín y Antonio Muñoz Molina. Bern: Peter Lang, 2000.

---. “Autoficción y enunciación autobiográfica". Signa: Revista de la Asociación Española de Semiótica 9 (2000): 531-551.

Molina Romero, María del Carmen. "Identité et alterité dans la langue de 1'autre". Thélème. Revista Complutense de Estudios Franceses 70 (2003): 69-79.

Monferrer Catalán, Luis "Del Habana a la melancolía. La obra literaria de la segunda generación del exilio en el Reino Unido". El exilio republicano de 1939 y la segunda generación. (Coords.) Manuel Aznar Soler y José Ramón López García. Sevilla: Renacimiento, 2011, 213-223.

Moreno Seco, Mónica y Ortuño Martínez, Bárbara. "Exiliadas españolas en Francia y en Argentina: identidades transnacionales y transferencias culturales". Storia delle donne 9 (2003). (http://www.fupress.net/index.php/sdd/article/view/14073)

Moyà-Freire, Aurelia. Vinc d'Arbeca. Una infantesa travessada per la guerra i l'exili. Lérida: a cargo del autor, 2014.

---. Ma vie en France: Cahier d'exil d'une adolescente espagnole, 1939-1943. Toulouse: Toulouse Presses universitaries, 2017.

Muñiz-Huberman, Angelina. Dulcinea encantada. México D.F.: Joaquín Mortiz, 1992. ---. Castillos en la tierra. México: Consejo Nacional para la Cultura y las Artes: Ediciones del Equilibrista, 1995.

---. El canto del peregrino: hacia una poética del exilio. Barcelona: GEXEL y UNAM, 1999.

---. Molinos sin viento. México: Aldus, 2001.

Naharro-Calderón, José María. "En el balcón vacio de la memoria y la memoria de En el balcón vacio". Archivos de la Filmoteca: Revista de estudios históricos sobre la imagen 33 (Octubre 1990): 150-161. 
Nieto, Felipe. La aventura comunista de Jorge Semprún. Exilio, clandestinidad y ruptura. Barcelona: Tusquets, 2014. Kindle file.

Nora, Eugenio de. La novela Española contemporánea. Madrid: Gredos, 1958.

Notaro, Giuseppina. "Bilingüísmo autobiográfico en el exilio de Jorge Semprún”. Sujeto exílico: epistolario y diarios: exilio en primera persona. Coord. Mercedes Acillona López. San Sebastián: Hamaika Bide Elkartea, 2010, 455-464.

Olney, James. Metaphors of Self: the meaning of autobiography. Princeton: Princeton University Press, 1972.

Olmedo, Iliana. "El lugar de la narrativa del exilio republicano en la historiografia literaria mexicana". Secuencia: revista de historia y ciencias sociales 85 (2013): 113-139.

Pachecho, Bettina. Mujer y autobiografía en la España contemporánea. San Cristóbal: Lito formas, 2001.

Pamies, Teresa. Los niños de la guerra. Barcelona: Bruguera, 1977.

Papastergiadis, Nikos. Dialogues in the Diasporas: Essays and conversations on Cultural Identity. London: Rivers Oram Press, 1998.

Parkinson Zamora, Lois. The Usable Past. The Imagination of History in Recent Fiction of the Americas. Cambridge: Cambridge University Press, 1997.

Patán, Federico. Último exilio. México: Universidad Veracruzana 1986.

---. De cuerpo entero. México: Corunda, 1991.

---. "Invitación a un exilio". Migraciones y exilio: Cuadernos de la Asociación

para el estudio de los exilios y migraciones ibéricos contemporáneos 1 (2000):

215-231.

---. Una infancia llamada exilio. México D.F.: Eón, 2010.

Payne, Judith. "Writing and Reconciling Exile: the Novels of Angelina MuñizHuberman”. Bulletin of Hispanic Studies 744 (2010): 431-459.

Paz, Octavio. El laberinto de la soledad. New York: Penguin Books, 1997.

Pérez, Tatiana. Memorias de Lara. Madrid: Magisterio Español, 1977.

Pérez Guerrero, Juan Carlos. "Franquismo e identidad en el exilio republicano en México". Actas del IV Simposio de Historia Actual: Logroño 17-19 de octubre 2002. Ed. Carlos Navajas Zubeldía. Logroño: Instituto de Estudios Riojanos, 2004. 
---. La identidad del exilio republicano en México. Madrid: Fundación Universitaria Española, 2008.

Peri Rossi, Cristina. "De estado de exilio". Debate Feminista 12 (abril 1996): 150-152. Perujo, Francisca. Pasar las líneas: cartas a un comandante. México: Joaquín Mortiz, 1977.

Piña Rosales, Gerardo. "El exilio como condición humana: la obra narrativa de Roberto Ruiz”. Revista de Filología y su didáctica 22-23 (1999-2000): 549-555.

Pla, Dolores. Los niños de Morelia: un estudio sobre los primeros refugiados españoles en México. México D.F.: Instituto Nacional de Antropología e Historia, 1999.

Pozuelo Yvancos, José María. De la autobiografía: teoría y estilos. Barcelona: Crítica, 2006.

Rama, Ángel. Transculturación narrativa en América Latina. Montevideo: Fondo de Cultura Económica, 1989.

Ramírez, Conchita. Diario de una niña exiliada (1936-1947). Sevilla: Imprenta Provincial de Sevilla, 2006.

Rico, Francisco. "Algunos recuerdos de Carlos Blanco Aguinaga". El exilio republicano de 1939: viajes y retornos. (Coords.) Manuel Aznar Soler, José Ramón López García, Francisca Montiel Rato y Juan Rodríguez. Sevilla: Renacimiento, 2014, 699-700.

Ricoeur, Paul. La lectura del tiempo pasado: memoria y olvido. Madrid: Arrecife, 1999. ---. La memoria, la historia, el olvido. Madrid: Editorial Trotta, 2003.

Rius, Luis. "Los españoles en México: Historia de una doble personalidad". El Heraldo (17 de febrero): 6.

Rivas, Enrique de. Cuando acabe la guerra. Valencia: Pre-textos, 1992.

---. "Los durmientes de la cueva: tiempo y espacio del exilio republicano de 1939”. El exilio literario español de 1939: Actas del Primer Congreso Internacional (Bellatera, 27 de noviembre - 1 de diciembre de 1995). (Coord.) Manuel Aznar Soler. Sant Cugat del Vallés: GEXEL, 1998. 85-91.

---. "De éxodos, exilios, guerras, poetas y generaciones. Poesía Española del exilio republicano de 1939: La segunda generación de poetas del exilio en México". El exilio literario de 1939, 70 años después. Eds. María Teresa González de Garay Fernández y José Díaz-Cuesta Galián. La Rioja: Universidad de la Rioja, 2013, 21-36. 
Rivera, Susana. Última voz del exilio: el grupo poético hispano-mexicano. Madrid: Hiperión, 1990.

Rodrigo, Antonina. Mujer y exilio 1939. Madrid: Flor del Viento Ediciones, 2003.

Rodríguez, Juan. "Españoles en casa, mexicanos fuera de ella: Max Aub y la segunda generación del exilio". Anales de la literatura española contemporánea 38, 1-2 (2013): 293-326.

---. "El mito del retorno en la obra de Enrique de Rivas". El exilio republicano de 1939. El exilio republicano de 1939: viajes y retornos. (Coords.) Manuel Aznar Soler, José Ramón López García, Francisca Montiel Rayo y Juan Rodríguez. Sevilla: Renacimiento, 2014, 110-123.

Romera Castillo, José. "Panorama de la literatura autobiográfica en España (19751991)”. Suplementos Anthropos 29 (1991): 170-184.

---. "Actualidad y formas lingüísticas de la escritura autobiográfica en la España actual". La memoria delle lingue (Atti del XXI Convengo Associazione Ispanisti Italiani). Vol. II. Ed. Domenico A. Cussato. Messina: Andrea Lippolis Editore, 2004, 9-35.

---. De primera mano. Sobre escritura autobiográfica en España (siglo XX). Madrid: Visor, 2006.

Ruiz, Roberto. "La segunda generación de escritores exiliados en México". El exilio de las Españas de 1939 en las Américas: ¿adónde fue la canción? Ed. José María Naharro Calderón. Barcelona: Anthropos, 1991.

---. "Homenaje a la segunda generación”. Escritores, editoriales y revistas del exilio republicano de 1939. Coord. Manuel Aznar Soler. Sevilla: Renacimiento, 2006, 1139-1140.

---. "Presencia: una revista de la segunda generación exiliada". Escritores, editoriales y revistas del exilio republicano de 1939. Coord. Manuel Aznar Soler. Sevilla: Renacimiento, 2006, 1041-1047.

Ruiz Sánchez, Ana. "Jorge Semprún o la memoria encarnada". Más allá de la frontera: cinco voces para Europa. Madrid: Calambur: 2007, 145-168.

Said, Edward. "Reflections on Exile". Reflections on Exile and Other Essays. Cambridge: Harvard University Press, 2000, 173-186.

Salinas, Jaime. Travesías. Memorias (1925-1955). Barcelona: Tusquets, 2003.

Santamaría, Luis. Agur Euskadi, hasta nunca. Madrid: Subdirección General de Información Administrativa y Publicaciones, 2008.

Santayana, George. Reason in Common Sense. New York: Dover Publications, 1980. 
Santos Díaz, Julia y Alted Vigil, Alicia. Eds. Actas del congreso internacional de la Guerra Civil Española, 1936-1939. Madrid: Sociedad Estatal de Conmemoraciones Culturales, 2008.

Sapir, Edward. Language: An Introduction to the Study of Speech. New York: Harcout, Brace \& Co., 1943.

Schacter, Daniel L. Searching for Memory: the Brain, the Mind, and the Past. New York: BasicBooks, 1996.

Seidel, Michael. Exile and the narrative imagination. London: Yale University Press, 1986.

Semilla Durán, María A. "A Mirror of History: the Self and its Reflections in Jorge Semprún's Oeuvre. Veinte años y un día: Duality and Vertigo". A Critical Companion to Jorge Semprún: Buchenwald, Before and After. Eds. Olivia Ferrán and Gina Hermann. Basingstoke: Palgrave Macmillan, 2014, 155-168.

Semprún, Carlos. El exilio fue una fiesta. Barcelona: Planeta, 1988.

Semprún, Jorge. El largo viaje. Trad. Jacqueline y Rafael Conte. Barcelona: Seix Barral, 1976.

---. El desvanecimiento. Trad. Javier Albiñana. Barcelona: Planeta, 1967.

---. Autobiografía de Federico Sánchez. Barcelona: Planeta, 1977.

---. La segunda muerte de Ramón Mercader. Trad. Carlos Pujol. Barcelona:

Planeta, 1978.

---. La algarabía. Trad. Adolfo Martín. Barcelona: Plaza \& Janés, 1982.

---. La montaña blanca. Trad. Emma Calatayud. Madrid: Alfagura, 1986.

---. Netchaiev ha vuelto.

---. Federico Sánchez se despide de ustedes. Barcelona: Tusquets, 1993.

---. La escritura o la vida. Trad. Thomas Kauf. Barcelona: Tusquets, 1995.

---. Mal et modernité suivi de “... vouz avez une tombe dans les nuages...”. París: Climats, 1995.

---. Adiós, luz de los veranos. Trad. Javier Albiñana. Barcelona: Tusquets, 1998.

---. Aquel domingo. Trad. Javier Albiñana. Barcelona: Tusquets, 1999, Kindle

File.

---. Viviré con su nombre, morirá con el mío. Trad. Carlos Pujol. Barcelona:

Tusquets, 2002.

---. Veinte años y un día. Barcelona: Tusquets, 2003.

---. Pensar en Europa. Barcelona: Tusquets, 2011.

---. Ejercicios de supervivencia. Trad. Javier Albiñana. Barcelona: Tusquets, 2016, Kindle file.

Sicot, Bernard. Ecos del exilio: 13 poetas hispanoamericanos: Antología. A Coruña: Ediciós do Castro, 2003. 
Siedel, Michael. Exile and the Narrative Imagination. New Haven: Yale University Press, 1986.

Simarro, Conchita. Diario de una niña en tiempos de guerra y exilio (1938-1944). Madrid: UNED, 2015.

Simón, Paula. “'Memorias de una niña de la guerra' de Isabel Argentina Álvarez Morán. Los niños del exilio y la búsqueda de su historia". El exilio republicano de 1939 y la segunda generación. (Coords.) Manuel Aznar Soler y José Ramón López García. Sevilla: Renacimiento, 2011, 306-314.

Smith, Sidonie. A Poetics of Women's Autobiography. Marginality and the Fictions of Self-Representation. Indianapolis: Indiana University Press, 1987.

---. Reading autobiography: a guide for interpreting life narratives. Minneapolis, University of Minnesota Press, 2001.

Smith, Sidonie y Watson, Julia. Women, Autobiography, Theory: a Reader. University of Wisconsin Press, 1998.

Souto, Artuto. "Sobre una generación de poetas hispanomexicanos". Diálogos 98 (marzoabril 1981): 330-337.

Steffen-Prat, Isabelle. "La memoria herida: En el balcón vacio»". En el balcón vacío. La segunda generación del exilio republicano en México. (Ed.) Javier Lluch-Prats. En el balcón vacío. La segunda generación del exilio republicano en México. Madrid: AEMIC, 2012, pp. 45-68.

Suárez, Ma Pilar. "La identidad en el exilio: Semprún y Montherlant”. Literatura y bcultura del exilio español de 1939 en Francia. Coords. Alicia Alted Vigil y Manuel Aznar Soler. Barcelona: Gexel, 1998, 213-228.

Tabori, Paul. The Anatomy of Exile. London: Harrap, 1972.

Tasis Moratinos, Eduardo. El exilio en la poesía de Tomás Segovia y Angelina MuñizHuberman. Bern: Peter Lang, 2004. Kindle file.

Todorov, Tzvetán. Los abusos de la memoria. Barcelona: Paidós Ibérica, 2000.

Torres Rabassa, Gerard. "Intertextualidad y dialogismo en la obra autobiográfica de Jorge Semprún: la escritura del yo como diálogo con el otro”. Caracaol 10 (2015): 118149.

Tortosa, Virgilio. Escrituras ensimismadas. La autobiografia literaria en la democracia española. Alicante: Universidad de Alicante, 2001. 
Ugarte, Michael. Shifting ground: Spanish Civil War exile literature. London: Duke University Press, 1989.

Ulacia, Paloma y Valender, James. "María Luisa: Porque «regresar es irse»”. Los hijos del exilio vasco: arraigo o desarraigo. Eds. José Ángel Ascunce Arrieta y María Luisa San Miguel Casillas. San Sebastián: Saturrarán, 2004, 355-379.

Van der Kolk, Bessel A. y Onno van der Hart. "The Intrusive Past: The Flexibility of Memory and the Engraving of Trauma". Trauma. Explorations in Memory. Ed. Cathy Caruth. Londres: Johns Hopkins University Press, 1995, 158-182.

Vázquez, Mary S. "Desengaño, sufrimiento y afirmación. Las memorias del niño exiliado, maquis y presidiario: Ángel Fernández”. El exilio republicano de 1939 y la segunda generación. (Coords.) Manuel Aznar Soler y José Ramón López García. Sevilla: Renacimiento, 2011, 609-615.

Vernan, Kathleen M. "El lenguaje de la memoria en la narrativa española contemporánea". Actas del IX Congreso de la Asociación Internacional de Hispanistas: 18-23 agosto 1986 Berlín. Coord. Sebastián Neumeister. Frankfurt: Vervuert, 1989, 429-438.

Villagrá, Andrés. "Lenguaje autobiográfico e identidad femenina en el exilio literario español". Las literaturas del exilio republicano de 1939. Ed. Manuel Aznar Soler. Barcelona: Gexel, 2000, 161-169.

Villanueva, Darío. "Realidad y ficción: la paradoja de la autobiografía”. Escritura autobiográfica: actas del II Seminario Internacional del Instituto de Semiótica Literaria y Teatral: Madrid, UNED; 1-3 julio 1992. Barcelona: Visor, 1993, 1532.

Zamudio Rodríguez, Luz Elena. "El exilio como motivo generador en la obra de Angelina Muñiz-Huberman”. El exilio literario español de 1939: Actas del Primer Congreso Internacional (Bellaterra, 27 de noviembre - 1 de diciembre de 1995). Volumen II. Ed. Manuel Aznar Soler. Barcelona: Gexel (1998): 239-248.

Zavala, Iris. "Las formas y funciones de una teoría crítica feminista. Feminismo dialógico". Breve historia de la literatura española (en lengua castellana). Eds. Myriam Díaz-Diocaretz e Iris Zavala. Barcelona: Anthropos, 1993, 27-76.

Zepedda, Karla P. Exile and Identity Formation in the Autobiographies of Twentieh Century Spanish Women Writers. Diss. University of Connecticut, 2007. Ann Arbor: MI, 2008. 
VITA

\title{
JUAN ANTONIO GODOY PEÑAS
}

\author{
Born, Málaga, Spain
}

2008-2012

B.A., Spanish

University of Málaga

Málaga, Spain

2012-2013

International Intern of Spanish

University of Guelph

Ontario, Canadá

2013-2014

M.A. in Spanish Literature

Complutense University of Madrid

Madrid, Spain

2014-2019

Phd Student

Florida International University and Complutense

University of Madrid

Miami, Florida and Madrid, Spain

2014-2016

Teaching Assistant

Graduate Teaching Assistanship

Pablo Ruiz-Orozco and Miguel Angel Quesada Memorial

Scholarship

Title VI in Language Teaching: MI-BRIDGE. In

collaboration with Dr. Melissa Baralt, Dr. Débora Gómez

and Dr. José Morcillo-Gómez.

Florida International University

Miami, Florida

$2017-2018$

Visiting Instructor of Florida International University

Morris and Anita Broad Research Fellowship

Qingdao University

Qingdao, China

2018-2019

Teaching Assistant

Harvard University

Cambridge, Massachusetts

Researcher Assistant

Cervantes Observatory at Harvard University

Cambridge, Massachusetts 


\section{PUBLICATIONS AND PRESENTATIONS}

Godoy Peñas, Juan A (2019). "Niños de la guerra en México: la desterritorialización como consecuencia del exilio a través de Carlos Blanco Aguinaga y Angelina Muñiz-Huberman”. Middle Atlantic Council of Latin American Studies. Stony Brook University. March 8-9.

Godoy Peñas, Juan A (2018). "El uso de la metodología task-based en la enseñanza de fines específicos. Caso práctico de marketing". XI Jornadas de Formación del Profesorado de ELE en China. Instituto Cervantes de Pekín. June 2nd-3rd.

Godoy Peñas, Juan A. "María Luisa Elío Bernal: en busca de la identidad perdida". Ámbitos Feministas 6 (Spring 2017): 43-57.

Godoy Peñas, Juan A (2016). "La formación de la identidad en los exiliados: Jorge Semprún y María Luisa Elío Bernal". Congreso internacional. Epistolarios, memorias y diarios en la cultura española del medio siglo. Historia e intimidad. Universidad Autónoma de Madrid. October 25-27th.

Godoy Peñas, Juan A (2016). "Las mujeres anónimas en el exilio: la domesticidad en sus relatos". XII Encuentro Internacional de Escritoras dedicado a Marjorie Stoneman Douglas. Florida International University. September 11-13rd.

Godoy Peñas, Juan A (2016). Reasons for disminished black student enrollment in Spanish courses: a qualitative study. LASA. May 31 st.

Godoy Peñas, Juan A (2016). "María Luisa Elío Bernal. Una identidad dicotómica: España y México". 8th Annual Interdisciplinary Conference on Hispanic Linguistics, Literature, and Cultures. University of Florida. February 20th.

Godoy Peñas, Juan A (2015).“Técnica narrativa. El juego del desdoblamiento: Tiempo de llorar y otros relatos de María Luisa Elío Bernal." SE Coastal Conference on Languages and Literatures, Georgia Southern University, Savannah. March 2627 th.

Hao, Blanca., trans. China. La pintura grabada en madera de Yangliuqing - Una impresión que traspasa la historia. By Ye Chunhui et al. Juan Godoy (Copy Editor). Tianjin: Editorial Audiovisual de Lenguas Extranjeras (In press). 